Destroy this report when no longer needed. Do not return it to the originator.

The findings in this report are not to be construed as an official

Department of the Army position unless so designated

by other authorized documents.

The contents of this report are not to be used for advertising, publication, or promotional purposes. Citation of trade names does not constitute an official endorsement or approval of the use of such commercial products. 


\begin{tabular}{|c|c|}
\hline REPORT DOCUMENTATION PAGE & $\begin{array}{l}\text { READ INSTRUCTIONS } \\
\text { BEFORE COMPLETING FORM } \\
\end{array}$ \\
\hline $\begin{array}{l}\begin{array}{l}\text { 1. REPORT NUMBEA } \\
\text { Technical Report GL-79-18 }\end{array} \\
\end{array}$ & 3. RECIPIENT'S CATALOG NUMBER \\
\hline \multirow[t]{2}{*}{$\begin{array}{l}\text { 4. TITLE (and Subtite) } \\
\text { CENTRIFUGAL MODEL ANALYSIS OF COAL WASTE } \\
\text { EMBANKMENT STABILITY }\end{array}$} & $\begin{array}{l}\text { 5. TYPE OF REPORT A PERIOD COVERED } \\
\text { FINAI rePOTE }\end{array}$ \\
\hline & 6. PERFORMING ORG. REPORT NUMBER \\
\hline \multirow{2}{*}{$\begin{array}{l}\text { 7. AUTHOR(o) Frank C. Townsend } \\
\text { Deborah J. Goodings } \\
\text { Andrew N. Schofield } \\
\text { Mosaid M. Al-Hussaini } \\
\text { 9. PERFORMING ORGANIZATION NAME AND ADDRESS } \\
\text { U. S. Army Engineer Waterways Experiment Station } \\
\text { Geotechnical Laboratory } \\
\text { P. 0. Box } 631 \text {, Vicksburg, Miss. } 39180\end{array}$} & $\begin{array}{l}\text { 8. CONTRACT OR GRANT NUMBER(*) } \\
\text { Contract No. H0282018 }\end{array}$ \\
\hline & $\begin{array}{l}\text { 10. PROGRAM ELEMENT, PROJECT, TASK } \\
\text { AREA Q WORK UNIT NUMAERS }\end{array}$ \\
\hline \multirow{2}{*}{$\begin{array}{l}\text { 11. CONTROLLING OFFICE NAME AND ADDRESS } \\
\text { U. S. Department of Interior, Bureau of Mines } \\
\text { Spokane Mining Research Center } \\
\text { Spokane, Wash. } 99207\end{array}$} & $\begin{array}{l}\text { 12. REPORT DATE } \\
\text { September } 1979\end{array}$ \\
\hline & $\begin{array}{l}\text { 13. NUMBER OF PAGES } \\
117\end{array}$ \\
\hline \multirow[t]{2}{*}{ 14. MONITORING AGENCY NAME A ADDRESS (II difforent from Controllind OHIlce) } & $\begin{array}{l}\text { 15. SECURITY CLASS. (ot thlo roport) } \\
\text { Unclassified }\end{array}$ \\
\hline & $\begin{array}{l}\text { 15a. DECLASSIFICATION/DOWNGRADING } \\
\text { SCHEDULE }\end{array}$ \\
\hline \multicolumn{2}{|l|}{$\begin{array}{l}\text { 16. DISTRIBUTION STATEMENT (of this Roport) } \\
\text { Approved for public release; distribution unlimited. }\end{array}$} \\
\hline \multicolumn{2}{|l|}{ 17. DISTRIBUTION STATEMENT (of the abotract enterod In Block 20, if different froen Report) } \\
\hline
\end{tabular}

18. TEMENTARY NOTES

19. KEY WORDS (Con"Inue on reveree side II necessary and Identily by block number)

Centrifugal models Seepage

Coal waste Shear strength

Embankments Stability

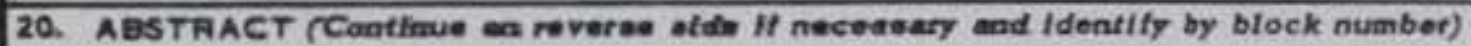

Centrifugal model embankments with varying geometries and materials were constructed of coal waste material, accelerated from 100 to 120 times earth's gravity, and subjected to various throughflow rates unt 11 failure occurred. Complementary laboratory tests were performed on the waste materials to obtain strength and permeability parameters for analytical calculations to predict observed centrifugal model behavior.

(Continued) 


\section{ABSTRACT (Continued)}

Failures in the form of deep-seated failure, or erosion and sediment transport or a combination of both, occurred in model embankments with $1 \mathrm{~V}: 1-1 / 2 \mathrm{H}$ and $1 \mathrm{~V}: 2 \mathrm{H}$ slopes when the phreatic surface due to seepage exited on the downstream slope. Positive seepage control, i.e., a toe drain successfully prevented sloughing and failures.

Slope stability analyses agreed we1l, albeit conservatively, with observed model performance. Factors of safety ranged from 0.7 to 1.02 at the instant of failure for models with retrogressing slips as compared with 1.05 to 1.7 for stable embankments. These models verified existing criteria of a minimum safety factor of 1.3 and the necessity of positive seepage control. 
This report was prepared by the U. S. Army Waterways Experiment Station (WES), Geotechnical Laboratory (GL), Vicksburg, Mississippi 39180, under U. S. Bureau of Mines Contract No. H0282018. The Contract was initiated under the Coal Mine Health and Safety/Safety Program. It was administered under the technical direction of the Spokane Mining Research Center (SMRC) with Mr. Bill M. Stewart acting as Technical Project Officer. Mr. David J. Askin was the Contract Administrator for the Bureau of Mines. This report is a summary of the work recently completed as a part of this contract during the period 0ctober 1977 to March 1979. This report was submitted by the authors on 24 March 1979.

The investigation was initiated in October 1977, when coal waste samples from the United States were sent to Cambridge University, England, where two series of centrifugal model tests were conducted under the principal direction of Professor Andrew N. Schofield, assisted by Ms. Deborah J. Goodings, Research Assistant, and Mr. Chris H. Collison, Research Technician. Other members of the Cambridge University staff who contributed significantly to the project were: Dr. R. G. James, Research Assistant R. N. Taylor, and Messrs. J. Doherty, W. Gwizdala, and R. Ward. Based upon these two series, two internal documents were prepared in limited quantity, these are: "Centrifugal Model Tests of Coal Waste Embankments" by Goodings et al,, 1977, and "Further Centrifugal Tests of Coal Waste Embankments" by Goodings and Schofield 1978. These two documents form the basis for Chapters $3,4,5,8$, and Appendix A. This report draws directly upon them, accordingly, except in certain instances quotations from the two internal documents are not specifically indicated. The theory of erosion and sediment transport in Chapter 3 and Appendix A is fully developed by Goodings (1979). Dr. F. C. Townsend, Research Group, Soil Mechanics Division (SMD), GL, WES, was the principal investigator of this project. He was present at Cambridge University for phases of both test series and prepared this report. Mr. Bill M. Stewart, SMRC, participated in the second test series. The stability and seepage analyses reported herein were performed by Dr. M. M. Al-Hussaini, Research Group, SMD. The investigation was accomplished under the general supervision of Mr. C. L. McAnear, Chief, SMD, and Mr. J. P. Sale, Chief, GL.

The success of this research was in a large part due to the excellent cooperation and technical expertise of the Cambridge Geotechnical Staff, specifically, Mr. C. H. Collison. Mr. Bill M. Stewart, SMRC, contributed significantly not only as Technical Project Officer, but on site during initial sampling operations and Centrifugal Model Test Series No. 2.

Directors of the WES during this study and preparation and publication of the report were COL J. L. Cannon, CE, and COL N. P. Conover, CE. Technical Director was Mr. F. R. Brown. 
FOREWORD . . . . . . . . . . . . . . . . . . . . . . . . . 1

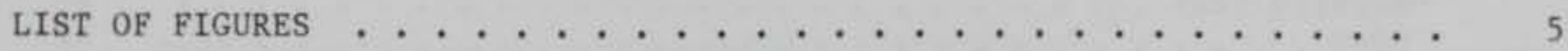

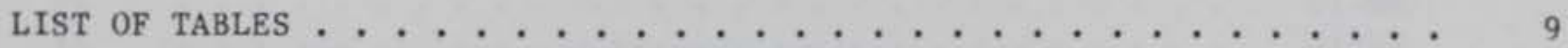

CHAPTER 1: SUMMARY . . . . . . . . . . . . . . . . . 10

Problem Statement . . . . . . . . . . . . . . . 10

Scope of Work . . . . . . . . . . . . . . . . . . 10

Pertinent Results and Conclusions . . . . . . . . . . . . 10

Recommended Research ....................... 11

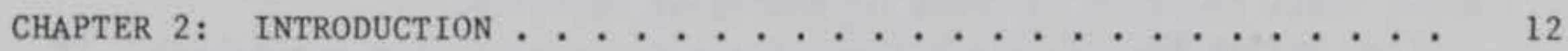

Purpose ......................... . . . . 12

Scope ...................... . . . . 13

CHAPTER 3: PRINCIPLES OF CENTRIFUgAL MODEL TESTING . . . . . . . . . . 14

General .................... . . . . . 14

Modeling Parameters Pertinent to Embankment Stability . . . . . . 14

Modeling rapid failure of undrained saturated clay slopes . . 14

Modeling seepage flow ................ . . 16

Modeling consolidation of saturated clay . . . . . . . . 16

Modeling time in unsaturated soils . . . . . . . . . 17

Modeling of bodily motions . . . . . . . . . . . . 17

Modeling seepage and deep-seated failures . . . . . . . . 18

Erosion and sediment transport . . . . . . . . . 18

CHAPTER 4: TEST EQUIPMENT, MATERIALS, AND TEST PROCEDURES . . . . . . 24

Centrifuge . . . . . . . . . . . . . . . . . . 24

Testing Procedures................. . . . . 24

Materials . . . . . . . . . . . . . . . . . . . 28

Model Construction . . . . . . . . . . . . . . . . 33

CHAPTER 5: MODEL TEST RESULTS . . . . . . . . . . . . . . 46

Model Tests Reported in Terms of Analogous Prototypes

(Test Series No. 1) . . . . . . . . . . . . . 46

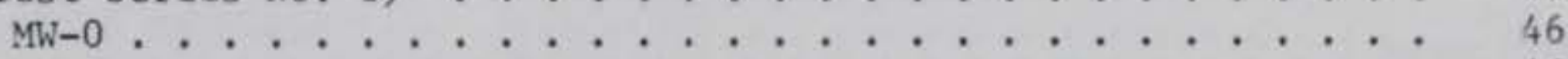

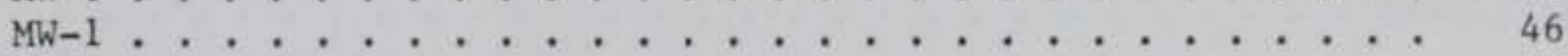

$\mathrm{MW}-2$. . . . . . . . . . . . . . . . 47

$\mathrm{MW}-2$. . . . . . . . . . . . . . . . 47

$\mathrm{MN}-3$. . . . . . . . . . . . . . . . . . 47

$\mathrm{MW}-4$. . . . . . . . . . . . . . . . 47

$\mathrm{MW}-5 . . .2 . . .2 . . .2 . . .2 .48$

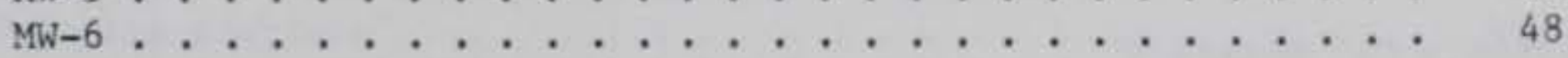




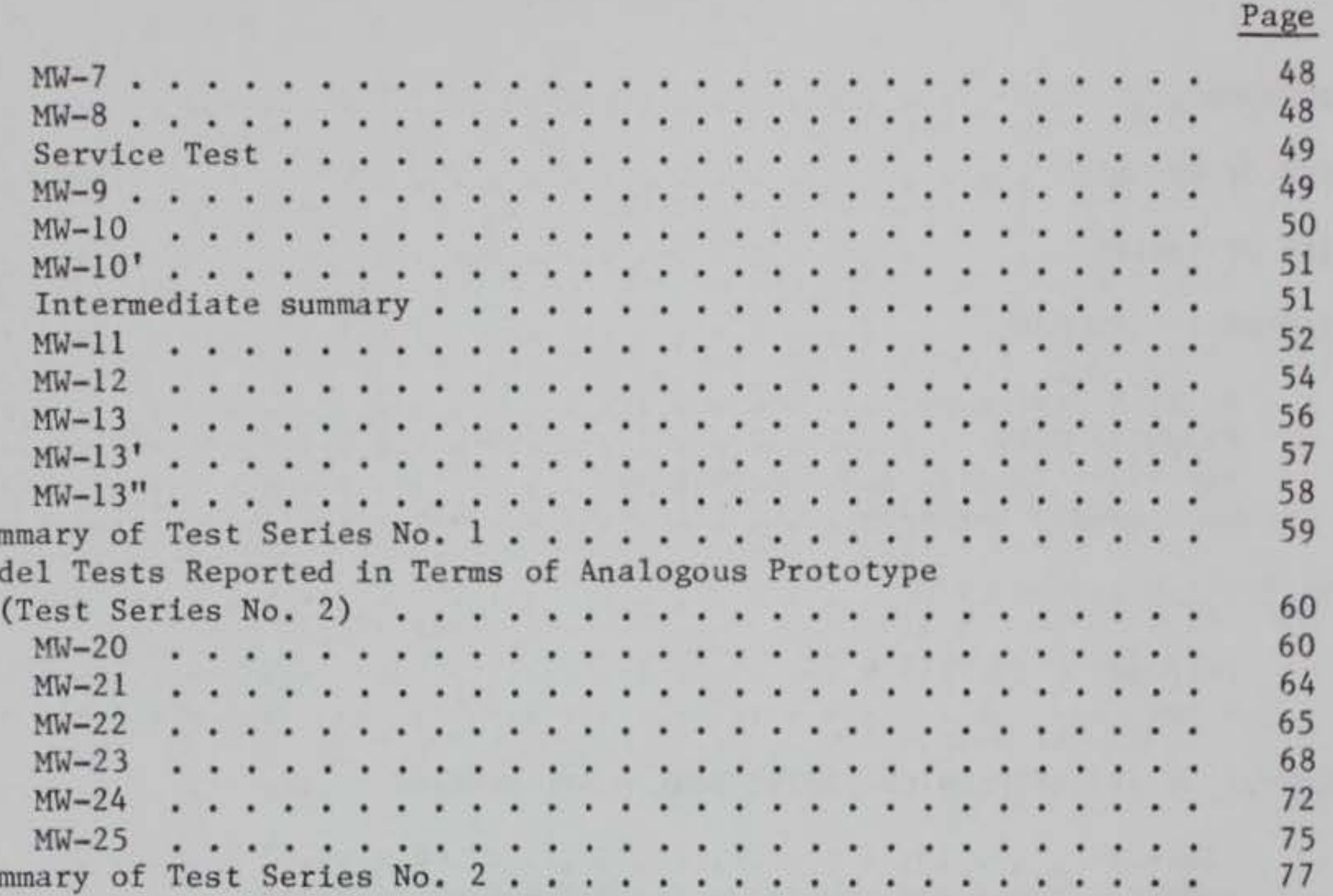

CHAPTER 6: ANALYSIS OF RESUltS . . . . . . . . . . . . . . 79

Seepage Analysis . . . . . . . . . . . . . . . . 79

Steady-State Seepage Through Uniform Section . . . . . . . . . 81

Steady Seepage Through Dam Section with Toe Drain $(M W-13)$. . . 88

CHAPTER 7: STABILITY ANALYSES . . . . . . . . . . . . . . . 90

Stability Analyses of Embankments with Seepage . . . . . . . . 90

Stability Analyses of Embankments with Toe Drain and Seepage . . . 99

Stability Analyses with No Seepage Forces (Model MW-24) . . . . 99

CHAPTER 8: INTERPRETATION OF MODEL EROSION . . . . . . . . . . . . 102

CHAPTER 9: CONCLUSIONS AND RECOMMENDATIONS . . . . . . . . . . . 106

Conclusions ...................... . . . 106

Recommendations ................... 107

REFERENCES . . . . . . . . . . . . . . . . . . 109

APPENDIX A: CHANGES IN DEPTH OF FLOW . . . . . . . . . . . . 111

APPENDIX B: CONVERSION FACTORS, U. S. CUSTOMARY TO METRIC (SI)

UNITS OF MEASUREMENT . . . . . . . . . . . . . . . . . . 115

APPENDIX C: NOTATION . . . . . . . . . . . . . . . 116 


\section{LIST OF FIGURES}

Figure

1 Change in erosion characteristics with change in

$\underline{\text { Page }}$ centrifugal acceleration ( $q$ constant)

2 Cambridge Geotechnical Centrifuge ..............

3 Front view of centrifugal strong box ........... 26

4 Back view of centrifugal strong box . . . . . . . . . 26

5 Closed circuit television (CCTV) view of centrifugal model . . .

6 Grain-size distributions of coal waste material used in model test series No. $1 \ldots \ldots$

7 Grafn-size distribution of coal waste material used in model test series No. 2 ...............

8 Results of 9-in.-diam triaxial compression tests on original coal waste material (SMRC) . . . . . . . . . . . .

9 Effective and total stress envelopes for material B used in centrifugal models $\mathrm{MW}-9$ through $\mathrm{MW}-13$. . . . . . . . .

10 Effective and total stress envelopes for material used in

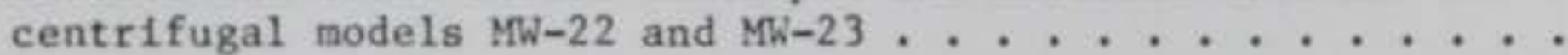

11 Effective and total stress envelopes for material used in centrifugal model $\mathrm{MW}-24$. . . . . . . . . . . . .

12 Effective and total stress envelopes for material used in centrifugal model $\mathrm{MW}-25$. . . . . . . . . . . . .

13 Effective stress envelope from direct shear box tests for models $\mathrm{MW}-22, \mathrm{MW}-23$, and $\mathrm{MW}-25$. . . . . . . . . .

14 Combined shear strength parameters for coal waste material used in centrifugal model tests ..............

15 View of model with template in place............

16 Completed model MW-13 with Plexiglas and picture frame bolted in place

View into loading bay

19 View of centrifugal strong box and mirror mounted on swinging platform ................ 


\section{LIST OF FIGURES (Continued)}

Figure

Page

20 View of centrifugal controls . . . . . . . . . . . .

21 Schematic drawing showing location of phreatic surface and slips for model test MW-9 . . . . . . . . . . . . . .

22 Schematic drawing showing location of phreatic surface and slips for mode1 test $\mathrm{MW}-10$. . . . . . . . . . . . .

23 Model MW-11 prior to centrifugal test . . . . . . . . .

24 Model MW-11 after centrifugal test . . . . . . . . .

25 Schematic drawing showing location of phreatic surface and slips for model test MW-11 . . . . . . . . . . . . 54

26 Model MW-12 after centrifugal test . . . . . . . . . .

27 Schematic drawing showing location of phreatic surface and

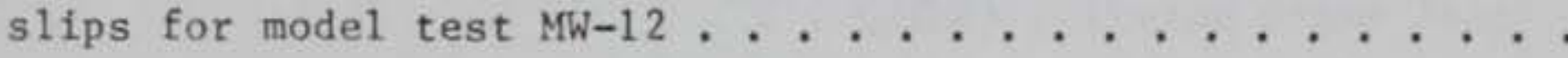

28 Detail of toe drain in model $\mathrm{MW}-13$ and debris exit hole . . .

29 Schematic drawing showing location of phreatic surface for model test MW-13 . . . . . . . . . . . . . .

30 Supply of kaolin slurry to reservoir of model MW-13 . . . . .

31 Model MW-13 after centrifugal test .............

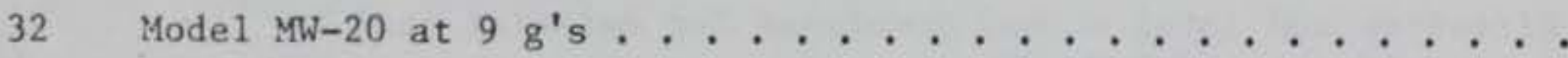

33 Model MW-20 at $120 \mathrm{~g}$ 's . . . . . . . . . . . .

34 Mode1 MW-20: displacements occurring between 9 and $120 \mathrm{~g}$ 's; numbers mark positions of piezometric tips . . . . . . .

35 Mode1 MW-20 at $120 \mathrm{~g}^{\prime} \mathrm{s}$, after erosion ..........

36 Model MW-20 after centrifugal test . . . . . . . . .

37 Mode1 MW-21 at $120 \mathrm{~g}^{\prime} \mathrm{s}$, during erosion ............

38 Mode1 MW-21 after centrifugal test . . . . . . . . . .

39 Mode1 MW-22 at $120 \mathrm{~g}^{\prime} \mathrm{s}$, without seepage ...........

40 Model MW-22 at $120 \mathrm{~g}^{\prime} \mathrm{s}$, with seepage.............

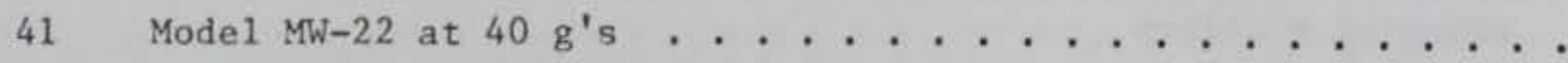




\section{LIST OF FIGURES (Cont1nued)}

Figure

$\underline{\text { Page }}$

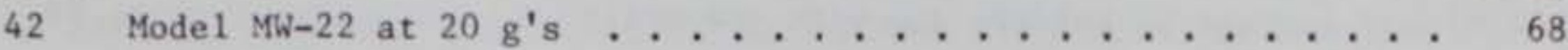

43 Mode1 MW-23 at $100 \mathrm{~g}$ 's . . . . . . . . . . . . . 69

44 Model MW-23 at $75 \mathrm{~g}$ 's . . . . . . . . . . . . 69

45 Model MW-23 at $1 \mathrm{~g}$ on centrifuge ............ 70

46 Model MW-23 at $66 \mathrm{~g}^{\prime} \mathrm{s}$. . . . . . . . . . . . . 71

47 Mode1 MW-23 after centrifugal test . . . . . . . . . . . 71

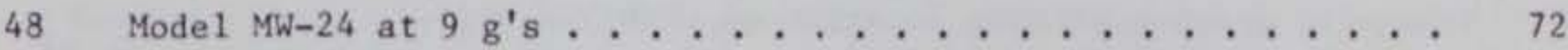

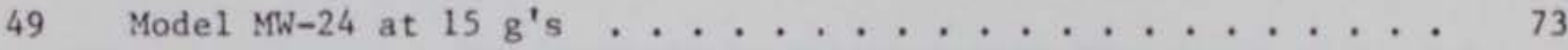

50 Model MW-24: rotational slip at $15 \mathrm{~g}$ 's relative to state at $9 \mathrm{~g}$ 's............... 73

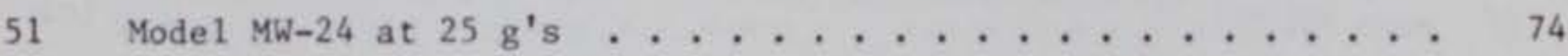

52 Model MW-24 after centrifugal test . . . . . . . . . . 74

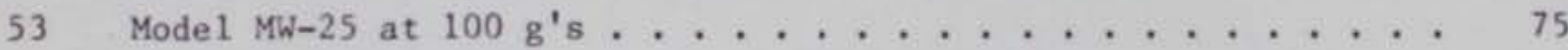

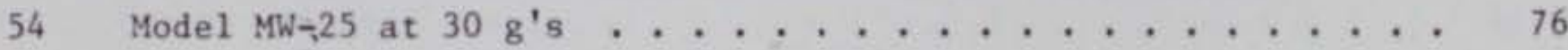

55 Model MW-25 at $30 \mathrm{~g}^{\prime} \mathrm{s}$, during eroston . . . . . . . . . 76

56 Model MW-25 after centrifugal test . . . . . . . . . . 77

57 Two-dimensional steady-state flow . . . . . . . . . . 80

58 Steady seepage surface through a dam . . . . . . . . . . 81

59 Comparison of observed and calculated phreatic surfaces for

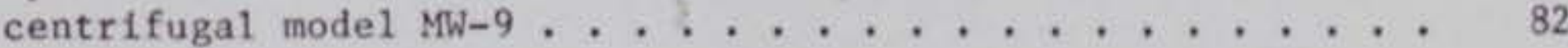

60 Comparison of observed and calculated phreatic surfaces for centrifugal model $\mathrm{MW}-10$. . . . . . . . . . . . .

61 Comparison of observed and calculated phreatic surfaces for centrifugal model MW-11 ................ 84

62 Comparison of observed and calculated phreatic surfaces for centrifugal model MW-23 ...............

63 Comparison of observed and calculated phreatic surfaces for centrifugal model MW-25 .............. 


\section{LIST OF FIGURES (Concluded)}

Figure

64 Steady seepage in uniform dam with toe drain ..........

65 Comparison of observed and calculated phreatic surfaces for centrifugal model $\mathrm{MW}-13$. . . . . . . . . . . . . . .

66 Modified Swedish method with finite slice procedure . . . . 93

67 Specification of parameters ............... . . 94

68 Schematic drawing showing location of observed and calculated failure surfaces for model test MW-9 . . . . . .

69 Schematic drawing showing location of observed and calculated fallure surfaces for model test MW-10 . . . . .

70 Schematic drawing showing location of observed and calculated failure surfaces for model test MW-11 . . . . .

71 Failure envelopes used in analyzing stability of model

test MW-24 
Table

$\underline{\text { Page }}$

1 Scaling Relations ................. 15

2 Experimental Data - Test Series No. . . . . . . . . . . 29

3 Experimenta1 Data - Test Series No. 2............. 30

4 Sumnary of Consolidated-Undrained Triaxial Compression Tests on Coal Waste Model Material . . . . . . . . . . . . 37

5 Summary of Water Contents and Densities for Centrifugal Models . . . . . . . . . . . . . . 41

6 Estimates of Coefficient of Permeability $k$ for Coal Waste Centrifugal Models . . . . . . . . . . . . . . 86

7 Stability Data for Coal Waste Centrifugal Models (Test Series No. 1) . . . . . . . . . . . . . . . 91

8 Stability Data for Coal Waste Centrifugal Models (Test Serles No. 2) ................... . 92

9 Sumnary of Stability Analyses of Coal Waste Embankments with Seepage ......................

10 Slope Stability Analysis Based upon Bishop and Morgensterns's (1960) Method ...................

11 Comparison of Predicted and Observed Model Erosion Phenomenon ..................... 


\section{CHAPTER 1: SUMMARY}

\section{Problem Statement}

Current practice for the design and analysis of coal waste embankments facilities is based upon small-scale laboratory tests to develop material behavior parameters, which are subsequently used in various analytical solutions. However, verification of this approach and the factor of safety used is only possible when failures occur; e.g., Teton Dam, Aberfan, and Buffalo Creek. Alternatively, soil modeling utilizing centrifugal techniques to increase gravity forces offers an attractive method for verifying currently employed analytical procedures. In this context, a series of centrifugal model tests simulating various prototype embankments was proposed to observe seepage and stability performance and to compare observed model behavior with analytical predictions based upon triaxial test data.

\section{Scope of Work}

Centrifugal model embankments with various geometries and materials were constructed of coal waste, accelerated using a 4-m-radius centrifuge from 100 to 120 times earth's gravity, and subjected to various throughflow rates until failure occurred. Companion triaxial tests on speciments at comparable model densities were performed to obtain shear strength and permeability parameters.

\section{Pertinent Results and Conclusions}

Failures were successfully induced in model embankments with $1 \mathrm{~V}: 1-1 / 2 \mathrm{H}$ and $1 \mathrm{~V}: 2 \mathrm{H}$ slopes when the phreatic surface due to seepage exited on the downstream slope and initiated sloughing at the toe. Shortly, following this minor distress at the toe, deep-seated failures occurred in the model slopes, which gradually retrogressed and formed $1 \mathrm{~V}: 4 \mathrm{H}$ slopes until catastrophic breaching of the embankment occurred. One model, constructed with a toe drain as a remedial method for providing positive seepage control, performed successfully at full reservoir pool, whereas a comparative model failed with a pool at 70 percent of full reservoir.

Estimates of the phreatic surface based upon Dupuit's parabolic assumption and the finite element method (FEM) seepage analysis agreed well with phreatic surfaces observed in models with vertical upstream slopes. However, in models with flatter upstream slopes, agreenent was less favorable. Nevertheless for both upstream slope conditions, theoretical estimates of the phreatic surface were higher (and thus more conservative) than surfaces observed in the models. Permeability estimates from seepage quantities measured in the models were approximately $10^{-3} \mathrm{~cm} / \mathrm{sec}$, while laboratory permeability values were approximately $10^{-5} \mathrm{~cm} / \mathrm{sec}$. 
Stability analysis using modified Swedish and simplified Bishop methods agreed well, albeit conservativly, with observed model performance. Calculated factors of safety ranged from 0.7 to 1.02 at the instant of failure for models with retrogressing slips. By comparison, factors of safety for stable embankments ranged from 1.05 to 1.7 . Thus, from the standpoint of stability, the often used minimum safety factor of 1.3 is sufficient. However, one notable exception was a rate of construction failure whose factor of safety using a bilinear total stress analysis was 3.6 , a great conservative error.

These model observations verify the adequacy of current analytical practice for the prototype embankments modeled. However, seepage control to prevent exiting of the phreatic surface on the downstream slope to prevent toe failures that retrogress cannot be overemphasized.

\section{$\underline{\text { Recommended Research }}$}

Specific areas pertinent to model tests conducted in this investigation that warrant additional research are: (a) rate of construction failures, their mechanisms of failure, and analytical techniques used in analyzing stability for this condition; and (b) improved seepage analyses of phreatic surface levels. Areas of considerable importance to mine waste embankment stability, but beyond the scope of this investigation, that warrant investigation are: (a) material type, (b) foundation conditions, and (c) seepage control provisions. 


\section{CHAPTER 2: INTRODUCTION}

Current practice for the design and analysis of coal refuse embankments facilities as outlined by the Mining Safety and Health Administration (MSHA), formerly the Mining Enforcement and Safety Administration (MESA) (Department of Interior, undated), is based upon small-scale laboratory tests to develop parameters for material behavior, which are subsequently used in various analytical solutions. Since it is virtually impossible to evaluate all limitations in this approach, the unknown degree of uncertainty is covered by safety factors. Full-scale testing is sometimes used to establish the validity of current design procedures and to verify the adequacy of factors of safety for man-made slopes. However, because failures are generated by gravity and since large soil masses and weights of material are required to cause gravity failures, full-scale testing is too costly to be often used. As a result, verification of the adequacy of current design and analysis approaches for man-made slopes are possible only when failures occur, e.g., Teton Dam, Buffalo Creek, Aberfan. However, in the case of most failures, adequate laboratory data and good instrumentation are lacking, thus limiting the precision of the analysis. Because of these and other considerations, soil modeling utilizing centrifugal techniques to increase self-weight forces offers an attractive method for verifying current analysis procedures.

Estimates by U. S. Department of Energy envisage increasing coal production from current levels of 600 million tons* per year to 1 billion tons per year by 1980 ; since current production levels already create vast tonnages of waste materials requiring disposal, future estimates predict even greater tonnages and disposal problems. Hence, verification and improvement of current waste disposal embankment design and safety criteria are warranted. In this context, a series of centrifugal model tests, capable of duplicating some events that could be anticipated in prototype embankments, appear likely to enhance current design and safety analysis of waste embankments.

\section{Purpose}

The objectives of this research were to conduct centrifugal model tests of coal waste embankments to obtain data of displacements, pore pressures, and mechanisms of slope failure, which could be compared with theoretical calculations currently employed for the purpose of verifying and/or improving these current analytical techniques. These tests would be attractive for the following reasons: (a) analysis of the failure of model slopes under known conditions leads to more reliable values for shear strength parameters than can be obtained by any other laboratory test method; (b) embankment stability observed in centrifugal models can be compared with conventional methods of stability calculations to determine the accuracy and to improve analytical methods; (c) the predictions of construction pore pressure distribution and

* A table of factors for converting U. S. customary units of measurement to metric (SI) units is presented in Appendix B. 
the stability of embankments and their foundations can be made through model analysis; and (d) gravitational slope failures observed in centrifugal tests correctly model the initial failure events.

\section{Scope}

To accomplish these objectives, material was sampled from a coal waste embankment and approximately two tons of material from the United States were shipped to Cambridge University, England, for centrifugal model tests. (Inasmuch as no geotechnical centrifugal facility presently (1979) exists in the United Staes, the Cambridge University Centrifugal Facility was used.) From this material, 19 centrifugal models were constructed by varying particlesize distribution of material, slope angle, reservoir geometry, foundation condition, seepage, and construction rate. Consolidated undrained triaxial compression tests with pore pressure measurements $(\bar{R})$ were performed on saturated specimens of the coal waste material used in the various models to obtain shear strength parameters. Failures observed in the centrifugal model tests were subsequently compared with results of conventional seepage and stability analyses of the models. 


\section{CHAPTER 3: PRINCIPLES OF CENTRIFUGAL MODEL TESTING}

\section{Genera1}

The basic concept of centrifuge model testing is to create a model similar in geometry, material properties, and boundary conditions to the fullscale prototype, and to subject the scale model to an acceleration such that the increase in self-weight stresses matches those at corresponding points in the prototype. The history and general theory of centrifugal testing for geotechnical applications is well described in the technical literature of Pokrovsky and Fyodorov (1975), Scott and Morgan (1977), Al-Hussaini (1977), Schofield (1978), and Lyndon and Schofield (1978).

Pokrovsky formulated two basic laws of similarity, which exist in centrifuge model testing:

a. If soils with identical friction, cohesion, and density are formed into two geometrically similar bodies, one a prototype of full scale and one a model of $1 / \mathrm{N}^{*}$ scale, and if the $1 / \mathrm{N}$ scale model is accelerated so that the self weight increases by $\mathrm{N}$ times, the stresses at corresponding points are then similar if they are similar on the boundaries.

b. Once the excess pore water pressure distribution has been made to correspond in model and protype, all subsequent primary flow processes of pore water are correctly modeled after time $t_{m}$ in the model that is less than time $t_{p}$ in the prototype in the ratio of the square of the scale factor $N$, i.e., $t_{m} / t_{p}=1 / N^{2}$.

Other scaling relationships are listed in Table 1.

\section{Modeling Parameters Pertinent to Embankment Stability}

Modeling parameters pertinent to the stability of coal waste embankments are: (a) height and geometry of embankment and strength of soil, (b) seepage conditions, and (c) times of pore pressure dissipation. These parameters will be discussed in the following paragraphs (Goodings et al., 1977; Goodings and Schofield, 1978).

Modeling rapid failure of undrained saturated clay slopes

Considering failure of undrained clay slopes, a condition where the angle of internal friction $\emptyset=0$, the nondimensional group, $c / \gamma H$ referred

* For convenience, symbols are listed and defined in the Notation (Appendix C). 
Table 1

Scaling Relationst

\begin{tabular}{|c|c|c|}
\hline Quantity & $\begin{array}{l}\text { Full Scale } \\
\text { (Prototype) }\end{array}$ & $\begin{array}{l}\text { Centrifugal } \\
\text { Model at N g's }\end{array}$ \\
\hline Linear dimension & 1 & $1 / \mathrm{N}$ \\
\hline Area & 1 & $1 / N^{2}$ \\
\hline Volume & 1 & $1 / N^{3}$ \\
\hline \multicolumn{3}{|l|}{ Time } \\
\hline in dynamic terms & 1 & $1 / \mathbb{N}$ \\
\hline in diffusion cases & 1 & $1 / \mathrm{N}^{2}$ \\
\hline in viscous flow cases & 1 & 1 \\
\hline Velocity (distance/time) & 1 & 1 \\
\hline Acceleration (distance/time ${ }^{2}$ ) & 1 & $\mathrm{~N}$ \\
\hline Mass & 1 & $1 / \mathrm{N}^{3}$ \\
\hline Force & 1 & $1 / \mathrm{N}^{2}$ \\
\hline Energy & 1 & $1 / N^{3}$ \\
\hline Stress (force/area) & 1 & 1 \\
\hline Strain (displacement/unit length) & 1 & 1 \\
\hline Density & 1 & 1 \\
\hline Energy density & 1 & 1 \\
\hline \multicolumn{3}{|l|}{ Frequency } \\
\hline in dynamic problems & 1 & N \\
\hline
\end{tabular}

* From Scott and Morgan, 1977. 
to as stability number appears in stability calculations. In this case, c is the undrained cohesion of the clay soil, and $\gamma \mathrm{H}$ is bulk weight of a vertical slice of height $H$. Such a clay slope can be modeled using identical clay soil with identical $c$ and $\gamma$, as well as a slope height reduced to $H / N$, where $\mathrm{N}$ is the scale of the model. By increasing gravity forces $\mathrm{N}$ times, the bulk weight will be $\mathrm{Ny}$ and the problem is modeled. For example, a prototype clay slope $75 \mathrm{ft}$ high could correspond to models centrifugally loaded to the equivalent of 90 or 120 times earth's gravity (g) with model heights of $75 \times 12 / 90=10 \mathrm{in}$. at $90 \mathrm{~g}^{\prime} \mathrm{s}$, or $75 \times 12 / 120=7.5 \mathrm{in}$. at $120 \mathrm{~g}^{\prime} \mathrm{s}$.

Modeling seepage flow

Steady-state seepage through an embankment can be represented by a flow net of $\mathrm{N}_{f}$ flow channels and $\mathrm{N}_{\mathrm{d}}$ equipotential drops, and the rate of flow $q$ at earth's gravity through a unit width of the embankment with permeability $k$ is given by:

$$
q=k \Delta h \frac{N_{f}}{N_{d}}
$$

where $\Delta h$ is the head drop through the embankment. A model embankment built of prototype material, which is geometrically similar to a prototype embankment but $\mathrm{N}$ times smaller in all external dimensions, will have a rate of seepage $v$ under $1-\mathrm{g}$ conditions $\mathrm{N}$ times smaller in the model than in the prototype in direct response to the fact that the driving force $\Delta h$ will be $\mathrm{N}$ times smaller in the model than in the prototype. If the same model were centrifugally loaded to $\mathrm{Ng}$ and the same flow net maintained at $\mathrm{Ng}$ as at $1 \mathrm{~g}$, then the driving force $\Delta \mathrm{h}$ would be increased $\mathrm{N}$ times with the increase in self weight as would be the rate of seepage; i.e., $v_{\mathrm{mNg}}=v_{\mathrm{m} 1 \mathrm{~g}} \times \mathrm{N}$. The rate of seepage in the model at $\mathrm{Ng}$ would then equal the rate of seepage in a prototype $\mathrm{N}$ times larger, i.e., $\mathrm{v}_{\mathrm{p}}=\mathrm{v}_{\mathrm{mNg}}$. This increase in velocity of water throughflow may be interpreted as modeling a soil of permeability $N$ times greater than the value of soil permeability measured at $1 \mathrm{~g}$.

Modeling consoli-

dation of saturated clay

The nondimensional factor, $\mathrm{T}_{\mathrm{v}}=\mathrm{c}_{\mathrm{v}} \mathrm{t} / \mathrm{H}^{2}$, appears in Terzaghi's primary consolidation calculations, where $c_{v}$, the coefficient of consolidation, depends upon permeability and compressibility, and $H$ is the length of the longest drainage path. Considering that $\mathrm{T}_{\mathrm{v}}=0.2$ for 50 percent consolidation, then for a prototype embankment with a drainage path of $75 \mathrm{ft}$ and an assumed $c_{v}$ of $50 \mathrm{ft}^{2} /$ year, $t_{50}=\mathrm{H}^{2} \mathrm{~T}_{\mathrm{v}} / \mathrm{c}_{\mathrm{v}}=(75)^{2} \times 0.2 / 50=22.5$ years. In comparison, for a centrifugal model at $1 / 90$ full scale and subjected to $90 \mathrm{~g}^{\prime} \mathrm{s}$, then $t_{50}=(75 / 90)^{2} \times 0.2 / 50 \times 365=1$ day to achieve half settlement. Hence, for consolidation processes or steady seepage, time in a centrifugal test reduces with the square of the model scale and acceleration. 
Modeling time in

unsaturated soils

When the upper zones of partially saturated soils are considered in a waste embankment, Terzaghi's consolidation calculations are inappropriate. Thus, drainage or compression of the upper unsaturated zones will be independent of the distance to externally drained boundaries, i.e., drainage path of model or prototype, which in turn indicates that deformation or settlement times likewise are independent of centrifugal model scale, such that $t_{p}=t_{m}$. Conversely, as discussed in the previous paragraph, settlement times for lower saturated zones are modeled by a factor $\mathrm{N}^{2}$. Taking the upper and lower zones of the waste embankment together, Malushitsky (1975) explained that the scale factor for deformation similarity between prototype and model must be between $\mathrm{N}^{0}$ and $\mathrm{N}^{2}$. Based upon a test series employing different models at different scales, termed "modeling of models," he was able to show that the scaling factor for time in these cases was $\mathrm{N}$.

Modeling of bodily motions

When movement of soil masses due to embankment failure is considered in models, the scale factor $N$ occurs in the time required for movement. The distance traveled by a mass starting from rest in an acceleration field is simply

$$
\mathrm{s}=\frac{1}{2} \mathrm{at} \mathrm{t}^{2}
$$

where $s=$ distance traveled

$\mathrm{a}=$ acceleration field

$\mathrm{t}=\mathrm{time}$

For a centrifugal model at $1 / \mathrm{N}$ scale and at an acceleration of $\mathrm{Ng}$, then time in the model will be reduced by a factor of $\mathrm{N}$ compared with the prototype as

$$
\begin{gathered}
t_{p}=\sqrt{\frac{{ }_{p}^{2 s_{p}}}{a_{p}}} \text { and } t_{m}=\sqrt{\frac{2 s_{m}}{a_{m}}} \text {, but } a_{p}=\frac{a_{m}}{N} \text { and } s_{p}=N s_{m} \\
t_{p}=\sqrt{\frac{2 N s_{m}}{\frac{a_{m}}{N}}}=\sqrt{\frac{2 N^{2} s_{m}}{a_{m}}}=N \cdot t_{m}
\end{gathered}
$$

A difficulty is immediately apparent for modeling geotechnical problems involving dynamic deformation with pore pressure dissipation and consolidation, as pore pressure dissipation and consolidation times will occur at a factor $\mathrm{N}^{2}$, while mass displacements will occur at a factor of $\mathrm{N}$. Therefore, in a centrifugal model where mass failure is due to high pore pressures, such that flow slides, liquefaction, or retrogressive action may be initiated, the pore 
pressures, which facilitate the further development and continuation of such movements, will dissipate disproportionately fast. To resolve this difficulty of different time scales in models, Rowe, Craig, and Proctor (1977) substituted a model material $N$ times less permeable than the prototype sand. This substitution ensured that whatever transient pore pressures were generated during a loading time would be retained in the model for $\mathrm{N}$ times longer than would have been the case if prototype material had been used. Thus, the model pore pressure dissipation time became $t_{p}=t_{m} \cdot N^{2} \cdot 1 / N=t_{m} \cdot N$, which is compatible with the prototype time for mass movement.

Modeling seepage

and deep-seated failures

In laboratory tests on any soil sample, it is common practice to remove oversized coarse particles to eliminate obvious size effects. This is also the case for centrifugal modeling. While removal of these coarse particles does not necessarily affect density or the angle of internal friction $\emptyset$, both of which are used in stability calculations, the permeability will obviously be reduced. Considering Hazen's observation that permeability of sands is proportional to $\left(\mathrm{D}_{10}\right)^{2}$ (diameter of soil particle having a size greater than 10 percent by weight of the particles), then reduction of all particle sizes by a factor will reduce permeability by the square of that factor. This change in permeability will result in a reduction not only in rates of throughflow, but also in rates of pore pressure dissipation. For example, if a model were accelerated to $100 \mathrm{~g}$ 's, it would be desirable to reduce permeability by a factor of 100 to keep pore pressure dissipation in similarity with mass model soil movements; this can be achieved by reducing the particle size by a factor of $10(\sqrt{100}=10)$.

In the case of deep-seated mass slope instability in an embankment subjected to steady seepage, failure depends upon the inclination and level of phreatic seepage line through the bank, but the quantities, $\gamma / \gamma_{w}, \emptyset, c$, enter into the calculations and not permeability or quantity of flow. With respect to initial failures, the events between prototype and model with similar phreatic surfaces would be similar even if permeabilities are not to scale. However, in respect to subsequent retrogression, development of liquefaction or flow sliding, similar behavior would not be anticipated unless permeabilities had been correctly scaled.

Erosion and

sediment transport\%

When water seeping through an embankment emerges either at the toe, or on the downstream slope as a spring, the resulting surface flow is no longer governed by Darcy's Law. Such conditions, including the extreme case of overtopping, can result in erosion leading to local steepening of the slope, retrogressive sliding, and possible breaching of the embankment. Thus, initiation of erosion clearly becomes an event to be avoided.

* Developed by Goodings, 1979. 
Olivier (1967) investigated the problem of safe overflow and throughflow in rockfill embankment dams, where throughflow is seepage through the rockfill, not piping. By first examining the problem theoretically for cases of overflow, and then simplifying and confirming it experimentally, he determined the threshold flow, i.e., that flow at which the movement of one particle will cause the movement of many others, in the following equation:

$$
q_{t}=k^{\prime} D_{50}^{3 / 2}\left(\frac{\gamma_{s}-\gamma_{w}}{\gamma_{w}}\right)^{5 / 3} s^{-7 / 6}
$$

where $q_{t}=$ threshold rate of flow

$k^{\prime}=$ constant accounting for packing, shape of particles, etc.

$\mathrm{D}_{50}=$ median grain size

$\gamma_{s}=$ unit weight of solids

$\gamma_{w}=$ unit weight of water

$\mathrm{S}=$ sine of downstream slope

In the case of combined over and throughflow, Olivier estimated that the equation would make a slightly conservative estimate of threshold flow. The derivation of this equation, which predicts the initiation of erosion under conditions of overflow, is based upon defining the flow at which the boundary shear stress exerted on particles equals the critical shear stress, i.e., the condition at which the particles will begin to move. Olivier defined the exerted shear stress as

$$
\tau=\gamma_{w} d S
$$

where $\tau=$ exerted shear stress

$$
d=\text { depth of flow }
$$

The critical shear stress can be defined as

$$
\tau_{c}=M\left(\gamma_{s}-\gamma_{w}\right) D_{50}
$$

where $\tau_{c}=$ critical shear stress

$M=$ constant, experimentally derived $(M=0.06$ when $d>9 \mathrm{~mm})$

Hence, erosion will occur when $\tau=\tau_{c}$, or

$$
\gamma_{w} d S=M\left(\gamma_{S}-\gamma_{w}\right) D_{50}
$$

However, in the case of centrifugal model at $1 / \mathrm{N}$ scale and accelerated to $\mathrm{Ng}$, but in which the rate of throughflow is constant, then certain changes occur in these equations and in the flow of water. Specifically, 
$\gamma_{w}$ and $\gamma_{s}$ are increased $N$ times, but $d$, under conditions of constant $q$, is reduced by a factor of $\mathrm{N}^{0.3}$ (see Appendix A, Equation A23). Thus, the equations for exerted and critical shear stress, Equations 3 and 4, respectively, become

$$
\begin{gathered}
d_{N g}=d_{1 g} N^{0.3} \\
\gamma_{w N g}=\gamma_{w 1 g}{ }^{N} \\
\tau_{N g}=\gamma_{w 1 g} d_{1 g} s^{0.7} \\
=\tau_{1 g} N^{0.7}
\end{gathered}
$$

and

$$
\tau_{c N g}=M\left(\gamma_{s 1 g}-\gamma_{w 1 g}\right) D_{50} \cdot N
$$

Equating these two, the critical depth of flow is determined as

$$
d_{1 g}=M\left(\frac{\gamma_{s 1 g}-\gamma_{w 1 g}}{\gamma_{w 1 g}}\right) \frac{D_{50} N^{0.3}}{S}
$$

and substituting this value into the Chezy-Manning equation for open channel flow, which was the basic equation used by Olivier (1967) for deriving Equation 2. The Chezy-Manning equation for wide open channel flow can be expressed as

$$
V=\frac{1.49 *}{n} d^{2 / 3} s^{1 / 2}
$$

where $d=$ depth of flow (hydraulic radius (R) for this case)

$\mathrm{S}=$ slope of the channel

Since $q=V A$, for a unit width,

$$
q=\frac{1.49 *}{n} d^{2 / 3} s^{1 / 2} \cdot d
$$

and the threshold flow at $\mathrm{Ng}$ appears as

$$
q_{t N g}=\frac{1.49 *}{n} M^{5 / 3} D_{50}^{5 / 3}\left(\frac{\gamma_{s 1 g}-\gamma_{w 1 g}}{\gamma_{w 1 g}}\right)^{5 / 3} S^{-7 / 6} N^{1 / 2}
$$

* The numerator of this equation is units dependent: when $d$ is in feet, the numerator $=1.49$; when $d$ is in metres, the numerator is 1.0 . 
This expression differs slightly from the form presented by olivier (1967) in Equation 2, but by substituting an expression used by Chang (1939)
as did Olivier, where

$$
\begin{aligned}
\mathrm{n} & =0.0166 \mathrm{D}_{50}^{1 / 6}\left(\mathrm{D}_{50} \text { in } \mathrm{mm}\right) \\
& =0.0525 \mathrm{D}_{50}^{1 / 6}\left(\mathrm{D}_{50} \text { in } \mathrm{m}\right)
\end{aligned}
$$

then Equation 13 can be written precisely as Equation 2 with the coefficient $k^{*}$ more explicity defined as

$$
k^{\prime}=\left(\frac{1.49^{*}}{0.0525 \mathrm{D}_{50}^{1 / 6}}\right) \mathrm{M}^{5 / 3}
$$

and

$$
q_{t N_{g}}=k^{\prime} D_{S 0}^{3 / 2}\left(\frac{\gamma_{s 1 g}-\gamma_{w 1 g}}{\gamma_{w 1 g}}\right)^{5 / 3} s^{-7 / 6} N^{1 / 2}
$$

In this context, the relationship between threshold flow in the model at $\mathrm{Ng}_{\mathrm{g}}, \mathrm{q}_{\mathrm{mNg}}$, and threshold flow in the prototype at $\mathrm{Ig}_{\mathrm{g}} \mathrm{q}_{\mathrm{p}} \mathrm{g}_{\mathrm{g}}$, will be

$$
\begin{gathered}
q_{m N_{g}}=k_{m}^{\prime} D_{50 m}^{3 / 2}\left(\frac{\gamma_{s 1 g}-\gamma_{w 1 g}}{\gamma_{w 1 g}}\right)^{5 / 3} s^{-7 / 6} N^{1 / 2} \\
q_{p 1 g}=k_{p}^{\prime} D_{50 p}^{3 / 2}\left(\frac{\gamma_{s 1 g}-\gamma_{w 1 g}}{\gamma_{w 1 g}}\right)^{5 / 3} s^{-7 / 6}
\end{gathered}
$$

Thus,

$$
\frac{q_{m N g}}{q_{p 1 g}}=\frac{k_{m}^{\prime}}{k_{p}^{\prime}}\left(\frac{D_{50 m}}{D_{50 p}}\right)^{3 / 2} N^{1 / 2}
$$

where Olivier (1967) determined values of $k$ for all sizes of granite to be 0.423 when $D_{50}$ is expressed in feet.

It is interesting to realize that in a given model where the two variable parameters are (a) the quantity of water flowing through the embankment and (b) the centrifugal acceleration, that initiation of erosion may be

* See footnote to Equation 11. 
achieved by increasing the throughflow while $\mathrm{N}$ remains constant, or by reducing $\mathrm{N}$ while retaining the throughflow as a constant. Figure 1 illustrates the latter of these effects.

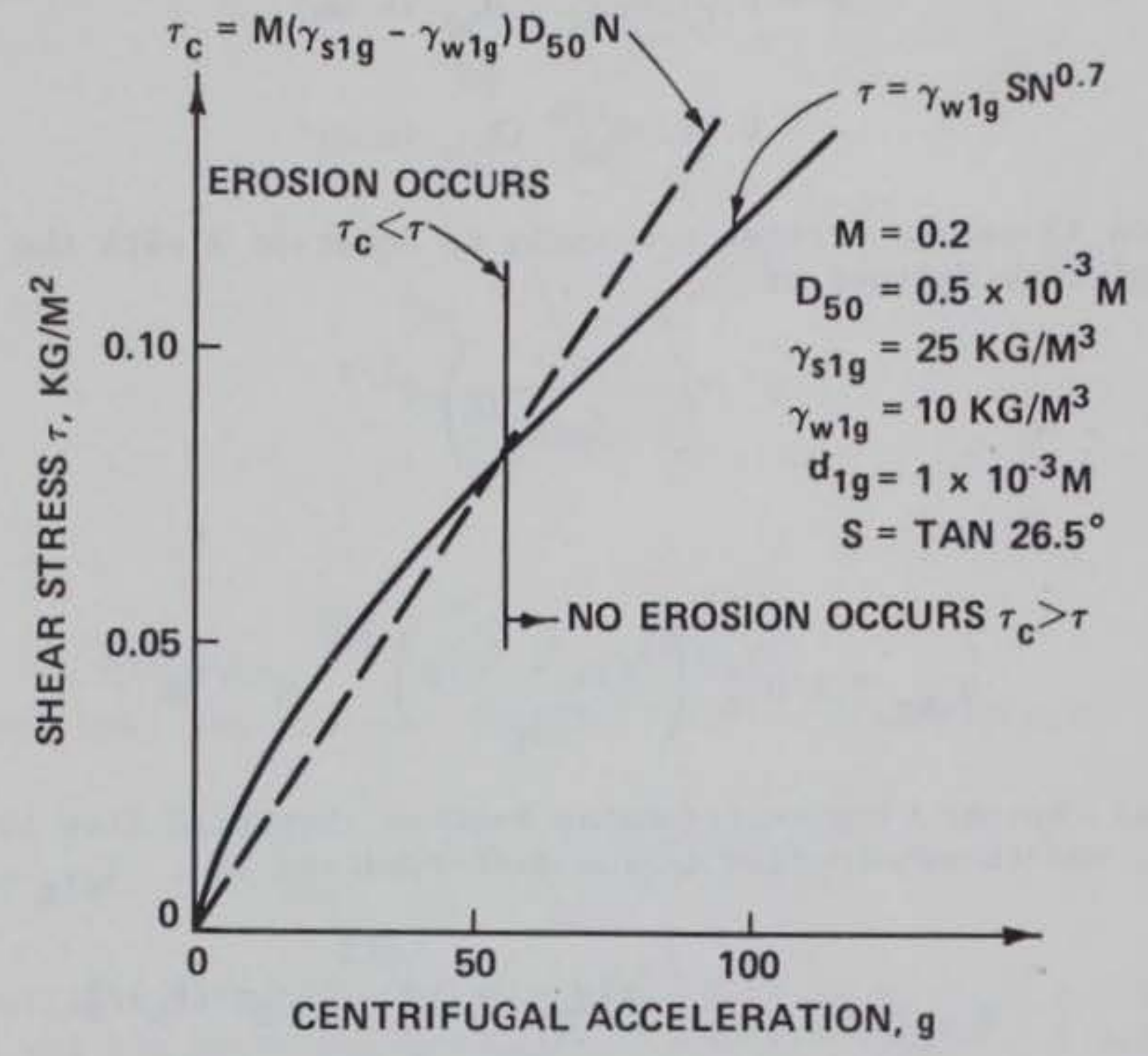

Figure 1. Change in erosion characteristics with change in centrifugal acceleration ( $\mathrm{q}$ constant) (from Goodings and Schofield, 1978)

The merit of a model is in its ability to predict full-scale events. Furthermore, it is important to derive the relationships between model and prototype overflows. Compare a $1 / \mathrm{N}$ scale model accelerated to $\mathrm{Ng}$ through which water moves at a velocity $V_{\mathrm{mNg}}$ to a prototype embankment through which water moves at $V_{p}$, such that $V_{p}=V_{m N g}$; then $q_{m}=q_{p / N}$ due to the increased height of the prototype. The initiation of erosion in the model is related to the prototype as follows: $\tau=\tau_{c}$ for both model and prototype and

$$
\frac{\tau_{\mathrm{mNg}}}{\tau_{\mathrm{cmNg}}}=\frac{\tau_{p}}{\tau_{\mathrm{cp}}}
$$

By substituting the appropriate forms of Equations 3 and 4 


$$
\frac{N M_{m}\left(\gamma_{s 1 g}-\gamma_{w 1 g}\right) D_{50 m}}{N \gamma_{w 1 g}{ }^{d}{ }_{m g} S}=\frac{M_{p}\left(\gamma_{s}-\gamma_{w}\right) D_{50 p}}{\gamma_{w}{ }^{d} S}
$$

and

$$
\frac{D_{50 m}}{D_{50 p}}=\frac{d_{m N g}}{d_{p}} \frac{M_{p}}{M_{m}}
$$

From Appendix A, when $q_{m}=q_{p} / n$, then

$$
\frac{\mathrm{dmNg}_{\mathrm{p}}}{\mathrm{d}_{\mathrm{p}}}=\left(\frac{\mathrm{n}_{\mathrm{m}}}{\mathrm{n}_{\mathrm{p}}}\right)^{3 / 5} \mathrm{~N}^{-0.9}
$$

which, from Chang's (1939) definition for $\mathrm{n}$, is equal to

$$
\frac{d_{m N g}}{d_{p}}=\left(\frac{D_{50 m}}{D_{50 p}}\right)^{1 / 10} N^{-0.9}
$$

then

$$
\begin{gathered}
\frac{\mathrm{D}_{50 \mathrm{~m}}}{\mathrm{D}_{50 \mathrm{p}}}=\left(\frac{\mathrm{D}_{50 \mathrm{~m}}}{\mathrm{D}_{50 \mathrm{p}}}\right)^{1 / 10} \mathrm{~N}^{-0.9} \frac{\mathrm{M}_{\mathrm{p}}}{\mathrm{M}_{\mathrm{m}}} \\
\frac{\mathrm{D}_{50 \mathrm{~m}}}{\mathrm{D}_{50 \mathrm{p}}}=\left(\frac{\mathrm{M}}{\mathrm{M}}\right)^{10 / 9} \mathrm{~N}^{-1}
\end{gathered}
$$

and

$$
\frac{{ }_{\mathrm{mNg}}}{\mathrm{d}_{\mathrm{p}}}=\left(\frac{\mathrm{M}_{\mathrm{p}}}{\mathrm{M}_{\mathrm{m}}}\right)^{1 / 9} \mathrm{~N}^{-1}
$$

This relationship is likely to be in contradiction to that required for the correct modeling of permeability, which is $k_{p}=k_{m 1 g} \cdot N$, for which

$$
\frac{D_{10 m}}{D_{10 p}}=N^{-1 / 2}
$$

Hence, two conflicting notional prototype grain-size distributions may be considered to be modeled simultaneously. One is defined in terms of $D_{10}$, which governs permeability and consequently the correct modeling of internal groundwater movement, and the other is defined in terms of $D_{50}$, which governs erosion. 
CHAPTER 4: TEST EQUIPMENT, MATERIALS, AND TEST PROCEDURES

\section{Centrifuge}

The Cambridge Geotechnical Centrifuge (Figure 2) has a working radius of $4 \mathrm{~m}$ from the rotor center to middepth of the soil in a model. The model is constructed inside a strong box (Figures 3 and 4 ). Typically, the embankment models were 25.4 by 76.2 by $15.2 \mathrm{~cm}$ ( $10 \mathrm{in}$. high, $30 \mathrm{in}$. long, and $6 \mathrm{in}$. deep). The strong box and model are attached to a swinging platform mounted on the end of the centrifugal arm. As the centrifuge is accelerated, the swinging platform swings into position and seats against the end of the centrifugal arm. In this position, the model lies in a horizontal plane with the centrifugal component of acceleration directed radially outward. To achieve $120 \mathrm{~g}$ 's at a radius of $4 \mathrm{~m}$, the required rotational speed $\omega$ is calculated as follows:

$$
w=\frac{120 \times 9.81}{4}=17.15 \mathrm{rad} / \mathrm{sec}=163.8 \mathrm{rpm} \text { required }
$$

Presently, the maximum mass including package and soil that can be safely accelerated is $900 \mathrm{~kg}$.

As the model lies in the horizontal plane at the end of the balanced rotor arm, observation of the plane section of the model can be made through a thick transparent plastic face of the strong box. The original viewing system employed overhead photography with rapid flash illumination as the model rotated past a stationary camera viewing through a part of the centrifuge the pit safety cover (roof). However, for the first test series, observation was by closed-circuit television (CCTV) with the video camera located at the rotor and a 45- deg mirror on the strong box (Figure 5). Although the mirror blocked the use of overhead photography, the CCTV permitted excellent observation and continuous recording of model events. For the second series, a 60-deg mirror that permitted overhead photography was used, but a less satisfactory TV image of the model was observed.

The centrifuge is provided with a number of electrical and hydraulic slip rings, which were capable of monitoring a displacement transducer that measured embankment crest settlement and supplying reservoir water.

\section{$\underline{\text { Testing Procedures }}$}

Previous to this study, the only known documented centrifugal tests on coal waste embankments were those of Malushitsky (1975), which were for clayey overburden soils and quite unlike the permeable granular material used in this test program. Hence, the testing program of this research evolved based upon experience gained in each previous test. Two test series were performed: specifically, (a) a series of 13 models tested from 


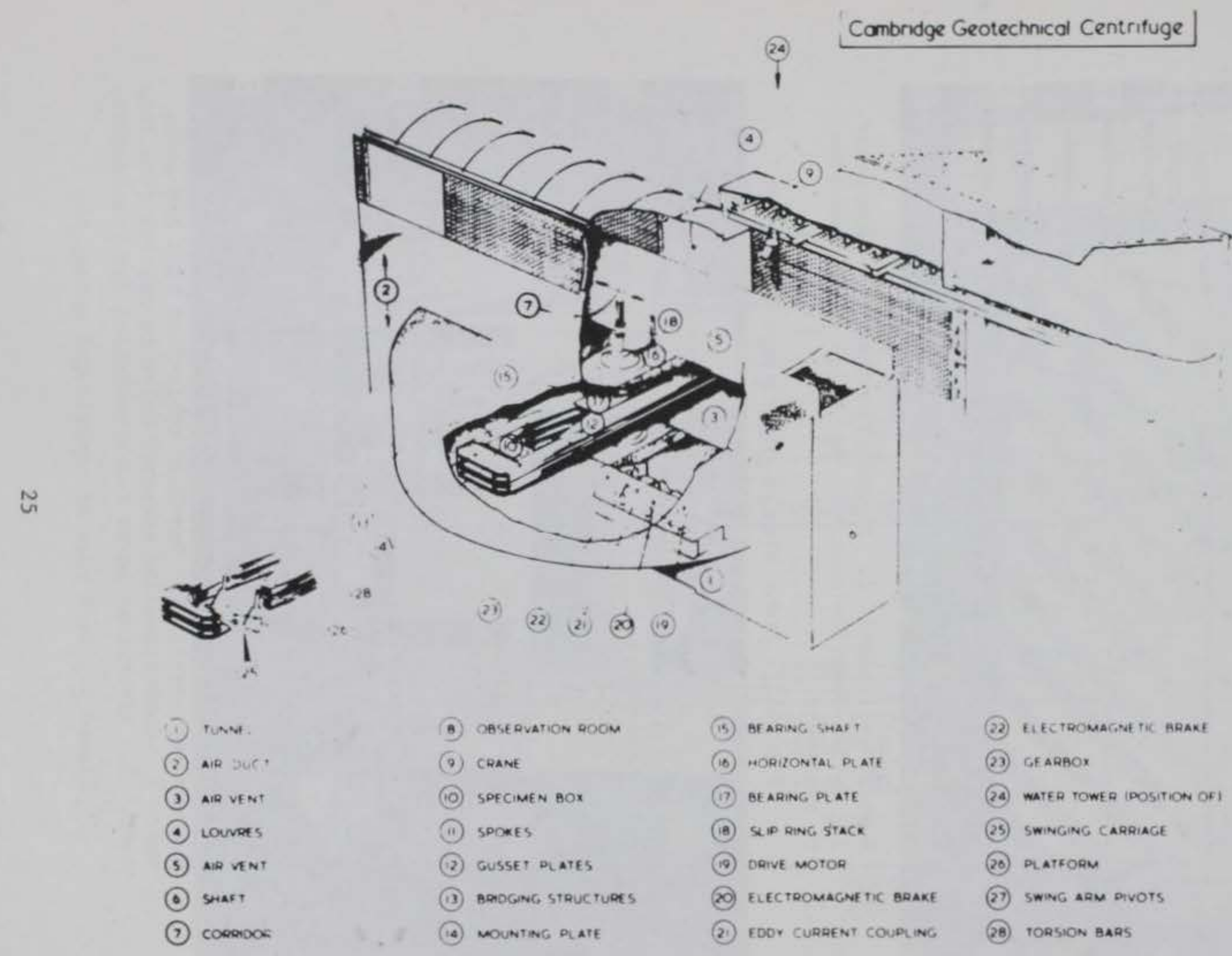

Figure 2. Cambridge Geotechnical Centrifuge (from Goodings et a1., 1979) 


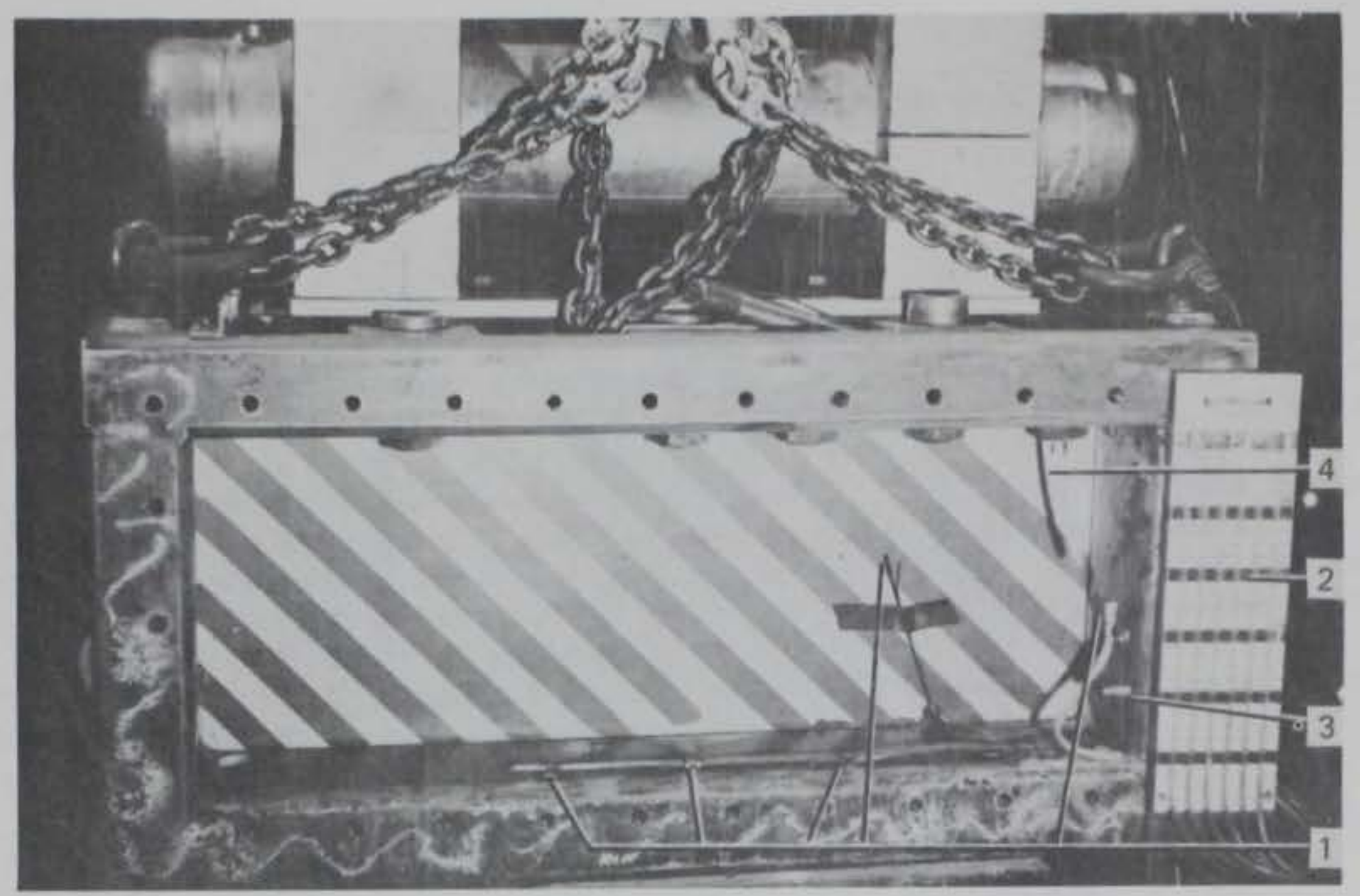

Numbers represent: 1. Piezometric tips. 2. Manometer. 3. Uplift overflow control. 4. Large water feed pipe to reservoir.

Figure 3. Front view of centrifugal strong box

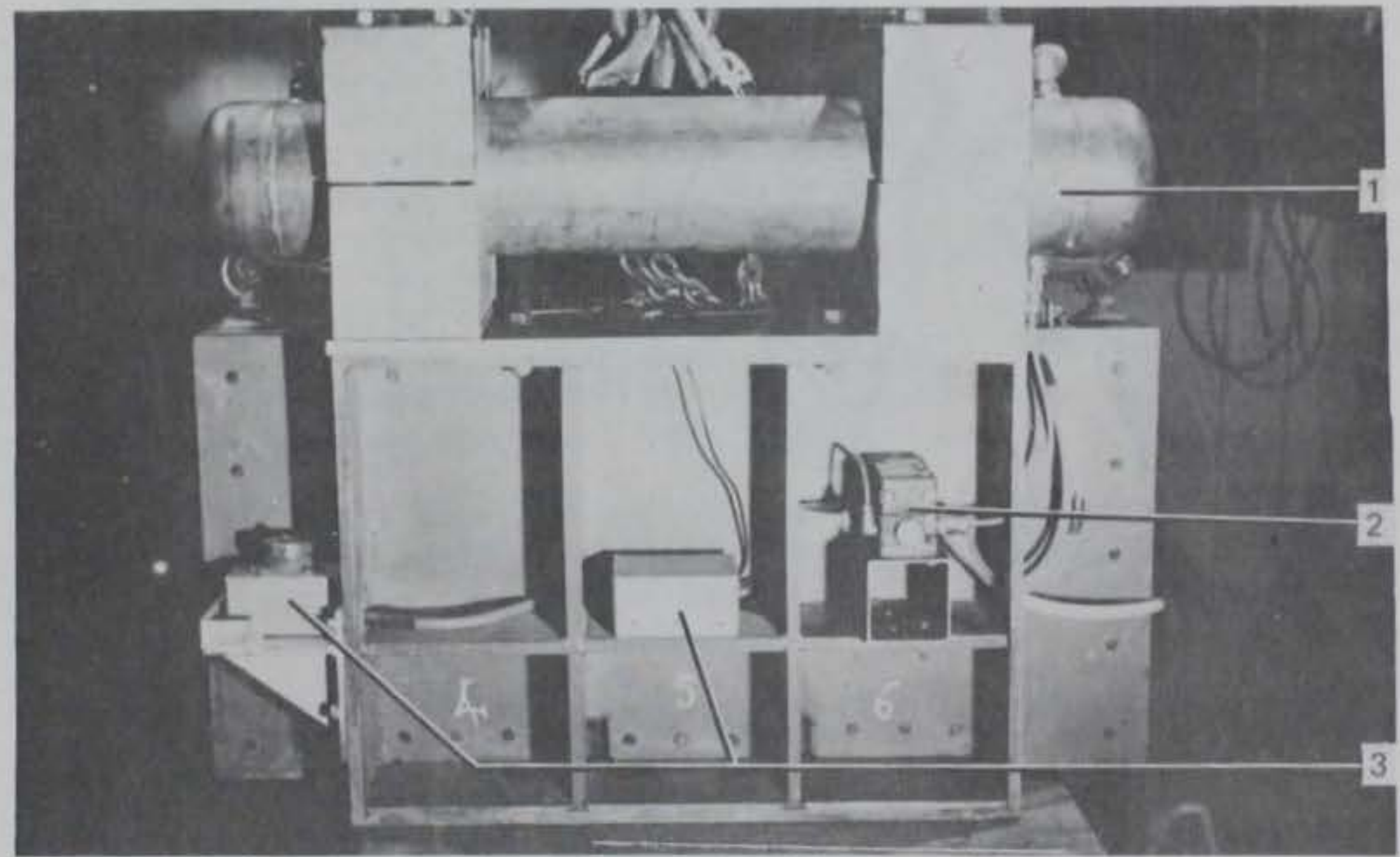

Numbers represent: 1 . One-half cubic-foot tank and mounting. 2. Compressed air operated valve to control flow from tank. 3. Electrical boxes for connections for transducers.

Figure 4. Back view of centrifugal strong box 


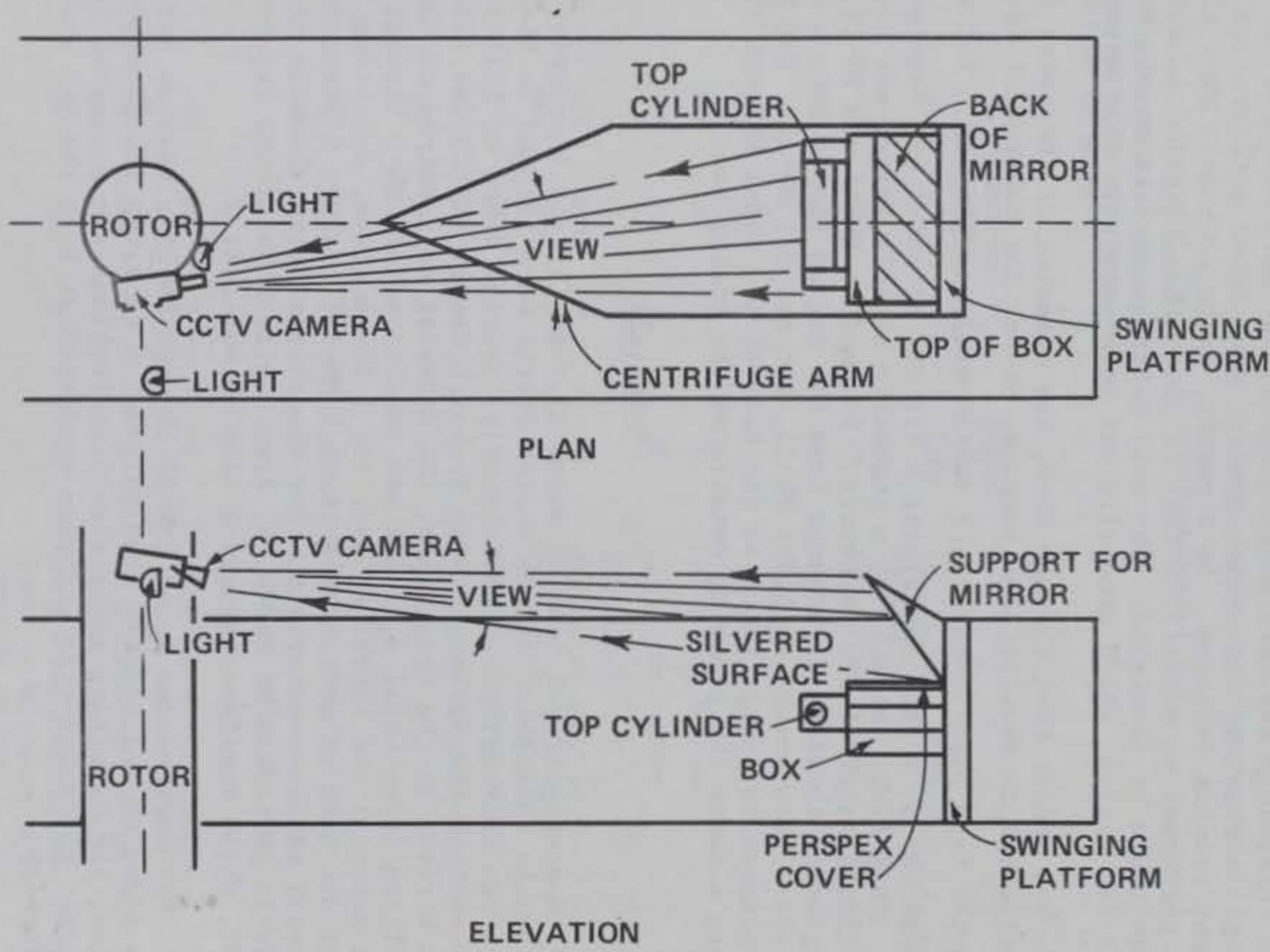

Figure 5. Closed circuit television (CCTV) view of centrifugal model 
October to December 1977, and (b) a series of 6 models tested in April and May 1978, listed in Tables 2 and 3, respectively. These tables present test data, model identification, model geometry, material used, and observations.

As shown in Table 2 , tests on models MW-0 through MW-3 were performed on material A. However, after these tests it became apparent that this material was much too permeable for the existing water supply as the maximum phreatic level obtainable was very small. Hence, the only water in the models was due to capillary saturation, which drained down under acceleration and flowed away without causing failures. As a result, tests on models $M W-4$ through $M W-13$ were performed on material B that is finer than material A, and high phreatic levels could be developed. The soil material used in models MW-20 through MW-25 was varied, which generally was more permeable than material B.

For models MW-4 through MW-8, the diameter of the water feed pipe was insufficient to develop high seepage; hence, for subsequent tests, a larger diameter feed pipe (capacity, $1 \mathrm{ft}^{3} / 20 \mathrm{~min}$ ) was plumbed. For models MW-9 through MW-13, a tank containing a $1 / 2 \mathrm{ft}^{3}$ of water was mounted on the strong box. This tank, operated by a pneumatic shuttle valve, was used to supply additional water to the reservoir. For models MW-11 and MW-12, this reservoir was plumbed to flush the debris from the failed slopes into a cavity beneath the box. This worked well for MW-11, but not for MW-12. For MW-13, the tank was plumbed to supply water to the base of the model through the key material. Figure 4 shows the plumbing details on the strong box.

\section{Materials}

Approximately 2 tons of minus $12.7-\mathrm{mm}(1 / 2-\mathrm{in.})$ material sampled from a coal waste embankment in the United States were shipped in 55-gal drums to Cambridge University. Simultaneously, several drums of full-size material were sent to the Spokane Mining Research Center (SMRC) for laboratory testing. Upon arrival at the University, the material was scalped on the $2.36-\mathrm{mm}$ sieve, resulting in material $\mathrm{A}$, which was used in models $\mathrm{MW}-0$ through $\mathrm{MW}-3$. Later this material was rescalped over the $1.18-\mathrm{mm}$ sieve, resulting in material $\mathrm{B}$, which was used in models MW-4 through MW-13. Figure 6 presents the grain-size analyses of these materials. For comparison, also shown is the sieve analysis of MW-13 performed at the U. S. Army Engineer Waterways Experiment Station (WES), which verifies the grain size of material B.

For test series No. 2 ( $M W-20$ through $M W-25$ ), various percentages of fines were added to and removed from material B to alter the permeability characteristics; the resulting grain-size distributions are presented in Figure 7 , which contains the grain-size analyses conducted at both the WES and Cambridge University.

Field density tests at the embankment site in New Mexico indicated the average dry density of the embankment was 98.1 pcf, with the average dry density of the minus $12.7-\mathrm{mm}(1 / 2-\mathrm{in}$.) fraction being 81.5 pcf. The average 


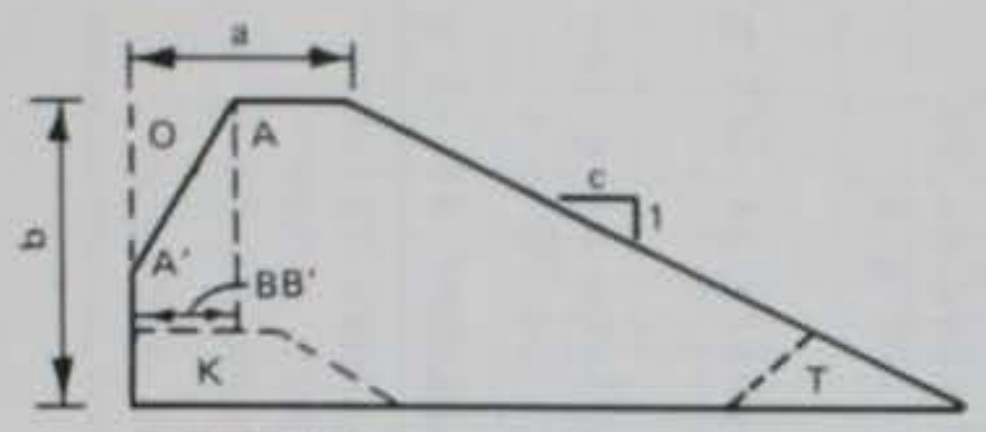
AA: DIAGONAL RESEAVOIR $O A^{\prime}=140 \mathrm{~mm}, O A=80 \mathrm{~mm}$ DESIGNATED D IN TABLE.
8B. VERTICAL RESERVOIR - FULL HEIGHT WIDTH $50 \mathrm{~mm}$ DESIGNATED $\vee$ IN TABLE.

R RESERVOIR IN MW: 3 AND AFTERWARDS $K$ KEY TRENCH POSITION IN MW-12 AND MW-13 T TOE DRAIN POSITION IN MW-13

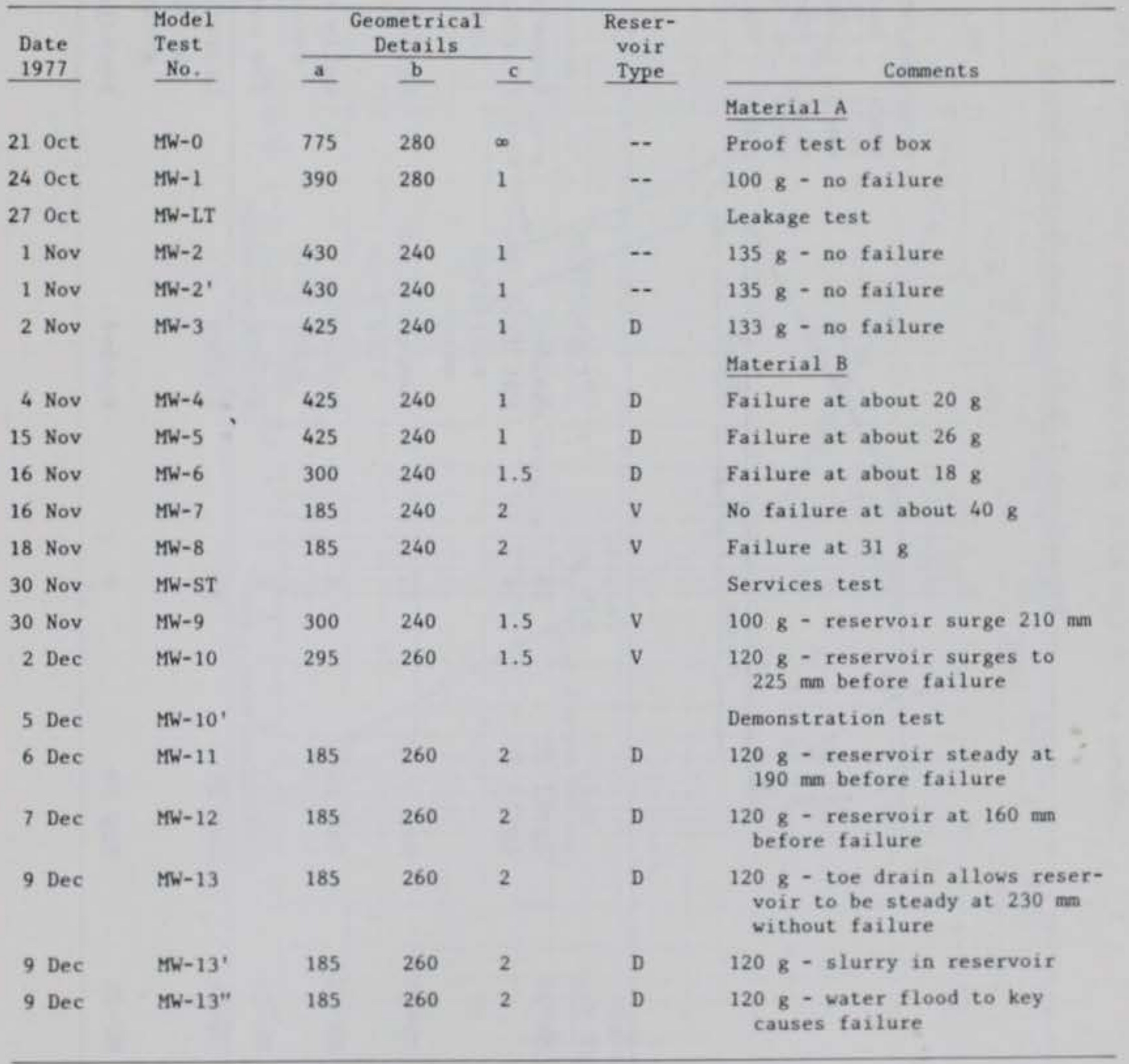


Table 3

Experimental Data - Test Series No. 2

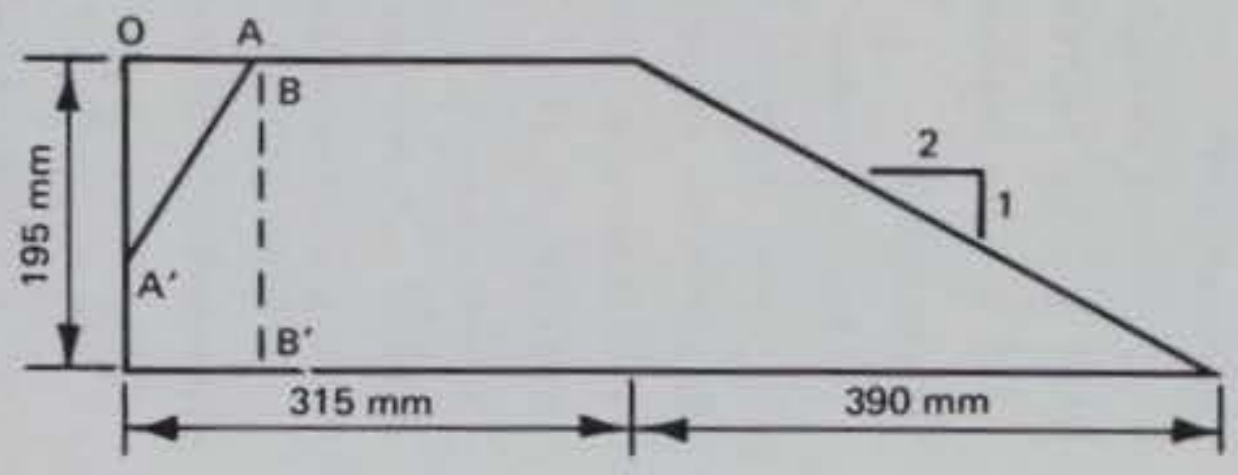

RESERVOIR TYPES:

MW-20 DIAGONAL RESERVOIR OAA

MW-21 $\quad \mathrm{OA}^{\prime}=130 \mathrm{~mm}$

MW-22 $\quad O A=80 \mathrm{~mm}$

MW-23 FULL HEIGHT RESERVOIR BB'

MW-24 OB $=70 \mathrm{~mm}$

MW-25 FULL HEIGHT RESERVOIR BB' $O B=190 \mathrm{~mm}$

\begin{tabular}{|c|c|c|c|c|}
\hline $\begin{array}{l}\text { Model } \\
\text { Test No. }\end{array}$ & Date & $\begin{array}{l}\text { Percent } \\
>75 \mu \mathrm{m}\end{array}$ & Preparation & Comments \\
\hline $\mathrm{MW}-20$ & $\begin{array}{ll}\text { April } & 25 \\
\text { April } & 26\end{array}$ & $\begin{array}{l}26 \\
26\end{array}$ & $\begin{array}{l}\text { Rodded } \\
\text { Cut from con- } \\
\text { solidated } \\
\text { mass }\end{array}$ & $\begin{array}{l}\text { Consolidation at } 90 \mathrm{~g} \text { 's for } 125 \mathrm{~min} \\
\text { Overtopping and erosion of } \\
\text { front face at } 120 \mathrm{~g} \text { 's }\end{array}$ \\
\hline$M W-21$ & May 4 & 13 & $\begin{array}{l}\text { Compacted on } \\
\text { clay base }\end{array}$ & Narrow erosion gully at $120 \mathrm{~g}^{\prime} \mathrm{s}$ \\
\hline$M W-22$ & May 10 & 8 & $\begin{array}{l}\text { Rodded on } \\
\text { clay base }\end{array}$ & $\begin{array}{l}\text { Gully down backplate as g re- } \\
\text { duced from } 120 \text { to } 30 \mathrm{~g}^{\prime} \mathrm{s}\end{array}$ \\
\hline MW-23 & May 23 & 8 & Rodded & Toe erosion initiated at $75 \mathrm{~g}^{\prime} \mathrm{s}$ \\
\hline$M W-24$ & May 25 & 34 & Rodded & $\begin{array}{l}\text { Undrained rotational failure } \\
\text { at } 15 \mathrm{~g} \text {; further retro- } \\
\text { gressive failure at } 50 \mathrm{~g}^{\prime} \mathrm{s}\end{array}$ \\
\hline$M W-25$ & May 29 & 9 & Rodded & Seepage beach at $100 \mathrm{~g}^{\prime} \mathrm{s}$ \\
\hline
\end{tabular}




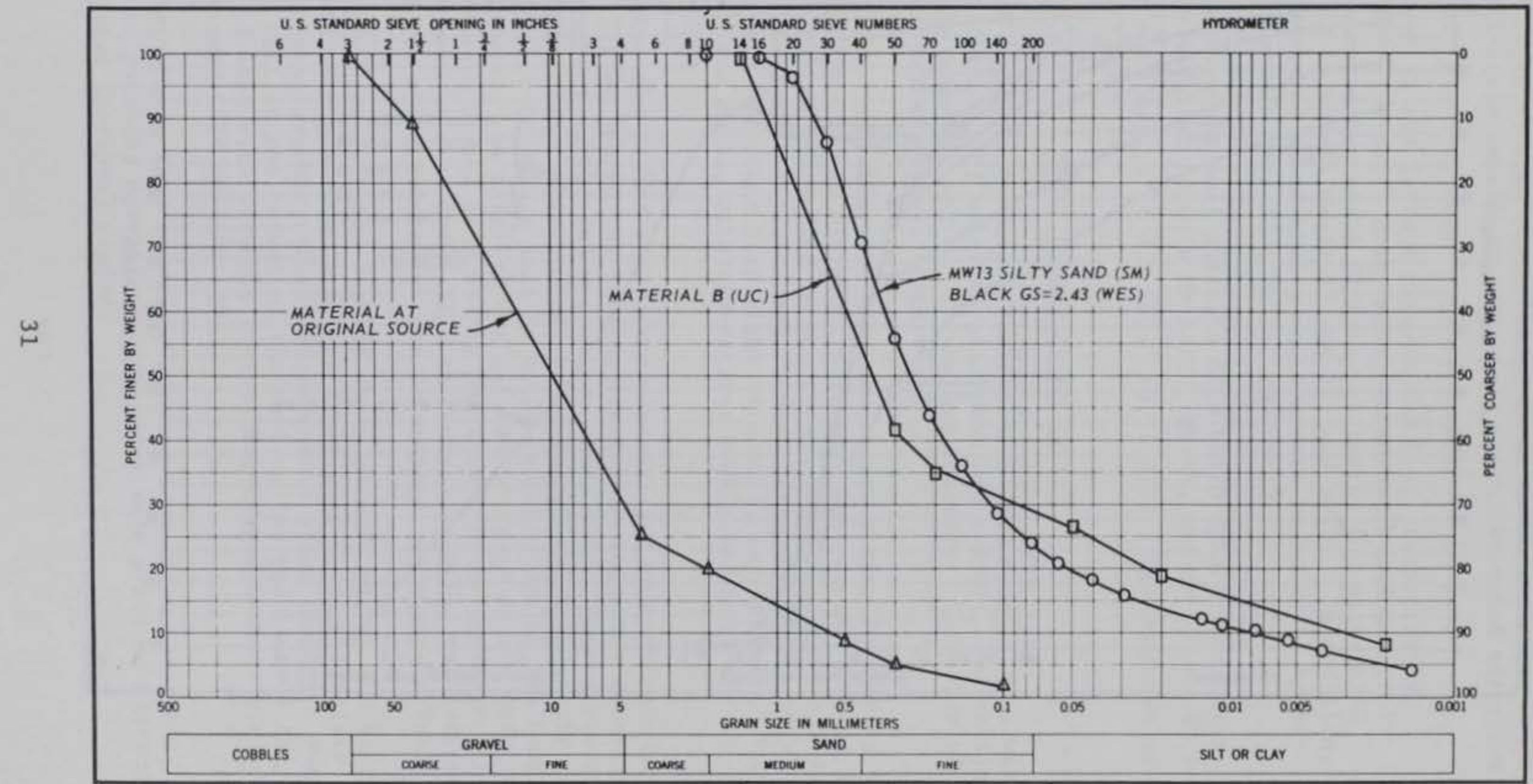

Figure 6. Grain-size distributions of coal waste material used in model test series No. 1 


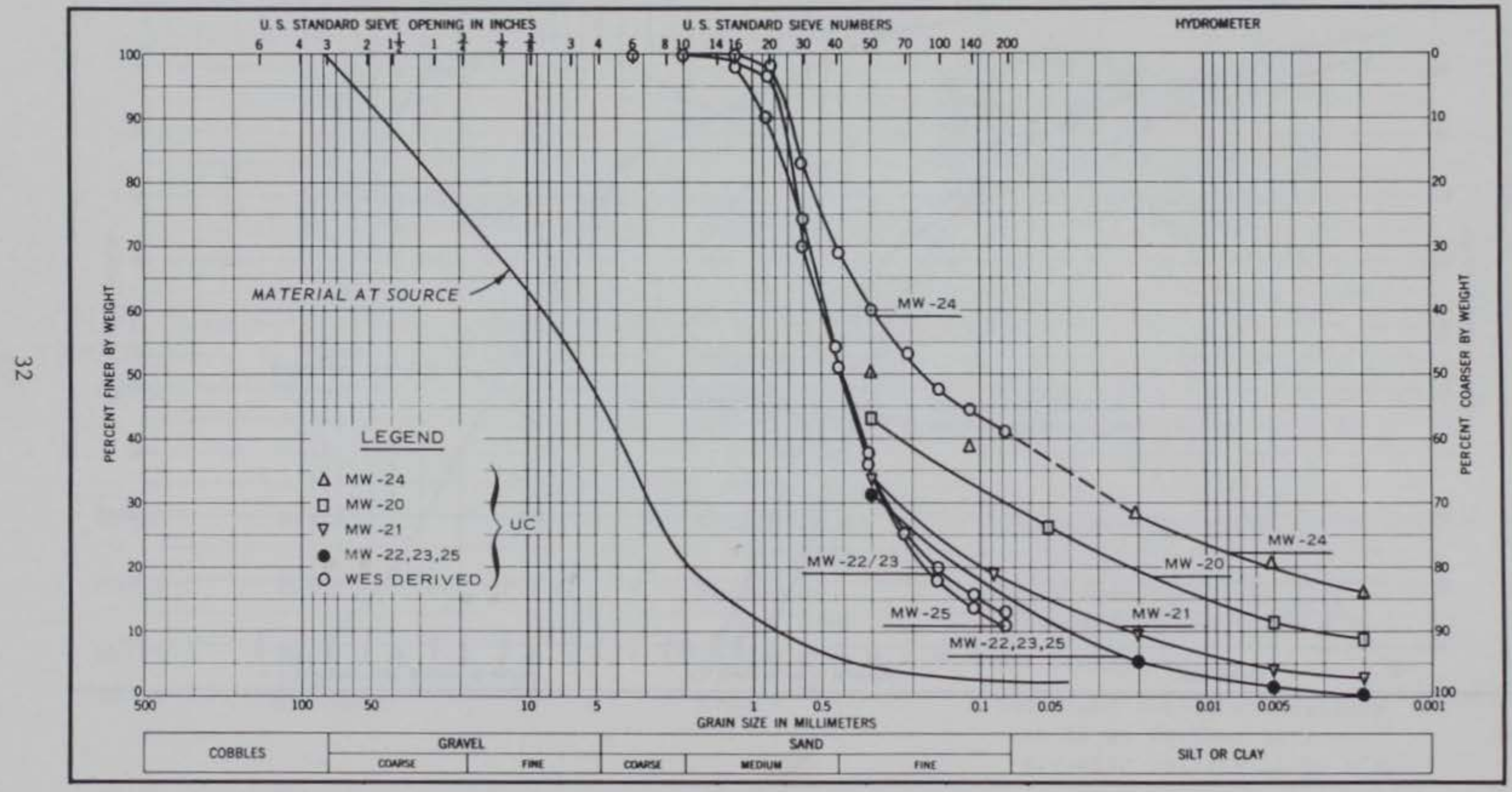

Figure 7. Grain-size distribution of coal waste material used in model test series No. 2 
water content of the embankment was 8.6 percent. Figure 8 presents the SMRC results of $228.6-\mathrm{mm}^{-}(9-\mathrm{in} .-)$ diam consolidated drained (CD) triaxial compression tests on the full-scale embankment material, which indicated effective strength parameters of $\emptyset^{\prime}=30.5 \mathrm{deg}, \quad c^{\prime}=11.0 \mathrm{kN} / \mathrm{m}^{2}(1.60 \mathrm{psi})$.

Figures 9 through 12 and Table 4 present and list, respectively, the results of $35.6-\mathrm{mm}-(1.4-\mathrm{in} .-)$ diam consolidated undrained triaxial tests with pore pressure measurements ( $\bar{R}$ triaxial tests) for material B and the materials used in models $M W-22 / 23$, MW-24, and $M W-25$. In addition, Table 4 lists the results of permeability measurements on triaxial specimens of material from models MW-22/23, MW-24, and MW-25.

Figure 13 presents additional strength data based upon direct shear tests at Cambridge on material used in MW-22/23, MW-24, and MW-25, which indicated values of $\emptyset^{\prime}=39 \mathrm{deg}, c^{\prime}=3.5 \mathrm{kN} / \mathrm{m}^{2}(0.51 \mathrm{psi})$. The combined results are present in Figure 14.

\section{Model Construction}

The sequence of model construction consisted of five basic steps, which were (a) template placement, (b) material placement and rodding, (c) marking of model, (d) template removal, and (e) strong box assembly. Each step of the sequence is described as follows (Figure 15):

a. Aluminum sheet templates outlining the slope, crest, and toe of the modeled embankment, and different sections, such as the key and toe drain, are fitted and wedged in the strong box and lightly oiled. Figure 15 shows the template used when making model MW-13, which had a diagonal reservoir (top right of model), key material (bottom right), and toe drain, although earlier models did not have all these features.

b. Subsequently, the sieved mine waste material and coarse drain material were placed behind the forming template. Since the material had not been wet sieved and was stored under water, during placement it had a slushy consistency, and it was rodded not for density control but rather to ensure that no voids remained behind the templates. After placement, the material was allowed to drain as the model and strong box were tilted to a 45-deg position. After drainage, the box and model were laid horizontally, the excess material was screeded away, and its moisture content was determined, as shown in Table 5.

c. The model surface was then lightly spray painted white, and silvered nylon beads were placed on a $15-$ by $30-\mathrm{mm}$ grid using a template to enhance photographic records of movements after testing. Note in Figure 15 that at the outset of the test series the back of the box had been painted with strongly contrasting diagonal white stripes, which enhanced CCTV observation.

d. The templates were then carefully removed from their positions, and last minute patching operations were undertaken prior to placing the Plexiglas (perspex) window. 
TRIAXIAL SHEAR

\begin{tabular}{|c|c|c|c|c|c|c|c|c|c|c|c|c|c|c|}
\hline \multirow{3}{*}{$\frac{y}{2}$} & \multicolumn{3}{|c|}{ FLACEMENT } & \multicolumn{3}{|c|}{ VOBO FATIO } & \multicolumn{6}{|c|}{ IEST VALUES RT FALUWE } & \multirow{2}{*}{\multicolumn{2}{|c|}{ 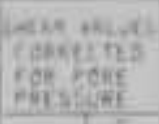 }} \\
\hline & beveris. & METLE & veskit & & $50 \cos 061+$ & & Finterta & racieftus & Matering & $\begin{array}{l}\text { vount: } \\
\text { chentit }\end{array}$ & atisets & bystates & & \\
\hline & $|F| r \mid$ & rovernet & entiphyos & Ftatencon] & bisteo & fatlone & Fysoune & Whit! & eistonst & twrite. & $|8 x|$ & insti & 1648 & $n \leq 1$ \\
\hline & & & & & FAILURE & AT MA & $x[M U M$ & STRES & 15. श्रमा10 & & & & & \\
\hline i & wis & n.5. & 28:? & Q.7x+! & c. $19+5$ & Qviste & $15 \cdot 0$ & 9.9 & 15,15 & 5. $91 \pi$ & A $\rightarrow+1$ & $7 \pi: 2$ & & \\
\hline 2 & 7sie & $9 .+8$ & $+7,7$ & e. $m+?$ & h-1064 & A. 2713 & inie & $0: 9$ & wo: & ains & 0.65 & Enis & $9.5 y$ & i.e. \\
\hline 3 & $33 / 2$ & a. 8 & +3.7 .8 & 0.3162 & 0.2971 & D.2175 & sed.dt & 0.0 & $60: 0$ & 11,32 & 12.71 & 129.1 & & \\
\hline & & & & & & & & & & & & & & \\
\hline & & & & & & & & & & & & & & \\
\hline & & & & & & & & & & & & & & \\
\hline & & & & & & & & & & & & & & \\
\hline
\end{tabular}
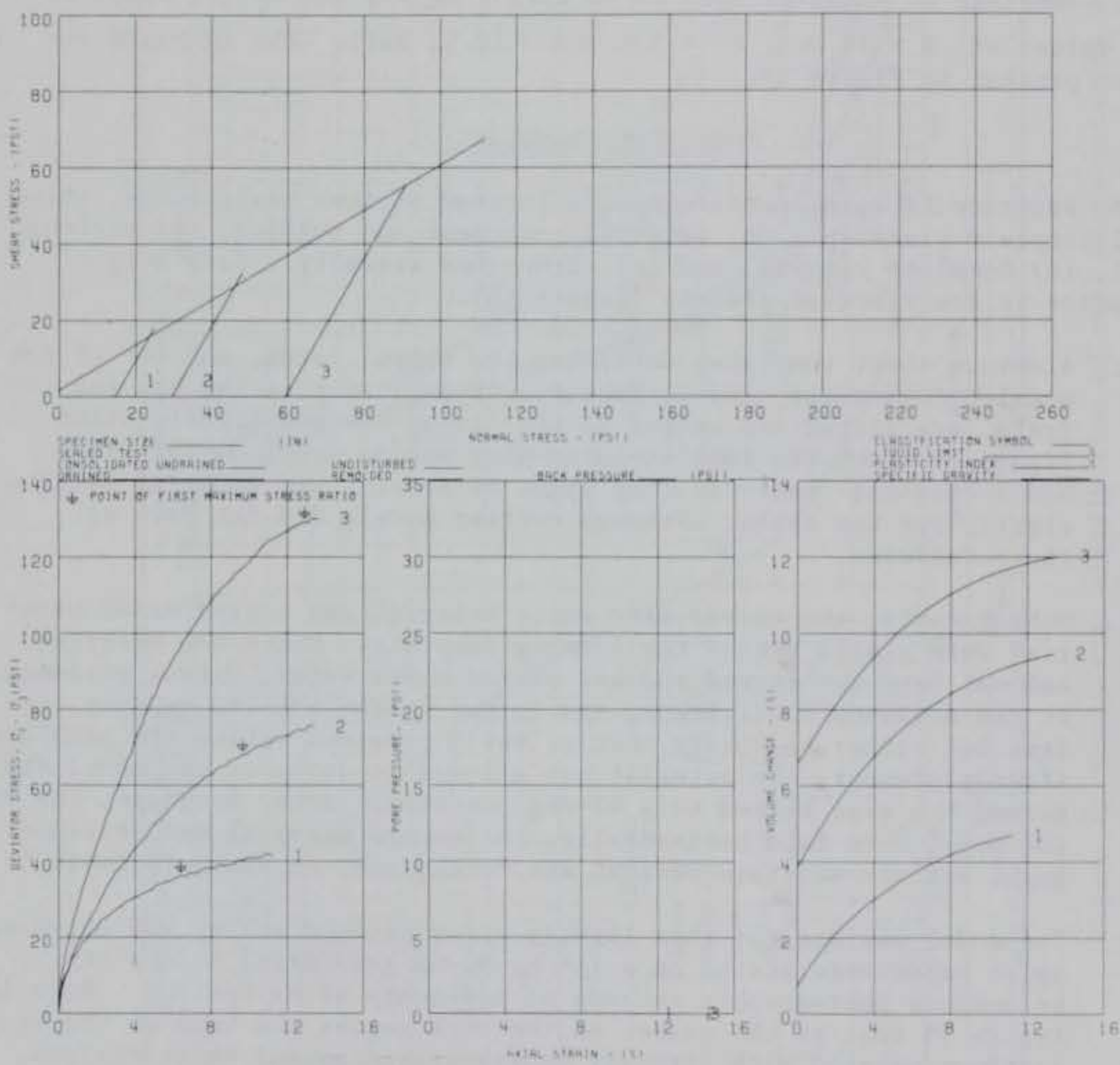

SAMPLE NO.

HOLE NO

DEPTH

[F T]

Figure 8. Results of 9-in.-diam triaxial compression tests on original coal waste material (SMRC) $\left(1 \mathrm{psi}=6.9 \mathrm{kN} / \mathrm{m}^{2}\right)$ 


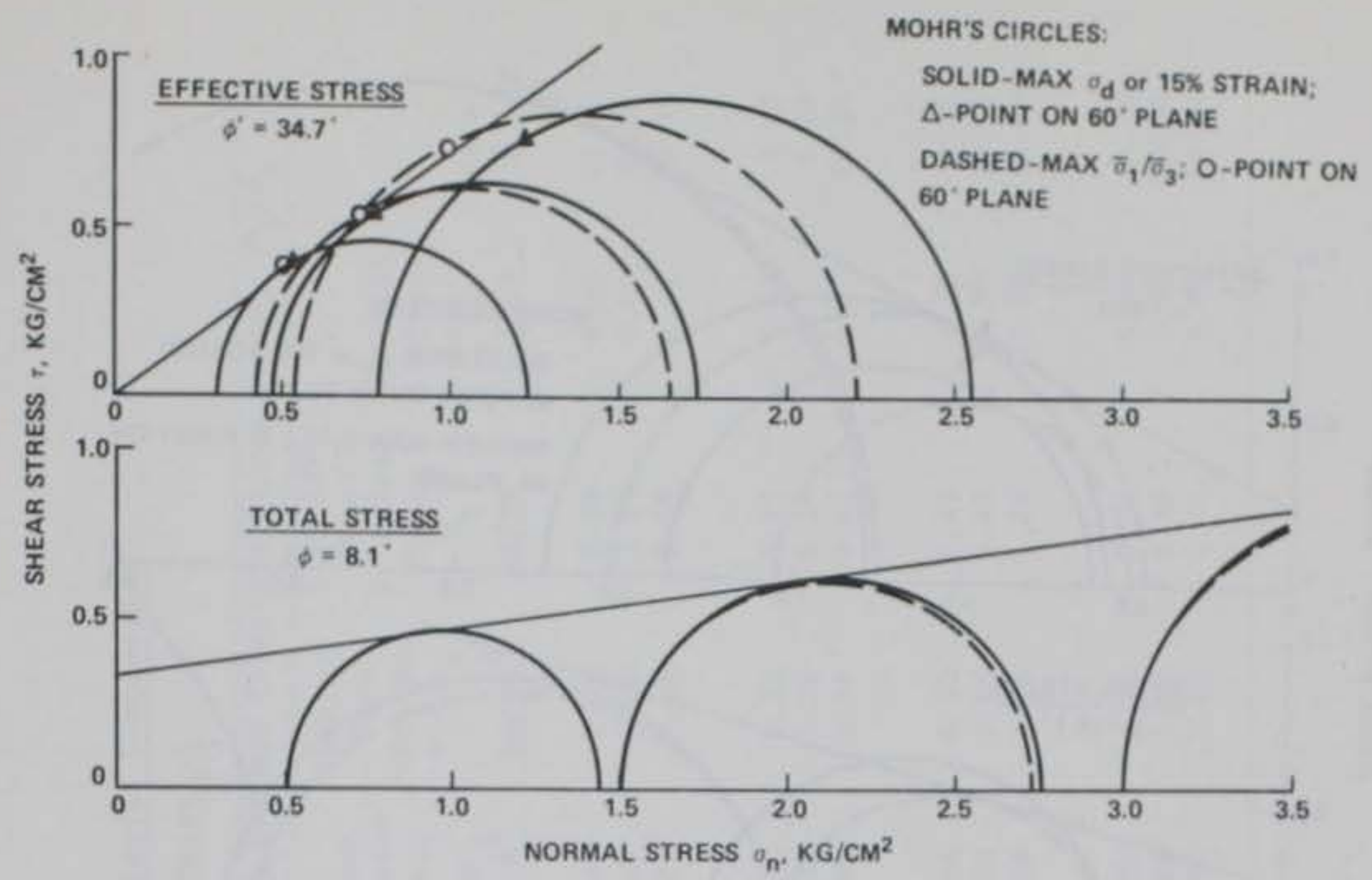

Figure 9. Ef fective and total stress envelopes for material B used in centrifugal models MW-9 through $\mathrm{MW}-13\left(1 \mathrm{~kg} / \mathrm{cm}^{2}=98 \mathrm{kN} / \mathrm{m}^{2}\right)$

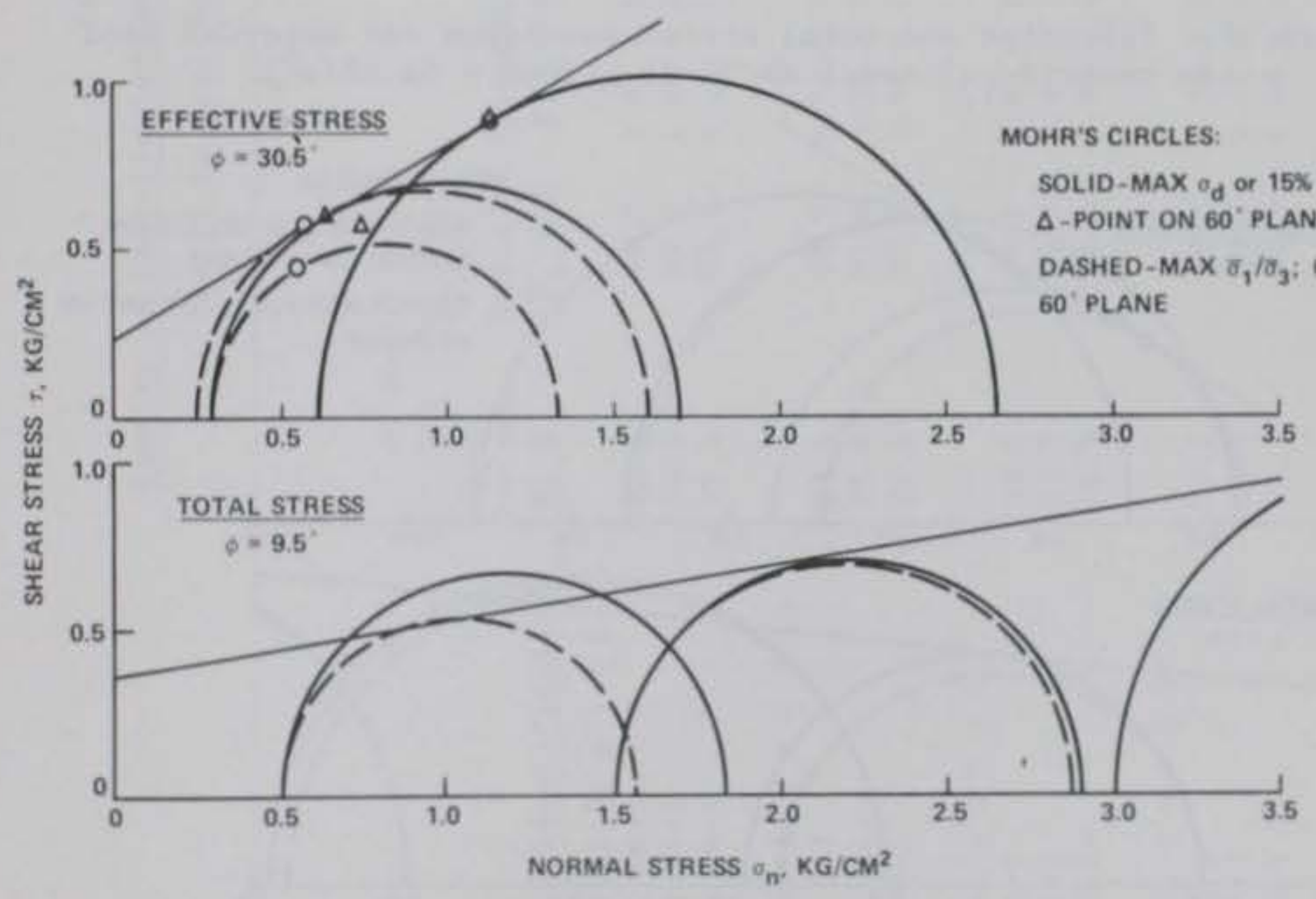

Figure 10. Effective and total stress envelopes for material used in centrifugal models $\mathrm{MW}-22$ and $\mathrm{MW}-23\left(1 \mathrm{~kg} / \mathrm{cm}^{2}=98 \mathrm{kN} / \mathrm{m}^{2}\right)$ 


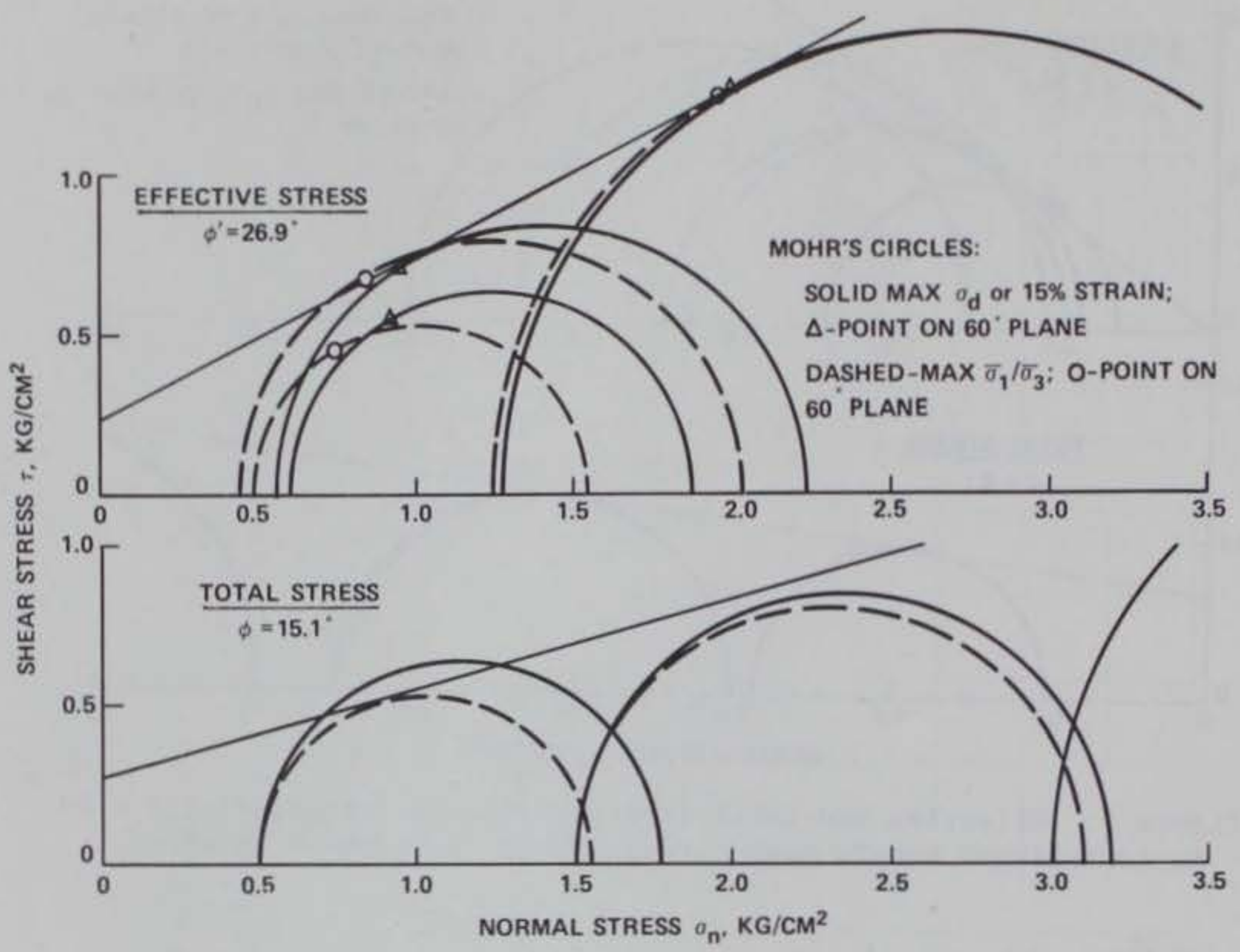

Figure 11. Effective and total stress envelopes for material used in centrifugal model $\mathrm{MW}-24\left(1 \mathrm{~kg} / \mathrm{cm}^{2}=98 \mathrm{kN} / \mathrm{m}^{2}\right)$

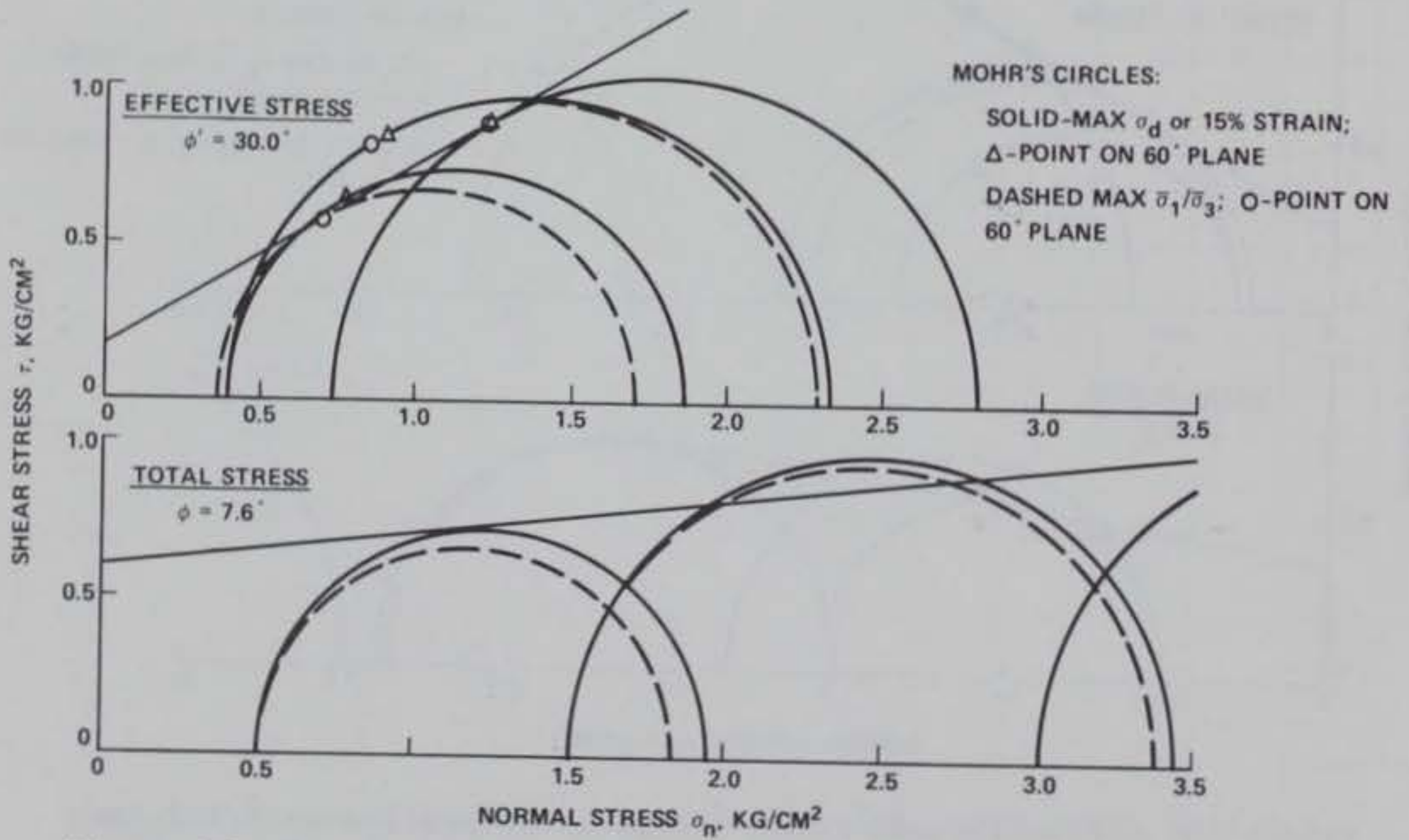

Figure 12. Effective and total stress envelopes for material used in centrifugal model $\mathrm{MW}-25\left(1 \mathrm{~kg} / \mathrm{cm}^{2}=98 \mathrm{kN} / \mathrm{m}^{2}\right)$ 
Table 4

Summary of Consolidated-Undrained Triaxial Compression

Tests on Coal Waste Model Material

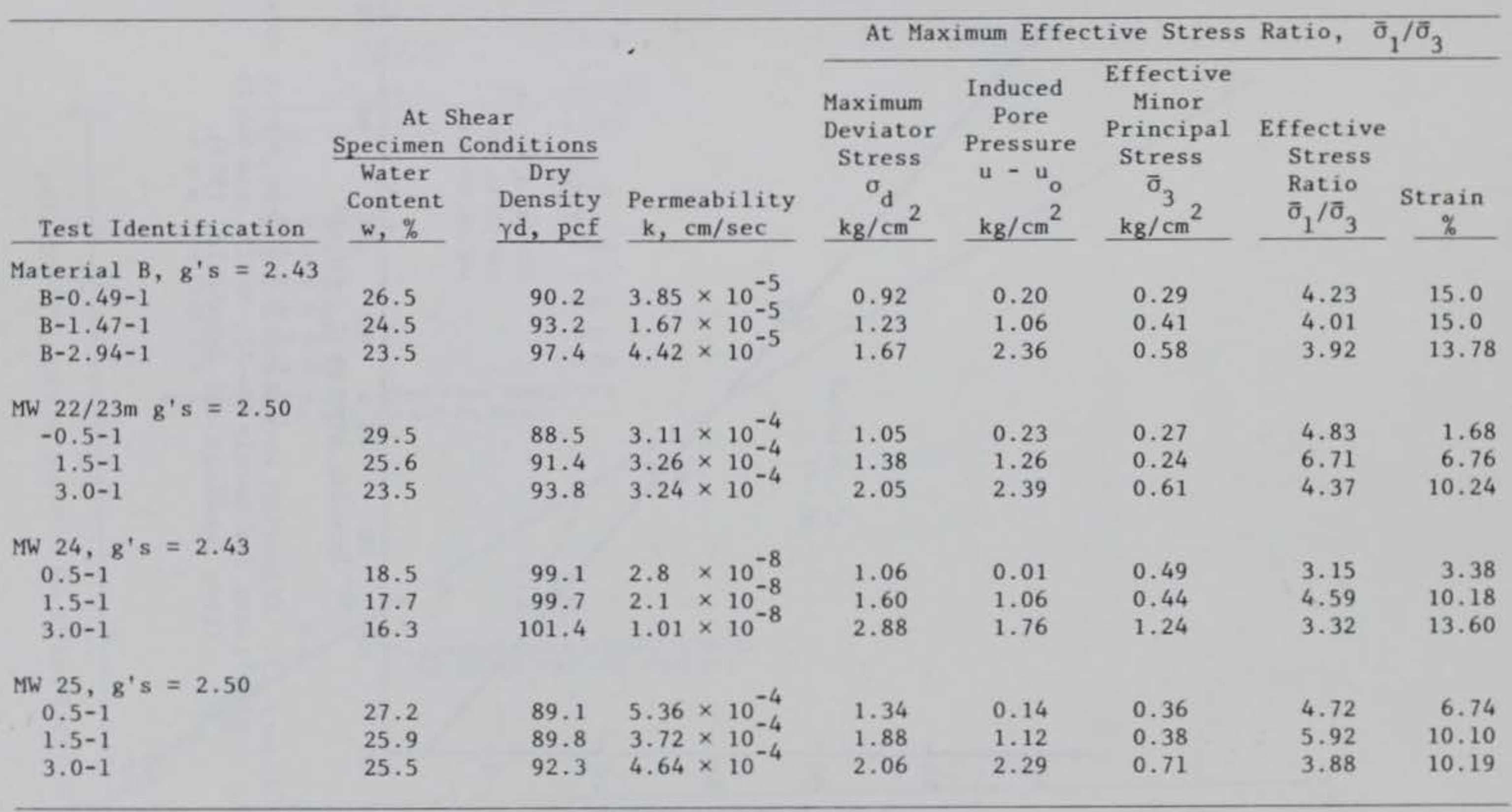




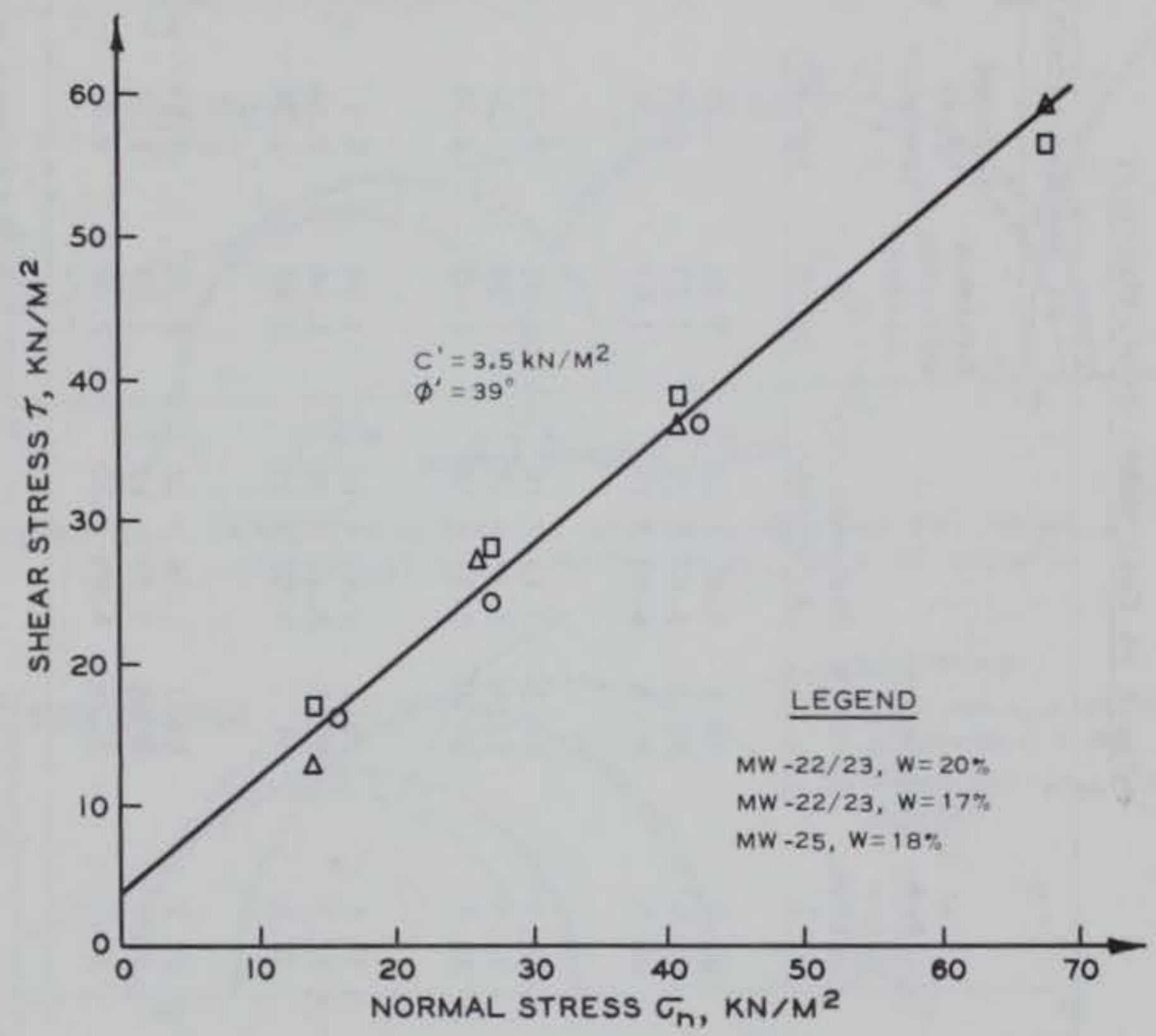

Figure 13. Effective stress envelope from direct shear box tests for models $\mathrm{MW}-22, \mathrm{MW}-23$, and $\mathrm{MW}-25$

(from Goodings and Schofield, 1978) 


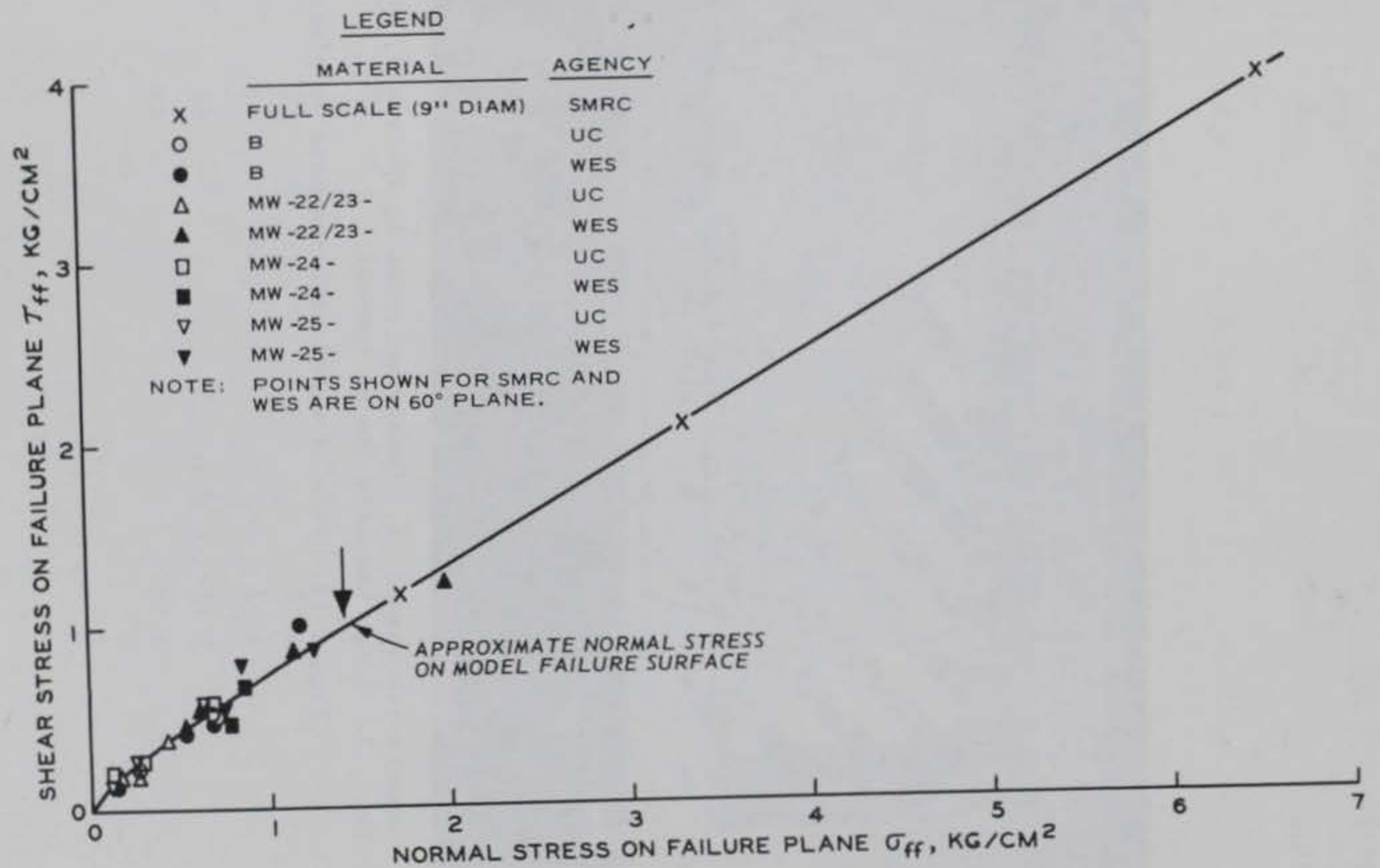

Figure 14. Combined shear strength parameters for coal waste material used in centrifugal model tests $\left(1 \mathrm{~kg} / \mathrm{cm}^{2}=98 \mathrm{kN} / \mathrm{m}^{2}\right)$ 


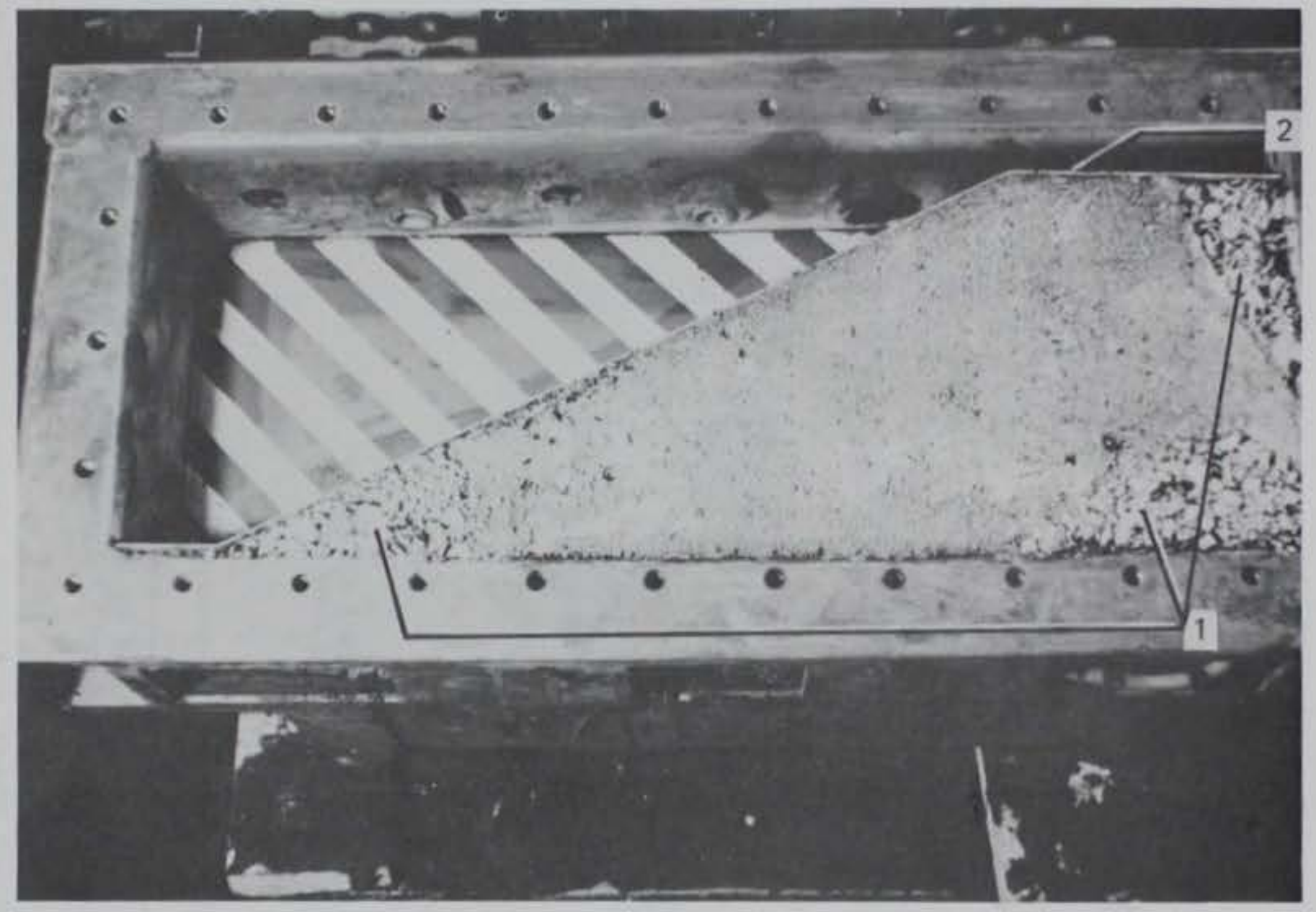

Numbers represent: 1. Coarse material in reservoir, key, and toe. 2. Slope template (to be removed)

Figure 15. View of model with template in place 
Table 5

Summary of Water Contents and Densities for Centrifugal Models

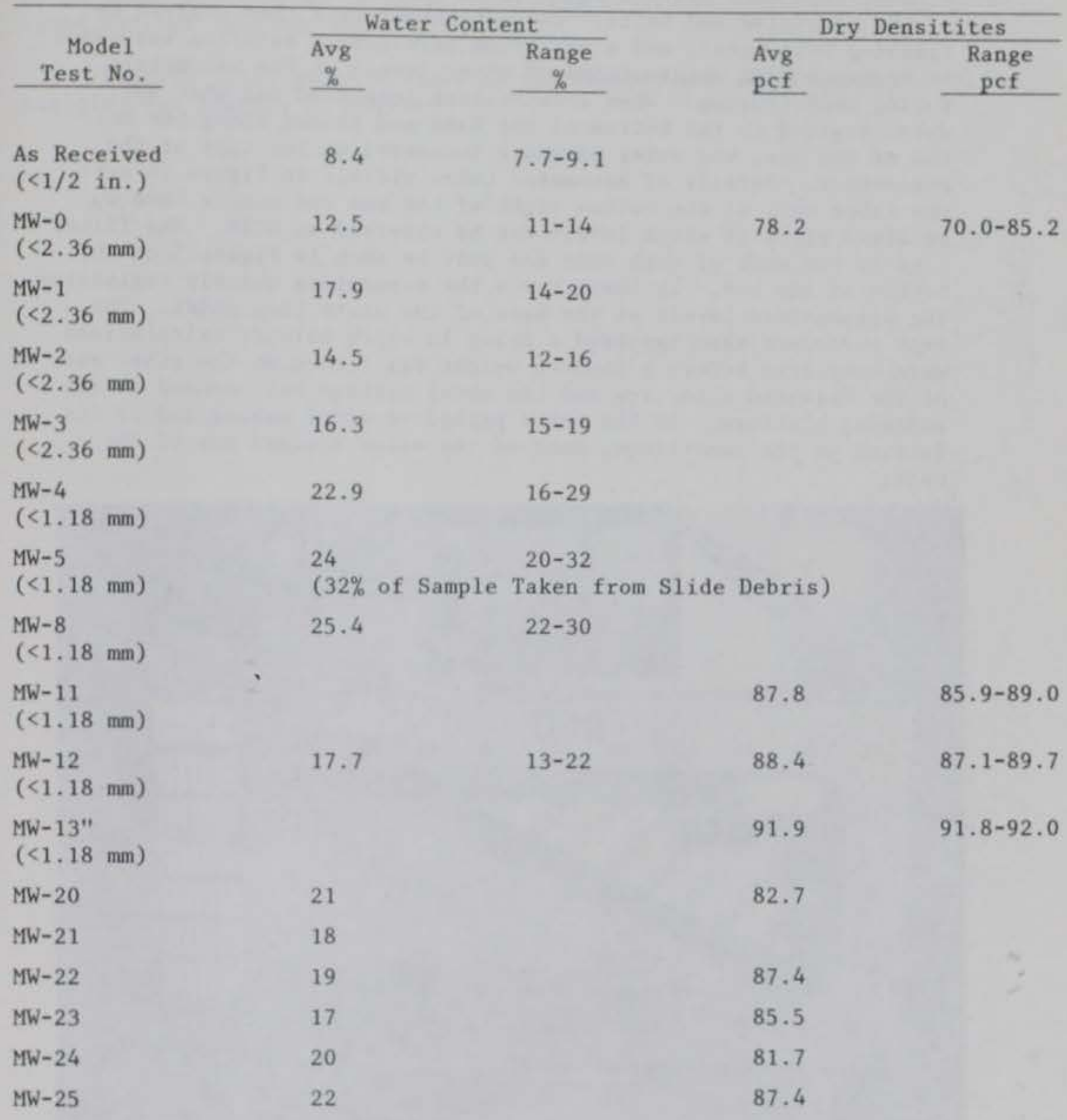


e. The final assembly step consisted of placing the lightly oiled Plexiglas window over the model, with its frame, and securing it by bolts (Figure 16). Sealing between the Plexiglas and box is accomplished by a sealant squirted on the edges prior to placement of the Plexiglas and bolts. The manometers were then deaired by flushing with water, and a potassium permaganate solution was added to enchance CCTV observations of water levels in the manometers during centrifuging. When acceleration increased and when any water drained to the bottom of the bank and flowed along the bottom of the box, the water pressure increased at the tips of the manometers. Details of manometer tubes visible in Figure 16 are: the tubes exit at the bottom right of the box and simply turn up as stand pipes in which levels can be observed on CCTV. The filter tips at the ends of each tube can just be seen in Figure 3 on the bottom of the box. In those tests the manometers quickly registered the piezometric levels at the base of the waste heap model. The test procedure then involved a delay in which balance calculations were completed before a counter weight was fitted at the other end of the balanced rotor arm and the model package was secured to its swinging platform. In the total period of model making and of its fitting on the centrifuge, much of the water drained out of the bank.

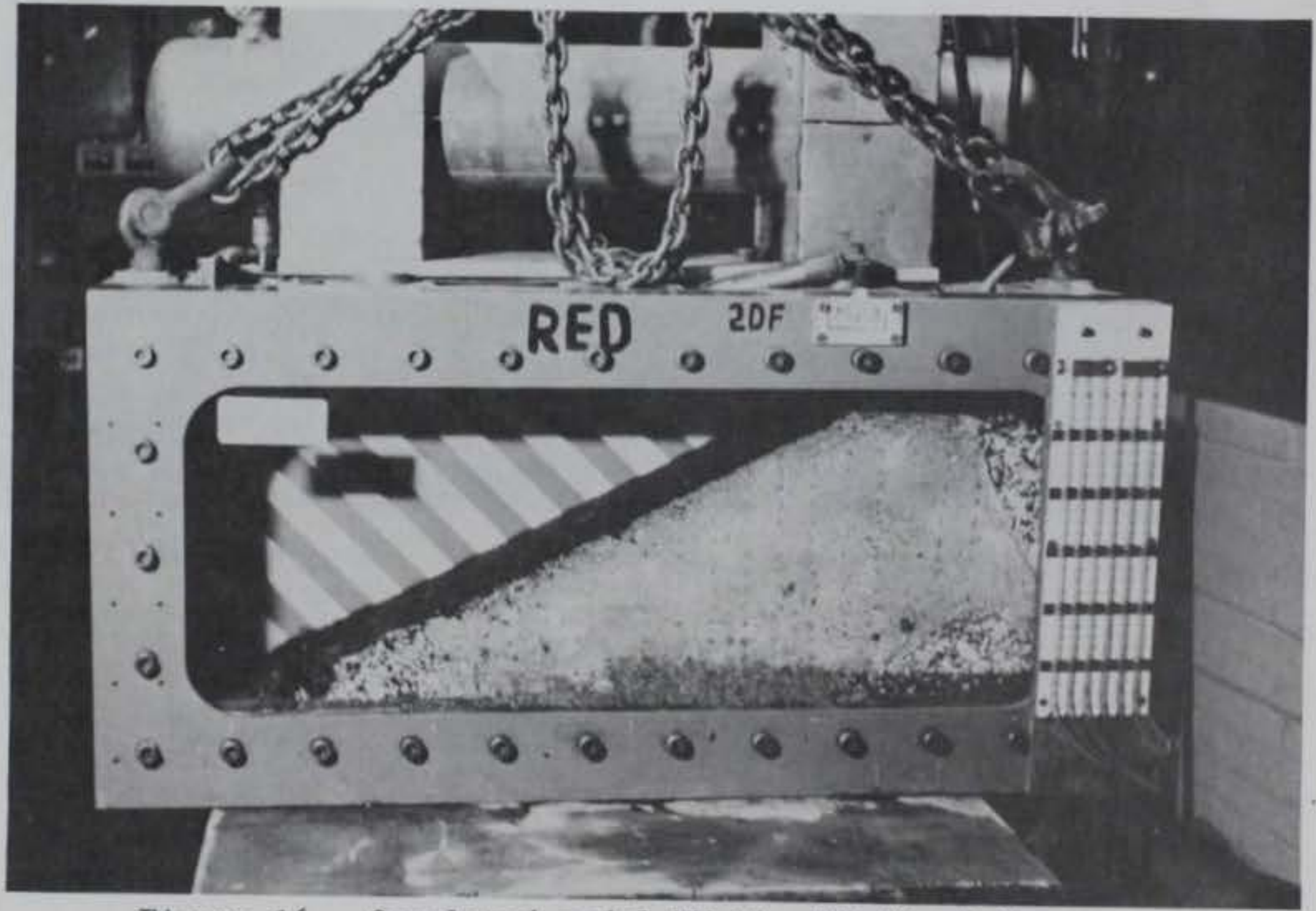

Figure 16. Completed model MW-13 with Plexiglas and picture frame bolted in place

This procedure of model preparation was used for all models, except $M W-0$, MW-20, and MW-21. Models $M W-0$ and $M W-20$ were formed by filling the box to a depth of $240-280 \mathrm{~mm}$ with coal waste material, accelerating this mass 
to 100 or $90 \mathrm{~g}$ 's and thus consolidating the material. The material was then brought to $1 \mathrm{~g}$, and the model slope was cut into this consolidated mass. Model MW-21 was statically compacted on a $10-\mathrm{mm}$-thick clay layer, in five $40-\mathrm{mm}$-thick lifts under $58-\mathrm{kN} / \mathrm{m}^{2}(8.4 \mathrm{psi})$ pressure, after which the model slope was cut into the material.

Figures 17-20 present views of the centrifugal facility pertinent to building and testing of models. 


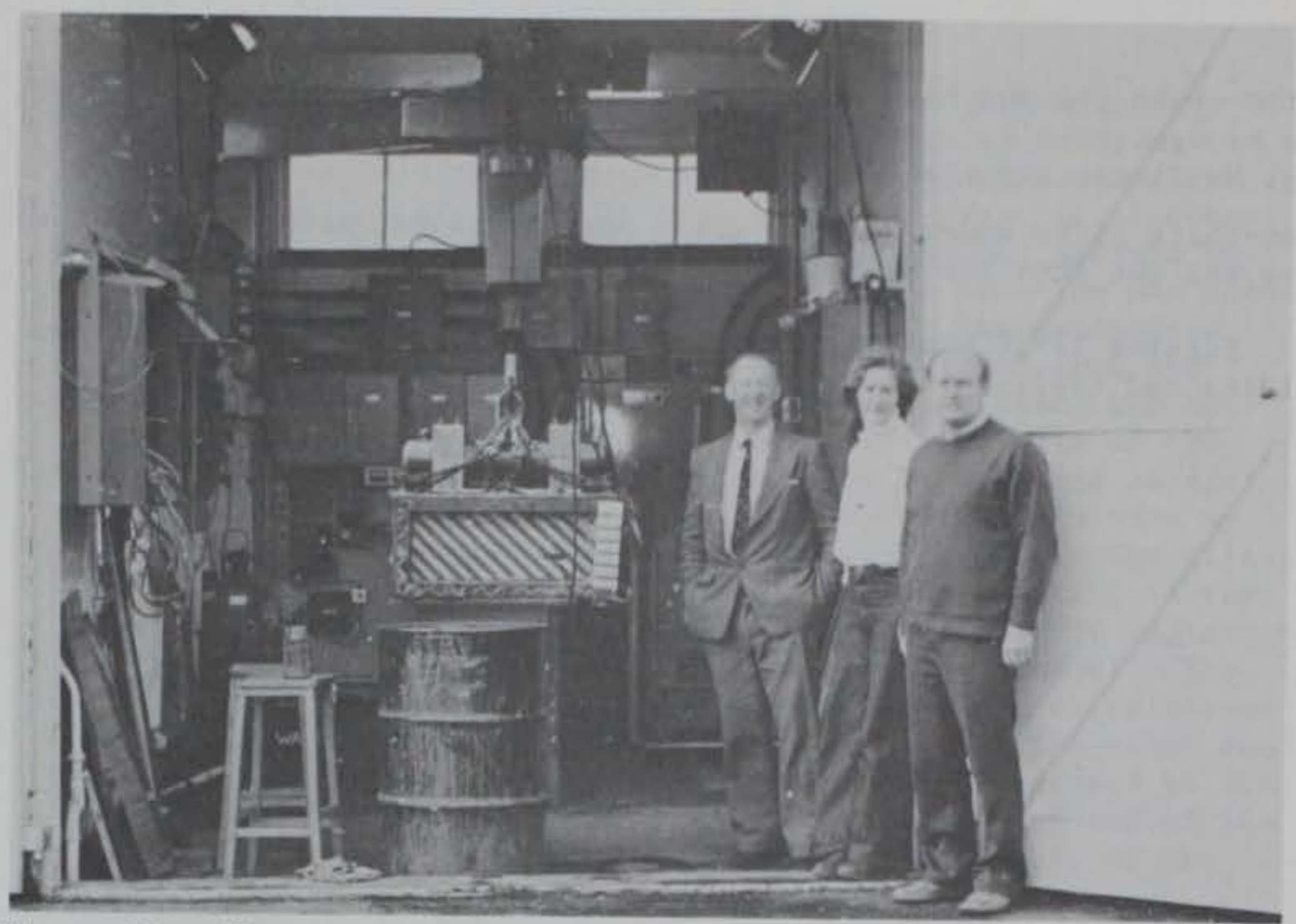

Figure 17. View into loading bay (left to right: R. G. "Jimmy" James, Deborah Goodings, and Andrew Schofield)

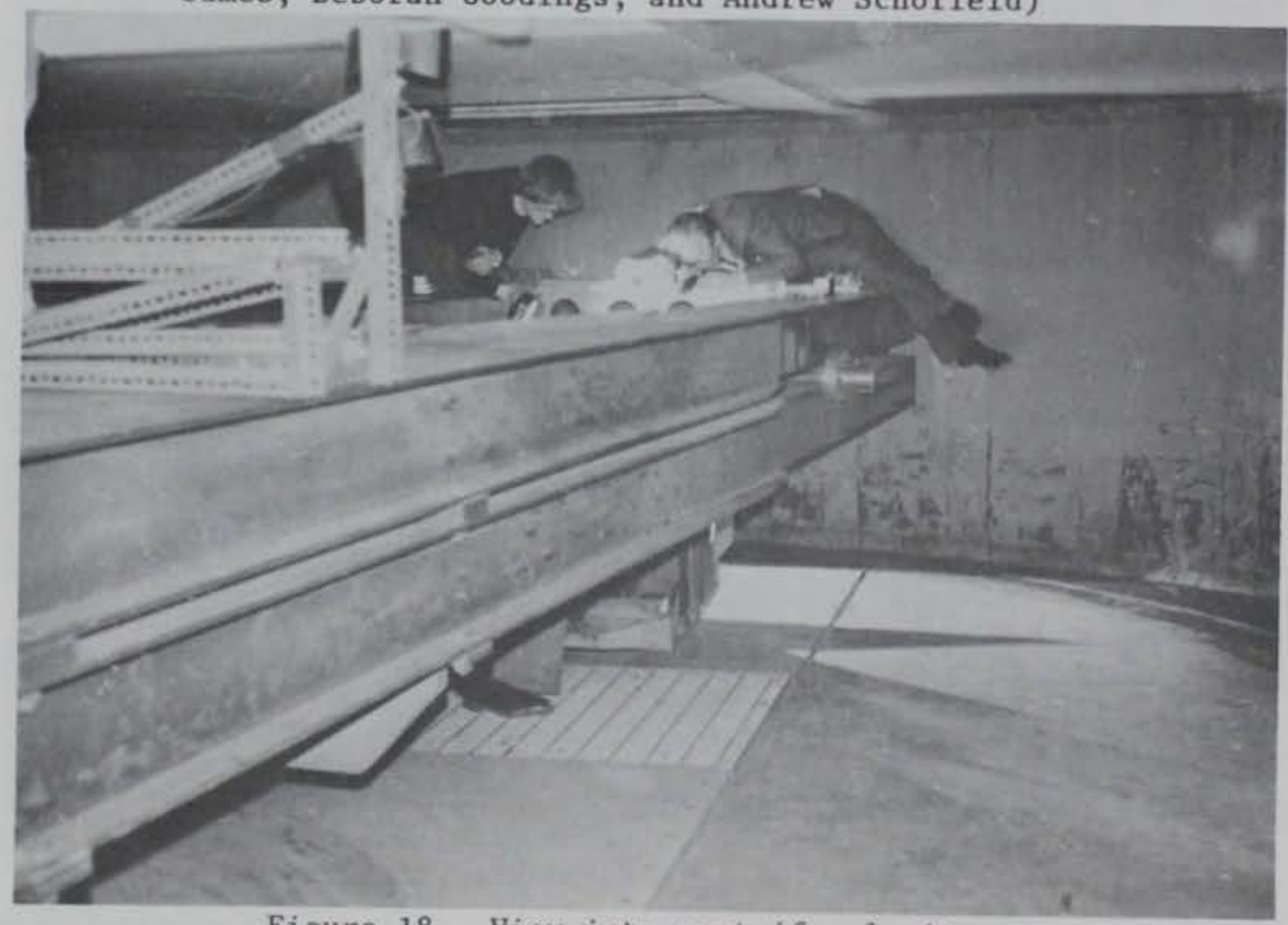

Figure 18. View into centrifugal pit 


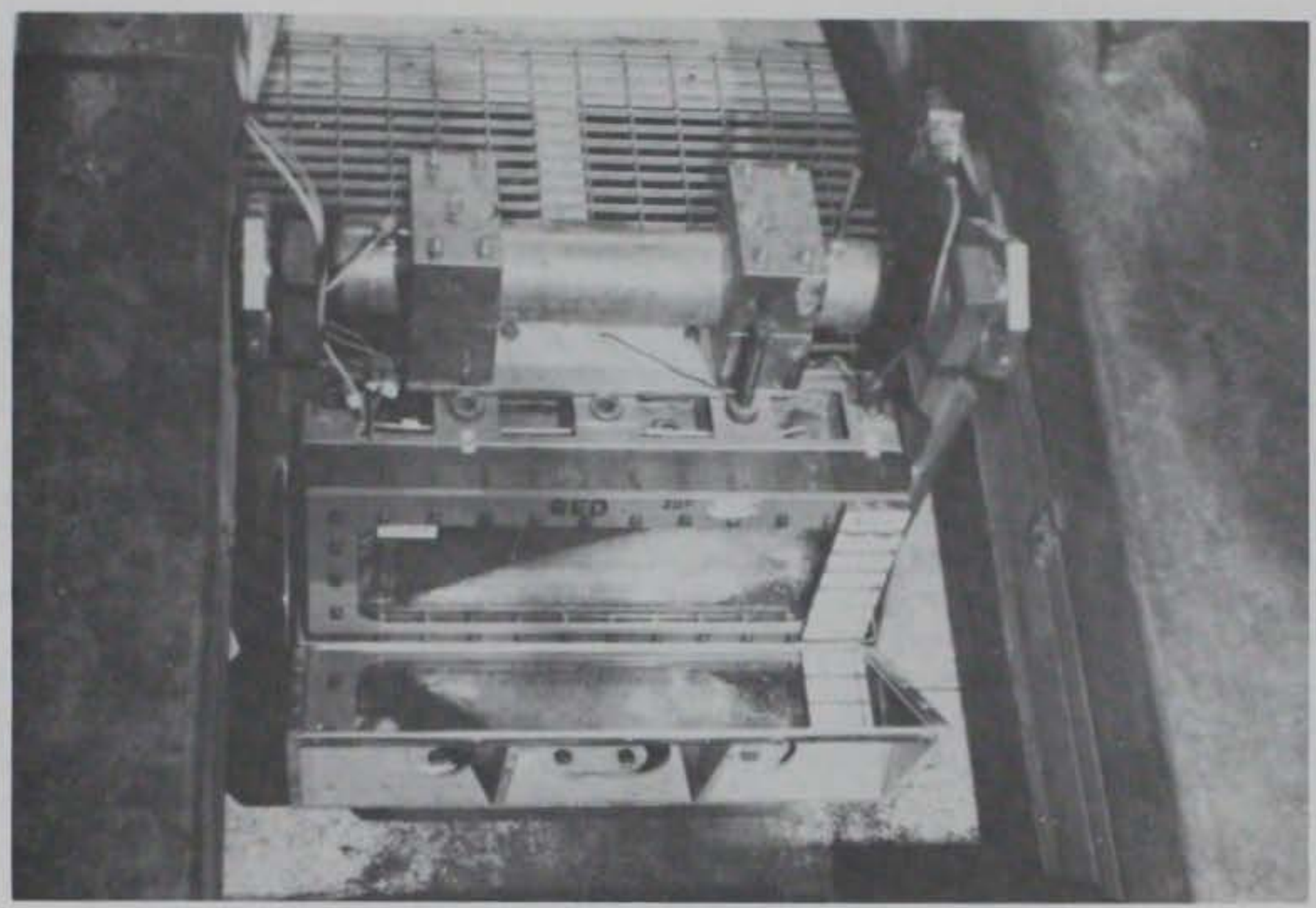

Figure 19. View of centrifugal strong box and mirror mounted on swinging platform (at $1 \mathrm{~g}$ )

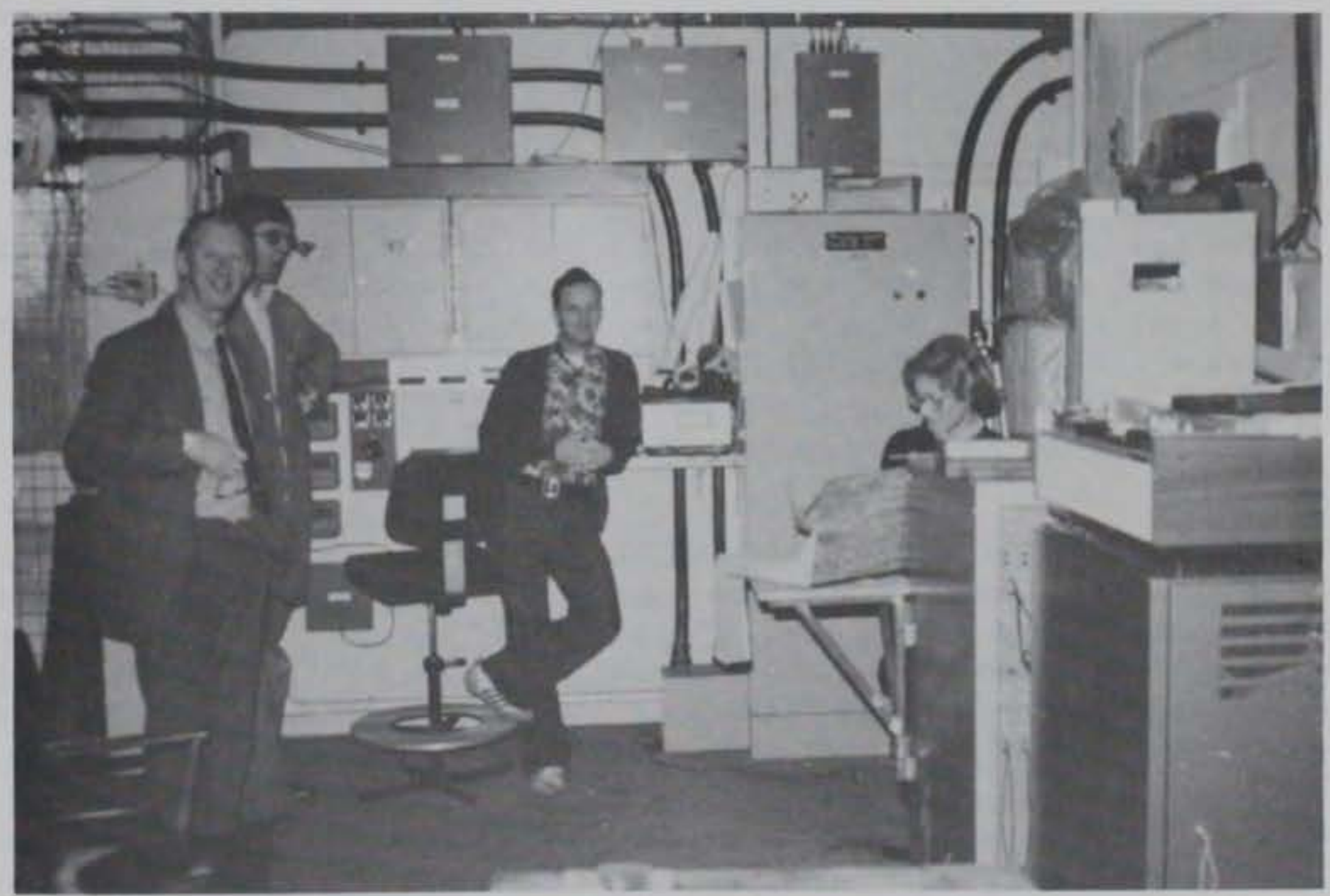

Figure 20. View of centrifugal controls (left to right:

"Jimmy" James, Chris Collison, Frank Townsend, and Deborah Goodings) 
The models, the testing of each, and the observed events are described herein in terms of analogous prototype. Since the testing program was to examine effects of slope angle, seepage, and material on stability, the prototype refers to a notional coal waste embankment $N$ times higher and $N$ times more permeable than the model, and not to any specific coal waste embankment. The model geometries for the first (December) and second (May) test series are summarized in Tables 2 and 3 , respectively. The posttest water contents and dry densities are summarized in Table 5 .

As explained previously, the critical factors in embankment-dam failures are usually the detrimental effects of seepage. Seepage and subsequent erosion can cause internal slope instability or external erosion failures; however, because the scaling laws regarding reduction in particle sizes for models are not the same for these two phenomena, then two different notional prototypes may be considered to be modeled simultaneously. Consequently, mode] events in which the two phenomena interact cannot be correctly related to a prototype event.

\section{Model Tests Reported in Terms of Analogous Prototypes (Test Series No. 1)}

Anticipating that failure due to a too rapid rate of embankment construction might be observed in coal waste embankments, the initial tests of this series were designed to investigate this problem.

$\underline{\mathrm{MW}-0}$

The box was entirely filled to a depth of $27.9 \mathrm{~cm}$ (11 in.) with water saturated coal waste material A (passing $2.36-\mathrm{mm}$ mesh), and the box was rapidly accelerated to $100 \mathrm{~g}$ 's and then stopped. At the end of the test, there was a compact rectangular body of material in the box, about $28.1 \mathrm{~cm}$ $(10-1 / 2$ in.) deep.

$\underline{\mathrm{MW}-1}$

The second test simply involved cutting a slope of $1 \mathrm{~V}: 1 \mathrm{H}$ in the compact body of material from $\mathrm{MW}-0$ and then again rapidly accelerating the box to $100 \mathrm{~g}$ 's. At the end of the test, the slope had not failed. It was at once clear that less steep slopes and less rapid rates of change of acceleration were unlikely to cause slope failure in the absence of other factors such as a greater height and a greater supply of water. The dry density of the waste afterwards was $1254 \mathrm{~kg} / \mathrm{m}^{3}(78.3 \mathrm{pcf})$.

Analogous prototype experience $(100 \times 10.5 / 12=87 \mathrm{ft})$. A $1 \mathrm{~V}: 1 \mathrm{H}$ slope is cut to a depth of $53 \mathrm{~m}(87 \mathrm{ft})$ in a body of drained compact coal waste of density $1254 \mathrm{~kg} / \mathrm{m}^{3}$ (78.3 pcf) and is seen to stand for a while without failure. 
From this test, it was obvious that a greater quantity of water must be supplied to subsequent models. It was anticipated that constructing subsequent models with a reservoir of free draining material filled with water would be adequate, and a leakage test was performed to verify sealing procedures.

$\underline{\mathrm{MW}-2}$

An embankment of uncompacted material A was formed with a slope of $1 \mathrm{~V}: 1 \mathrm{H}$ and was accelerated rapidly to $135 \mathrm{~g}$ 's without slope failure. The intention was to test a slope with more water, but most of the placement water had drained away in the inevitable delay before the test began. The slope afterwards was $22.9 \mathrm{~cm}$ ( 9 in.) high. For this case, the fill slope behaved as an excavated slope.

$\underline{M W-2}$

Since that slope had not failed, water was poured through a funnel onto the top surface of the model, and the model was again accelerated rapidly to $135 \mathrm{~g}^{\prime} \mathrm{s}$ and stopped. There was still no slope failure although some erosion had been caused by pouring in water.

Analogous prototype experience $(135 \times 9 / 12=101 \mathrm{ft})$.

An embankment of drained waste is constructed rapidly to a height of $30.8 \mathrm{~m}$ (101 ft) without slope failure.

$\underline{\mathrm{MW}-3}$

To introduce more water in flight without erosion, the upstream side of the next model embankment was made with a diagonal reservoir full of coarse waste, as shown at the top of Table 2, to which water could be directly supplied. The model was accelerated rapidly to $133 \mathrm{~g}^{\prime} \mathrm{s}$, and water was fed into the reservoir. The slope did not fail.

Analogous prototype experience $(133 \times 9 / 12=99.5 \mathrm{ft})$.

Another embankment of drained coal waste constructed

rapidly to a height of $30.3 \mathrm{~m}(99.5 \mathrm{ft})$ with water

pouring continuously through the embankment does not

fail.

$\mathrm{MW}-4$

At this point, the finer graded material B had been prepared by scalping and removing particles coarser than a $1 / 20-i n$. sieve $(1.18-\mathrm{mm}$ mesh). A fourth model was made with this material at a slope of $1 \mathrm{~V}: 1 \mathrm{H}$. In a Polaroid photograph taken at about $10 \mathrm{~g}$ 's, the slope was seen to be intact. Water supply began, and the model was accelerated quickly to $132 \mathrm{~g}$ 's; the bank-top displacement transducer unexpectedly went off scale at an acceleration of about $20 \mathrm{~g}$ 's, but the speed increase was not interrupted. After the test, it was discovered that the slope had failed and a portion had flowed into an almost horizontal layer. 
Analogous prototype experience. An attempt is made to construct a high embankment of coal waste at a slope of $1 \mathrm{~V}: 1 \mathrm{H}$ by dumping waste across a flowing stream, but the embankment slips and flows unexpectedly at a $4.6-\mathrm{m}(15-\mathrm{ft})$ height.

$\underline{M W-5}$

A fifth model was made of material $B$ and tested in the same way as the fourth model, but in the next test careful observations were made during the speed increase. Failure was indicated by a sudden displacement of the bank top displacement transducer at $26 \mathrm{~g}^{\prime} \mathrm{s}$.

Analogous prototype experience. A second attempt to construct a high heap of coal waste at a slope of $1 \mathrm{~V}: 1 \mathrm{H}$ by dumping waste across a flowing stream again fails, this time at a height of $5.9 \mathrm{~m}$ $(19.5 \mathrm{ft})$.

MW-6

The sixth model was constructed of material B at a less steep slope of $1 \mathrm{~V}: 1.5 \mathrm{H}$. In the test to again increase the level of saturation during the acceleration phase, water was supplied to the reservoir. The slope failed at $18 \mathrm{~g}^{\prime} \mathrm{s}$.

Analogous prototype experience. In the next attempt to construct a coal waste embankment across a flowing stream, the slope is reduced to $1 \mathrm{~V}: 1.5 \mathrm{H}$, but the embankment slips and flows when it reaches a height of $4.1 \mathrm{~m}(13.5 \mathrm{ft})$. The difference between this height and the heights reached in the two previous tests of steeper slopes suggests that flow rates in the stream are not well controlled.

$\underline{M W-7}$

The seventh model was constructed using material B with a slope of $1 \mathrm{~V}: 2 \mathrm{H}$ and with a new vertically formed reservoir at the back of the bank. It was accelerated in $10 \mathrm{~min}$ to $40 \mathrm{~g}$ 's without a feed of water to the reservoir. It did not fail, and from Polaroid photographs it was deduced that the moisture present in the material during model forming had drained away. At this point, water was introduced to the reservoir but did not achieve failure. When the acceleration was then reduced from 40 to 15 to $1 \mathrm{~g}$ with the water supply continuing, a small toe failure was observed. The test was now stopped, and water continued to be fed into the model until it eroded and failed at $1 \mathrm{~g}$. This sequence of events cannot be described too well in terms of analogous prototype events. It became obvious, however, that the previous failures in models MW-4, MW-5, and MW- 6 must have been due to the transient flow of placement water plus water fed to the reservoir at lower acceleration before the speed increase, which had been a rather uncontrolled process.

$\underline{M W-8}$

In a further test to confirm the result of $\mathrm{MW}-7$, a model of the same 
geometry and material as $\mathrm{MW}-7$ was tested with water fed into the reservoir during acceleration. The model failed at $31 \mathrm{~g}$ 's.

Analogous prototype experience. A coal waste embankment is constructed to a height of $9.1 \mathrm{~m}(30 \mathrm{ft})$ across a flowing stream with a slope of $1 \mathrm{~V}: 2 \mathrm{H}$ and fails when a height of $7.1 \mathrm{~m}(23.2 \mathrm{ft})$ is reached.

\section{Service test}

Various changes were made to provide additional water to the models. Two provisions were made to increase the water supply to the reservoir; a $1 / 2-\mathrm{ft}^{3}$ water tank operated by an air shuttle valve with provision for refilling during flight and larger tubing was fitted to the box, and larger diameter tubing was installed to supply the model reservoir. A mirror was fabricated and fitted on the model box so that continuous viewing on the CCTV was available. Four manometers were fitted for observing pore pressures at various locations within the model. These provisions were checked out by a service test, and it was found that the water tank could be emptied in $1 / 2$ min at 120 $\mathrm{g}^{\prime} \mathrm{s}$, and that water could be continuously supplied to the model reservoir at a rate of $1 / 20 \mathrm{ft}^{3} / \mathrm{min}$.

$\underline{\mathrm{MW}-9}$

This model was made using material B built at a slope of $1 \mathrm{~V}: 1.5 \mathrm{H}$ and slowly accelerated safely past the critical 15 - to $30-\mathrm{g}$ 's phase, where previous models had failed. The manometer tubes seen on the CCTV monitor gave a clear and direct observation of transient high piezometric levels at the base of the heap and permitted precise control of centrifugal speed changes. When the model had reaçhed $100 \mathrm{~g}$ 's and the manometer levels were seen to be low, water was then supplied to the reservoir from the new feed pipe, and a rapid rise in the piezometric levels at the base of the heap was observed. The phreatic level was also clearly observed to rise on the CCTV monitor. As the reservoir level surged upward, the phreatic levels reached the position sketched in Figure 21 and retrogressive failure was observed to begin. After failure, the debris lay as a beach, through which seepage could proceed without further retrogression, and choked the exit. When some tank water was flushed into the reservoir, the water levels rose even higher in the heap. When seepage reached the model surface, water began to flow along the slope, and the reservoir wall was rapidly breached. This flow of water eroded the gully.

Analogous prototype experience. A coal waste embankment $22.4 \mathrm{~m}$ $(73.6 \mathrm{ft})$ high is constructed with a slope of $1 \mathrm{~V}: 1.5 \mathrm{H}$ and with the reservoir filled with coarse rocks behind the embankment. A small stream is directed into the reservoir, and water begins to flow out from the embankment toe. Additional streamflow raising the reservoir level then causes slippages of the embankment face, which form a stable beach with steady seepage underneath the embankment. A much larger streamflow is then diverted into the reservoir, which 


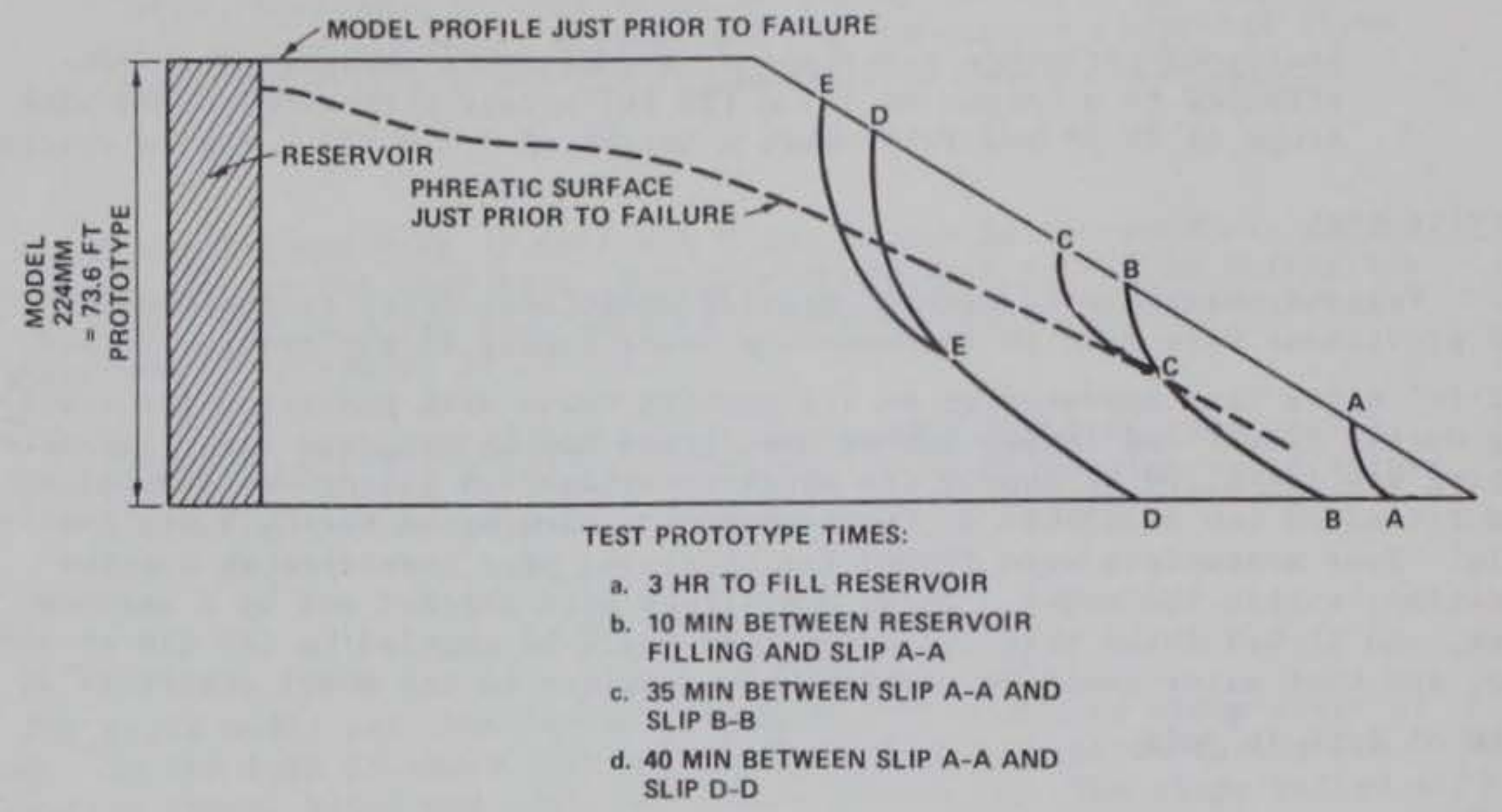

Figure 21. Schematic drawing showing location of phreatic surface and slips for model test MW-9

leads in rapid succession to a rise of the reservoir level, saturation of the coal waste embankment surface, water flow, erosion, and catastrophic breaching of the embankment. The time from occurrence of the initial toe slippage until practically breaching the embankment was $140 \mathrm{~min}$.

$\underline{M W-10}$

To confirm the results of $M W-9$, but using a higher acceleration, a model using material B was constructed with a $1 \mathrm{~V}: 1.5 \mathrm{H}$ slope. This model was higher (as shown in Table 2) and was accelerated slowly to $120 \mathrm{~g}$ 's. At this stage, the reservoir was slowly filled, and attempts were made to determine seepage flow rates. The final increment of flow was perhaps applied too quickly, and the phreatic line sketched in Figure 22 probably does not reflect a steadystate condition. The full flow from the large feed pipe was at a rate about $1 / 50 \mathrm{ft}^{3}$ in about $26 \mathrm{sec}$ through our $1 / 2-\mathrm{ft}$-wide model: assuming that the prototype permeability is 120 times more than the model, then this is equivalent to a seepage flow rate of about $2 \times 1 / 50 \times 120 / 26=0.185 \mathrm{ft}^{3} / \mathrm{sec}$ per foot of prototype embankment. Full flow from the feed pipe led to toe erosion and retrogressive slips sketched in Figure 22. The location of the two major slip surfaces $\mathrm{B}-\mathrm{B}$ and $\mathrm{C}-\mathrm{C}$ closely repeated the result of the test on model $M W-9$ in Figure 21.

Analogous prototype experience. A coal waste embankment is built to a height of $28.6 \mathrm{~m}(94 \mathrm{ft})$. Flow of water from a reservoir 


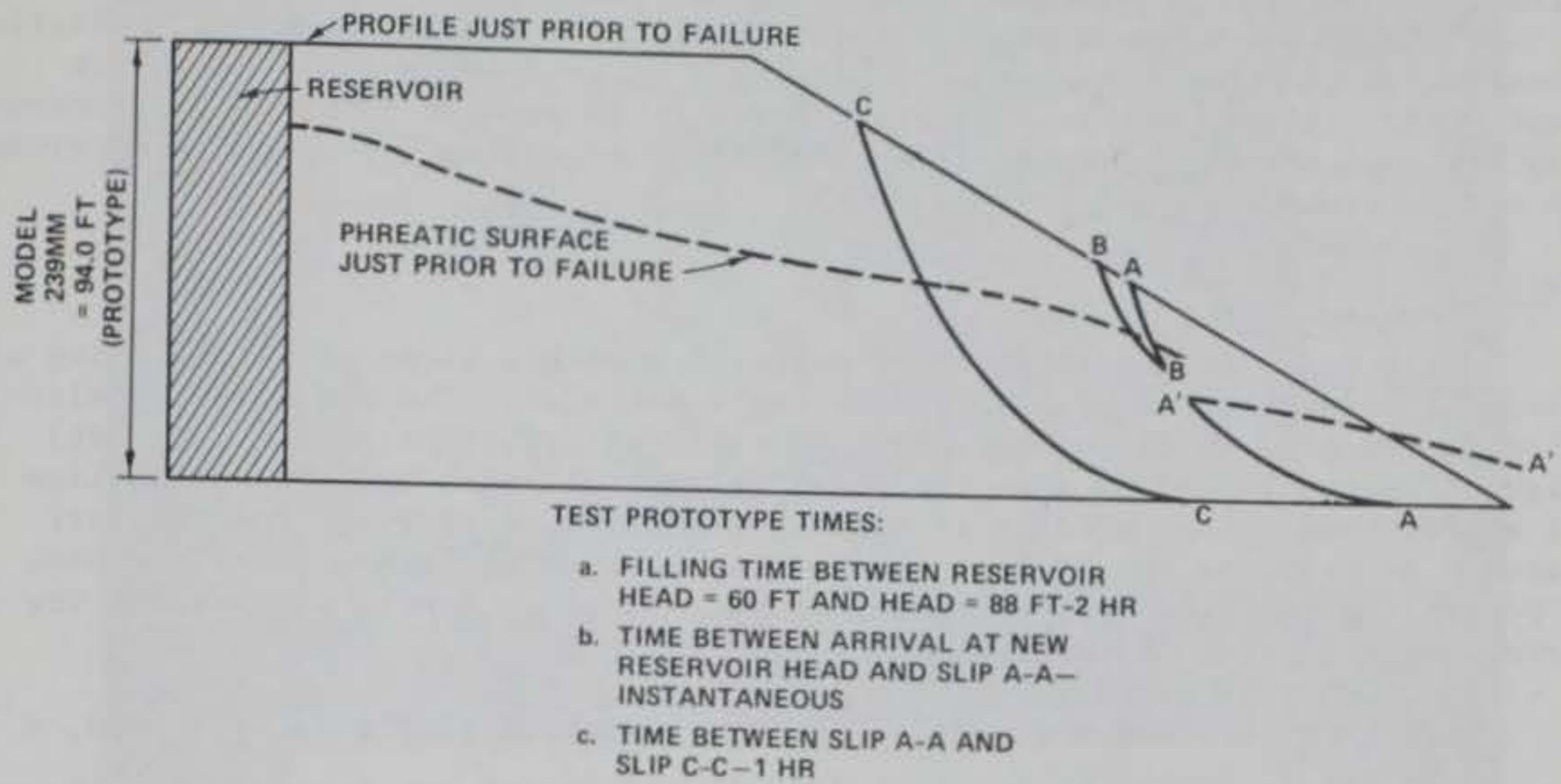

Figure 22. Schematic drawing showing location of phreatic surface and slips for model test MW-10

through the embankment leads to retrogressive slips when the seepage flow is about $18.5 \mathrm{ft}^{3} / \mathrm{sec}$ per $100 \mathrm{ft}$ of prototype embankment. The time between the initial observance of distress at the toe and major failure, was only $1 \mathrm{hr}$.

MW-10

At this stage, it was clear that water stored in the $1 / 2-\mathrm{ft}^{3}$ tank was not sufficient to cause failure, and the model could be replumbed to reposition the outlet from the tank to help clear debris at the toe of the slope. This new system required verification; hence MW-10 was reaccelerated, and it was found that the new flushing system could remove debris from the embankment slope and cause reactivation of retrogression failure.

Intermediate summary

Based upon the tests described above and experience gained from the models, it was apparent that these model tests can provide qualitative information concerning failures of coal waste embankments, but could not be used quantitatively on site-specific boundary conditions for precise analysis. From this consideration, the following test procedures were planned: (a) to perform all subsequent tests with slopes of $1 \mathrm{~V}: 2 \mathrm{H}$, (b) to perform a test with a "key" of coarse material similar to a feature of the original embankment sampled in the United States, (c) to perform a test with slurry in the reservoir rather than water, and (d) to perform a test with a toe drain. Detail (a) is based upon personal communication with SMRC that slopes currently 
permitted for waste embankments must be flatter than $1 \mathrm{~V}: 2 \mathrm{H}$. Detail (b) was planned to furnish information concerning an apparent practice of constructing a "key" to prevent embankment sliding. Detail (c) is based upon the realistic observation that waste embankments generally impound tailing slurries, not just water. Hence, a test utilizing slurry would furnish information concerning drainage design and a possible remedial measure should seepage be observed on a downstream embankment slope.

MW-11

This model was constructed of material B with a slope of $1 \mathrm{~V}: 2 \mathrm{H}$, using a diagonal reservoir filled with coarse waste material. The model was accelerated to $120 \mathrm{~g}$ 's, which corresponds to a notional prototype $28.5 \mathrm{~m}$ ( $95.3 \mathrm{ft}$ ) high. Figures 23 and 24 show the model before and after the test. The line of the original slope profile is clearly visible in Figure 24, and the dark mass of material at the back of the box can be seen to have settled by about 7 percent by the time full acceleration was reached. Supply of water to the reservoir was carefully controlled:

a. When the reservoir was at the equivalent of $15.5-\mathrm{m}(51-\mathrm{ft})$ head, a flow rate to the model of $1 / 50 \mathrm{ft}^{3}$ in $96 \mathrm{sec}$ was measured. This rate corresponds to a flow through a notional prototype $(120$ times more permeable) of about $2 \times 1 / 50 \times 120 / 96=0.05 \mathrm{ft}^{3} / \mathrm{sec}$ per foot.

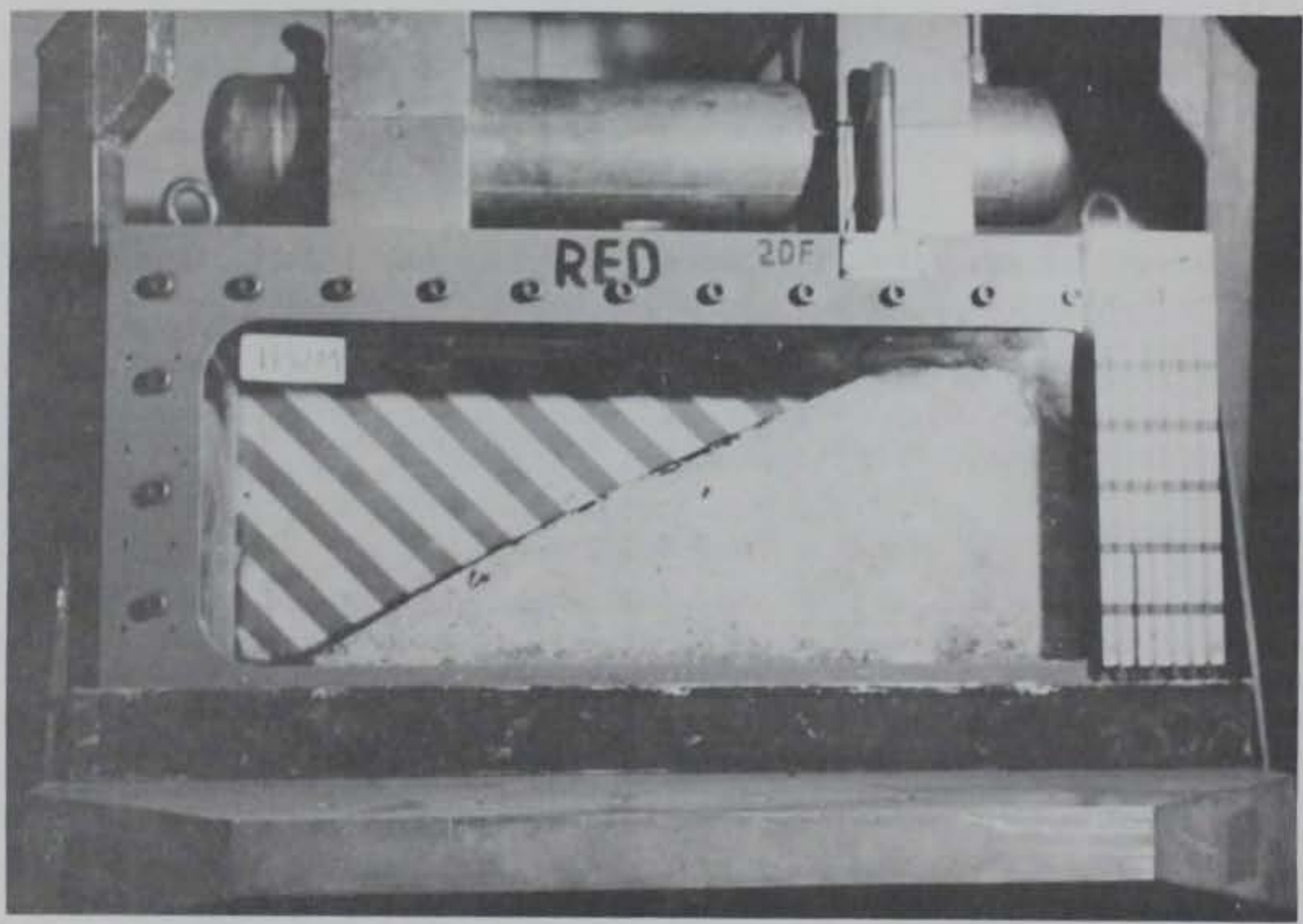

Figure 23. Model MW-11 prior to centrifugal test 


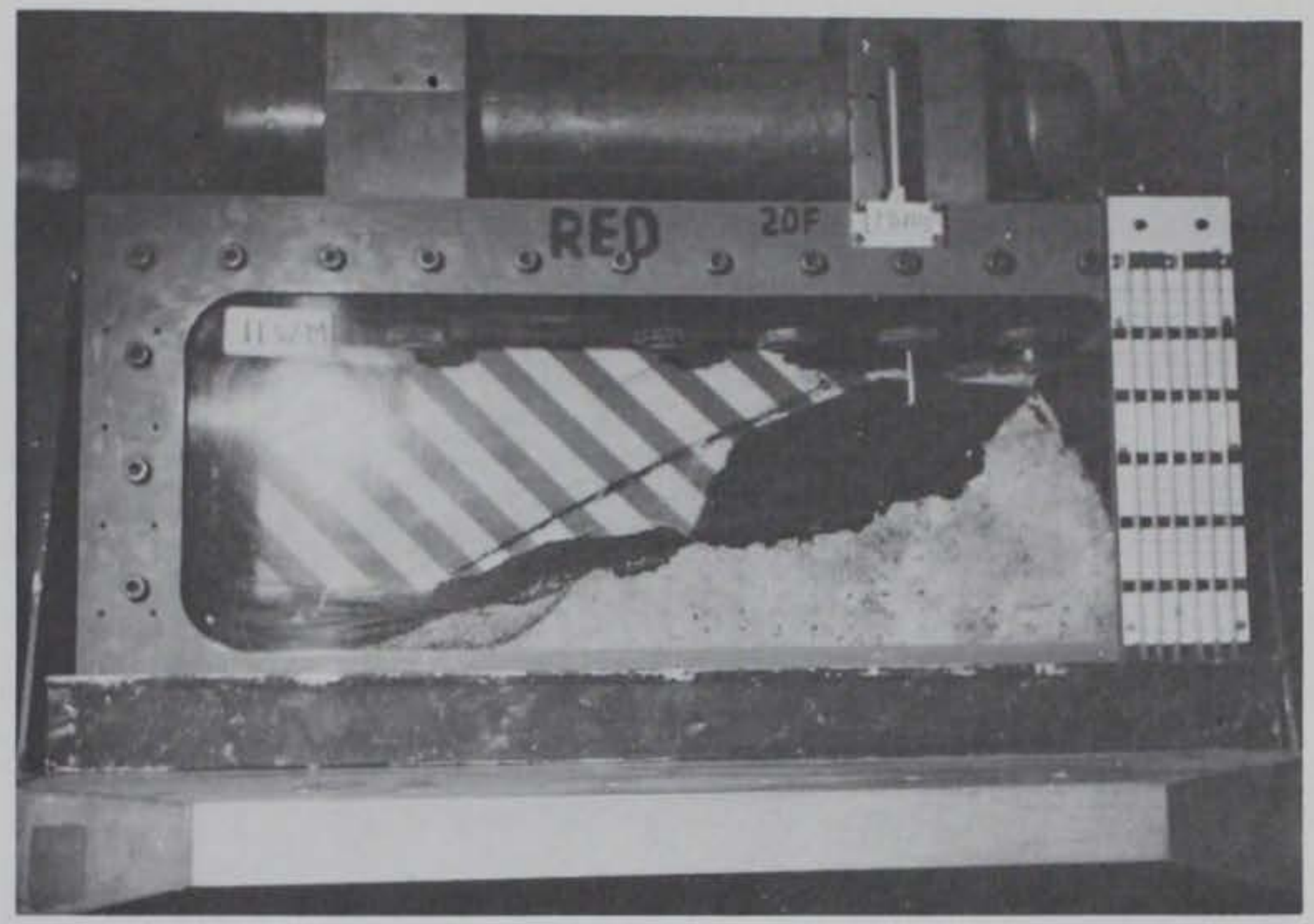

Figure 24. Model MW-11 after centrifugal test

b. When the reservoir was at the equivalent of $22.8-\mathrm{m}(74.8-\mathrm{ft})$ head, the flow rate to the model was measured as $1 / 50 \mathrm{ft}^{3}$ in $29 \mathrm{sec}$, which corresponds to about $2 \times 1 / 50 \times 120 / 29=0.17 \mathrm{ft}^{3} / \mathrm{sec}$ per foot.

At this stage, a series of successive retrogressions occurred as indicated in Figure 25. After each slip, the accumulated debris formed a beach at a slope of about $10 \mathrm{deg}$, with steady seepage from the reservoir onto the beach. Some failures were initiated by local erosion at the top of the beach (e.g., E-E in Figure 25). In this connection, it is significant to note that the steel surface of the base of the box had not been roughened, and sliding may have occurred along this surface. The times of retrogression scaled by the factor $\mathrm{N}=120$ are also listed in Figure 25. The slope was gradually eroded as shown in Figure 24. The rate of failure was accelerated by raising the reservoir to full height, after which the retrogression of erosion and slip eventually led to a catastropic breach of the reservoir wall and to rapid erosion of a gully.

Analogous prototype experience. A coal waste embankment with slope of $1 \mathrm{~V}: 2 \mathrm{H}$ is built to a height of $29.0 \mathrm{~m}(95.3 \mathrm{ft})$. A steady supply of water from the reservoir through the base of the embankment leads to failure at the toe when the reservoir is only three-fourths full. Subsequent embankment failure is a gradual deterioration of the slope to a grade of about $1 \mathrm{~V}: 6 \mathrm{H}$. When the reservoir level is raised to full height, more rapid retrogression leads to a breach of the reservoir wall. The time between initial observance of toe failure and catastrophic breaching of the embankment was 5 days. 


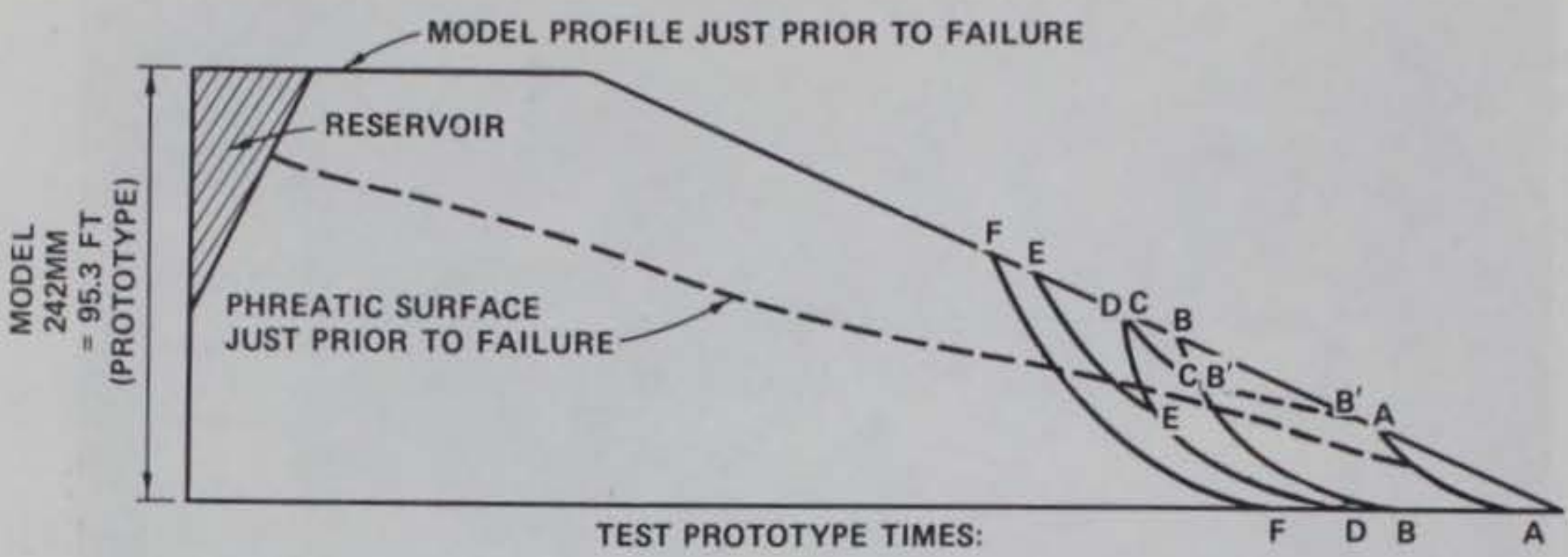

a. 20 MIN BETWEEN ARRIVAL AT NEW RESERVOIR

b. 4 HR BETWEEN SLIP A-A AND SLIP F-F

c. 5 DAYS BETWEEN SLIP A-A AND BREACHING OF RESERVOIR

Figure 25. Schematic drawing showing location of phreatic surface and slips for model test MW-11

$\mathrm{MW}-12$

This was a model of material $\mathrm{B}$, with a diagonal reservoir, $1 \mathrm{~V}: 2 \mathrm{H}$ slope, and with an inclusion of "key" material of coarse waste $(2.36-12.5 \mathrm{~mm}) \mathrm{at}$ the center of the bank. Such a "key" feature had been included in the original waste embankment in the southwestern United States from which the model material had been obtained. The model was accelerated to $120 \mathrm{~g}$ 's for stress similarity with a notional prototype $29.0 \mathrm{~m}(95.3 \mathrm{ft})$ high. Reservoir filling proceeded slowly over a period equivalent to 2 days, by which stage the reservoir level was only at an equivalent prototype height of $19.2 \mathrm{~m}(63 \mathrm{ft})$, when toe failure began. The reservoir supply feed was interrupted to measure a flow of $1 / 50 \mathrm{ft}^{3}$ in $72 \mathrm{sec}$ equivalent to $2 \times 1 / 50 \times 120 / 72=0.067 \mathrm{ft}^{3} / \mathrm{sec}$ per foot of prototype. Unfortunately, the debris removal system then became inoperable due to problems with the hydraulic slip rings. However, although failure was incomplete (Figure 26), the significant point was that failure had been initiated at the toe when the reservoir level was significantly lower than model MW-11 with no key. The presence of the key material allowed the seepage failure to be initiated and to progress under a lower reservoir head. The phreatic line just before failure and the initial slip surfaces are sketched in Figure 27.

Analogous prototype experience. Another coal mine waste embankment is constructed to a height of $29.0 \mathrm{~m}(95.3 \mathrm{ft}$ ) with a $1 \mathrm{~V}: 2 \mathrm{H}$ slope. A rapid raising of the reservoir pool to $19.2 \mathrm{~m}(63 \mathrm{ft})$ in 2 days causes seepage through the embankment, initiating a toe failure. Thus, an embankment with a central key experiences erosion at only two-thirds full height; whereas a comparable embankment without key 


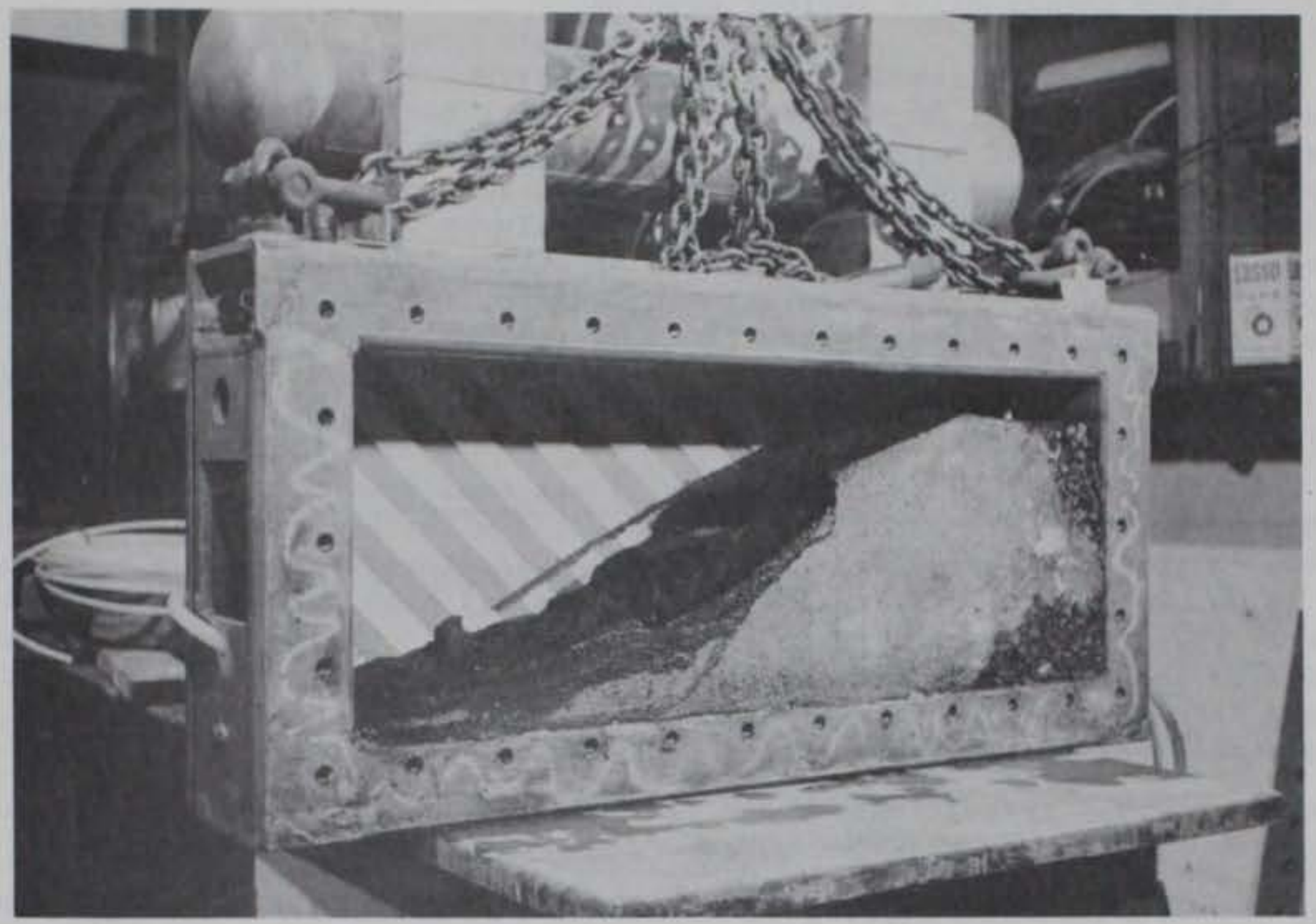

Figure 26. Model MW-12 after centrifugal test

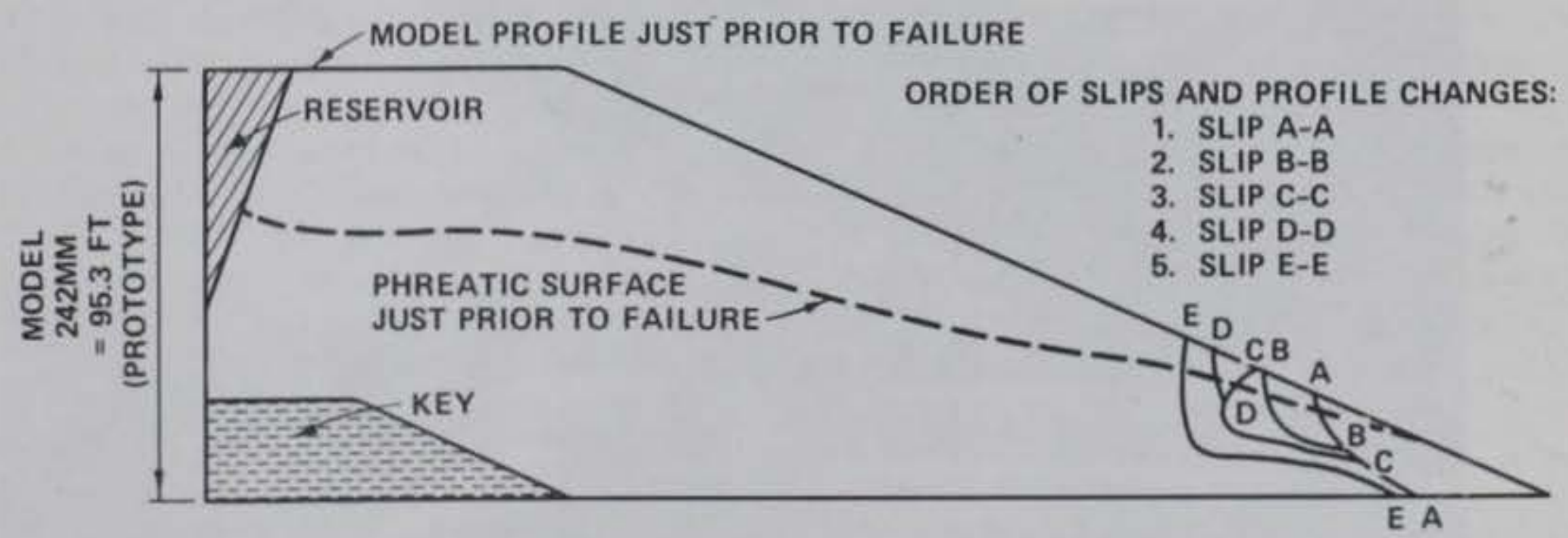

Figure 27. Schematic drawing showing location of phreatic surface and slips for model test MW-12 
experiences erosion when three-fourths full. Inability to remove slope debris halts further erosion.

Having thus established that a notional prototype could not retain a full reservoir of water, it was decided to explore three effects with the one remaining model of test series No. 1. First, a toe drain would be constructed to examine its effect on embankment stability. Secondly, a slurry would be introduced into the reservoir to ascertain if slurry fill in the reservoir produced the same flow and pore pressures as water. Thirdly, the effect of supplying water to the "key" material flushed from the tank to simulate a buried spring would be investigated.

MW-13

This final model of test series No. 1 was constructed of material B to resemble $M W-12$, but with a toe drain constructed with the same grain size as the "key" material (Figure 28). The model was accelerated to $120 \mathrm{~g}$ 's at which state it was in similarity with a $29.7-\mathrm{m}-(97.3-\mathrm{ft}-)$ high notional prototype with a $1 \mathrm{~V}: 2 \mathrm{H}$ slope and a toe drain of coarse material. Water was subsequently supplied to the reservoir, and the phreatic line rose to almost full height, reaching an equivalent prototype height of $27.6 \mathrm{~m}(90.55 \mathrm{ft})$ at which it remained stable for the equivalent of 7 days without any distress at the toe of the bank. At this stage, the seepage flow of $1 / 50 \mathrm{ft}^{3}$ in $24 \mathrm{sec}$ was equivalent to a prototype flow of $2 \times 1 / 50 \times 120 / 24=0.2 \mathrm{ft}^{3} / \mathrm{sec}$ per foot. This heavy seepage flow passed safely through the toe drain. Figure 29 shows the

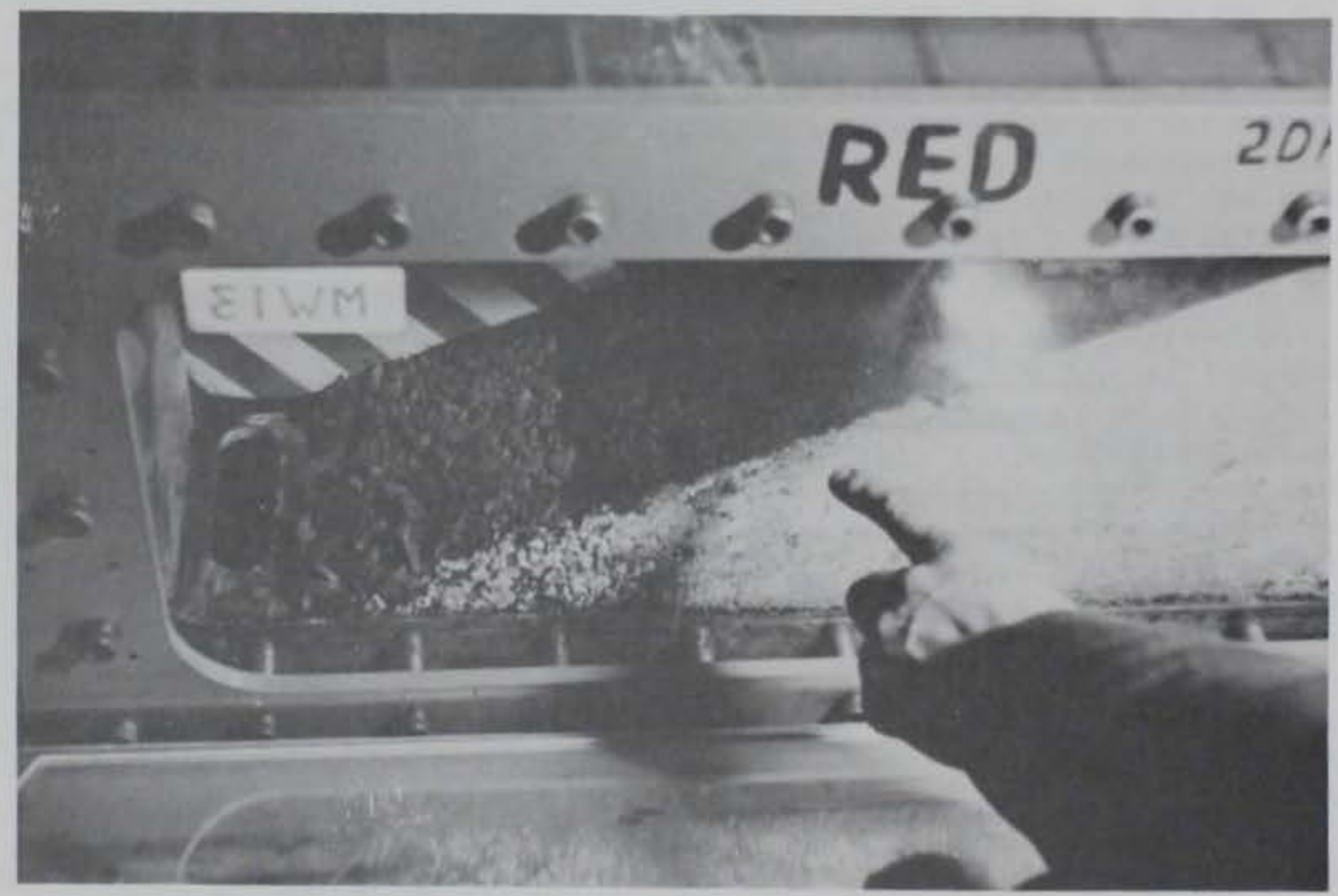

Figure 28. Detail of toe drain in model MW-13 and debris exit hole 


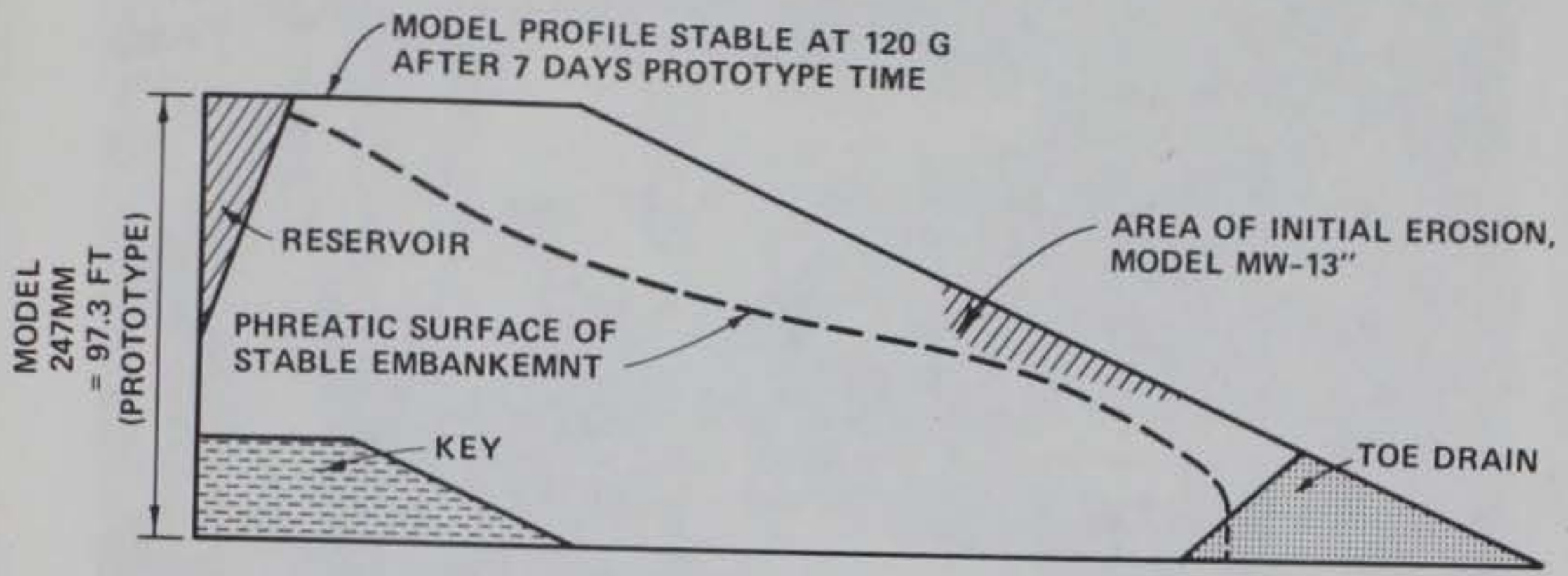

Figure 29. Schematic drawing showing location of phreatic surface for model test MW-13

location of the phreatic line. The test was then stopped, keeping the model intact.

Analogous prototype experience. A coal waste embankment containing an undrained "key" of coarse material, and downstream drainage control via a toe drain is constructed on a $1 \mathrm{~V}: 2 \mathrm{H}$ slope to a height of $27.6 \mathrm{~m}(97.3 \mathrm{ft})$, at which condition it is stable. Subsequently, reservoir filling is initiated and full reservoir capacity is achieved., With this full reservoir head, the embankment successfully passes seepage of $0.2 \mathrm{ft}^{3} / \mathrm{sec}$ per foot through the toe drain and remains stable.

$\underline{M W-13^{\prime}}$

With the model at $1 \mathrm{~g}$, a thin kaolin slurry at about 200 percent moisture content was used to fill the coarse reservoir material (Figure 30 ). The model was centrifuged to $120 \mathrm{~g}$ 's, and it was observed that the quantity of seepage water was drastically reduced in comparison with flows from the water filled reservoir and there was no piezometric response at the base of the model. The model was stopped, and the process repeated with a thicker slurry mixed at about 100 percent moisture content, which again did not generate any observable pore pressures or seepage flow through the embankment when reaccelerated to $120 \mathrm{~g}$ 's. An examination of the slurry and coal waste interface showed that the slurry had formed an impermeable membrane at the interface. The model was reaccelerated to $120 \mathrm{~g}$ 's, and water was introduced into the reservoir. However, realizing that the impermeable membrane of slurry prevented seepage and created a risk of accidentally overtopping the embankment and causing an erosion failure, the feed water was stopped, and the model was decelerated with the model remaining intact. 


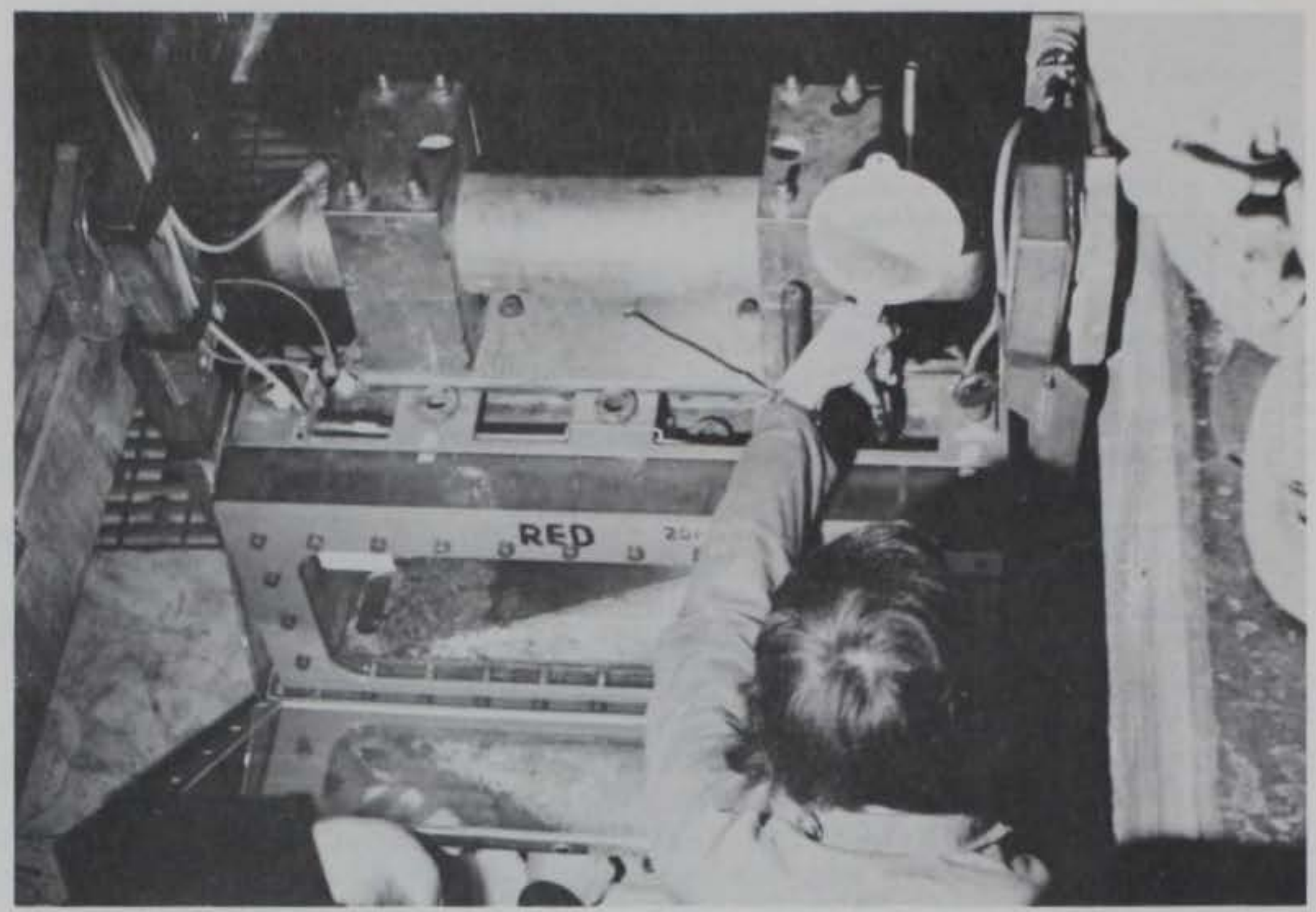

Figure 30. Supply of kaolin slurry to reservoir of model MW-13

Analogous prototype experience. An embankment identical to that of $\overline{M W}-13$ is constructed to a height of $27.6 \mathrm{~m}(97.3 \mathrm{ft})$. Tailing slurry is then impounded behind the embankment. However, the gradation of the embankment material and consistency of the slurry are such that an impermeable membrane is formed on the upstream embankment face practically sealing the embankment against any seepage.

$\underline{M W-13^{\prime \prime}}$

Since the model was still intact, and the reservoir incapable of passing seepage due to the impermeable slurry membrane, a final probe to explore the risk of groundwater flow from a spring in the foundation was planned. Even where springs are not present before the tailings pond is constructed, there may be a risk of the high water pressures at the base of the pond generating new groundwater flow. The model was accelerated to $120 \mathrm{~g}^{\prime} \mathrm{s}$, at which condition it was stable, and water was supplied to the "key" to simulate the presence of an intermittant spring. The first flush of water caused a groundwater mound to rise rapidly in the embankment, and it appeared to flow along the surface parallel to the slope for a short length just above the toe drain, as indicated by the shaded area in Figure 29. This seepage caused a small local slip there, but the water then drained away safely through the toe drain. A second flooding of water into the key material caused the whole bank to become saturated, and water then began to flow over the embankment crest. Erosion began at once and proceeded with great rapidity; within 20 min of equivalent prototype time, the bank was totally breached with a deep gully down which "slurry" flowed from the reservoir (Figure 31). 


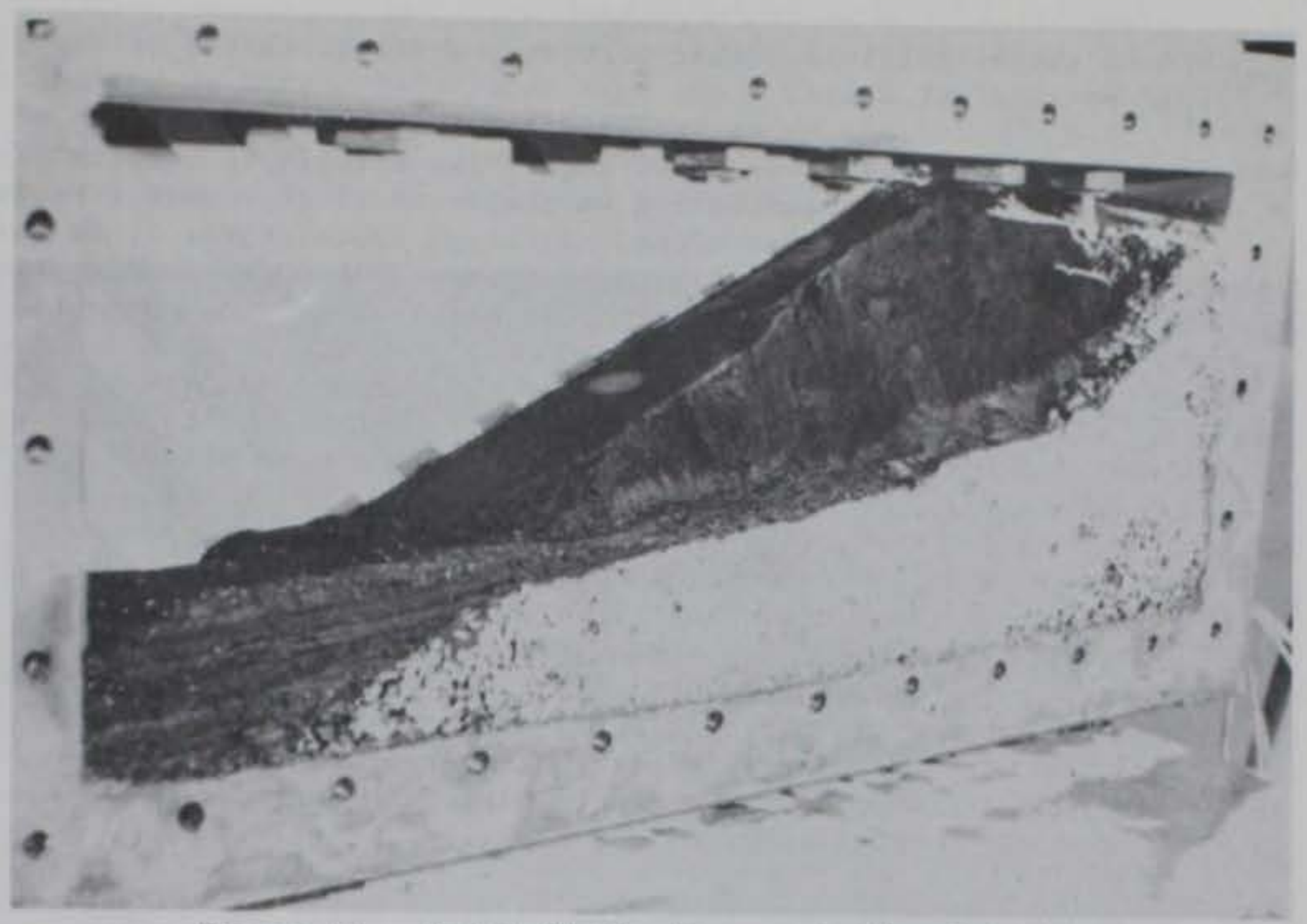

Figure 31. Model MW-13 after centrifugal test

Analogous prototype experience. A coal waste embankment identical to MW-13 impounding tailing slurry is constructed over an undetected spring. The flow of water from the spring is sufficient to cause the phreatic surface to exit on the downstream slope and thus create a localized "soft spot" prior to draining into the toe drain.

Subsequent filling of the reservoir by tailings diminishes its storage capacity, until a heavy storm causes heavy seepage via covered springs saturating the embankment and filling the reservoir until overtopping occurs. Overtopping the embankment rapidly erodes the embankment until breaching occurs.

\section{Summary of Test Series No. 1}

These 13 tests constitute test series No. 1, from which the following phenomenological conclusions were made:

a. The materials tested could be constructed into stable embankments up to approximately $100 \mathrm{ft}$ high on slopes of $1 \mathrm{~V}: 1 \mathrm{H}$ for material A and $1 V: 1.5 \mathrm{H}$ for material B safely, provided the phreatic surface remained low within the embankment. The material could be placed in a wet state and would compact under self-weight. Attention should be given to the observation of the phreatic surface during construction via standpipes or piezometers to ensure safety during construction. 
Since the material is rather pervious, drainage should be rapid if placed in a wet state.

b. Embankments of material B were highly susceptible to surface erosion and seepage failure and failed on slopes of $1 \mathrm{~V}: 2 \mathrm{H}$ whenever seepage exited on the downstream slope. Although speculative, it is quite likely that material A likewise is susceptible to surface erosion and seepage failures. However, this material was too permeable for the water supply to the model, and high phreatic surfaces could not be achieved. An obvious solution is to provide adequate drainage control, i.e., chimney drains, horizontal drains, or toe drains, which could prevent high phreatic surfaces from exiting on the downstream slope.

c. The impoundment of fine-grained tailings (slurry) may enhance stability, assuming that the gradation of the embankment prevents throughflow of the fines and instead an impermeable membrane forms on the upstream face. The presence of this impermeable membrane may sufficiently lower the phreatic surface, thereby eliminating seepage failures on the downstream face. However, it is not recommended that complete dependence should be placed on an impermeable slurry membrane to control seepage.

d. The highly erodible nature of the material makes these embankments defenseless should overtopping occur. In the case of MW-13", only approximately $4 \mathrm{~min}$ of prototype time were required to completely erode and breach a $30.5-\mathrm{m}-(100-\mathrm{ft}-)$ high embankment. Hence, it is imperative that adequate spillway facilities be provided and careful considerations be given to the fact that as the tailings are disposed the storage capacity diminishes.

e. The presence of a "key" trench in these models reduced the limiting reservoir height from three fourths to two thirds of the embankment height. It would appear that providing exit drainage from the "key" would be beneficial or that a safer practice would be to place the coarse "key" material as a toe drain. The exiting of springs in conjunction with potential high water pressures that can be generated at the bottom of tailings warrants careful examination of foundation strata prior to construction of a waste embankment.

\section{Model Tests Reported in Terms of Analogous Prototype (Test Series No. 2)}

$\underline{\mathrm{MW}-20 *}$

Material of gradation B, but containing 26 percent fines (Figure 7) was placed in the box; however, it would not drain freely under its own self-weight

* MW-20 indicates Model No. 0 of test series No. 2, not model No. 20. 
to the point where capillary pore pressures (effective cohesion) would hold it together during normal laboratory handling. Hence, the box was filled to $242 \mathrm{~mm}$ and consolidated on the centrifuge at $90 \mathrm{~g}$ 's for $125 \mathrm{~min}$. The model was brought to $1 \mathrm{~g}$, and a profile of $1 \mathrm{~V}: 2 \mathrm{H}$ was cut into the partially saturated soil mass (Figure 32 ) and then gradually accelerated to $120 \mathrm{~g}^{\prime} \mathrm{s}$ in

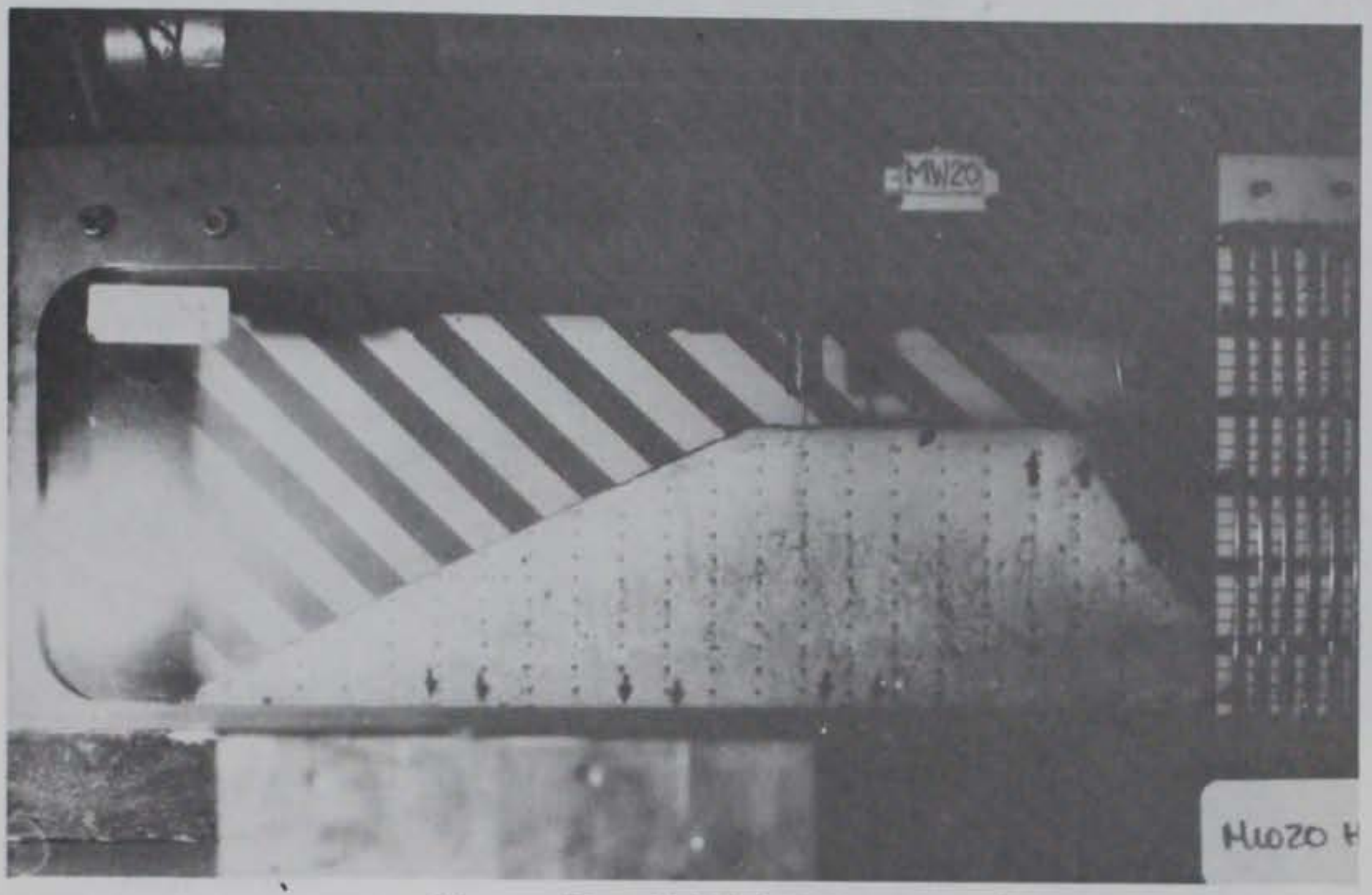

Figure 32, Model MW-20 at $9 \mathrm{~g}^{\prime} \mathrm{s}$

$64 \mathrm{~min}$ (Figures 33 and 34). Water was then supplied to the reservoir at a flow rate of $1.37 \times 10^{-3} \mathrm{ft}^{3} / \mathrm{sec}$ per foot or $127 \mathrm{~mm}^{3} / \mathrm{sec}$ per millimetre of model width. Unfortunately, this flow rate exceeded the seepage rate of the model; hence, the reservoir soon reached maximum storage, overtopping the embankment, causing erosion and breaching of the crest, and thus constituting failure (Figures 35 and 36 ).

Analogous prototype experience. A coal mine waste fill project is constructed to initial height of $22 \mathrm{~m}(72.2 \mathrm{ft})$ settling to $20 \mathrm{~m}(65.6 \mathrm{ft})$ over 2 years and draining into a single culvert $64 \mathrm{~m}(210 \mathrm{ft})$ from the fartherest point of the fill horizontally. After this period, a slope of $1 \mathrm{~V}: 2 \mathrm{H}$ is cut into the fill and its height simultaneously increased to $23.4 \mathrm{~m}(76.8 \mathrm{ft})$. Additional permeability tests indicate the permeability of the embankment is $1.44 \times 10^{-4} \mathrm{~mm} / \mathrm{sec}$. The slope is stable until 


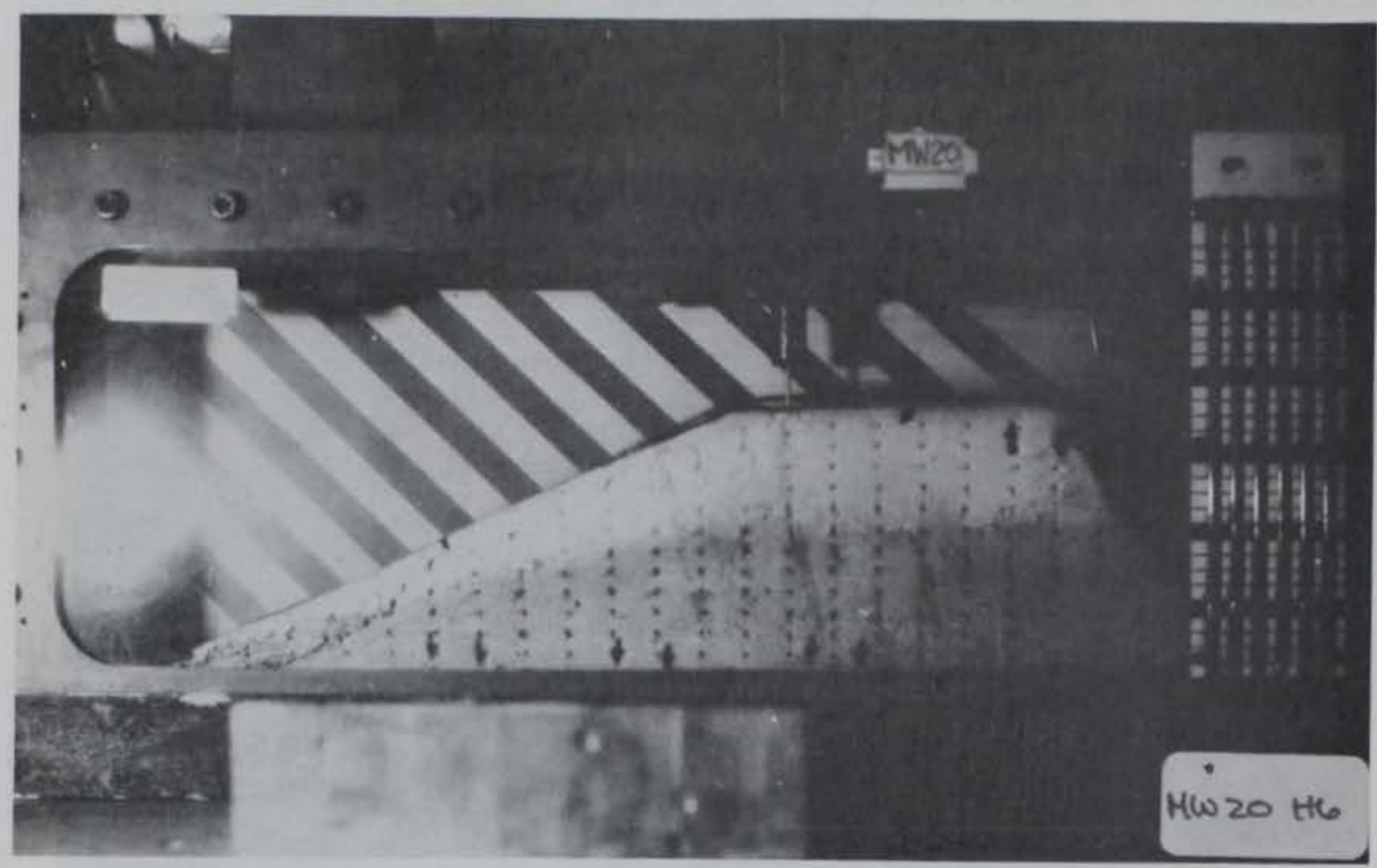

Figure 33. Model MW-20 at $120 \mathrm{~g}$ 's

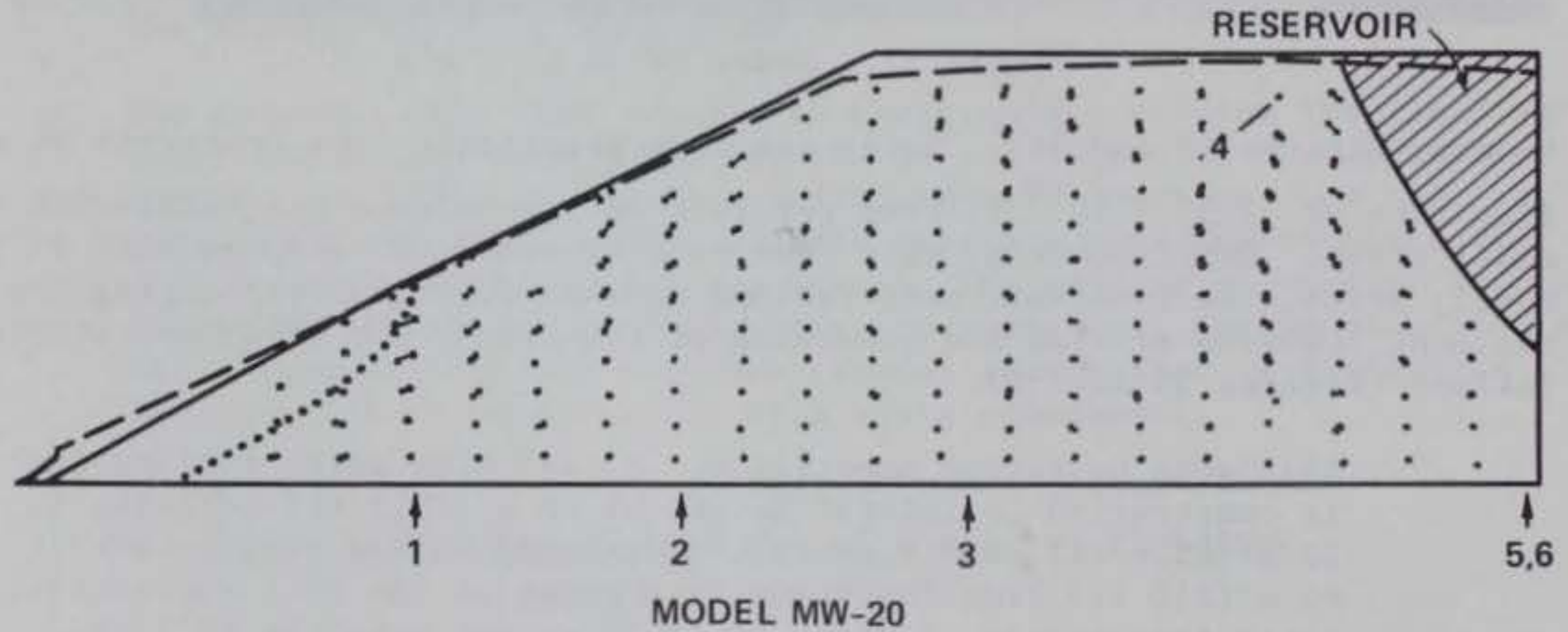

Figure 34. Mode1 MW-20: displacements occurring between 9 and $120 \mathrm{~g}$ 's; numbers mark positions of piezometric tips 


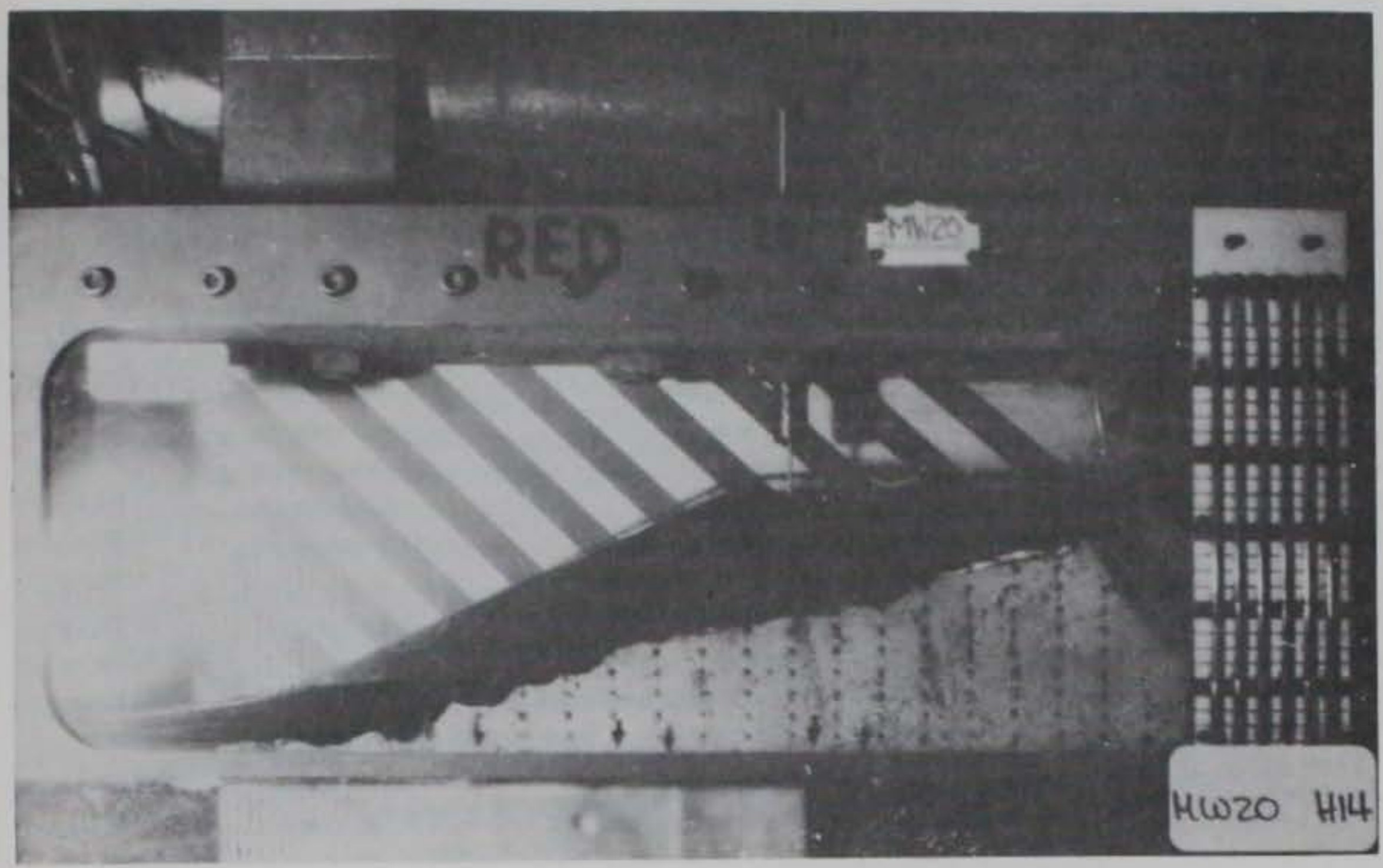

Figure 35. Model $\mathrm{MW}-20$ at $120 \mathrm{~g} ' \mathrm{~s}$, after erosion

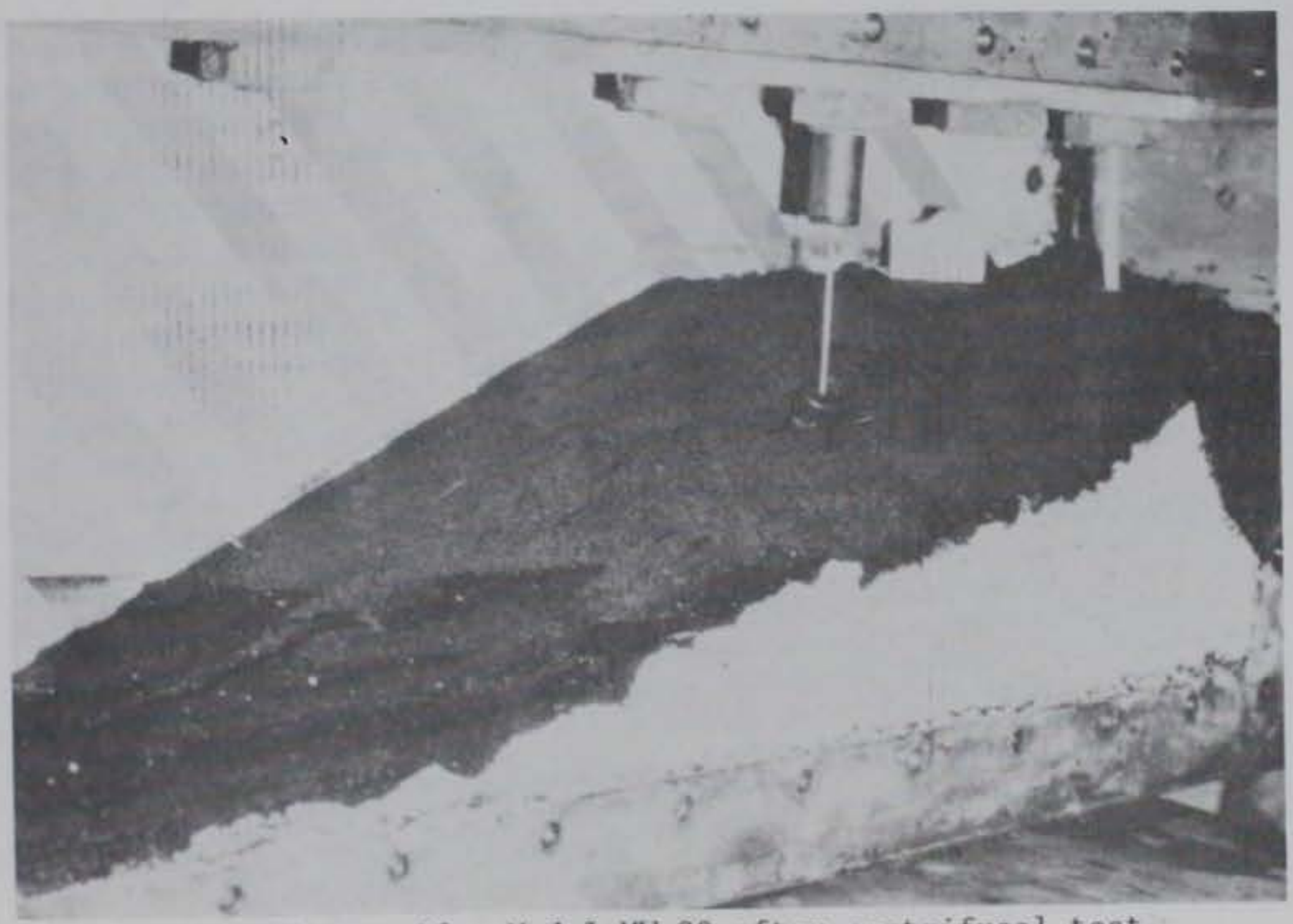

Figure 36. Model MW-20 after centrifugal test 
flood conditions corresponding to $0.161 \mathrm{ft}^{3} / \mathrm{sec}$ per foot or $1.5 \times 10^{-2} \mathrm{~m}^{3} / \mathrm{sec}$ per metre of embankment width cause an overflow, which cascades down the face of the slope, eroding away the slope and eventually breaching the embankment.

$\mathrm{MW}-21$

A 195-mm-high embankment of coal waste material containing 13 percent fines (Figure 7) was statically compacted on a 10-mm-thick kaolin clay layer $\left(w_{f}=49\right.$ percent) in five $40-m m-t h i c k$ lifts under $58-k N / m^{2}(8.4-p s i)$ pressure using a hydraulic jack and steel plate. After compaction, a $1 \mathrm{~V}: 2 \mathrm{H}$ slope was cut into the material. The model was gradually accelerated to $120 \mathrm{~g}$ 's in $56 \mathrm{~min}$, at which condition it was stable. The reservoir behind the embankment was subsequently filled to a height of $187 \mathrm{~mm}$ causing a throughflow of $8.1 \times 10^{-4} \mathrm{ft}^{3} / \mathrm{sec}$ per foot or $75 \mathrm{~mm}^{3} / \mathrm{sec}$ per millimetre of model width. This through seepage caused an erosion gully to develop on the slope at a vertical height of $114 \mathrm{~mm}$, which coincided with the bottom of the fourth layer where the throughflow emerged (Figure 37). The test was stopped, and this erosion gully investigated; then the model reaccelerated to $120 \mathrm{~g}$ 's, the reservoir filled, and flow reestablished. However, no additional piping deterioration was observed (Figure 38 ).

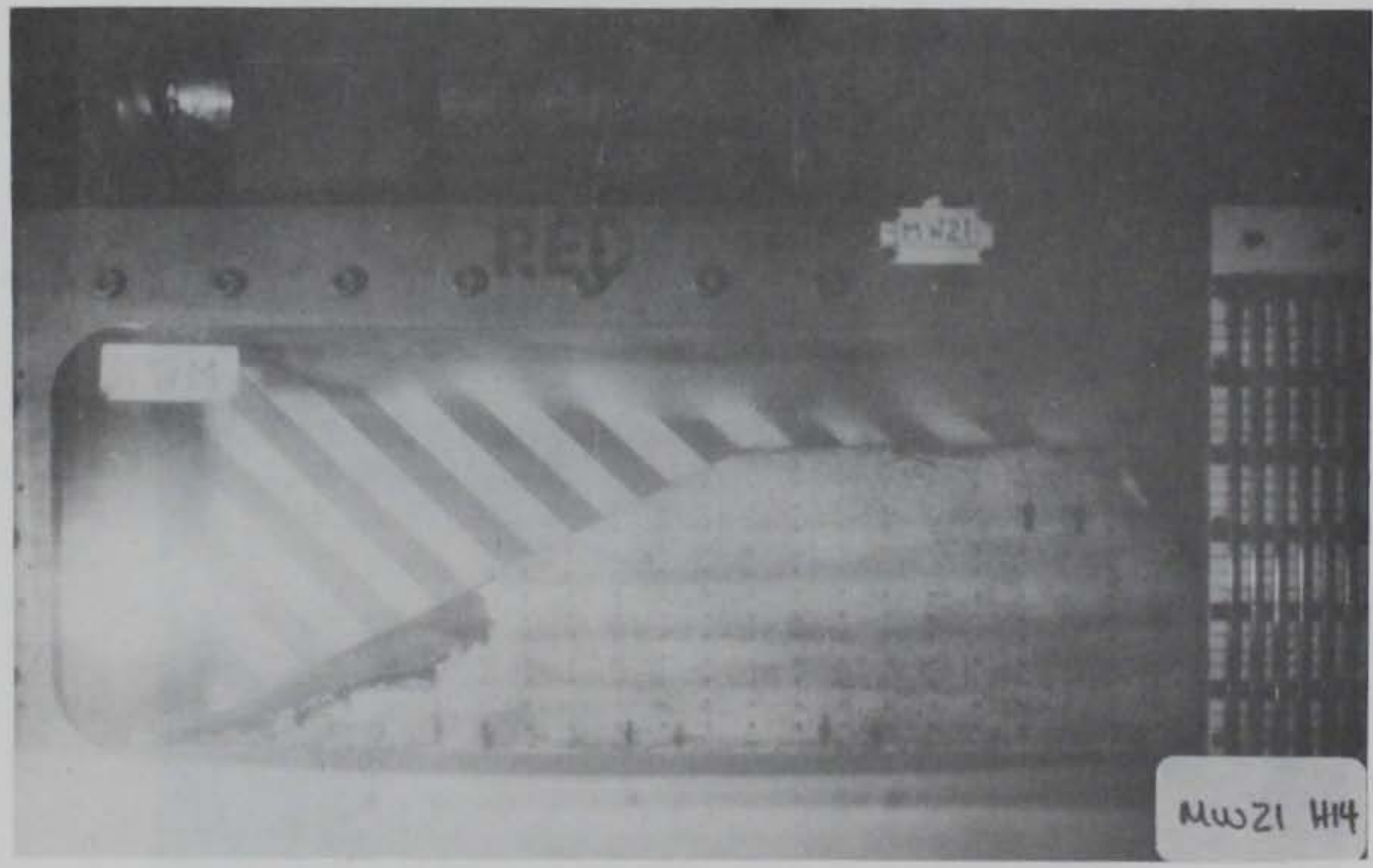

Figure 37. Mode1 MW-21 at $120 \mathrm{~g}$ 's, during erosion 


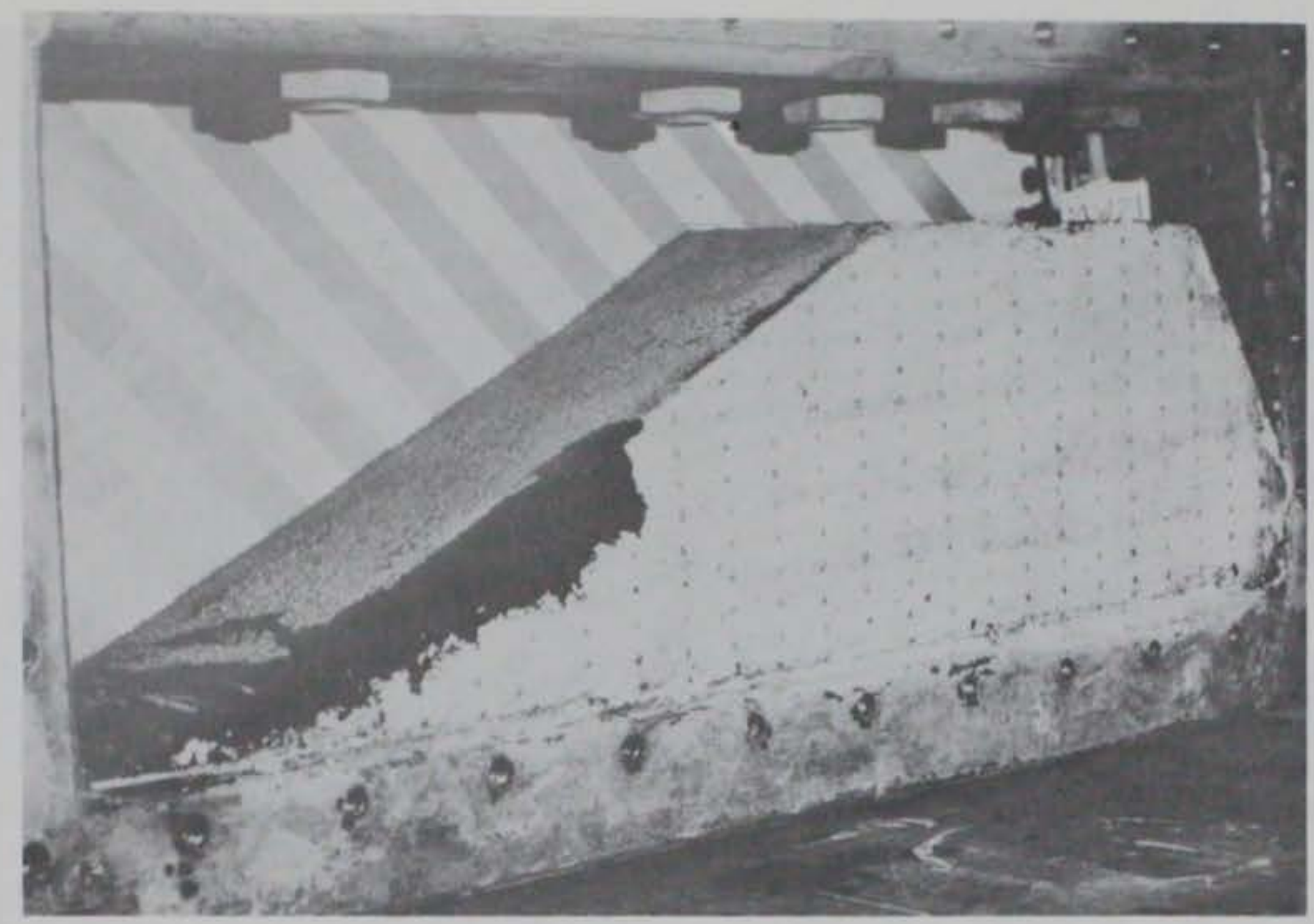

Figure 38. Model MW-21 after centrifugal test

Analogous prototype experience. An embankment with a downstream slope of $1 \mathrm{~V}: 2 \mathrm{H}$ was constructed by compaction in five equal $4.8-\mathrm{m}$ lifts under $58-\mathrm{kN} / \mathrm{m}^{2}$ pressure to a height of $23.4 \mathrm{~m}$, exhibiting charactetistic segregation of the fine fraction to the top of each 1ift. A clay seam, $1.2 \mathrm{~m}(3.9 \mathrm{ft})$ thick, underlies the foundation. Raising the reservoir to $22.4 \mathrm{~m}(73.5 \mathrm{ft}$ ) (96 percent of full capacity) causes seepage at a rate of $0.1 \mathrm{ft}^{3} / \mathrm{sec}$ per foot or $9 \times 10^{-3} \mathrm{~m}^{3} / \mathrm{sec}$ per metre of embankment width to emerge and form an erosion gully up to 60 percent of the slope height, carrying away sediment, which would simulate prototype material of the same density $\left(\mathrm{G}_{\mathrm{s}}=2.36\right)$. It may be possible that continued throughflow may have caused further erosion and eventual breaching, but the model remained stable throughout the test.

\section{MW-22}

Material corresponding to gradation MW-22 in Figure 7 and containing 8 percent fines was formed by rodding behind a template into a model $195 \mathrm{~mm}$ high with a slope of $1 \mathrm{~V}: 2 \mathrm{H}$ over a soft $10 \mathrm{-mm}$ clay layer, identical to that used in the previous model MW-21. The model was accelerated in 43 min to $120 \mathrm{~g}$ 's (Figure 39), whereupon the maximum water supply of $1.1 \times 10^{-3} \mathrm{ft}^{3} / \mathrm{sec}$ per foot or $109 \mathrm{~mm}^{3} / \mathrm{sec}$ per millimetre of model width was introduced and the 


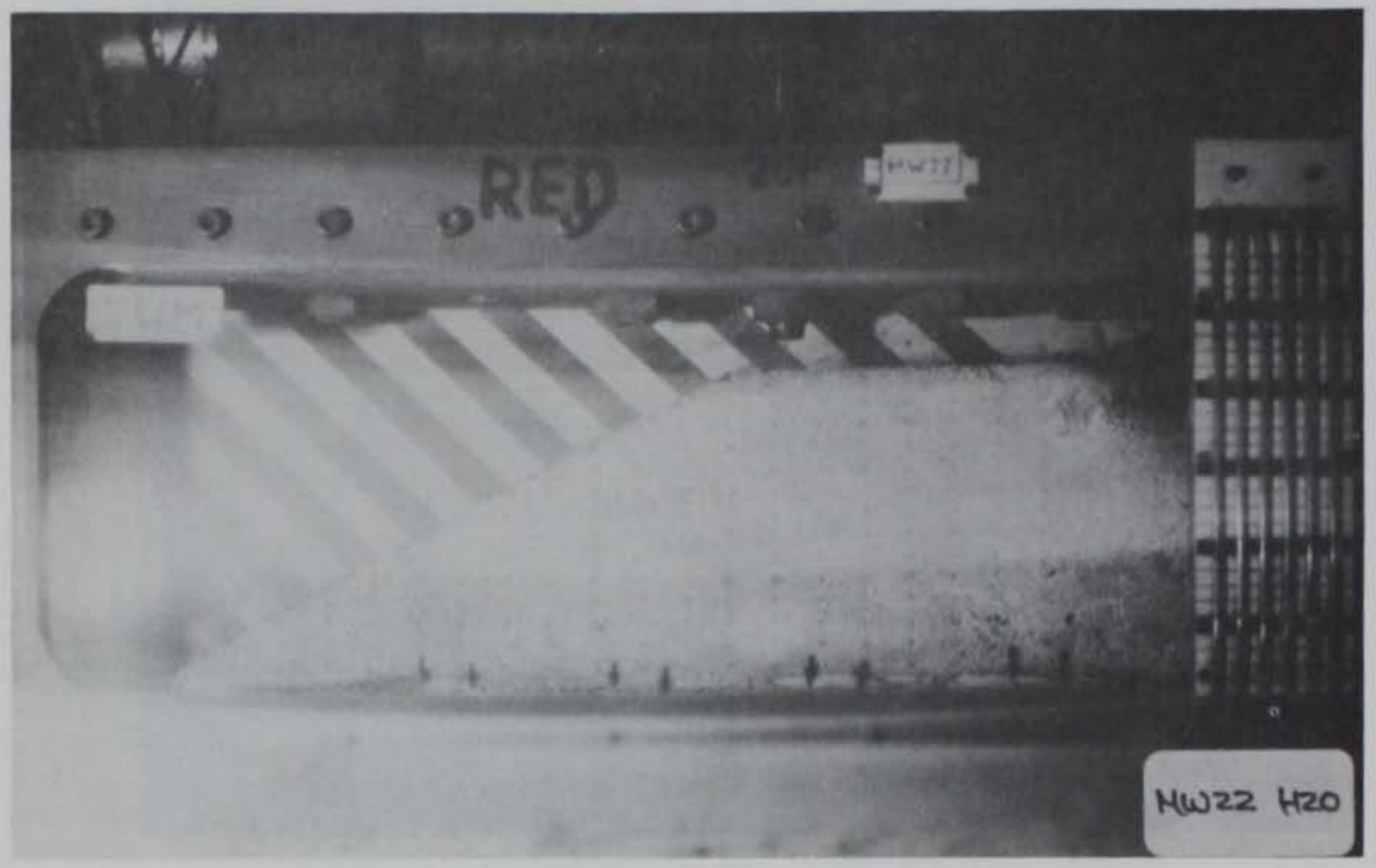

Figure 39. Model MW-22 at $120 \mathrm{~g}^{\prime} \mathrm{s}$, without seepage

embankment was stable (Figure 40). With this maximum water supply, the centrifuge speed was slowly reduced to $40 \mathrm{~g}^{\prime} \mathrm{s}$ (Figure 41 ), and erosion was initiated on the side of the model not visible to the camera. By the time $20 \mathrm{~g}$ 's was achieved, erosion and sediment transport had caused an unacceptable blanket of sediment to spread downstream (Figure 42) and had failed.

Analogous prototype experience. A stable embankment with a final height of $21.7 \mathrm{~m}(71.2 \mathrm{ft}$ ) is constructed in 1.8 days ( $43 \mathrm{~min}$ times average acceleration divided by 1440) with a downstream slope geometry of $1 \mathrm{~V}: 2 \mathrm{H}$. A salient feature of the embankment configuration is the presence of an upstream vertical cutoff wall $7.8 \mathrm{~m}(25.6 \mathrm{ft})$ high beneath the reservoir (Table 3). A $1.2-\mathrm{m}-(3.9-\mathrm{ft}-)$ thick clay seam underlies the foundation. The embankment safely impounds a crest level $15-\mathrm{m}-(49.2-\mathrm{ft}-)$ deep reservoir, while passing a throughflow of $0.19 \mathrm{ft}^{3} / \mathrm{sec}$ per foot or $1.3 \times 10^{-2} \mathrm{~m}^{3} / \mathrm{sec}$ per metre of embankment width in a free-fall configuration over the cutoff wall. The phreatic surface is quite low, and seepage occurs only at the toe. Simultaneously decreasing the effective height, which in turn decreases permeability (see Modeling seepage flow, Chapter 3 ) causes the free-fall condition to be drowned out; localized erosion occurs at the toe of the embankment, which is now only $7.8 \mathrm{~m}(25.6 \mathrm{ft})$ high and is passing through a flow equivalent to $0.04 \mathrm{ft}^{3} / \mathrm{sec}$ per foot or $4 \times 10^{-3} \mathrm{~m}^{3} / \mathrm{sec}$ per metre of embankment width from a reservoir $6.5 \mathrm{~m}$ 


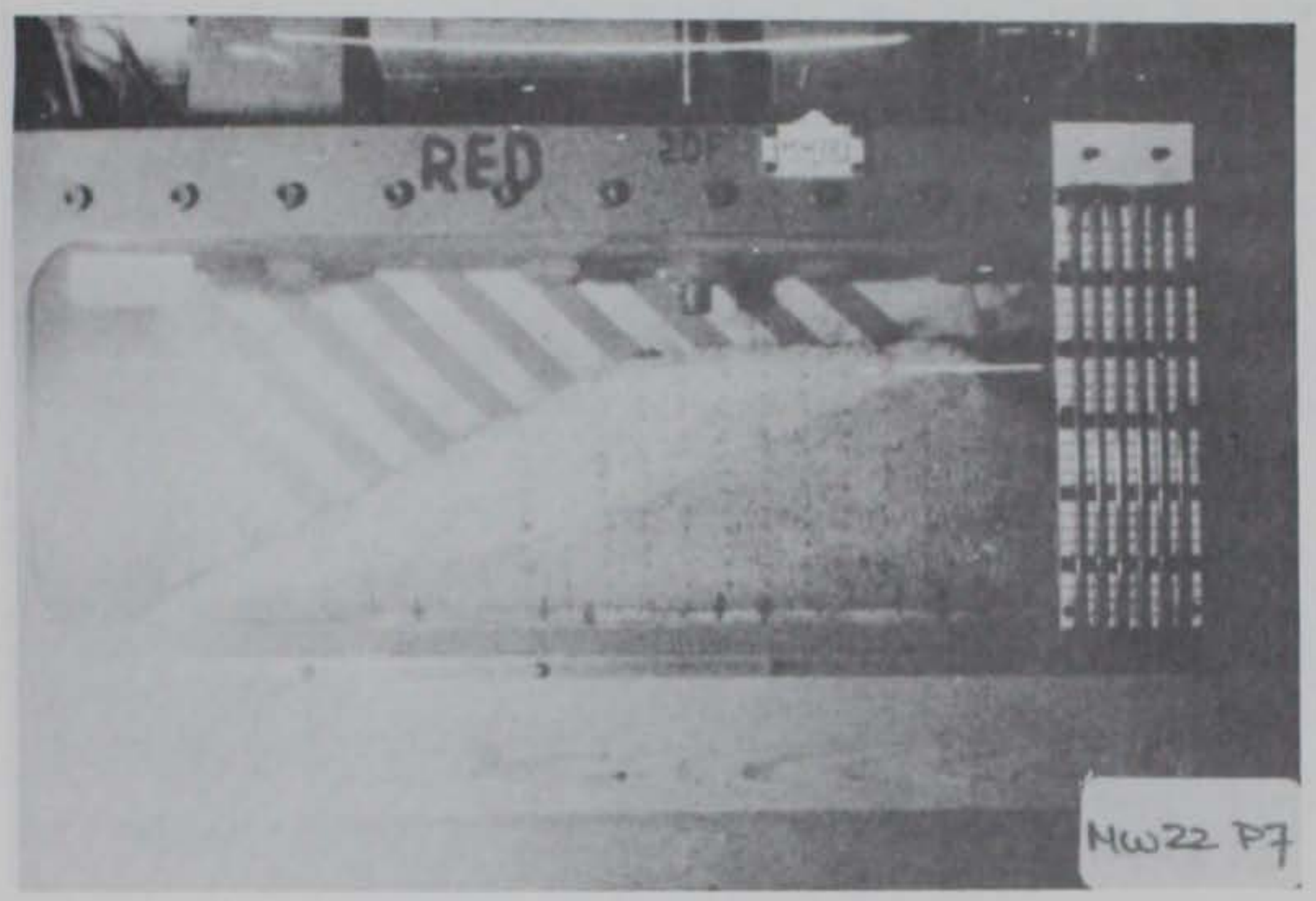

Figure 40. Model MW-22 at $120 \mathrm{~g}$ 's, with seepage

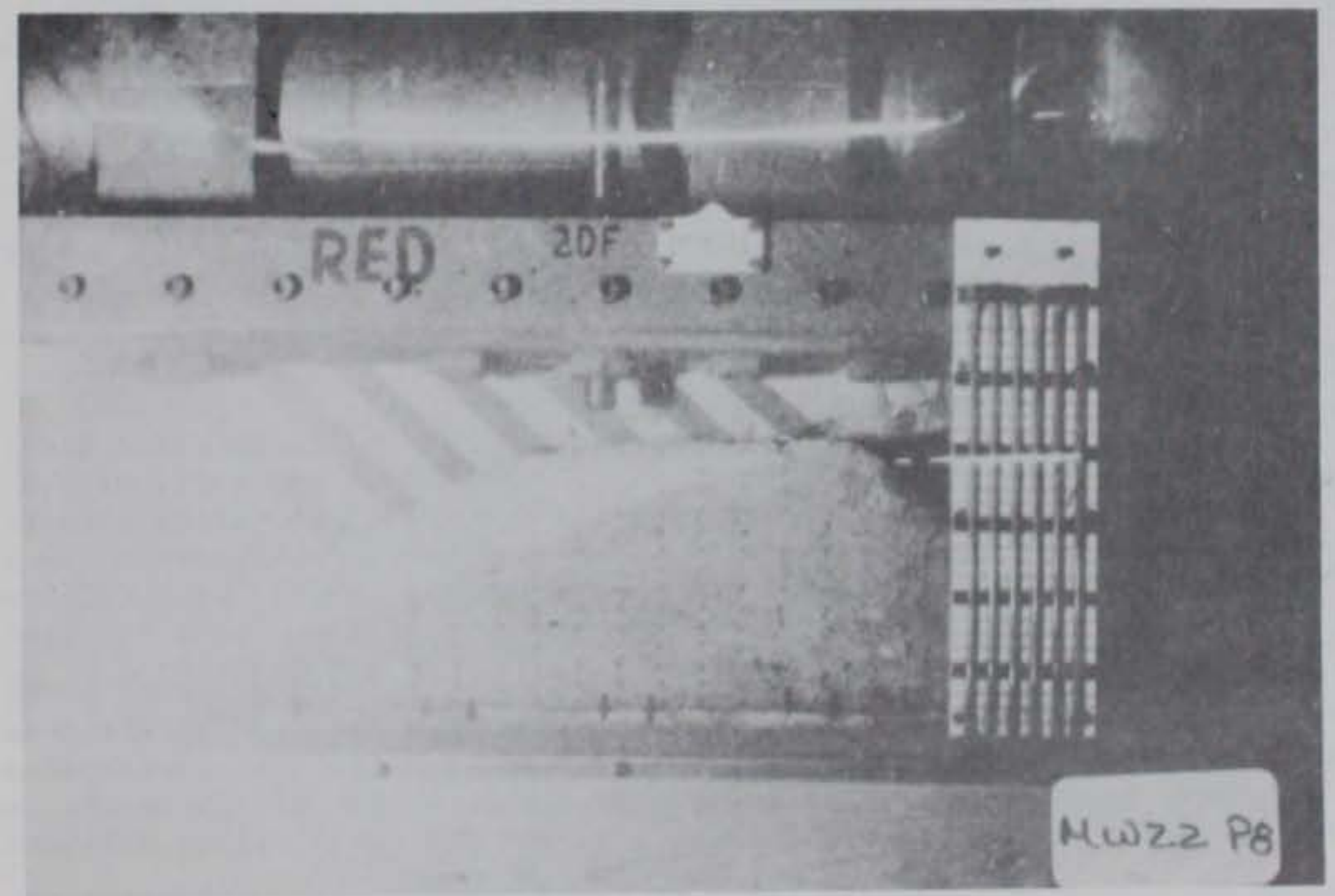

Figure 41. Model MW-22 at $40 \mathrm{~g}^{\prime} \mathrm{s}$ 


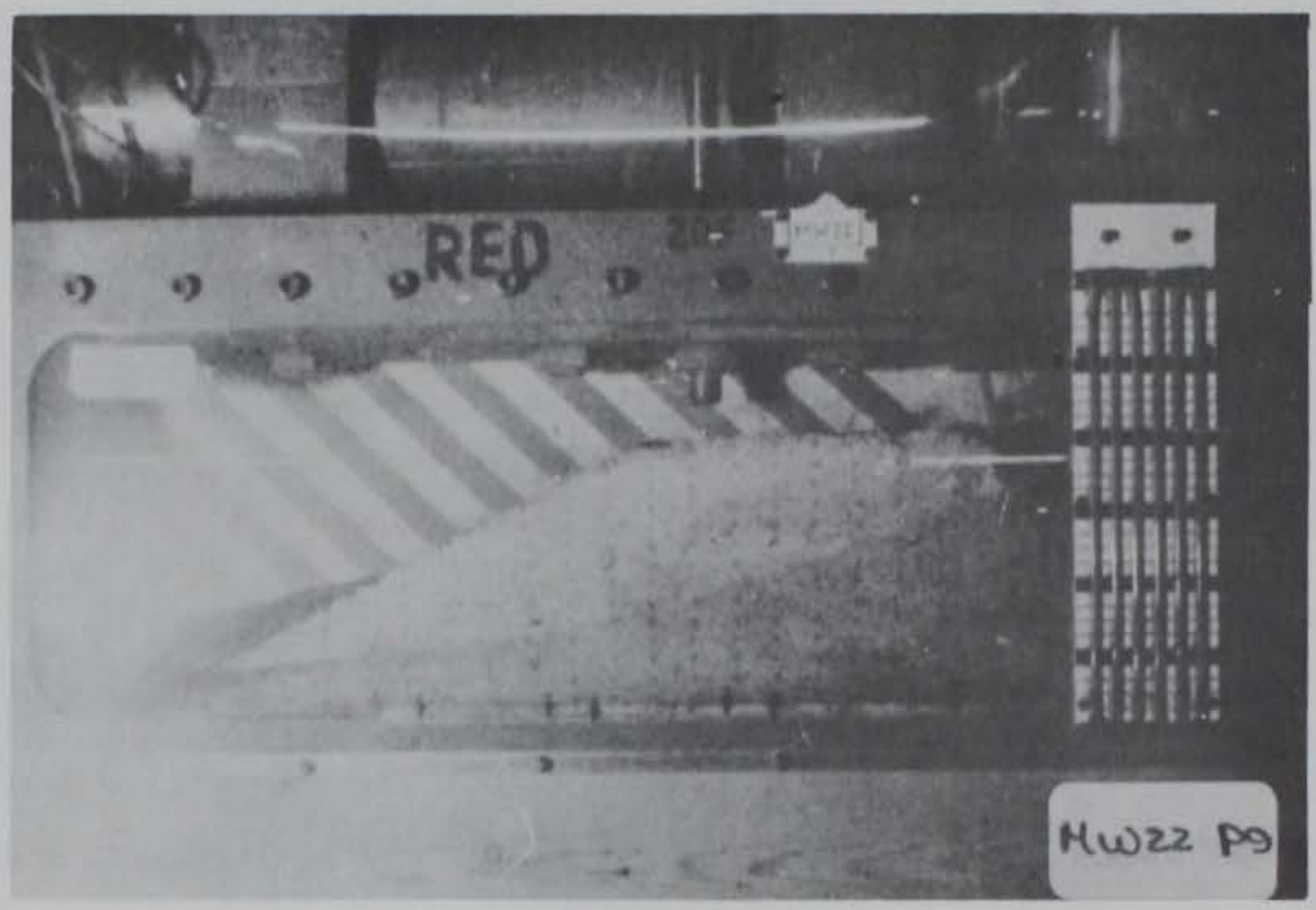

Figure 42. Model MW-22 at $20 \mathrm{~g}^{\prime} \mathrm{s}$

$(21.3 \mathrm{ft})$ deep. The cutoff wall is now only $2.4 \mathrm{~m}(7.9 \mathrm{ft})$ high but is no longer effective. Further seepage is attracted to the area, signified by the apparent increase in permeability.

The last notional prototype is an embankment $3.6 \mathrm{~m}$ high, passing through a flow of $0.02 \mathrm{ft}^{3} / \mathrm{sec}$ per foot or $2 \times 10^{-3} \mathrm{~m}^{3} / \mathrm{sec}$ per metre of embankment width from a full reservoir. An unacceptable bank of waste material has been formed downstream of the slope, unrealistically blocking further erosion.

MW-23

This model was similar to $M W-22$ in construction and in material used, but without the clay foundation layer. Also, model MW-23 was built with a full-height vertical reservoir, which prevents free-fall conditions occurring by applying a full-height water supply. The model was accelerated to $100 \mathrm{~g}$ 's (Figure 43), and then the speed was reduced to various levels, with different flow rates, to establish data to determine the permeability. At a throughflow rate of $1.21 \times 10^{-3} \mathrm{ft}^{3} / \mathrm{sec}$ per foot or $112 \mathrm{~mm}^{3} / \mathrm{sec}$ per millimetre of model width at $75 \mathrm{~g}$ 's, erosion was noted to have occurred on the side of the model not visible to the camera (Figures 44 and 45 ). Once initiated, the erosion was aggravated by the concentration of water drawn to that point; as the centrifuge speed was reduced from 100 to $66 \mathrm{~g}^{\prime} \mathrm{s}$, and the water supply ultimately increased to $3.54 \times 10^{-3} \mathrm{ft}^{3} / \mathrm{sec}$ per foot or $329 \mathrm{~mm}^{3} / \mathrm{sec}$ per millimetre of 


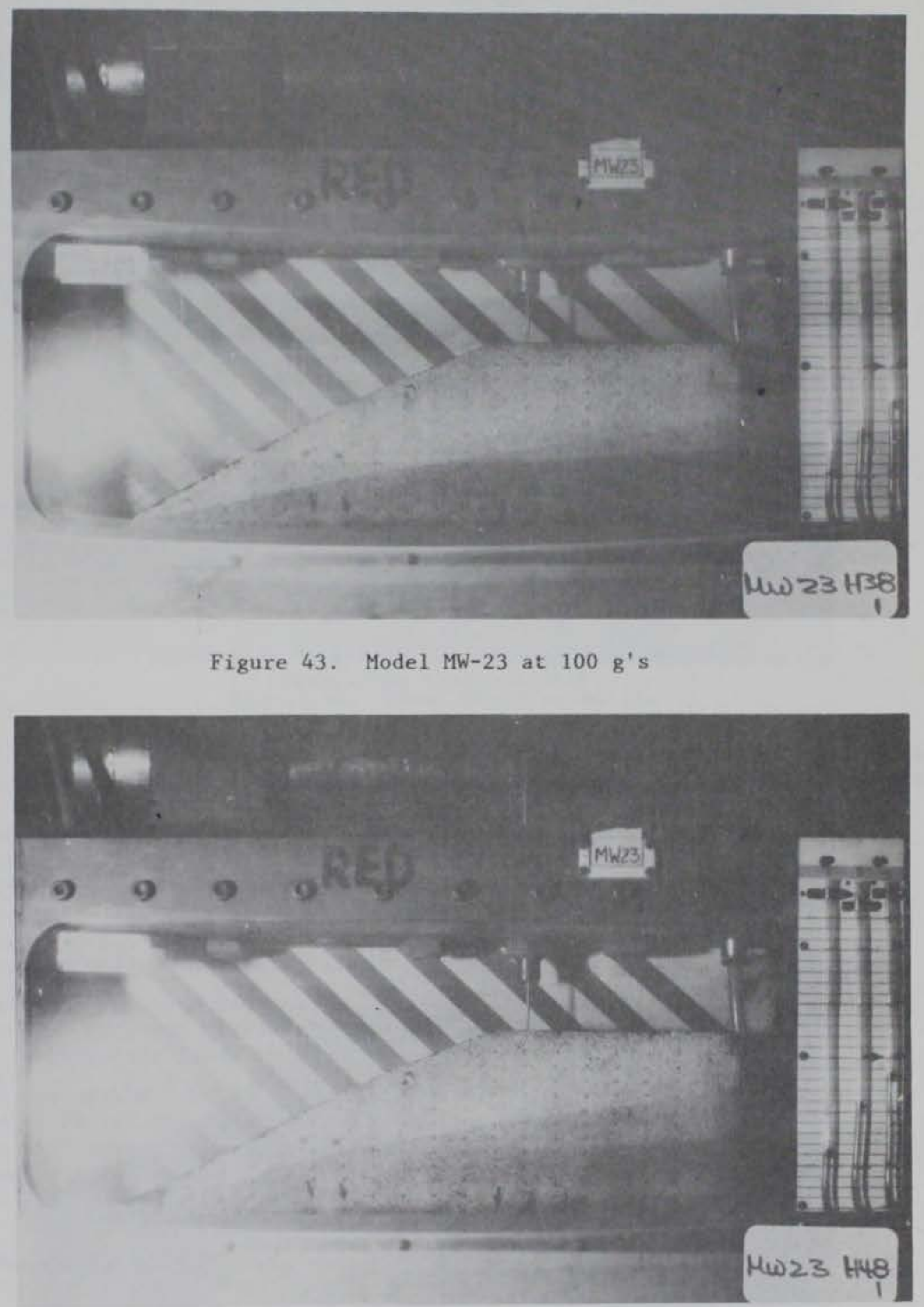

Figure 44. Model MW-23 at $75 \mathrm{~g}^{\prime} \mathrm{s}$ 


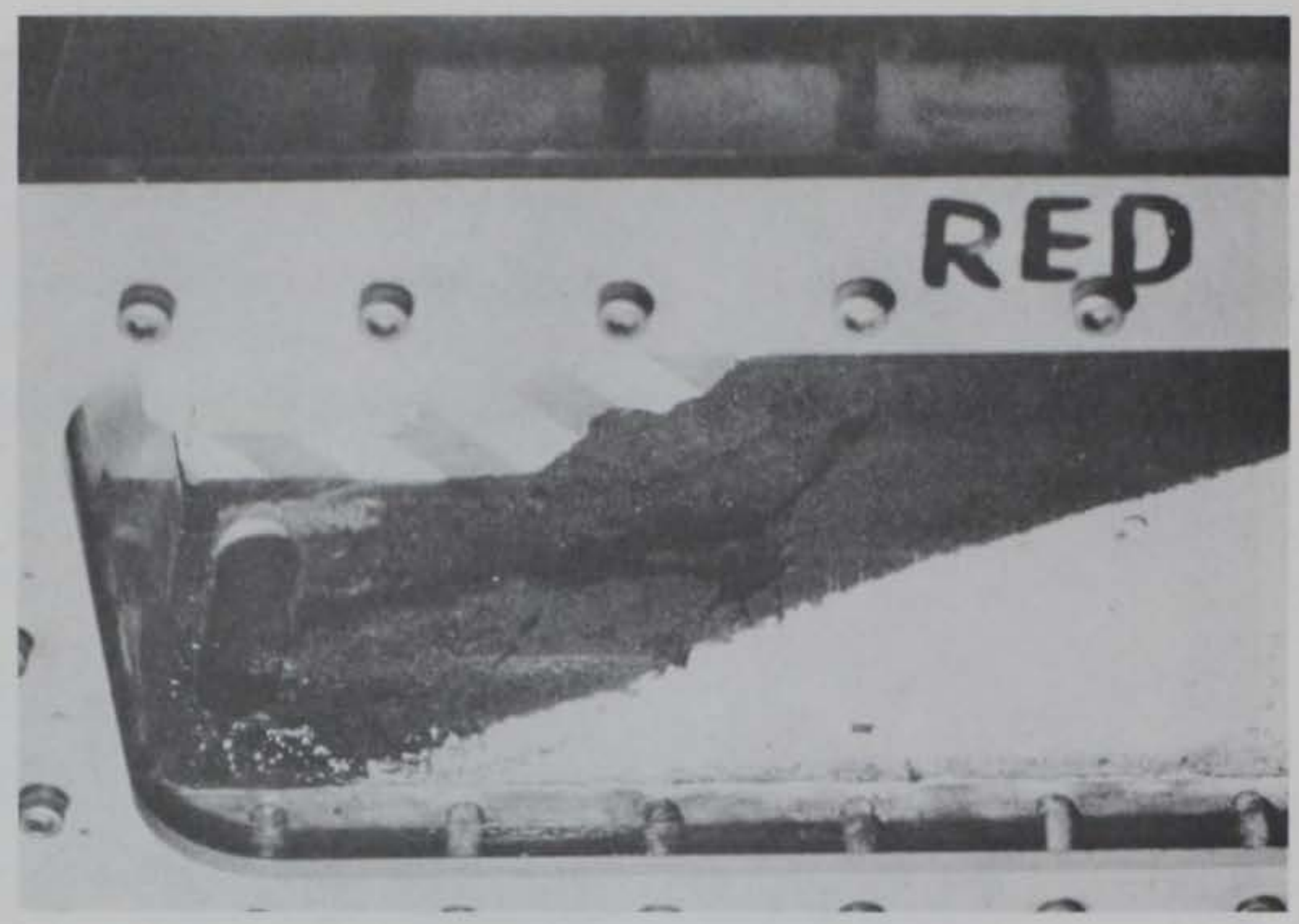

Figure 45. Model MW-23 at $1 \mathrm{~g}$ on centrifuge (intermediate photograph)

model width, the erosion reached a clearly unacceptable level (Figure 46), forming a uniform blanket of debris across the model (Figure 47).

Analogous prototype experience. As with model MW-22, this model simulates several notional prototypes of different heights, permeabilities, and throughflows, but with constant strength parameters. A prototype embankment of height $18.5 \mathrm{~m}(60.7 \mathrm{ft})$, with permeability equal to $44 \mathrm{~mm} / \mathrm{sec}$, impounding a reservoir $11.5 \mathrm{~m}(37.7 \mathrm{ft})$ deep, i.e., 62 percent of full capacity, and permitting a throughflow of $0.12 \mathrm{ft}^{3} / \mathrm{sec}$ per foot or $1.1 \times 10^{-2} \mathrm{~m}^{3} / \mathrm{sec}$ per metre of embankment width is shown to be stable. By simultaneously changing height and permeability of the embankment for the same model throughflow, an embankment-dam passing a throughflow of $0.8 \times 10^{-2} \mathrm{~m}^{3} / \mathrm{sec}$ per metre of embankment width from a reservoir $9.1 \mathrm{~m}$ in height or at 66 percent of full capacity is found to be unstable with respect to erosion. Once begun, the weakened point attracts more water. The final eroded profile occurred when the notional prototype was an embankment-dam $12 \mathrm{~m}(39.4 \mathrm{ft})$ in height, passing a throughflow of $0.2 \mathrm{ft}^{3} / \mathrm{sec}$ per foot or $2 \times 10^{-2} \mathrm{~m}^{3} / \mathrm{sec}$ per metre of embankment width. 


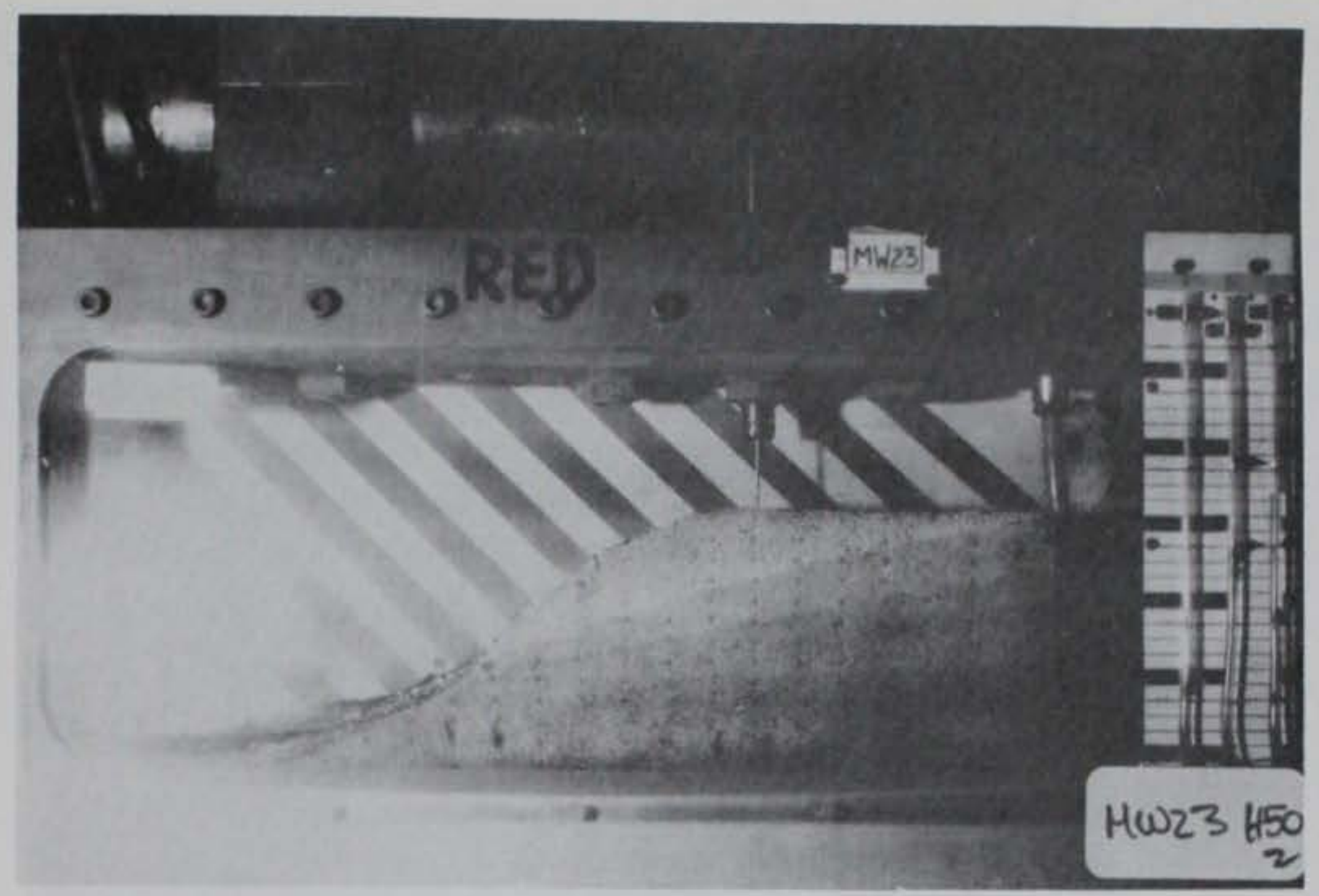

Figure 46. Mode1 MW-23 at $66 \mathrm{~g}$ 's

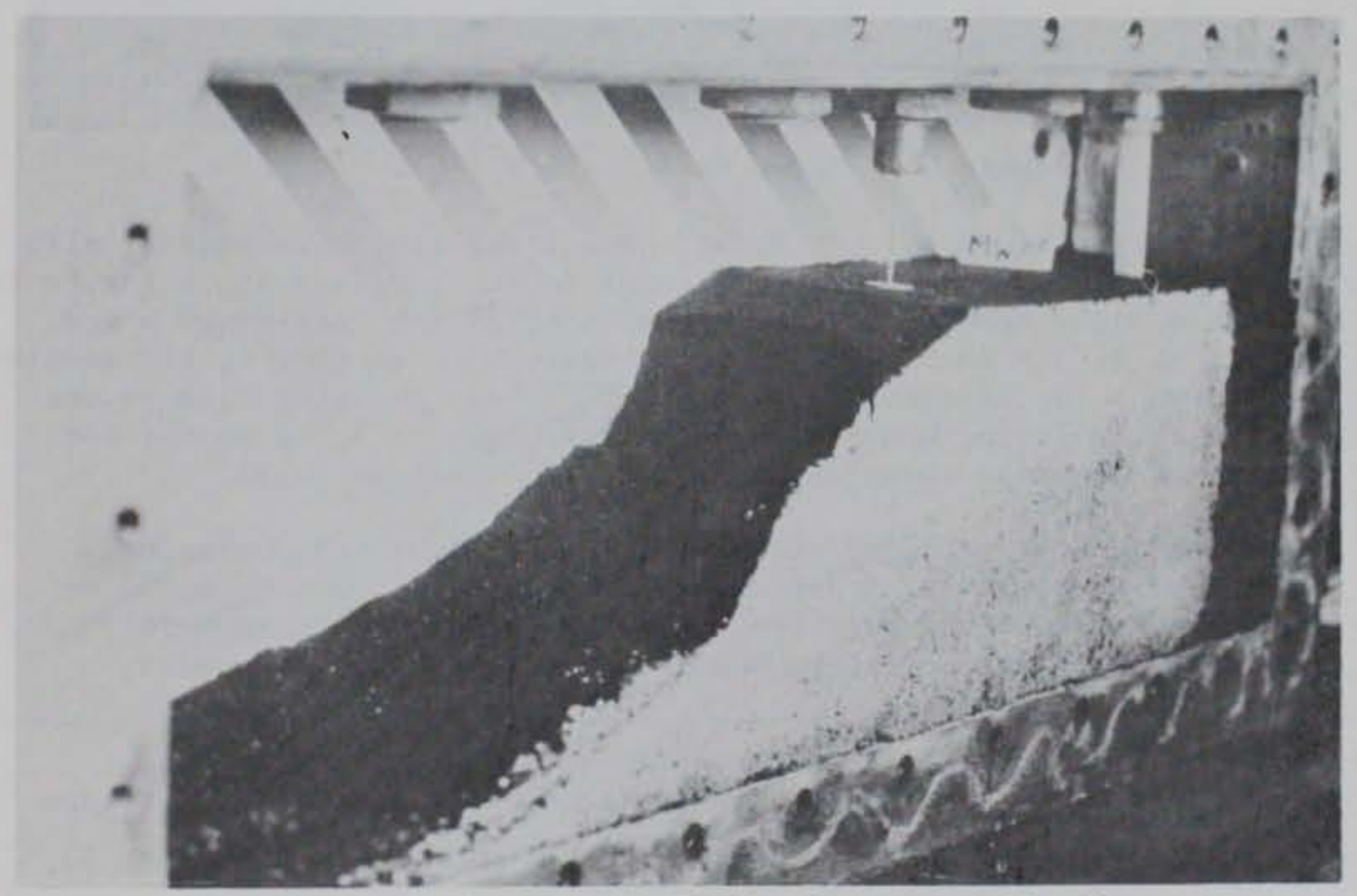

Figure 47. Model $\mathrm{MW}-23$ after centrifugal test 
This model was prepared of material containing 34 percent fines (Figure 7) and a geometry identical to $\mathrm{MW}-23$, accelerated to $9 \mathrm{~g}$ 's over $90 \mathrm{sec}$, and left at that speed for $13.5 \mathrm{~min}$ (Figure 48). It was further accelerated, and

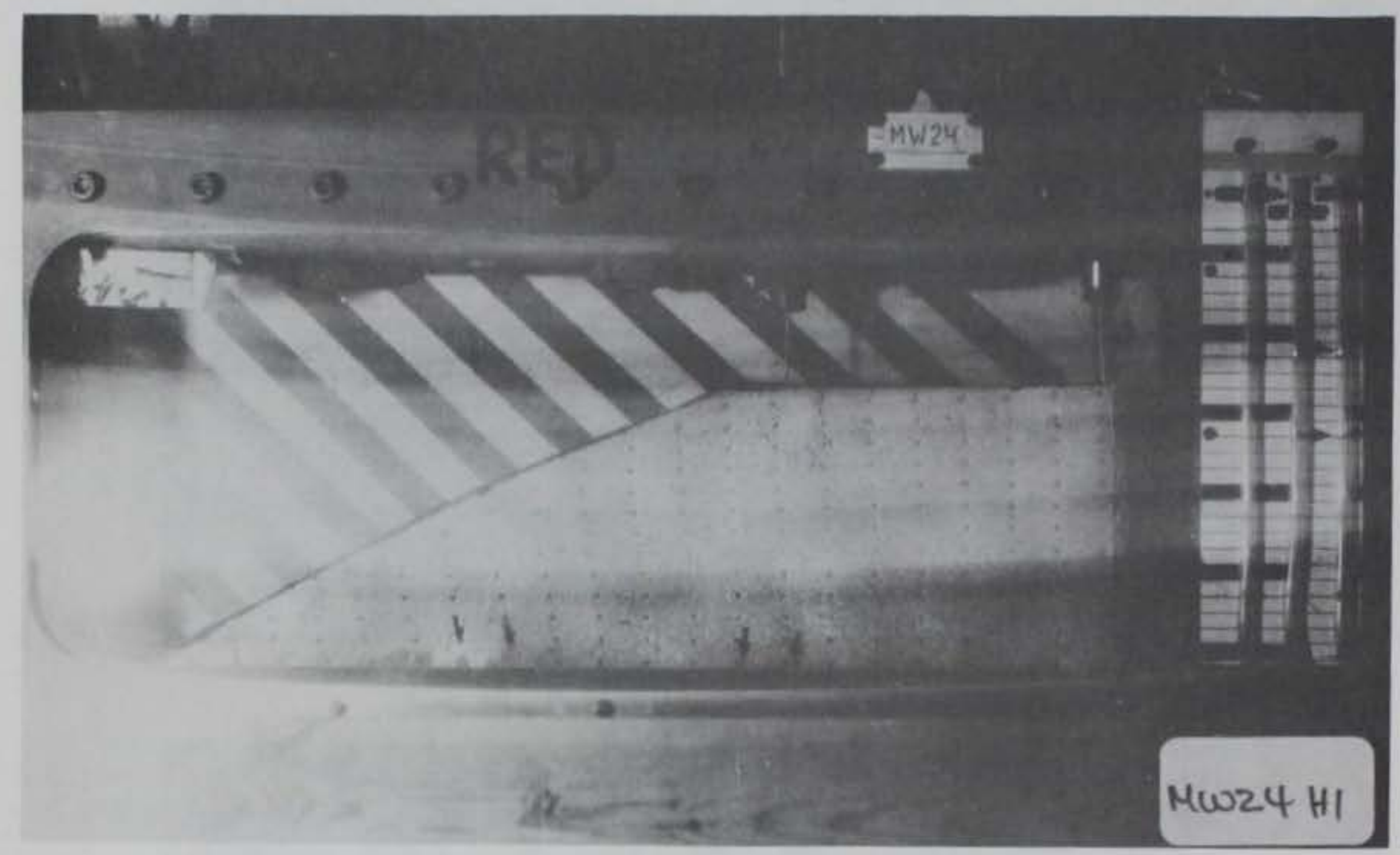

Figure 48. Model MW-24 at $9 \mathrm{~g}^{\prime} \mathrm{s}$

immediately upon achieving $15 \mathrm{~g}$ 's, it failed in a conventional rotational slip circle (Figures 49 and 50). The intact wedge of debris reclined at 16 deg to the horizontal (Figure 51). When further accelerated to $25 \mathrm{~g}$ 's, the wedge moved first to a position $10 \mathrm{deg}$ to the horizontal (Figure 52); at $50 \mathrm{~g}$ 's, the remaining scarp developed a retrogressive failure. The debris was supported at one end by the centrifugal strong box and formed at an angle of 7 deg to the horizontal, leaving no definite scarp in the remaining intact material.

Analogous prototype experience. This model simulates a rate of construction failure. A prototype embankment is built to a height of $1.7 \mathrm{~m}(5.6 \mathrm{ft})$ over a half-hour period and then left to consolidate for $18 \mathrm{hr} . *$ When, however, an attempt is made

* Since embankment failure resulted from excessive rate of construction creating high pore pressures, the governing time factor comparing prototype with model is $\mathrm{N}^{2}$ (see Modeling consolidation of saturated clay, Chapter 3 ). Hence, $13.5 \mathrm{~min} \times 9^{2} \div 60=18.2 \mathrm{hr}$. 


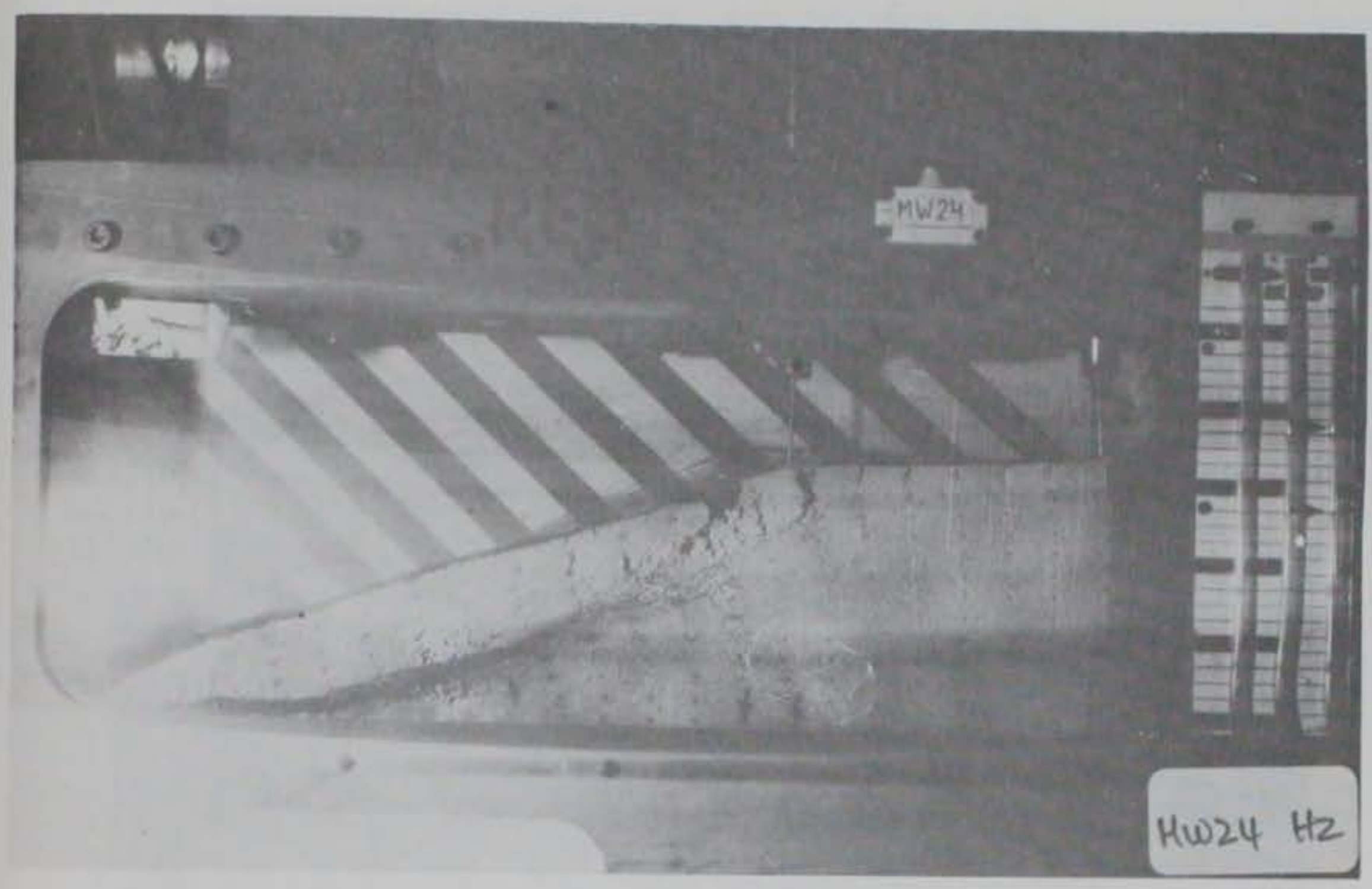

Figure 49. Model MW-24 at $15 \mathrm{~g}$ 's

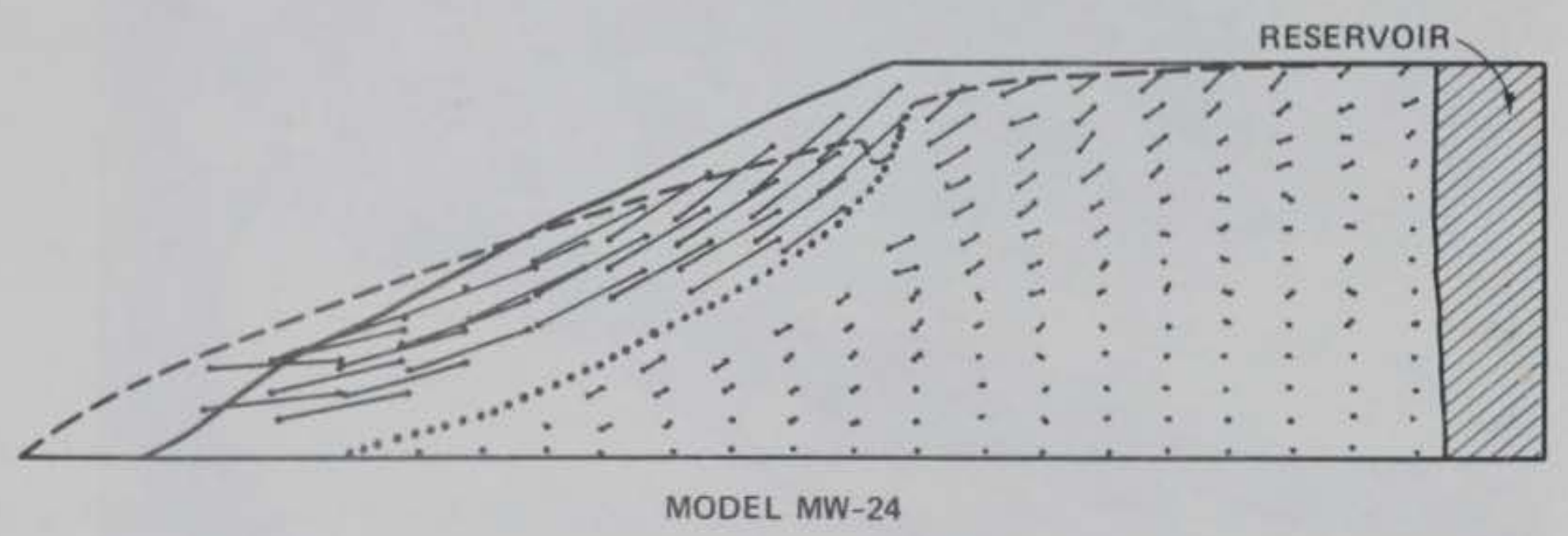

Figure 50. Model MW-24: rotational slip at $15 \mathrm{~g}^{\prime} \mathrm{s}$ relative to state at $9 \mathrm{~g}^{\prime} \mathrm{s}$ 


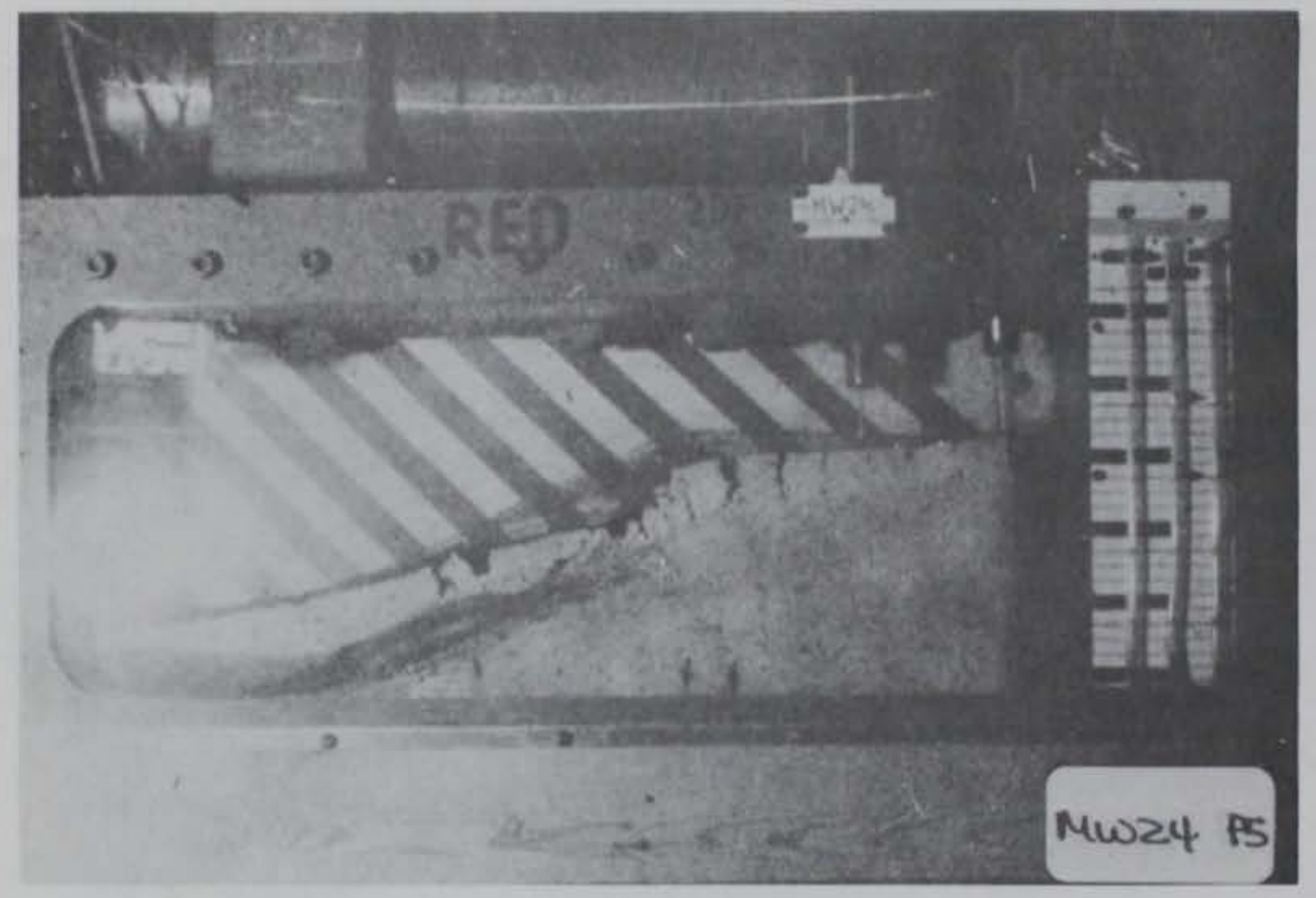

Figure 51. Model MW-24 at $25 \mathrm{~g}^{\prime} \mathrm{s}$

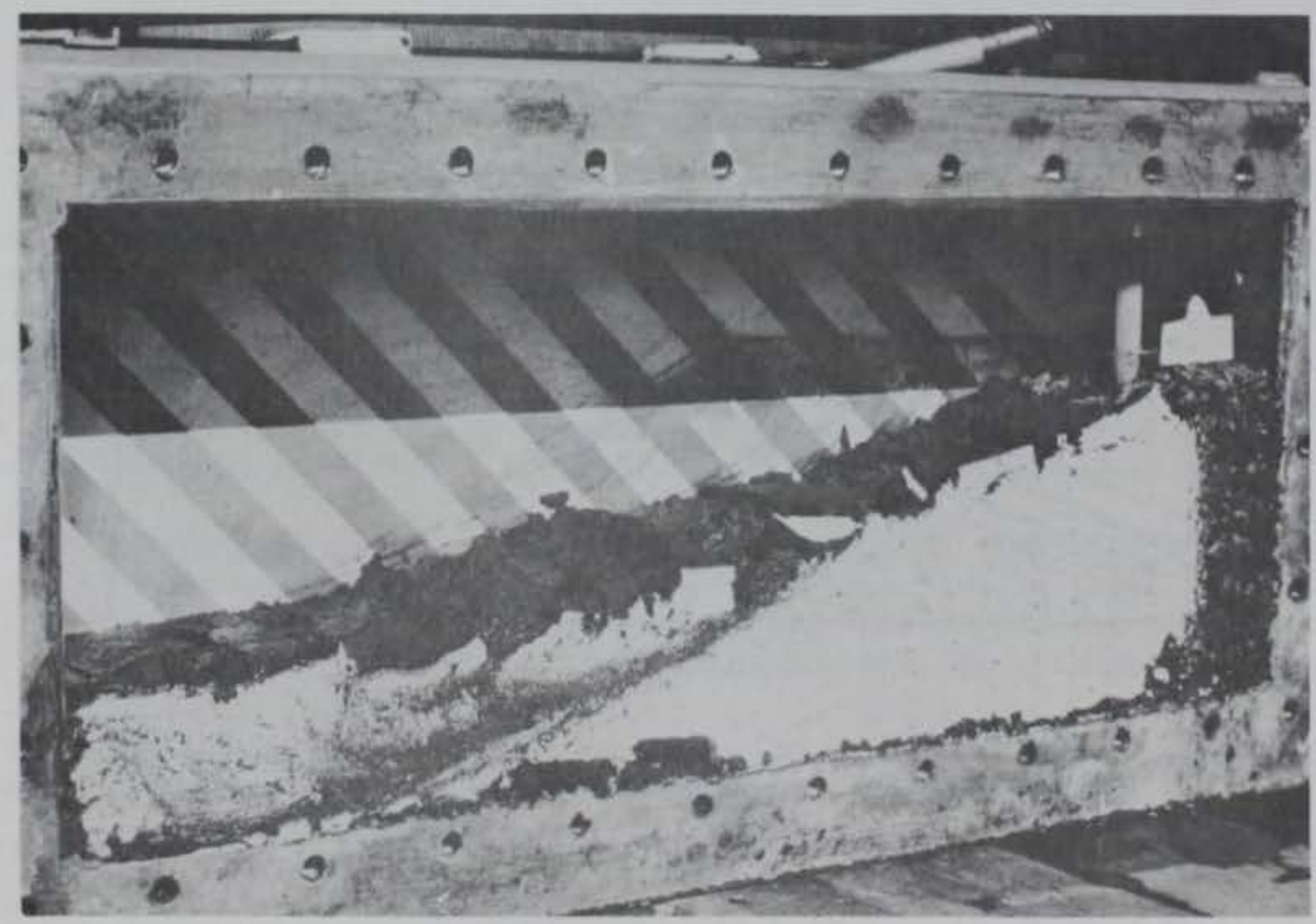

Figure 52. Model MW-24 after centrifugal test 
to increase the height of the embankment to $2.8 \mathrm{~m}(9.2 \mathrm{ft})$, the slope immediately fails upon reaching that height and stabilizes at 16 deg to the horizontal, as compared with the original $1 \mathrm{~V}: 2 \mathrm{H}$ slope of $26.5 \mathrm{deg}$. Two subsequent increases in height demonstrate the delicate nature of the stability achieved; i.e., a final attempted increase to $9.25 \mathrm{~m}(30.3 \mathrm{ft})$ causes the material to stabilize at 7 deg to the horizontal when the foot of the material is stopped by a valley wall or some similarly immovable feature.

$\mathrm{MW}-25$

This model of material containing 9 percent fines (Figure 7) was prepared identically to $M W-23$ but with a much wider vertical reservoir due to the decreasing supply of model soil. The model was accelerated to $100 \mathrm{~g}$ 's over 22 min (Figure 53), after which time various combinations of throughflows and

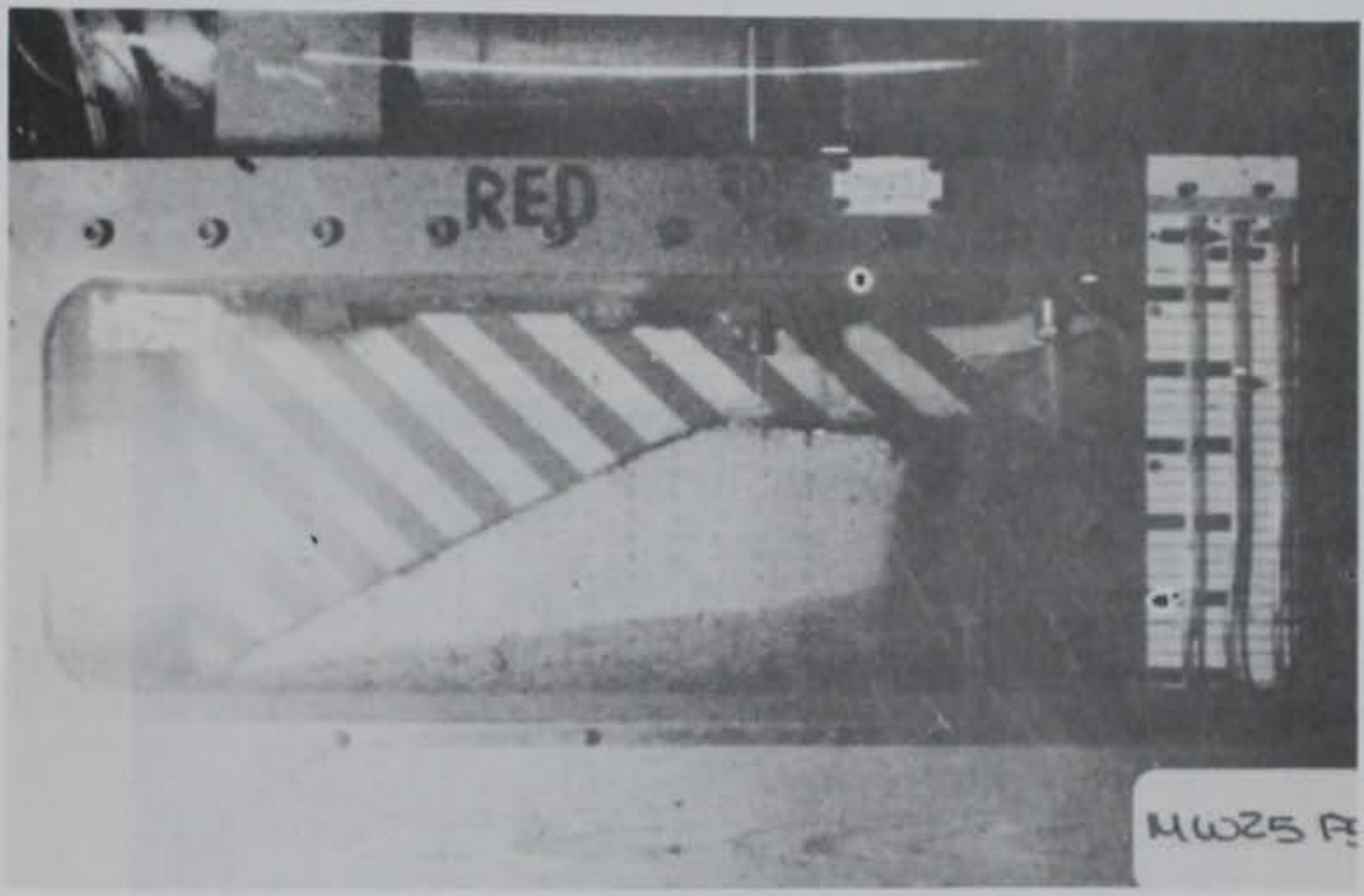

Figure 53. Model MW-25 at $100 \mathrm{~g}^{\prime} \mathrm{s}$

centrifugal accelerations were tried to establish permeability. At $100 \mathrm{~g}$ 's, with a flow rate of $1.3 \times 10^{-3} \mathrm{ft}^{3} / \mathrm{sec}$ per foot or $121 \mathrm{~mm}^{3} / \mathrm{sec}$ per millimetre of embankment width, the slope was stable; for the same model flow rate, erosion began to occur when the speed of the centrifuge was reduced to $30 \mathrm{~g}$ 's (Figures 54). The erosion was permitted to continue at $30 \mathrm{~g}$ 's for 4 min (Figures 55 and 56 ).

Analogous prototype experience. As in MW-22 and MW-23, several different prototypes are simulated. An embankment of height $18.6 \mathrm{~m}$ $(61.0 \mathrm{ft})$, impounding a reservoir $8.9 \mathrm{~m}(29.2 \mathrm{ft})$ high or 48 percent 


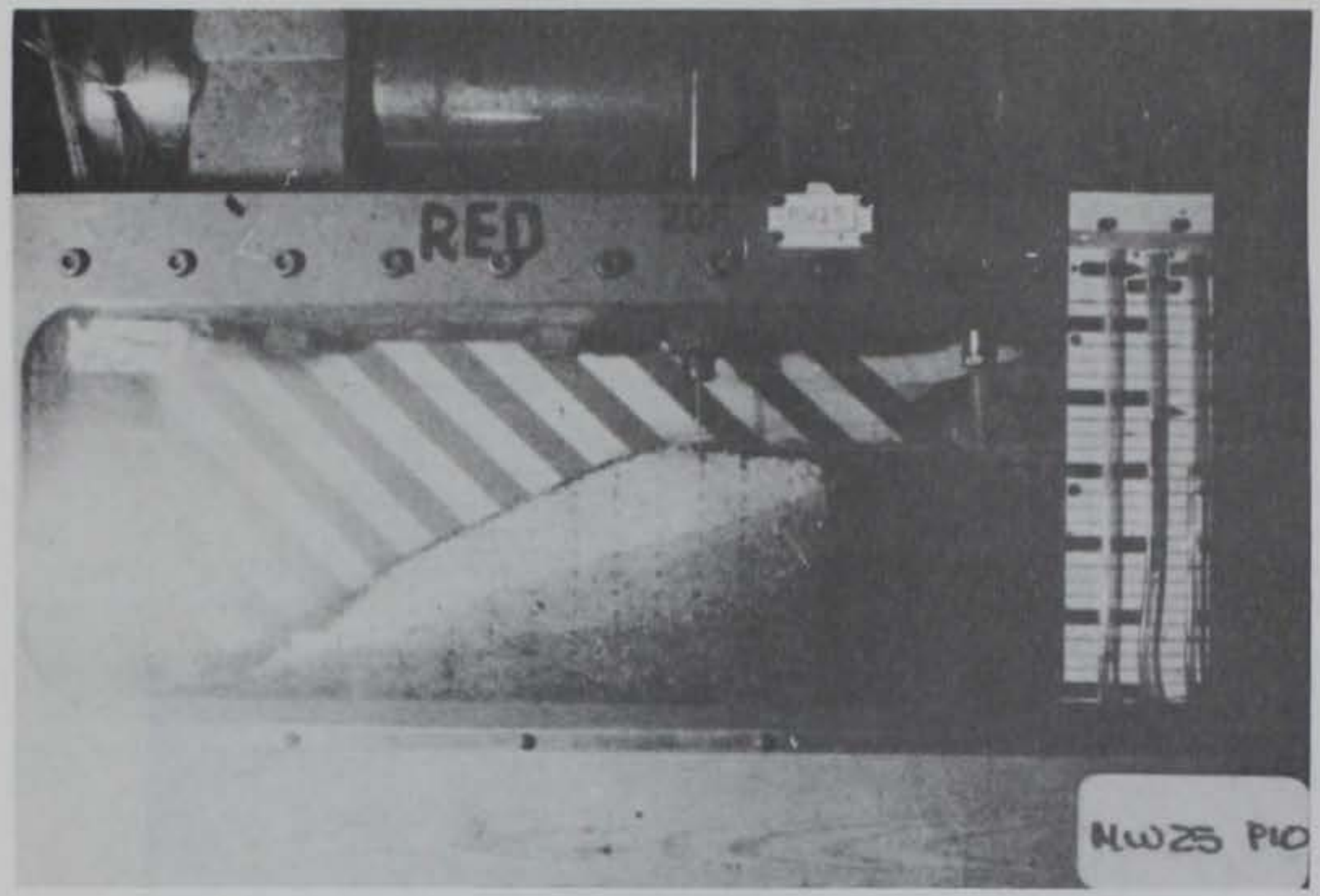

Figure 54. Model $\mathrm{MW}-25$ at $30 \mathrm{~g}^{\prime} \mathrm{s}$

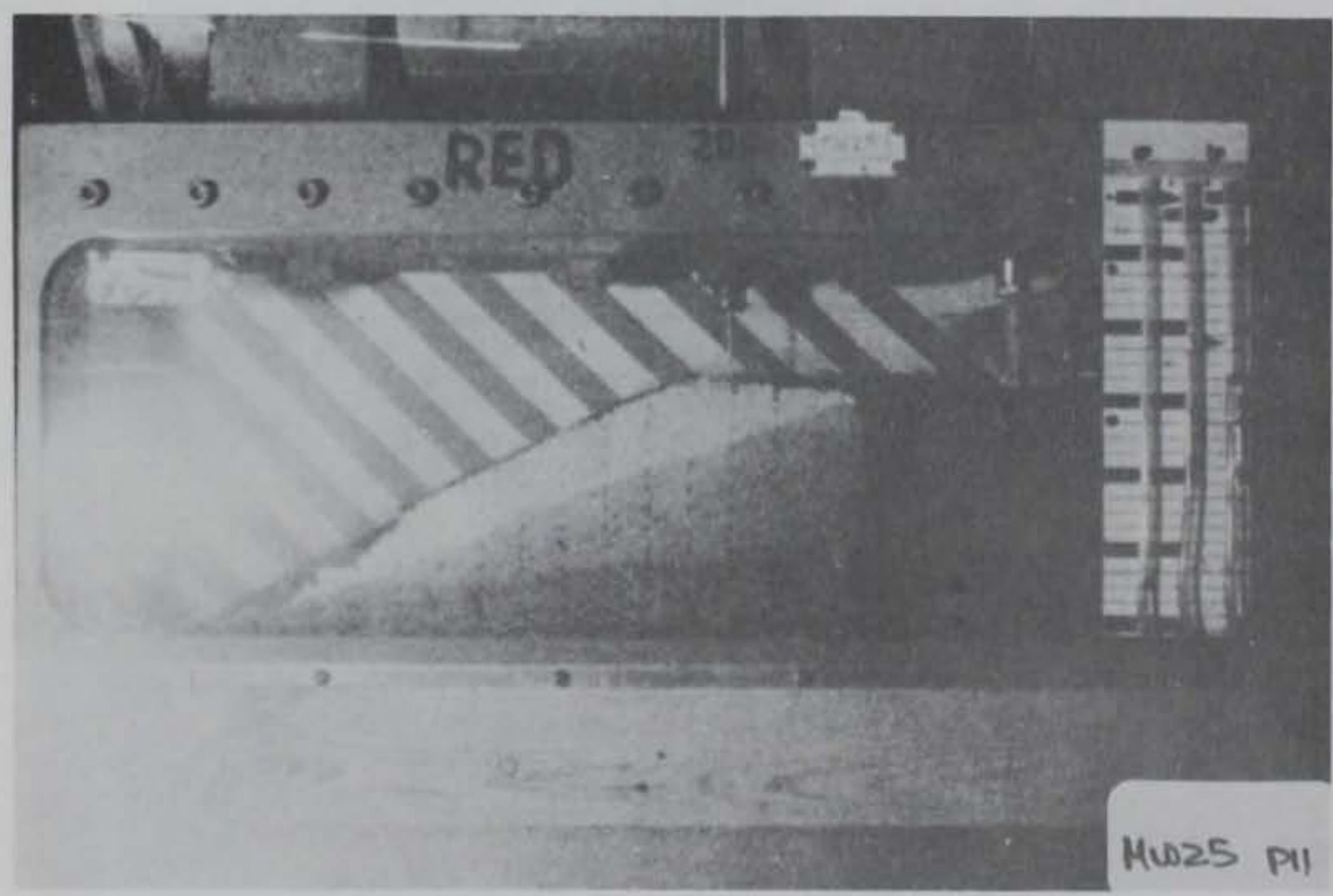

Figure 55. Model $\mathrm{MW}-25$ at $30 \mathrm{~g}$ 's, during erosion 


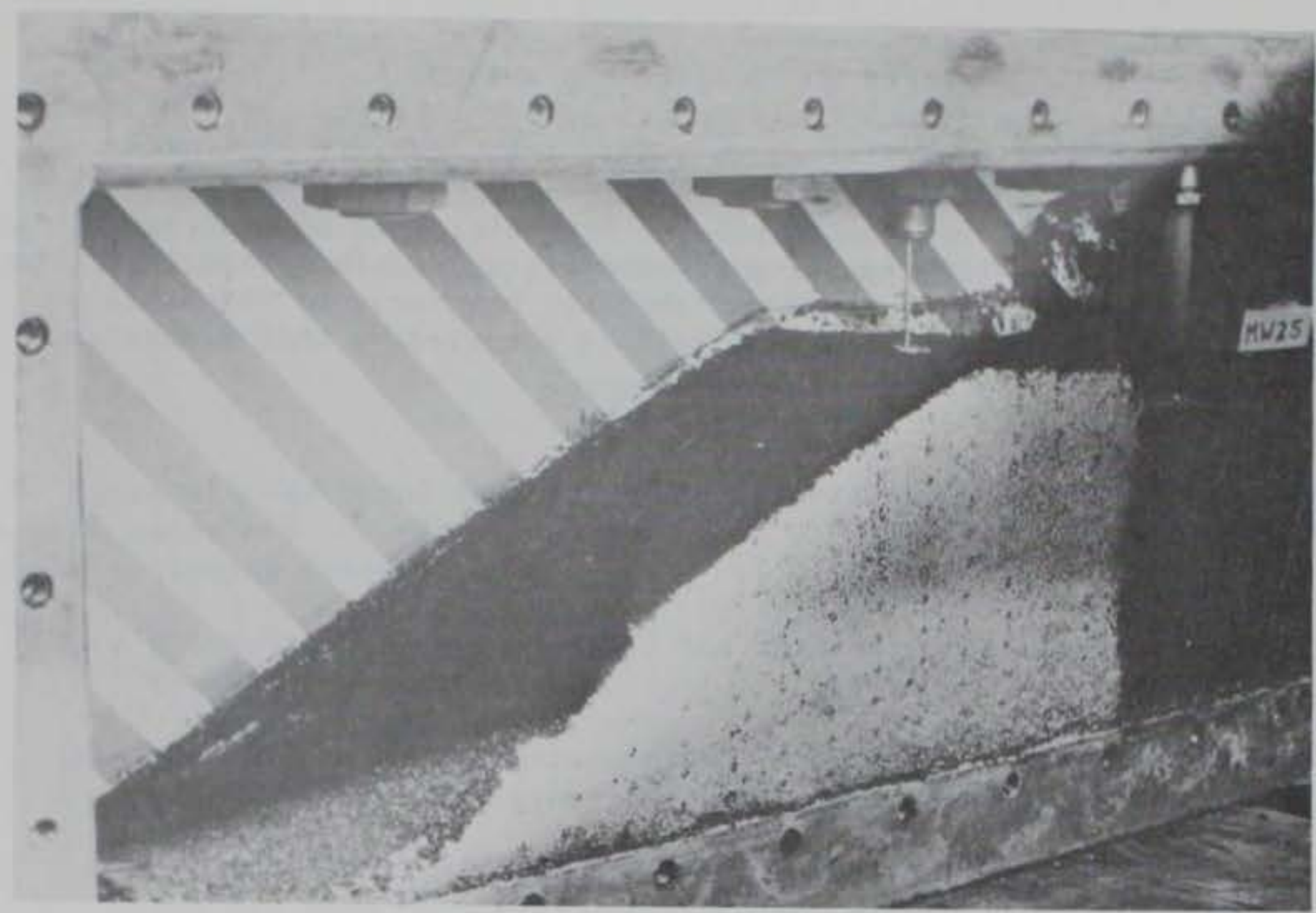

Figure 56. Model MW-25 after centrifugal test of capacity and passing flow of $0.13 \mathrm{ft}^{3} / \mathrm{sec}$ per foot or $1.2 \times 10^{-2} \mathrm{~m}^{3} / \mathrm{sec}$ per metre of embankment width, was found to be stable. However, simultaneously decreasing the embankment height and perpeability, so that the embankment was $5.6 \mathrm{~m}(18.4 \mathrm{ft})$ high and the reservoir depth was $4.7 \mathrm{~m}(15.4 \mathrm{ft})$ or at 84 percent capacity, resulted in an equivalent throughflow of $0.4 \mathrm{ft}^{3} / \mathrm{sec}$ per foot or $0.4 \times 10^{-2} \mathrm{~m}^{3} / \mathrm{sec}$ per metre of embankment width, which caused erosion at the toe, thus constituting failure.

\section{Summary of Test Series No. 2}

It is quite evident from this series of tests that particle-size distribution and, consequently, permeability are two of the most important factors governing the type of failure. Permeable embankments, i.e., MW-22, $M W-23$, and $M W-25$, can permit passing of high seepage quantities maintaining overall mass stability but fail because of erosion. Less permeable embankments, MW-20 and MW-24, while reducing seepage throughflow and thus eliminating concern regarding throughflow erosion problems, are susceptible to rate of construction failures or overflow erosion. For embankments of intermediate permeabilities, based upon test series No. 1, mass instability preceded by toe erosion can be the mode of failure.

For these models, the nature of the foundation layer did not affect 
embankment stability. The foundation strength is adequate for the embankment height, and its permeability sufficiently lower; then, failure must occur within the embankment itself.

The effect of compaction in lifts probably increased the strength of the embankment with respect to mass slope instability; however, the throughflow erosion resistance was not improved, and failure occurred by this mechanism. 


\section{CHAPTER 6: ANALYSIS OF RESULTS}

The results of seepage, stability, and erosion analysis for the various model geometries and materials used are discussed and compared with events observed in the centrifuge in the following paragraphs.

\section{Seepage Analysis}

Since all earth and coal refuse embankments are, to some degree, pervious to water and therefore susceptible to seepage, seepage is of concern for the following reasons:

a. Water lost through or under the structure may be polluted and will require treatment.

b. The pore water pressures in the embankment and its foundation greatly affect the stability of the embankment.

c. An excessive hydraulic gradient on the embankment slope or at the toe can lead to piping, erosion, and destructive uplift pressures.

Of paramount importance in seepage analysis is the location of the phreatic surface. Its location is required for flow net construction to estimate permeabilities and stability analyses. Hence, the phreatic surfaces were located using conventional methods for various percentages of reservoir heights of prototype embankments.

Because of the boundary conditions imposed on the model, the corresponding prototype dams were assumed to be resting on an impervious boundary, and the seepage flow through the dam is considered two-dimensional. For homogeneous dams, Dupuit's (1863) formula, which assumed that Laplace equation for steady flow (Figure 57) is satisfied, can be used to estimate location of the phreatic surface. Thus,

$$
\frac{\partial^{2}(h)}{\partial x^{2}}+\frac{\partial^{2}(h)}{\partial y^{2}}=0
$$

Since the $x$-axis is an impervious boundary, then the velocity gradient $\partial^{2}(h) / \partial^{2}\left(y^{2}\right)$ can be reduced to zero, and Equation 27 will be reduced to the following:

$$
\frac{\partial^{2}(h)}{\partial^{2} x^{2}}=0
$$




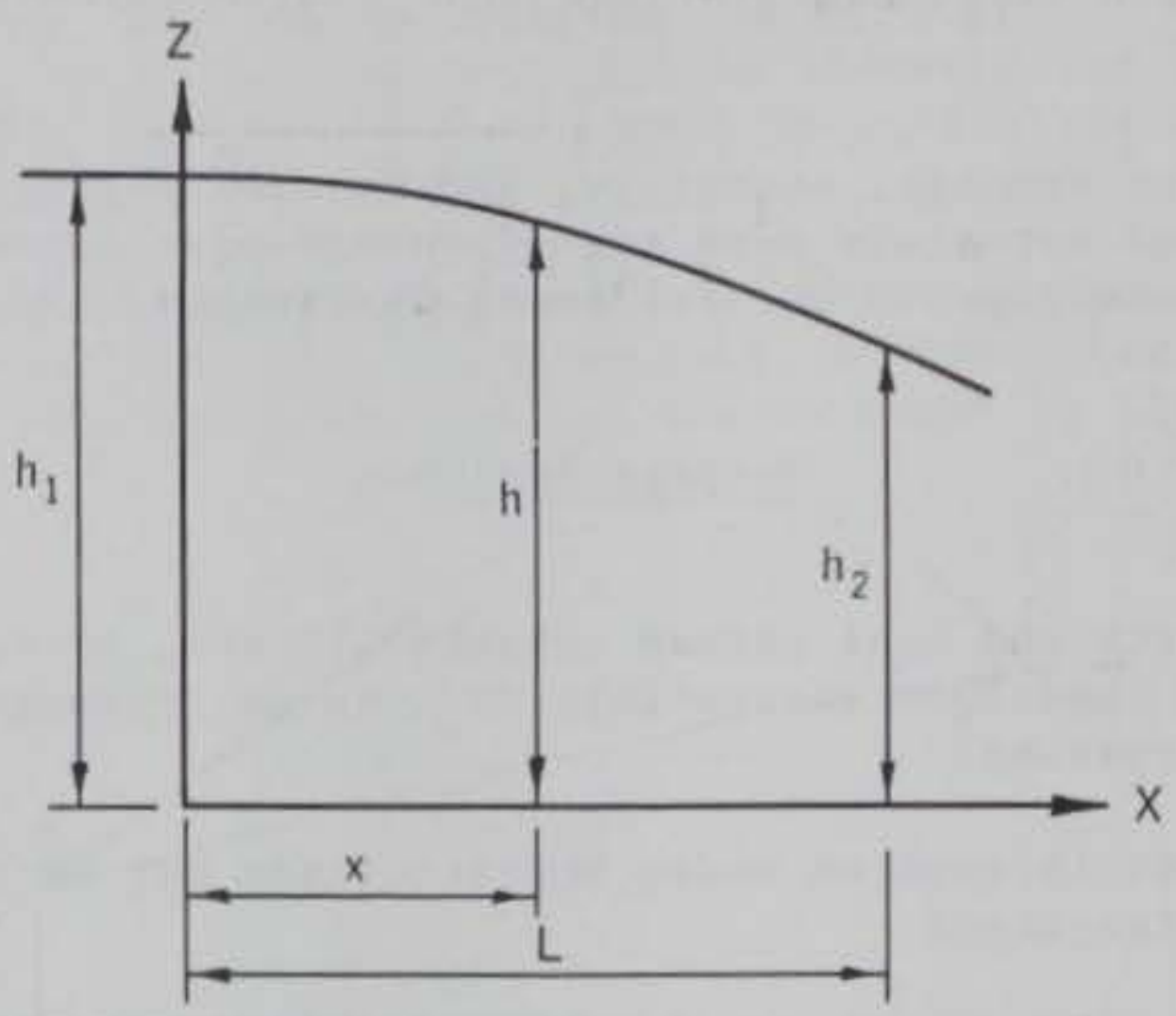

Figure 57. Two-dimensional steady-state flow

which after integration and applying the boundary conditions leads to the following expression that is parabolic:

$$
h=\left[h_{1}^{2}-\left(h_{1}^{2}-h_{2}^{2}\right) \frac{x}{L}\right]^{1 / 2}
$$

The discharge per unit width through any vertical section in Figure 57 can be estimated from Darcy's equation

$$
\mathrm{q}=\mathrm{kia} / \ell
$$

where $q=$ flow rate per unit width

$\mathrm{k}=$ coefficient of permeability

$i=$ the hydraulic gradient, i.e., head loss per unit length

$\mathrm{a}=$ the cross-sectional area through which flow occurs

$\ell=$ unit width

Thus,

$$
q=-k h \frac{d h}{d x}=\frac{k\left(h_{1}^{2}-h_{2}^{2}\right)}{2 L}
$$

In case of an embankment resting on an impervious base with no tail water, Van Terson (1916-1917) applied Equation 30 to the triangle ABC shown in Figure 58 to obtain an expression for the discharge $q$ as

$$
q=-k h \frac{d h}{d x}=k a \sin \alpha \tan \alpha
$$


where $\alpha=$ the downstream slope angle

$a=$ the length of seepage surface that can be expressed as

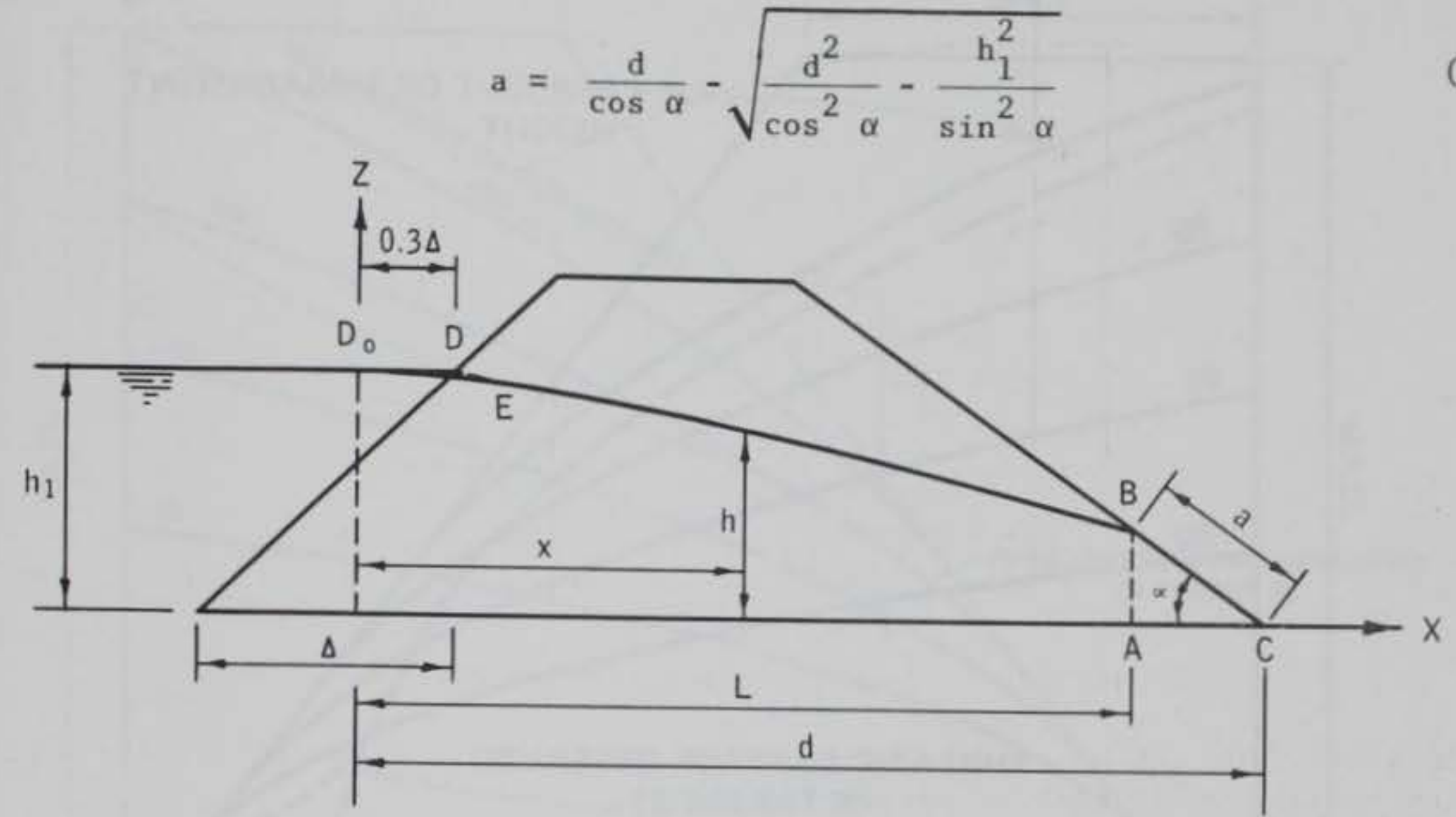

Figure 58. Steady seepage surface through a dam

It has been recommended by Casagrande (1940) that point $D_{0}$ rather than point D (Figure 58) be taken as the starting point of the line of seepage where $D_{Q}$ is $0.3 \Delta$ from $D$ at the upstream reservoir surface. The actual entrance of the seepage surface is obtained by sketching the arc DE normal to the upstream slope and tangent to the parabolic surface at point $E$.

Equation 29 was used in determining the phreatic surface, while Equations 31 and $32 \%$ were used to determine the discharge per unit width of the prototype embankments.

\section{Steady-State Seepage Through Uniform Section}

Six uniform prototype embankment sections were analyzed by conventional techniques to locate the phreatic surface and estimate the isotropic permeability of the material. Four prototype embankment sections (MW-9, MW-10, $M W-23$, and $M W-25$ ) have vertical upstream reservoir faces, while $M W-11$ and $M W-13$ have diagonal upstream faces. The phreatic surfaces for each embankment section were calculated for $100,80,60$, and 40 percent of the maximum reservoir level or crest elevation, as shown in Figures 59 through 63 . Also presented in

* This equation for a is slightly different from that recommended by Casagrande $(1940)$, where $a=\sqrt{h_{1}^{2}+d^{2}}-\sqrt{d^{2}-h^{2} \cot ^{2} \alpha}$. Both equations give practically identical results for values of a . 


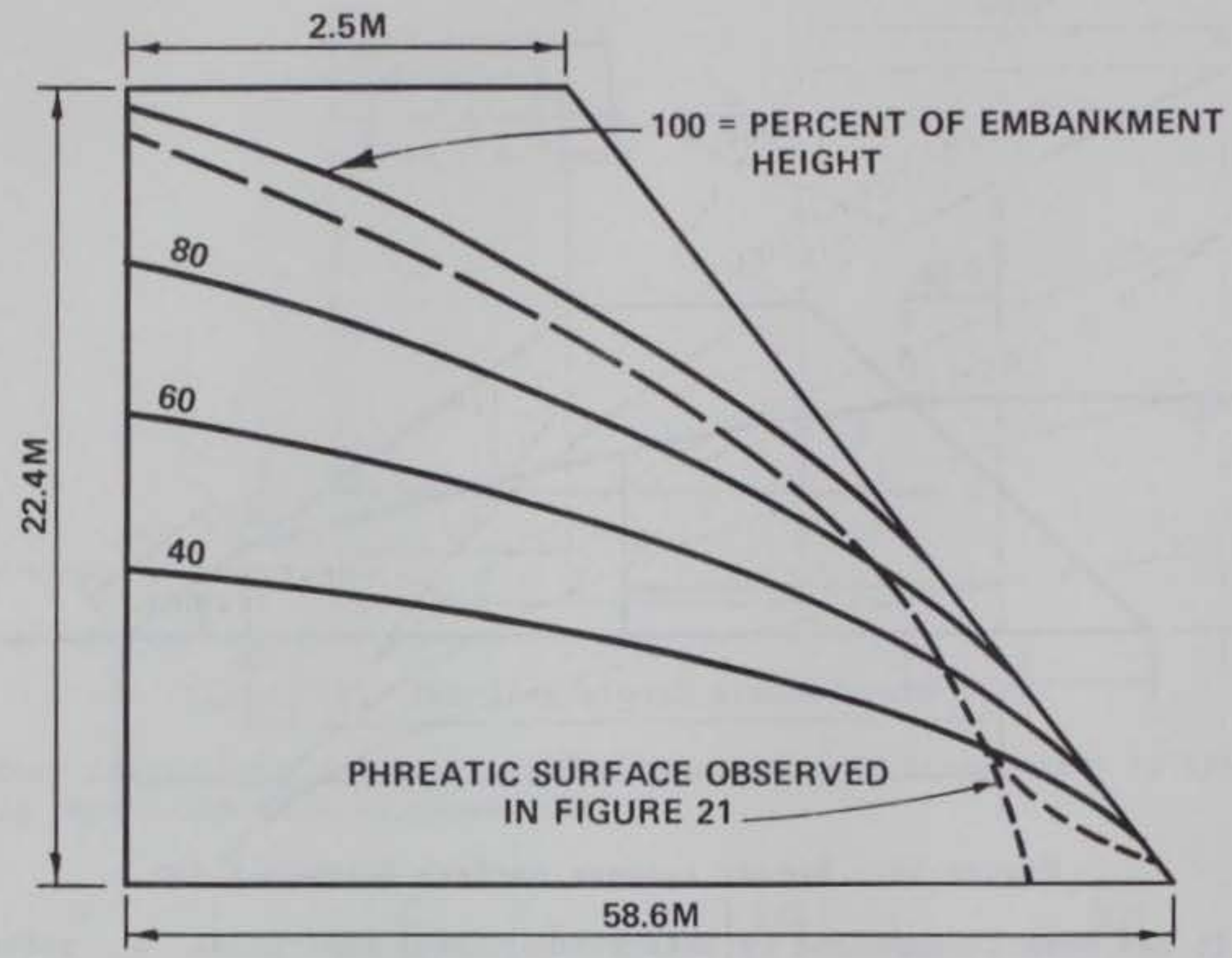

Figure 59. Comparison of observed and calculated phreatic surfaces for centrifugal model MW-9

these figures are the phreatic surfaces as observed on the CCTV monitors or photographs of the centrifugal models. For embankments with a vertical reservoir face, the observed phreatic surface closely resembles the calculated parabolic surfaces, with the exceptions that the modeled surfaces are more linear than parabolic, their gradients are much steeper, and they intersect the downstream slope at lower elevations. However, in the case of the model embankments with diagonal reservoir faces, the lower vertical section simulates a vertical cutoff, which is reflected as a free-fall tendency in the phreatic surface. For this reason, the observed centrifugal model phreatic surfaces deviate from the calculated values as shown in Figure 61 for MW-11 and later in Figure 65 for MW-13. In an attempt to understand the effect of the vertical cutoff on the phreatic surface of models with diagonal reservoirs, a two-dimensional FEM seepage analyses (Tracy, 1973) was performed. Model MW-11 with a diagonal reservoir was selected as representative, while model MW-23 with a vertical reservoir was selected for comparison and control. The results of these FEM analyses are also presented in Figures 61 and 62 and show that the FEM phreatic surface essentially duplicates Dupuit's (1863) parabola for both reservoir conditions.

The coefficient of permeability $k$ per unit length can be calculated by Equation 31, knowing values of length of seepage surface a calculated by Equation 32. In addition, permeability values can be estimated from flow 


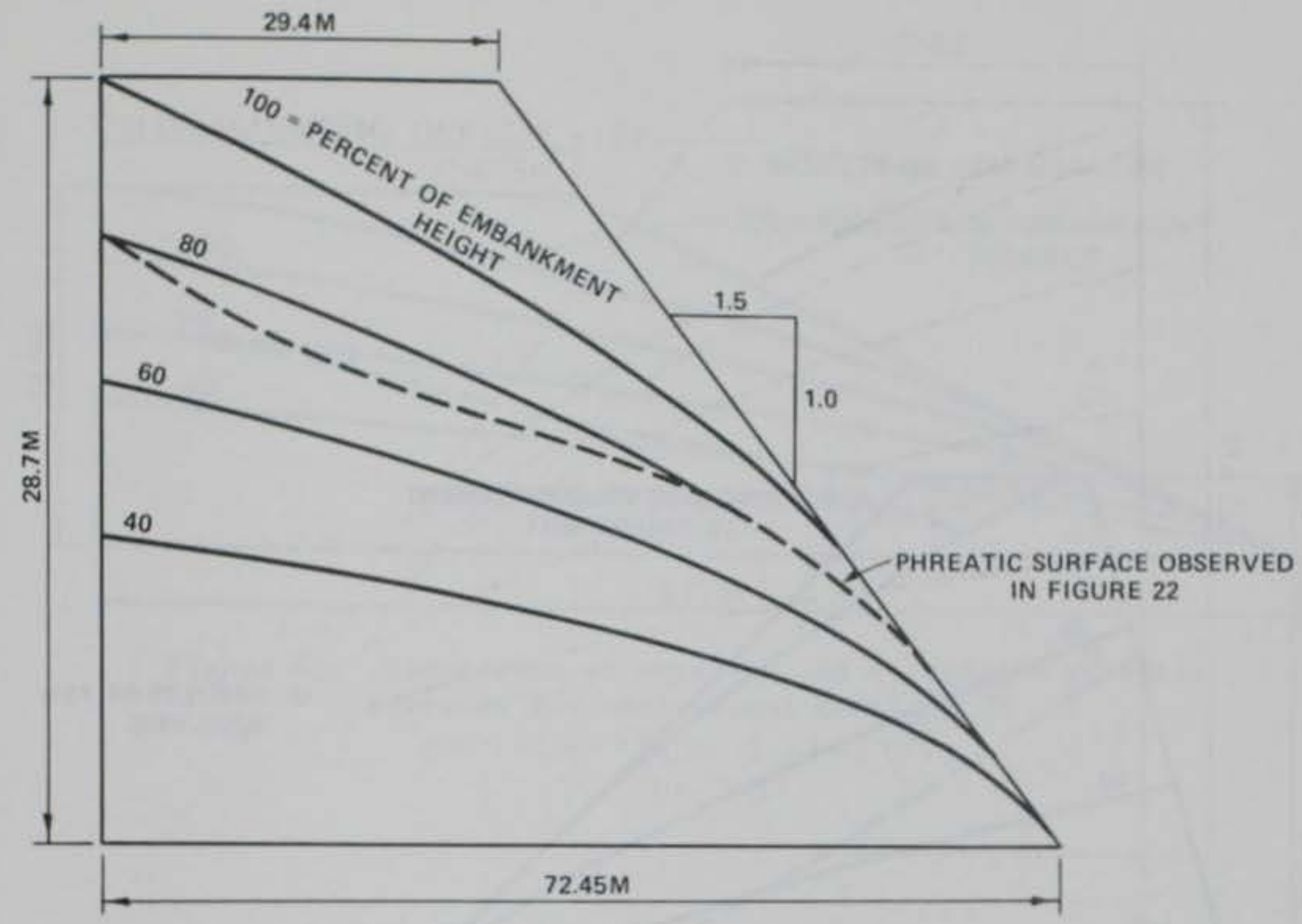

Figure 60. Comparison of observed and calculated phreatic surfaces for centrifugal model MW-10

nets and by knowing the quantity of seepage $q$ per unit length. For this case, the relationship

$$
k=\frac{q}{h N} \cdot \frac{N_{d}}{N_{f}}
$$

where

$$
\begin{aligned}
q= & \text { flow rate per unit length through the embankment } \\
\mathrm{hN}= & \text { height of prototype reservoir } \\
\mathrm{N}_{\mathrm{d}} / \mathrm{N}_{\mathrm{f}}= & \text { number of equipotential drops } \mathrm{N}_{\mathrm{d}} \text { divided by the number of } \\
& \text { flow channels } \mathrm{N}_{\mathrm{f}} \text { from a flow net (this value is also a } \\
& \text { reciprocal of shape factor) }
\end{aligned}
$$

Although only appropriate for clean coarse sands and gravels, Hazen's equation (Equation 33) also provides estimates of permeability based upon grain-size distribution using the relationship

$$
k=100\left(D_{10}\right)^{2}
$$

where

$$
\begin{aligned}
\mathrm{k} & =\text { permeability, } \mathrm{cm} / \mathrm{sec} \\
\mathrm{D}_{10} & =\text { diameter of } 10 \text { percent size, } \mathrm{cm}
\end{aligned}
$$




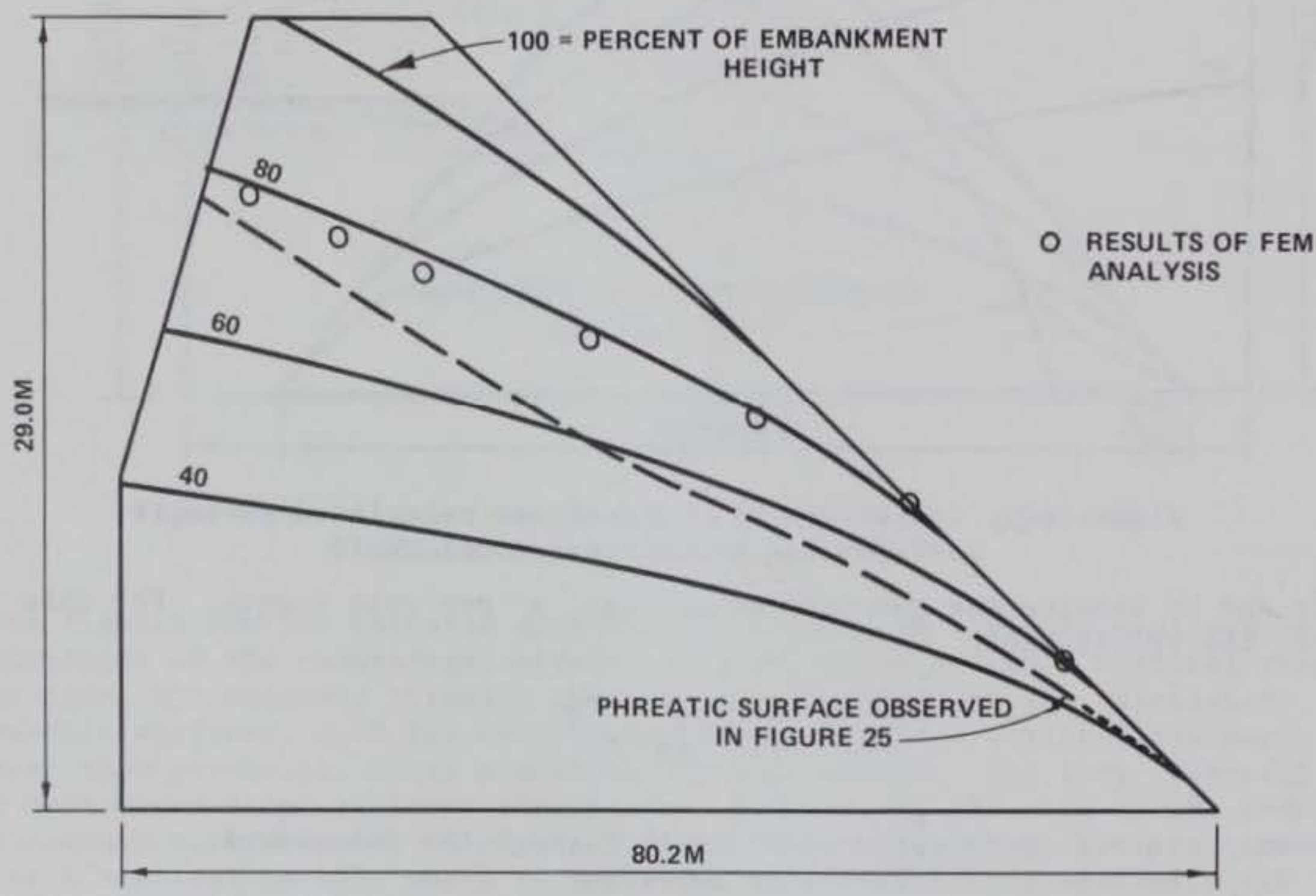

Figure 61. Comparison of observed and calculated phreatic surfaces for centrifugal model MW-11 


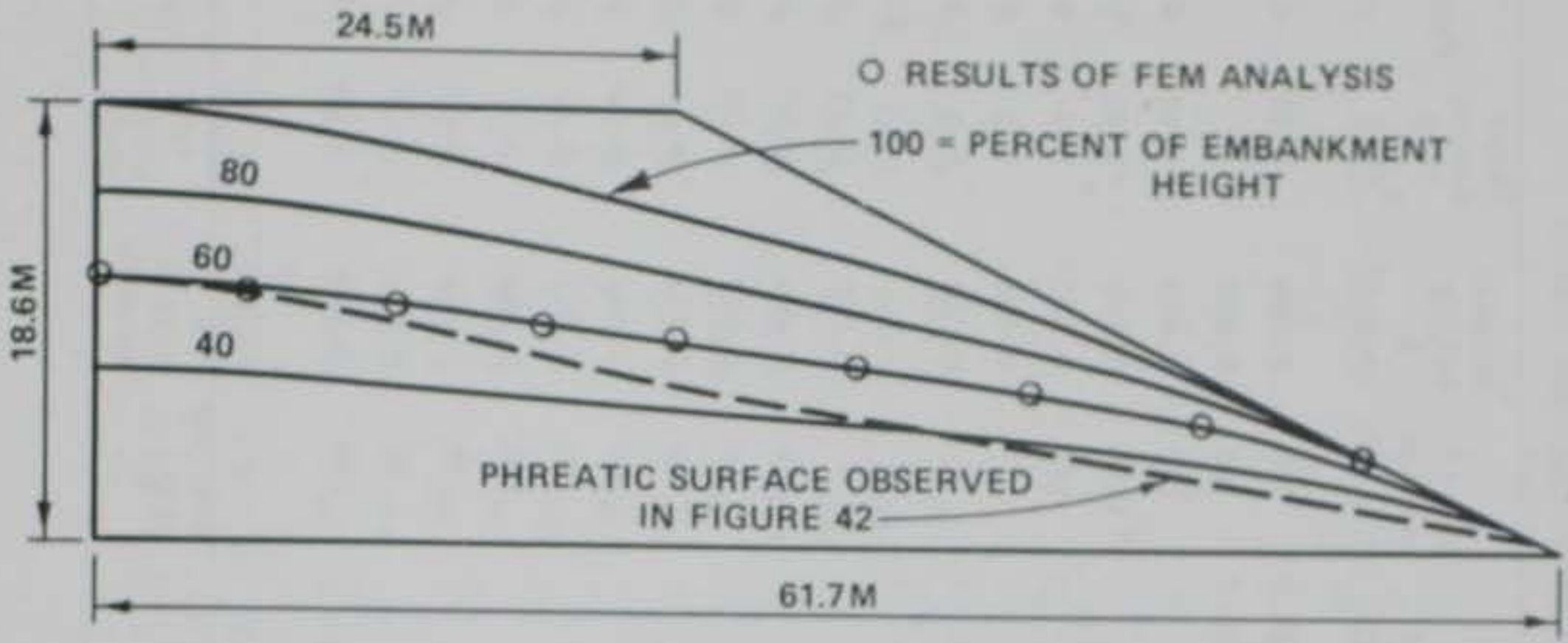

Figure 62. Comparison of observed and calculated phreatic surfaces for centrifugal mode1 $M W-23$

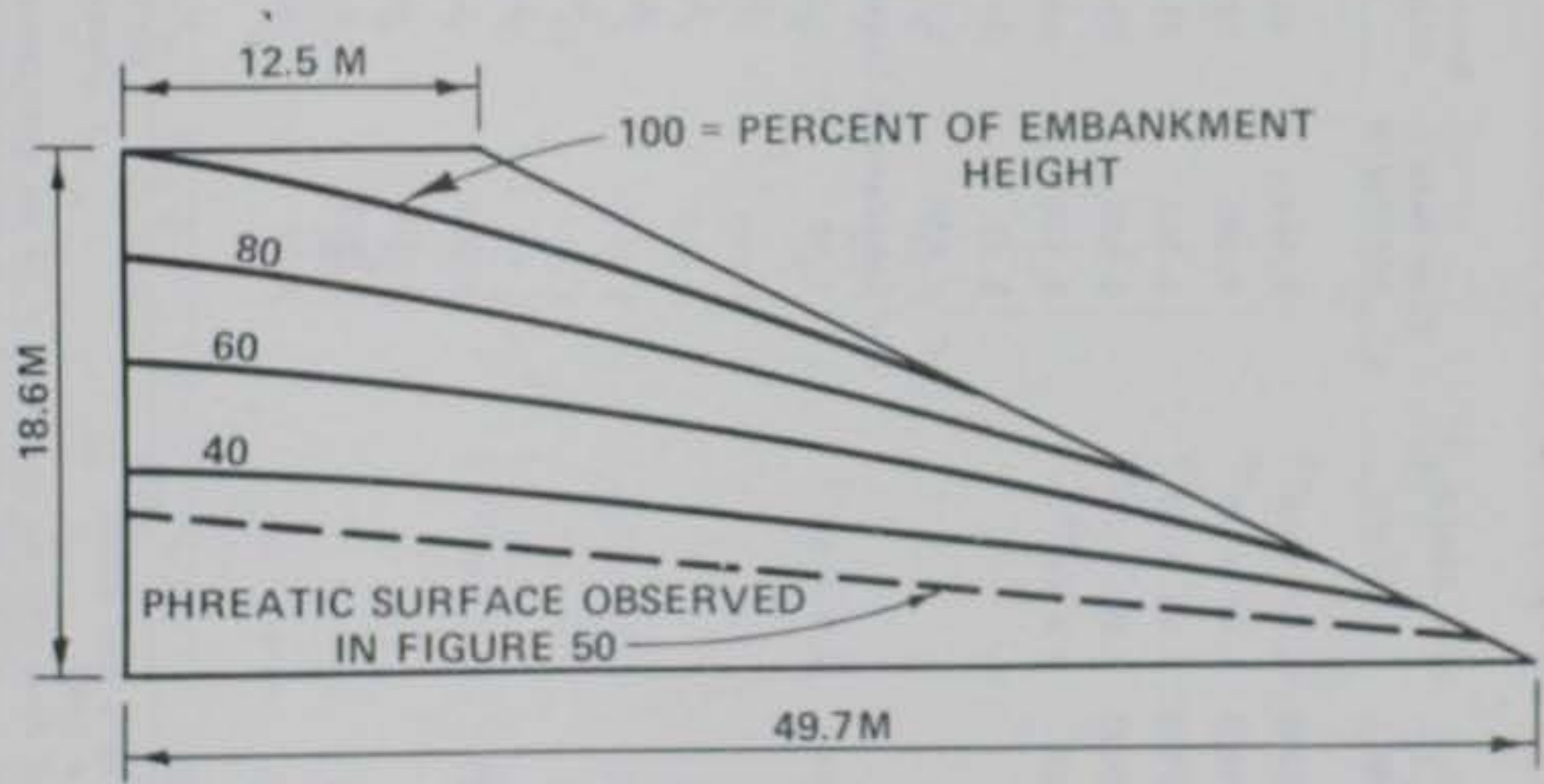

Figure 63. Comparison of observed and calculated phreatic surfaces for centrifugal model $\mathrm{MW}-25$ 
Table 6

Estimates of Coefficient of Permeability $k$ for Coal Waste Centrifugal Models

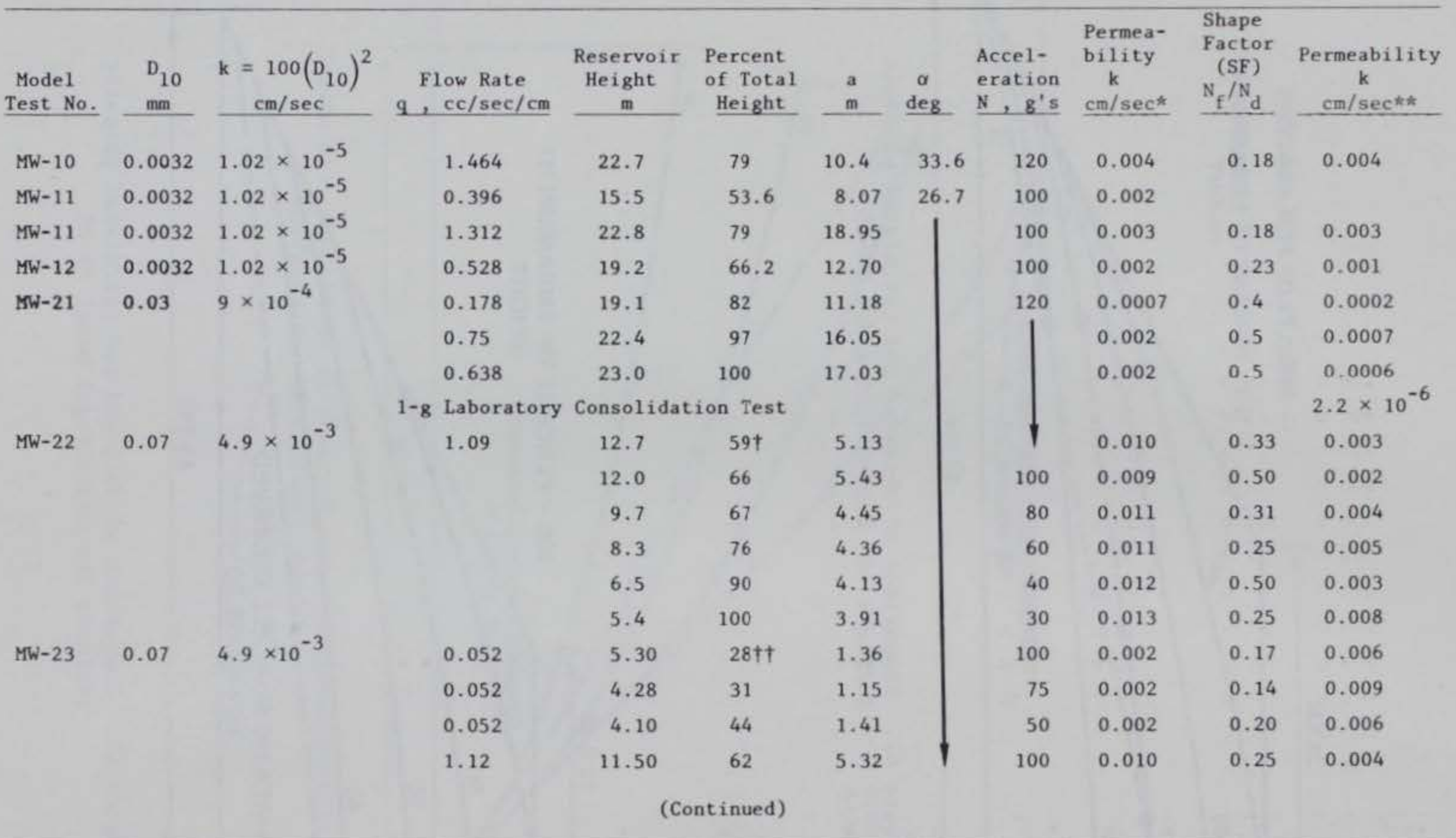

$\Rightarrow k=q / a \sin \alpha \tan \alpha$

삭 $k=q / h N \times 1 / S F$

$\dagger$ Calculated from $195 \mathrm{~mm}$ original - $14 \mathrm{~mm}$ settlement $=181 \mathrm{~mm}$.

†† Calculated from $195 \mathrm{~mm}$ original $-9 \mathrm{~mm}$ settlement $=186 \mathrm{~mm}$. 
Table 6 (Concluded)

\begin{tabular}{|c|c|c|c|c|c|c|c|c|c|c|c|}
\hline $\begin{array}{c}\text { Model } \\
\text { Test No. }\end{array}$ & $\underset{\mathrm{mm}}{\mathrm{D}_{10}}$ & $\begin{array}{c}\mathrm{k}=100\left(\mathrm{D}_{10}\right)^{2} \\
\mathrm{~cm} / \mathrm{sec}\end{array}$ & $\begin{array}{l}\text { Flow Rate } \\
\mathrm{g}, \mathrm{cc} / \mathrm{sec} / \mathrm{cm}\end{array}$ & $\begin{array}{c}\text { Reservoir } \\
\text { Height } \\
\text { m } \\
\end{array}$ & $\begin{array}{l}\text { Percent } \\
\text { of Total } \\
\text { Height } \\
\end{array}$ & $\mathrm{m}^{\mathbf{a}}$ & $\begin{array}{r}\alpha \\
\text { deg } \\
\end{array}$ & $\begin{array}{l}\text { Accel- } \\
\text { eration } \\
\mathrm{N}, \mathrm{g}^{\prime} \mathrm{s} \\
\end{array}$ & $\begin{array}{l}\text { Permea- } \\
\text { bility } \\
\text { k } \\
\mathrm{cm} / \mathrm{sec}^{*}\end{array}$ & $\begin{array}{l}\text { Shape } \\
\text { Factor } \\
(\mathrm{SF}) \\
\mathrm{N}_{\mathrm{f}} / \mathrm{N}_{\mathrm{d}}\end{array}$ & $\begin{array}{c}\text { Permeability } \\
\mathrm{k} \\
\mathrm{cm} / \mathrm{sec} \star \star \\
\end{array}$ \\
\hline \multirow{6}{*}{$\begin{array}{l}M W-23 \\
\text { (Cont'd) }\end{array}$} & \multirow[t]{6}{*}{0.07} & \multirow[t]{6}{*}{$4.9 \times 10^{-3}$} & 1.12 & 9.08 & 65 & 4.40 & 26.7 & 75 & 0.012 & 0.17 & 0.007 \\
\hline & & & 1.06 & 11.50 & 62 & 5.32 & & 100 & 0.009 & 0.20 & 0.005 \\
\hline & & & 1.06 & 8.84 & 72 & 4.74 & & 66 & 0.010 & 0.20 & 0.006 \\
\hline & & & 1.06 & 6.70 & 72 & 3.59 & & 50 & 0.015 & 0.20 & 0.008 \\
\hline & & & 3.29 & 13.90 & 75 & 7.76 & & 100 & 0.019 & 0.18 & 0.013 \\
\hline & & & 3.29 & 12.08 & 98 & 9.08 & & 66 & 0.018 & 0.20 & 0.014 \\
\hline \multirow[t]{6}{*}{$M W-25$} & \multirow[t]{6}{*}{0.07} & \multirow[t]{6}{*}{$4.9 \times 10^{-3}$} & 0.055 & 5.7 & $31+t$ & 1.77 & & 100 & 0.001 & 0.17 & 0.006 \\
\hline & & & 0.055 & 4.33 & 31 & 1.34 & & 76 & 0.002 & 0.17 & 0.008 \\
\hline & & & 0.094 & 7.2 & 39 & 2.67 & & 100 & 0.002 & 0.17 & 0.008 \\
\hline & & & 1.21 & 8.9 & 48 & 3.97 & & 100 & 0.014 & 0.17 & 0.008 \\
\hline & & & 1.21 & 4.71 & 84 & 3.81 & & 30 & 0.014 & 0.33 & 0.008 \\
\hline & & & 1.21 & 3.50 & 94 & 3.28 & & 20 & 0.017 & 0.50 & 0.007 \\
\hline
\end{tabular}


Accordingly, Table 6 presents estimates of permeability values based upon the previously mentioned three methods for various models. A cursory examination of the data shows that for the first test series, $k$ values were in the range of $10^{-3}$, with excellent agreement between flow net based estimations and phreatic surface based estimations (Equation 31). Likewise, the fact that Hazen's equation provided approximately the same values lends some confidence to the values shown.

By comparison, $k$ values previously presented in Table 4, obtained from triaxial compression tests, are in the range of $10^{-5}$ for test series No. 1 models, and $10^{-4}$ for test series No. 2 models. Thus, a fairly poor agreement was obtained between laboratory and model $k$ values. This lack of agreement may be due to leakage occurring along the base or sides of the model, resulting in higher apparent permeabilities.

The increases in permeability for the test series No. 2 models with time are indicative that either the fine portion has been washed through and out of the material, or just prior to failure, tunnels or pipes are forming in the embankment.

\section{Steady Seepage Through Dam Section with Toe Drain (MW-13)}

For this model, a trapezoidal toe drain was used to control seepage through the dam as shown in Figure 64. Under such conditions, the coefficient of permeability of the drain is very much greater than that of the dam proper, and the interface between the drain and the dam is considered as an equipotential line.
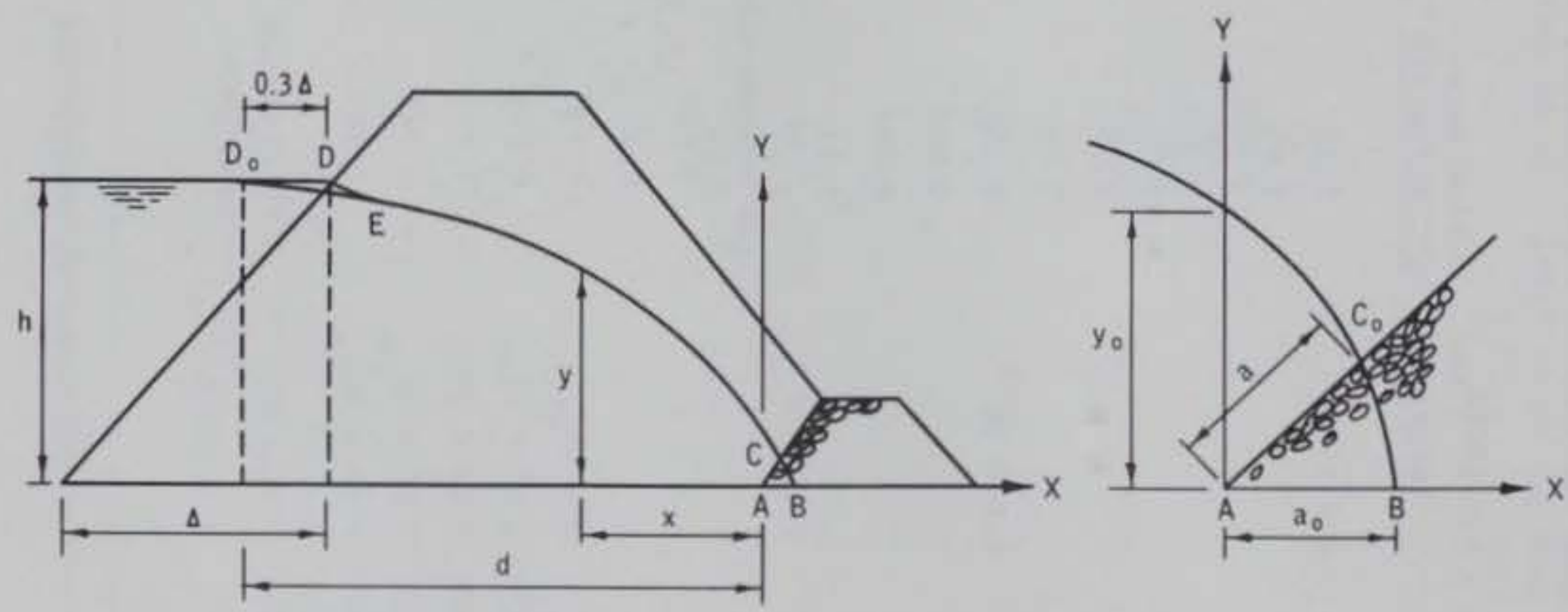

Figure 64. Steady seepage in uniform dam with toe drain

It has been assumed by Casagrande (1940) that the free seepage surface is a parabola that starts at point $D_{0}$ as shown in Figure 64 , where $D_{0}$ is $0.3 \Delta$ from D. The entrance condition is adjusted by sketching the arc DE normal to the upstream face and tangent to the parabolic free surface at point 
E . The parabola for the free surface shown in Figure 64 can be defined as

$$
x=\frac{y_{0}^{2}-y^{2}}{2 y_{0}}
$$

where

$$
y_{0}=d^{2}+h^{2}-d
$$

and

$$
a_{0}=\frac{1}{2} y_{0}
$$

Casagrande solution, as shown in Figure 64 and expressed in Equation 34 , was used for determining the free seepage surface through coal waste dam section MW-13. The seepage surfaces were calculated for $100,80,60$, and 40 percent of the dam height as shown in Figure 65. Also presented are the results of FEM seepage analyses (Tracy, 1973).

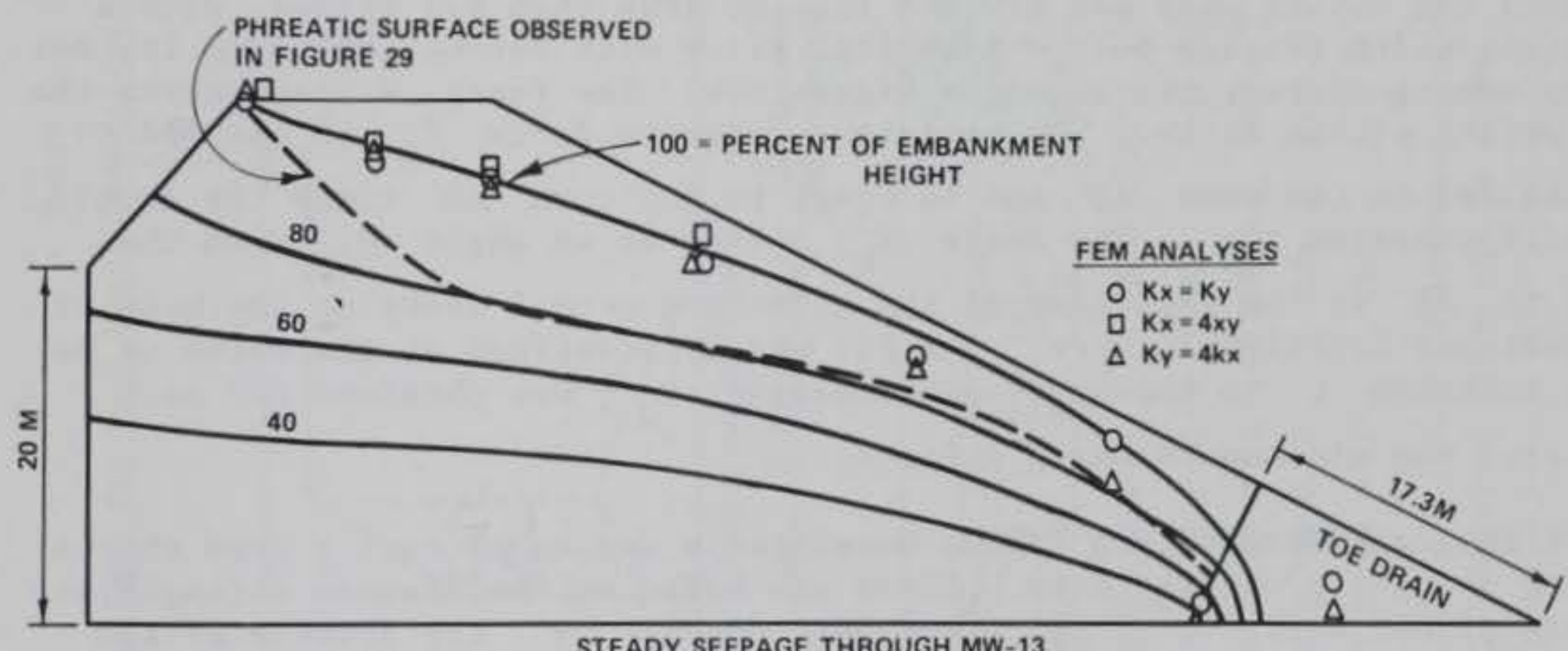

Figure 65. Comparison of observed and calculated phreatic surfaces for centrifugal model MW-13 


\section{CHAPTER 7: STABILITY ANALYSES}

It is important in centrifugal modeling to compare results with not only prototype events but also numerical forms of analysis. Since one objective was to evaluate the MSHA, formerly MESA (Dept. of Interior, undated), criteria for designing coal waste embankments, this section examines the factors of safety (FS) recommended with those of the various models. In this fashion, an estimate of the appropriateness of the recommended FS can be made.

Stability analyses utilizing computer programs of the Swedish, simplified Bishop, and modified Swedish methods, as described in EM 1110-2-1902 (Dept. of Army, 1970), were performed by the WES. Independently, stability analyses utilizing Bishop and Morgenstern's (1960) stability charts were performed by Cambridge University. The strength parameters utilized by both the WES and Cambridge University for the first and second test series are presented in Tables 7 and 8 , respectively, and discussed previously in Chapter 4 (Materials).

The WES computer programs perform the analyses using a circular arc failure surface as shown in Figure 66 . The arcs were located by the use of a grid system that automatically varies the center of rotation seeking the critical arc; the moving mass was divided into no less than six slices, with a convenient width (Figure 66a). A typical slice with forces acting on it, but with no seepage forces, is shown in Figure $66 \mathrm{~b}$. The force $W$ represents the total weight of the slice. The resistive cohesive force $C_{D}$ is assumed to act parallel to the cord $\mathrm{AB}$ and is equal to the cord $\mathrm{AB}$ times the developed unit cohesion $C_{D}$. The force $F_{D}$ acting at an angle $\emptyset_{D}$ with the normal to $A B$ is the resultant of the effective normal force at the base of the developed frictional force. The FS, which is defined as the ratio of material cohesion $C$ to the developed cohesion $C_{D}$, was obtained for each trial arc, the minimum FS being selected.

Bishop and Morgenstern (1960) developed a series of easily used charts defining stability coefficients. These are based on the drained strength parameters of the soil, 'c', $\emptyset^{\prime}$, and bulk density $\gamma$, the profile of the slope defined by the parameters B, H, and D (Figure 67), and the pore pressure parameter $r_{u}$ defined as

$$
r_{u}=\frac{u}{\gamma h}
$$

\section{Stability Analyses of Embankments with Seepage}

Stability analyses were performed by the WES on the same five model embankments for which seepage analyses had been performed; specifically, MW-9, $M W-10$, MW-11, MW-23, and MW-25. For all these models, the phreatic surface 
Table 7

Stability Data for Coal Waste Centrifugal Models (Test Series No. 1)

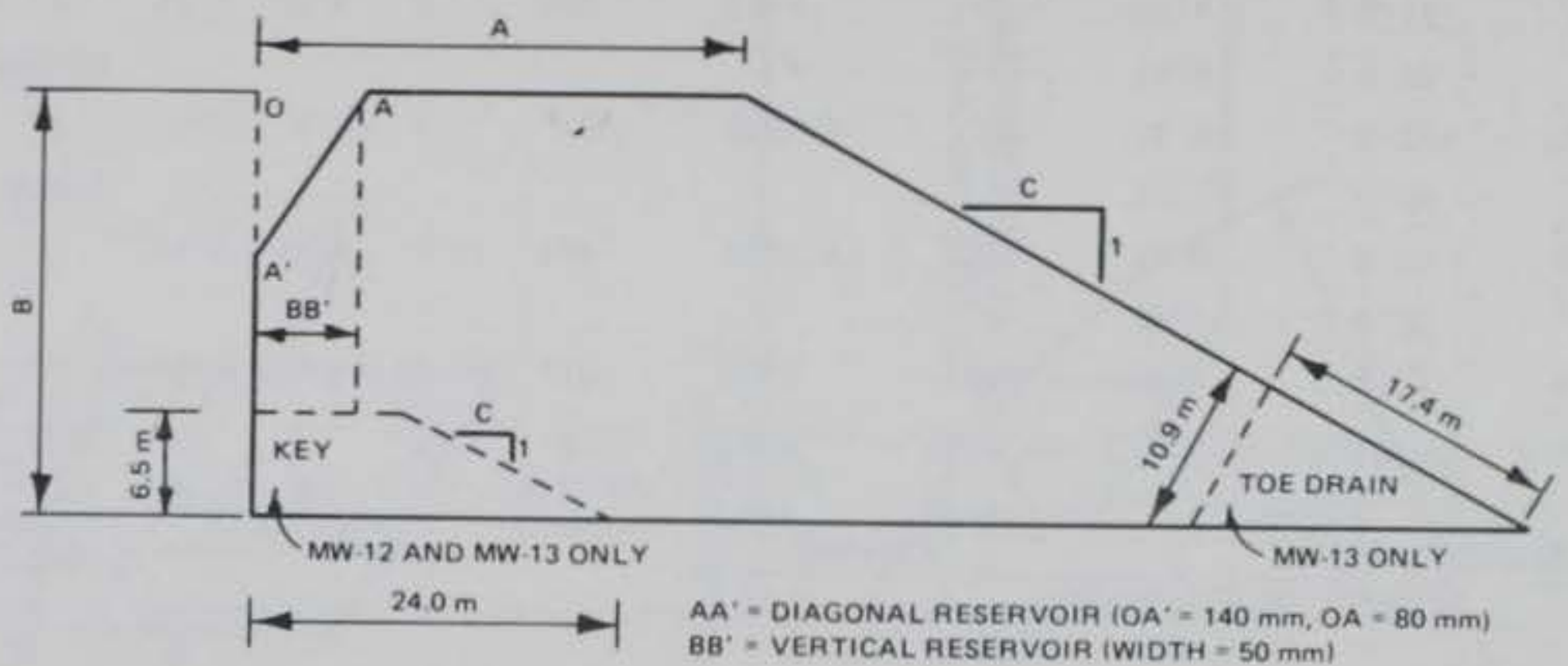

\begin{tabular}{|c|c|c|c|c|c|c|c|c|c|c|c|c|c|c|}
\hline \multirow{4}{*}{$\begin{array}{l}\text { Model } \\
\text { Test } \\
\text { No. } \\
\end{array}$} & \multicolumn{7}{|c|}{ Geometry } & \multirow{4}{*}{$\begin{array}{c}\text { Accel- } \\
\text { leration } \\
8 \\
\end{array}$} & \multicolumn{6}{|c|}{ Stability Parameters } \\
\hline & \multicolumn{3}{|c|}{ Model } & \multirow{3}{*}{$\begin{array}{l}\text { Reser- } \\
\text { voir } \\
\text { Type }\end{array}$} & \multirow{2}{*}{\multicolumn{3}{|c|}{ Prototype }} & & \multicolumn{2}{|c|}{ Density } & \multicolumn{4}{|c|}{ Shear Strength } \\
\hline & A & B & C & & $A$ & & $\mathrm{C}$ & & \multirow{2}{*}{$\begin{array}{c}\text { Wet } \\
\mathrm{kg} / \mathrm{m}^{3} \\
\end{array}$} & \multirow{2}{*}{$\begin{array}{c}\text { Dry } \\
\mathrm{kg} / \mathrm{m}^{3}\end{array}$} & \multicolumn{2}{|c|}{ Effective } & \multicolumn{2}{|c|}{ Total } \\
\hline & $\mathrm{mm}$ & $\mathrm{men}$ & $\mathrm{mm}$ & & m & $\mathrm{m}$ & m & & & & $g^{\prime}$, deg & c; $\mathrm{kg} / \mathrm{cm}^{2}$ & $\emptyset$, deg & c, $\mathrm{kg} / \mathrm{cm}$ \\
\hline$M W-9$ & 300 & 240 & 1.5 & v & 30.0 & 22.4 & 1.5 & 100 & 1702.1 t & $1361.7^{* 2}$ & 34.7 & 0.025 & 8.1 & 0.33 \\
\hline $\mathrm{MW}-10$ & 295 & 260 & 1.5 & v & 35.4 & 28.7 & 1.5 & 120 & 1416 & 1252.8 & & & & \\
\hline $\mathrm{MW}-11$ & 185 & 260 & 2.0 & D & 22.2 & 29.0 & 2 & 120 & 1659.7 내해 & 1406.6 & & & & \\
\hline $\mathrm{NW}-12$ & 185 & 260 & 2.0 & D & 22.2 & 29.0 & 2 & 120 & 1671.1 & 1416.2 & & & & \\
\hline$M W-13$ & 185 & 260 & 2.0 & D & 22.2 & 29.6 & 2 & 120 & 1737.2 & 1472.3 & & & & \\
\hline
\end{tabular}

* Prototype dimensions = model dimensions times the $\mathrm{g}$ level.

int $\rightarrow$ stimated. 
Table 8

Stability Data for Coal Waste Centrifugal Models (Test Series No. 2)

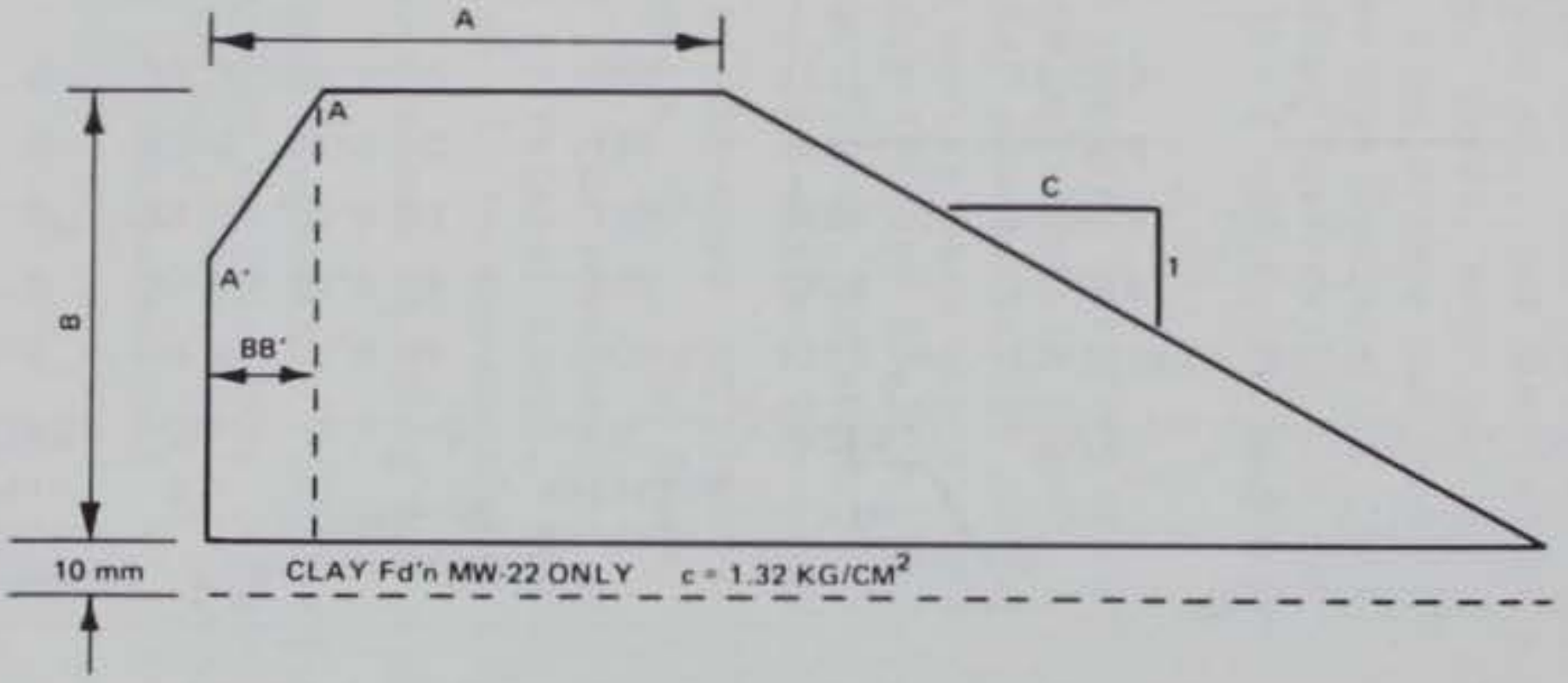

\begin{tabular}{|c|c|c|c|c|c|c|c|c|c|c|c|c|c|c|c|}
\hline \multirow{4}{*}{$\begin{array}{l}\text { Model } \\
\text { Test } \\
\text { No. } \\
\end{array}$} & \multirow{2}{*}{\multicolumn{7}{|c|}{ Geometry }} & \multirow{4}{*}{$\begin{array}{l}\text { Accel- } \\
\text { leration } \\
\quad 8 \\
\end{array}$} & \multicolumn{6}{|c|}{ Stability Parameters } & \\
\hline & & & & & & & & & \multicolumn{2}{|c|}{ Density } & \multicolumn{4}{|c|}{ Shear Strength } & \\
\hline & $A$ & \multicolumn{2}{|c|}{ Mode 1} & \multirow{2}{*}{$\begin{array}{l}\text { Reser- } \\
\text { voir } \\
\text { Type } \\
\end{array}$} & \multicolumn{3}{|c|}{ Prototype } & & \multirow{2}{*}{$\begin{array}{c}\text { Wet } \\
\mathrm{kg} / \mathrm{m}^{3}\end{array}$} & \multirow{2}{*}{$\begin{array}{l}\text { Dry } \\
\mathrm{kg} / \mathrm{m}^{3}\end{array}$} & \multicolumn{2}{|c|}{ Effective } & \multicolumn{2}{|c|}{ Total } & \\
\hline & $\mathrm{mm}$ & $\mathrm{mm}$ & $\mathrm{mm}$ & & $\mathrm{m}$ & m & m & & & & Q, deg & $\mathrm{c}^{\prime} \mathrm{kg} / \mathrm{cm}^{2}$ & $\emptyset$, deg & c, $\mathrm{kg} / \mathrm{cm}^{2}$ & \\
\hline \multirow[t]{2}{*}{$\mathrm{MW}-22$} & 315 & 195 & 2 & D & 37.8 & 21.7 & 2 & 120 & 1666 & 1400 & 30.5 & 0.23 & 9.5 & 0.36 & WES \\
\hline & & & & & & & & & & & 38.4 & 0.05 & & & UC \\
\hline$M W-23$ & 315 & 195 & 2 & v & 31.5 & 18.6 & 2 & 100 & 1534.4 & 1370 & 30.5 & 0.23 & 9.5 & 0.36 & WES \\
\hline \multirow[t]{2}{*}{$M W-24$} & 315 & 195 & 2 & V & 4.72 & 2.77 & 2 & 15 & 1565.5 & 1310 & $26.9 \div$ & $0.24 \div$ & $15.1^{\%}$ & $0.28 \%$ & WES \\
\hline & & & & $\mathrm{BB}^{\prime}=70$ & & & & & & & 36.6 & 0.08 & & & UC \\
\hline \multirow[t]{2}{*}{$M W-25$} & 315 & 195 & 2 & V & 31.5 & 18.6 & 2 & 100 & 1708 & 1400 & 30.0 & 0.18 & 7.6 & 0.60 & WES \\
\hline & & & & $\mathrm{BB}^{\prime}=190$ & & & & & & & 40.7 & 0.01 & & & UC \\
\hline
\end{tabular}

* See Figure 71 for bilinear envelope used for analyzing MW- 24. 


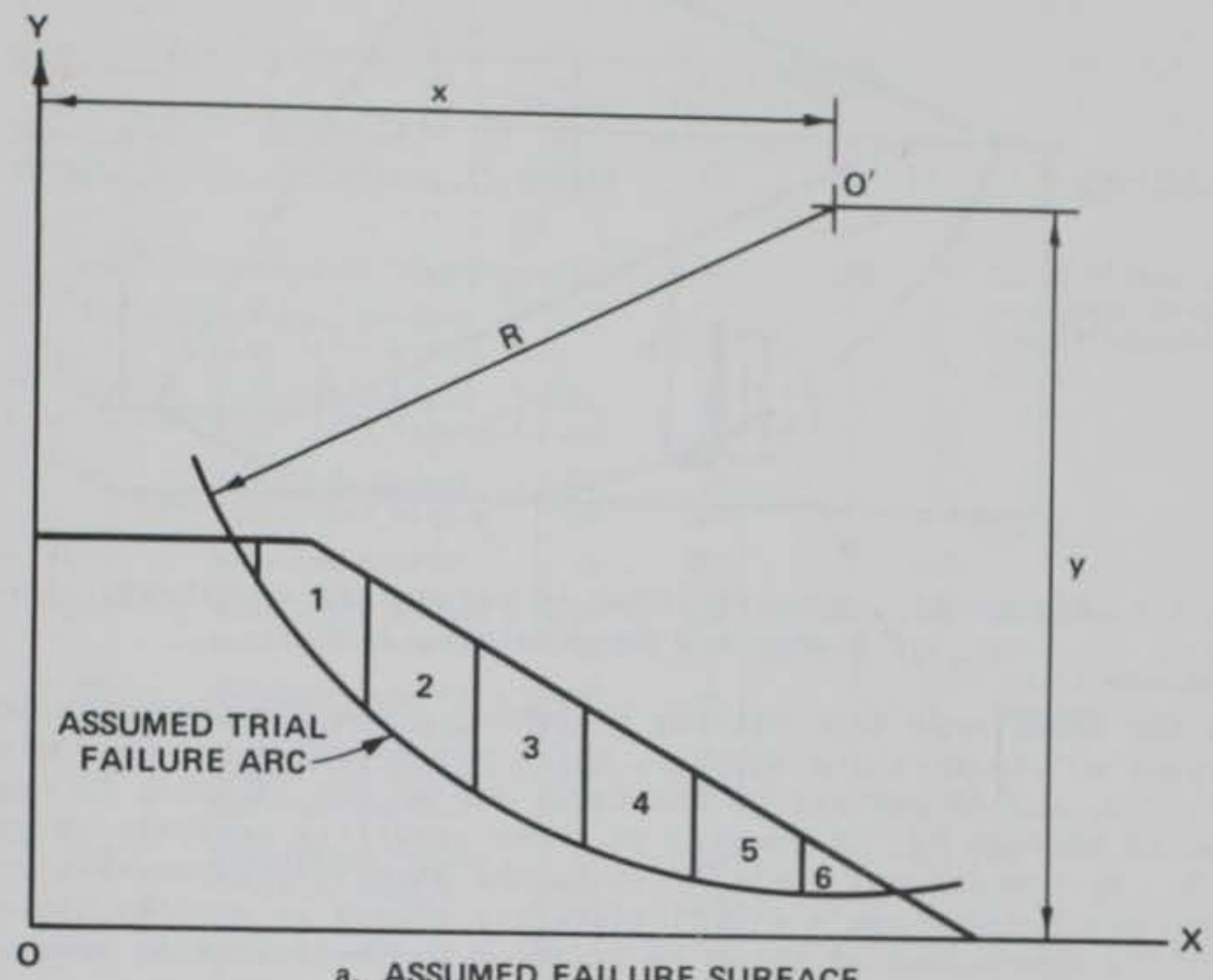

a. ASSUMED FAILURE SURFACE

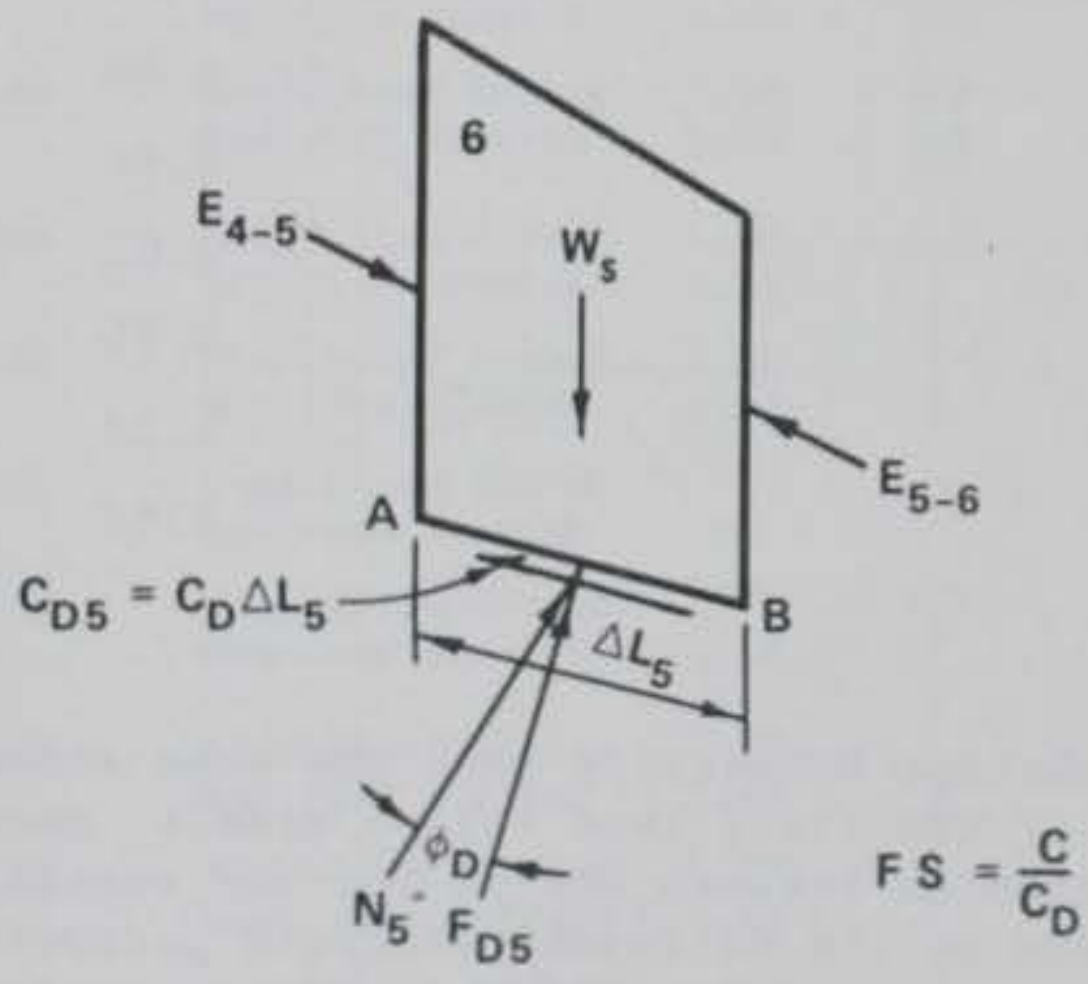

b. FORCES ON A SLICE

Figure 66. Modified Swedish method with finite slice procedure 


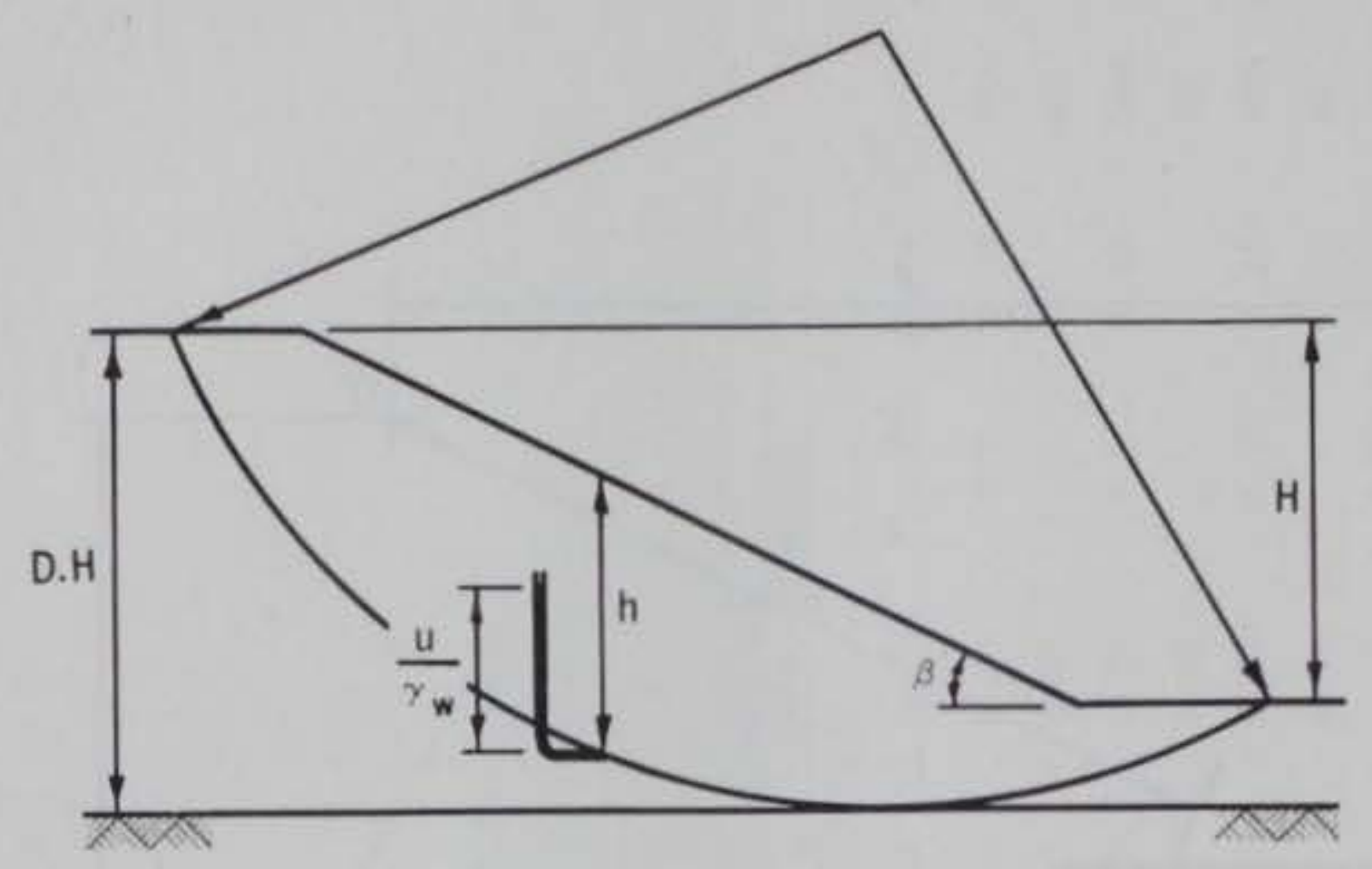

Figure 67. Specification of parameters (courtesy of Bishop and Morgenstern, 1960)

exited on the downstream face causing sloughing. The FS were calculated for several cases of steady-state seepage, which corresponded to reservoir levels of $100,80,60$, and 40 percent of the total dam height, similar to those shown in Figures 59 through 63. A summary of these stability analyses is presented in Table 9. By comparison, Table 10 lists the stability parameters and the FS from Bishop and Morgenstern's (1960) stability charts as used by Cambridge University. A comparison of these FS is shown in the following tabulation:

Factors of Safety When Failure Observed in the Models

\begin{tabular}{lcc}
\hline Model & WES (Modified Swedish) & $\begin{array}{c}\text { Cambridge } \\
\text { (Bishop and Mor }\end{array}$ \\
\cline { 2 - 2 } MW-9 & 0.79 & 0.80 \\
MW-10 & 0.72 & 0.94 \\
MW-11 & 0.70 & 1.02 \\
MW-12 & 0.88 & 0.85 \\
MW-23 & 1.70 & 1.16 \\
MW-25 & 1.70 & 1.50
\end{tabular}

Because the WES and Cambridge University used the same strength parameters for determining the FS of the first test series models, excellent agreement was obtained. The differences between the FS for the second test series models (MW-23 and $\mathrm{MW}-25$ ) is due to the different strength parameters determined by the WES and Cambridge. Nevertheless, these FS correctly predict phenomena observed in the centrifugal models. That is, slopes for MW-9, MW-10, $M W-11$, and MW-12 were unstable and failed, while slopes of MW-23 and MW-25 were correctly predicted as stable. Failure of these latter models was by erosion, which is not considered by these analyses. 
Table 9

Sumnary of Stability Analyses of Coal Waste Embankments with Seepage

\begin{tabular}{|c|c|c|c|c|c|c|c|}
\hline & Reservoir & & & Critica & 1 Arc & & \\
\hline $\begin{array}{l}\text { Model } \\
\text { Test No. }\end{array}$ & \begin{tabular}{l}
\multicolumn{1}{c}{ Versus } \\
Embankment \\
Height, \% \\
\end{tabular} & $\begin{array}{l}\text { Method of } \\
\text { Analysis }\end{array}$ & $\begin{array}{c}\text { Factor } \\
\text { of } \\
\text { Safety } \\
\end{array}$ & $\begin{array}{l}\text { Radius of } \\
\text { Rotation } \\
\text { ft } \\
\end{array}$ & $\begin{array}{r}x \\
f t \\
\end{array}$ & $\begin{array}{r}y \\
f t\end{array}$ & Remarks \\
\hline \multirow[t]{5}{*}{$M W-9$} & 100 & Simplified Bishop & 0.52 & 80 & 200 & 80 & \multirow{5}{*}{$\begin{array}{l}\text { Model failed at a } \\
\text { reservoir height of } \\
88 \% \text { of embankment } \\
\text { height }\end{array}$} \\
\hline & 80 & $\begin{array}{l}\text { Modified Swedish } \\
\text { Simplified Bishop }\end{array}$ & & & & & \\
\hline & 60 & $\begin{array}{l}\text { Modified Swedish } \\
\text { Simplified Bishop }\end{array}$ & $\begin{array}{l}0.84 \\
0.98\end{array}$ & $\begin{array}{l}80 \\
80\end{array}$ & & & \\
\hline & 40 & $\begin{array}{l}\text { Modified Swedish } \\
\text { Simplified Bishop }\end{array}$ & $\begin{array}{l}1.02 \\
1.20\end{array}$ & $\begin{array}{r}80 \\
140\end{array}$ & & $\prod_{140}^{1}$ & \\
\hline & & Modified Swedish & 1.15 & 140 & 1 & 140 & \\
\hline \multirow[t]{4}{*}{$M W-10$} & 100 & $\begin{array}{l}\text { Simplified Bishop } \\
\text { Modified Swedish }\end{array}$ & $\begin{array}{l}0.30 \\
0.55\end{array}$ & 100 & 230 & 100 & \multirow{4}{*}{$\begin{array}{l}\text { Model failed at a } \\
\text { reservoir height of } \\
78 \% \text { of embankment } \\
\text { height }\end{array}$} \\
\hline & 80 & $\begin{array}{l}\text { Simplified Bishop } \\
\text { Modified Swedish }\end{array}$ & $\begin{array}{l}0.60 \\
0.70\end{array}$ & & & & \\
\hline & 60 & $\begin{array}{l}\text { Simplified Bishop } \\
\text { Modified Swedish }\end{array}$ & $\begin{array}{l}0.68 \\
0.74\end{array}$ & 1 & & 1 & \\
\hline & 40 & $\begin{array}{l}\text { Simplified Bishop } \\
\text { Modified Bishop }\end{array}$ & $\begin{array}{l}1.17 \\
1.09\end{array}$ & $\begin{array}{l}130 \\
130\end{array}$ & 1 & $\begin{array}{l}130 \\
130\end{array}$ & \\
\hline \multirow[t]{4}{*}{$\mathrm{MW}-11 / 12$} & 100 & $\begin{array}{l}\text { Simplified Bishop } \\
\text { Modified Swedish }\end{array}$ & $\begin{array}{l}0.57 \\
0.57\end{array}$ & $\begin{array}{l}150 \\
150\end{array}$ & 275 & $\begin{array}{l}150 \\
150\end{array}$ & \multirow{4}{*}{$\begin{array}{l}\text { Models MW-11 and } \\
\text { MW-12 failed at } \\
\text { reservoir heights of } \\
79 \text { and } 66 \% \text { of em- } \\
\text { bankment height, } \\
\text { respectively }\end{array}$} \\
\hline & 80 & $\begin{array}{l}\text { Simplified Bishop } \\
\text { Modified Swedish }\end{array}$ & $\begin{array}{l}0.67 \\
0.66\end{array}$ & $\begin{array}{l}125 \\
125\end{array}$ & 1 & 125 & \\
\hline & 60 & $\begin{array}{l}\text { Simplified Bishop } \\
\text { Modified Swedish }\end{array}$ & $\begin{array}{l}1.13 \\
1.03\end{array}$ & $\begin{array}{l}100 \\
150\end{array}$ & 250 & $\begin{array}{l}100 \\
150\end{array}$ & \\
\hline & 40 & $\begin{array}{l}\text { Simplified Bishop } \\
\text { Modified Swedish }\end{array}$ & $\begin{array}{l}1.48 \\
1.48\end{array}$ & $\begin{array}{l}100 \\
100\end{array}$ & 1 & $\begin{array}{l}100 \\
100\end{array}$ & \\
\hline \multirow[t]{4}{*}{$M W-23$} & 100 & $\begin{array}{l}\text { Simplified Bishop } \\
\text { Modified Swedish }\end{array}$ & $\begin{array}{l}1.46 \\
1.39\end{array}$ & 110 & 170 & 110 & \multirow{3}{*}{$\begin{array}{l}\text { Model stable, but } \\
\text { erosion occurs at a } \\
\text { reservoir height of } \\
66 \% \text { of embankment } \\
\text { height }\end{array}$} \\
\hline & 80 & $\begin{array}{l}\text { Simplified Bishop } \\
\text { Modified Swedish }\end{array}$ & $\begin{array}{l}1.66 \\
1.62\end{array}$ & l & 1 & 1 & \\
\hline & 60 & $\begin{array}{l}\text { Simplified Bishop } \\
\text { Modified Swedish }\end{array}$ & $\cdots$ & $\cdots$ & $\cdots$ & $\cdots$ & \\
\hline & 100 & $\begin{array}{l}\text { Simplified Bishop } \\
\text { Modified Swedish }\end{array}$ & $\begin{array}{l}2.14 \\
2.18\end{array}$ & 110 & 170 & 110 & \multirow[t]{3}{*}{$\begin{array}{l}\text { Model stable, but } \\
\text { erosion occurs at a } \\
\text { reservoir height of } \\
84 \% \text { of embankment } \\
\text { height }\end{array}$} \\
\hline \multirow{2}{*}{$M W-25$} & 80 & $\begin{array}{l}\text { Simplified Bishop } \\
\text { Modified Swedish }\end{array}$ & $\begin{array}{l}1.62 \\
1.64\end{array}$ & 1 & 1 & 1 & \\
\hline & 40 & $\begin{array}{l}\text { Simplified Bishop } \\
\text { Modified Swedish } \\
\text { Simplified Bishop } \\
\text { Modified Swedish }\end{array}$ & $\begin{array}{l}\cdots \\
2.18 \\
2.03\end{array}$ & $\dddot{i}$ & $\pi$ & $\pi$ & \\
\hline
\end{tabular}


Table 10

$\underline{\text { Slope Stability Analysis Based upon Bishop and Morgenstern's (1960) Method }}$

Safety Factor $=S F=m-n\left(r_{u}\right)$, where $r_{u}=\frac{u}{\gamma_{\text {sat }}{ }^{H}}$

For MW-9, $-10,-11,-12,-13$ : use WES parameters: $c^{\prime}=11 \mathrm{kN} / \mathrm{m}^{2}$

$\emptyset^{\prime}=30.5^{\circ}$

For MW-22, -23,-25: use shear box parameters: $\quad c^{\prime}=3.5 \mathrm{kN} / \mathrm{m}^{2}$

Let $\gamma_{\text {sat }}=16 \mathrm{kN} / \mathrm{m}^{2} \times \mathrm{N}$.

$\emptyset^{\prime}=39^{\circ}$

\begin{tabular}{|c|c|c|c|c|c|c|c|c|}
\hline $\begin{array}{c}\text { Mode1 } \\
\text { Test } \\
\text { No. } \\
\end{array}$ & $\mathrm{r}_{\mathrm{u}}$ & $\begin{array}{l}\text { Slope } \\
\cot \beta\end{array}$ & $\begin{array}{r}\mathrm{H} \\
\mathrm{mm}\end{array}$ & $\underline{\mathrm{Ng}}$ & $\frac{c^{\prime}}{\gamma_{s}}{ }^{H}$ & $\mathrm{~m}$ & $\mathrm{n}$ & SF \\
\hline$M W-9$ & 0.4 & 1.5 & 240 & 100 & 0.029 & 1.35 & 1.38 & 0.80 \\
\hline$M W-10$ & 0.3 & 1.5 & 260 & 120 & 0.022 & 1.35 & 1.38 & 0.94 \\
\hline $\mathrm{MW}-11$ & 0.38 & 2 & 260 & 120 & 0.022 & 1.63 & 1.6 & 1.02 \\
\hline $\mathrm{MW}-12$ & 0.49 & 2 & 260 & 120 & 0.022 & 1.63 & 1.6 & 0.85 \\
\hline$M W-13$ & 0.41 & 2 & 260 & 120 & 0.022 & 1.63 & 1.6 & 0.97 \\
\hline$M W-22$ & 0.02 & 2 & 195 & 120 & 0.012 & 1.88 & 2.0 & 1.83 \\
\hline$M W-23$ & 0.35 & 2 & 195 & 100 & 0.014 & 1.88 & 2.0 & 1.16 \\
\hline$M W-25$ & 0.19 & 2 & 195 & 100 & 0.013 & 1.88 & 2.0 & 1.50 \\
\hline
\end{tabular}


The conservative nature of the triaxial strength parameters and stability analyses is evident in comparing the reservoir height when the FS was 1.0 and when failure was observed. The FS was 1.0 for reservoir heights of 50 to 60 percent for the first test series models, yet failure was not observed until reservoir heights of 80 to 90 percent were obtained in the models. From these considerations, the FS of 1.3 to 1.5 recommended by the MSHA, formerly MESA (Dept. of Interior, undated) appears quite conservative for these models, but appropriate.

A comparison between observed failure surfaces in the first test series centrifugal models with the critical arcs estimated by the stability analyses are shown in Figures 68, 69, and 70, which correspond to Figures 21, 22, and 25. The fact that these critical arcs agree quite favorably with the failure surfaces observed in the models lends confidence to the FS derived by the analysis.

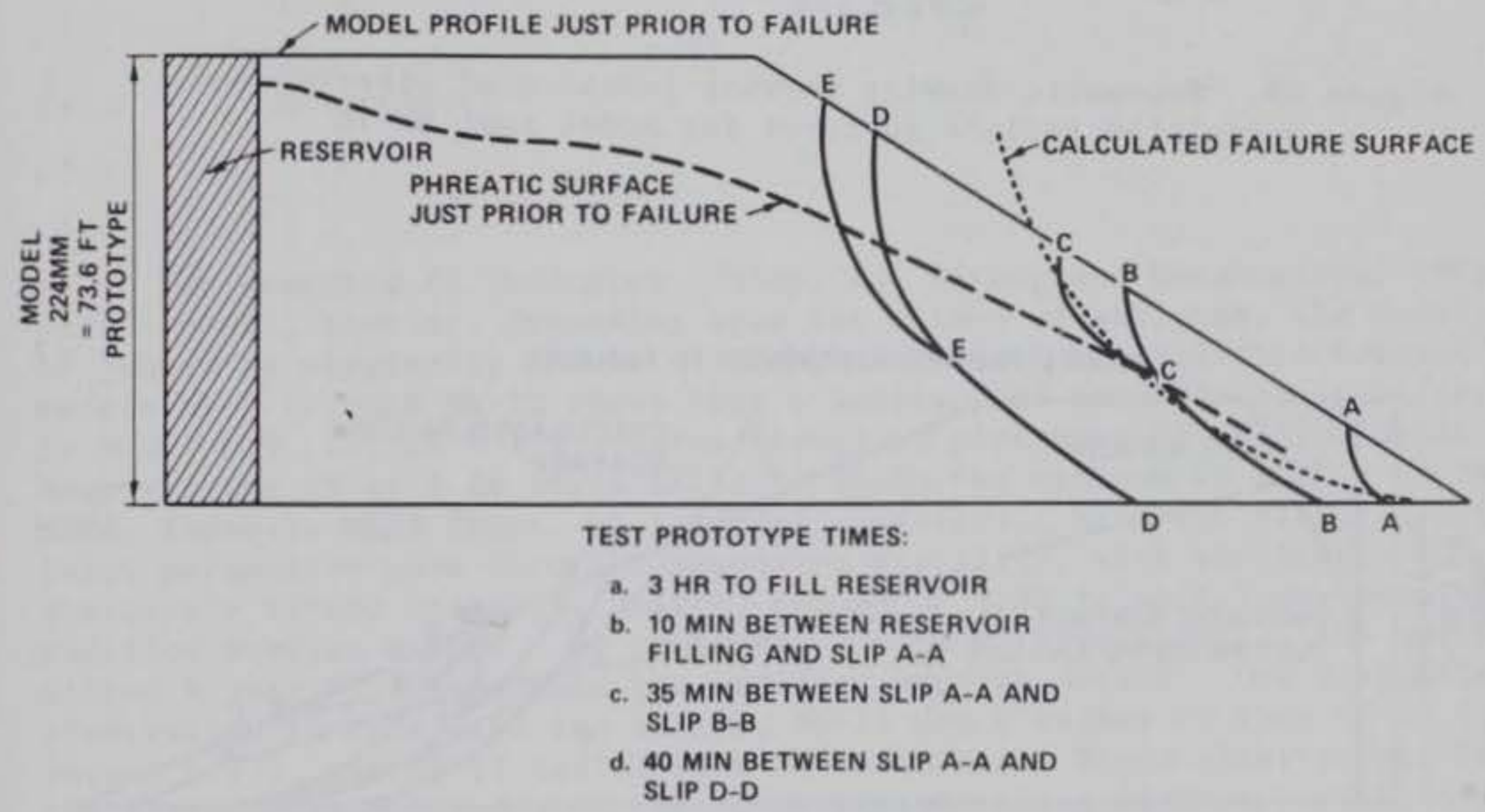

Figure 68. Schematic drawing showing location of observed and calculated failure surfaces for model test MW-9 


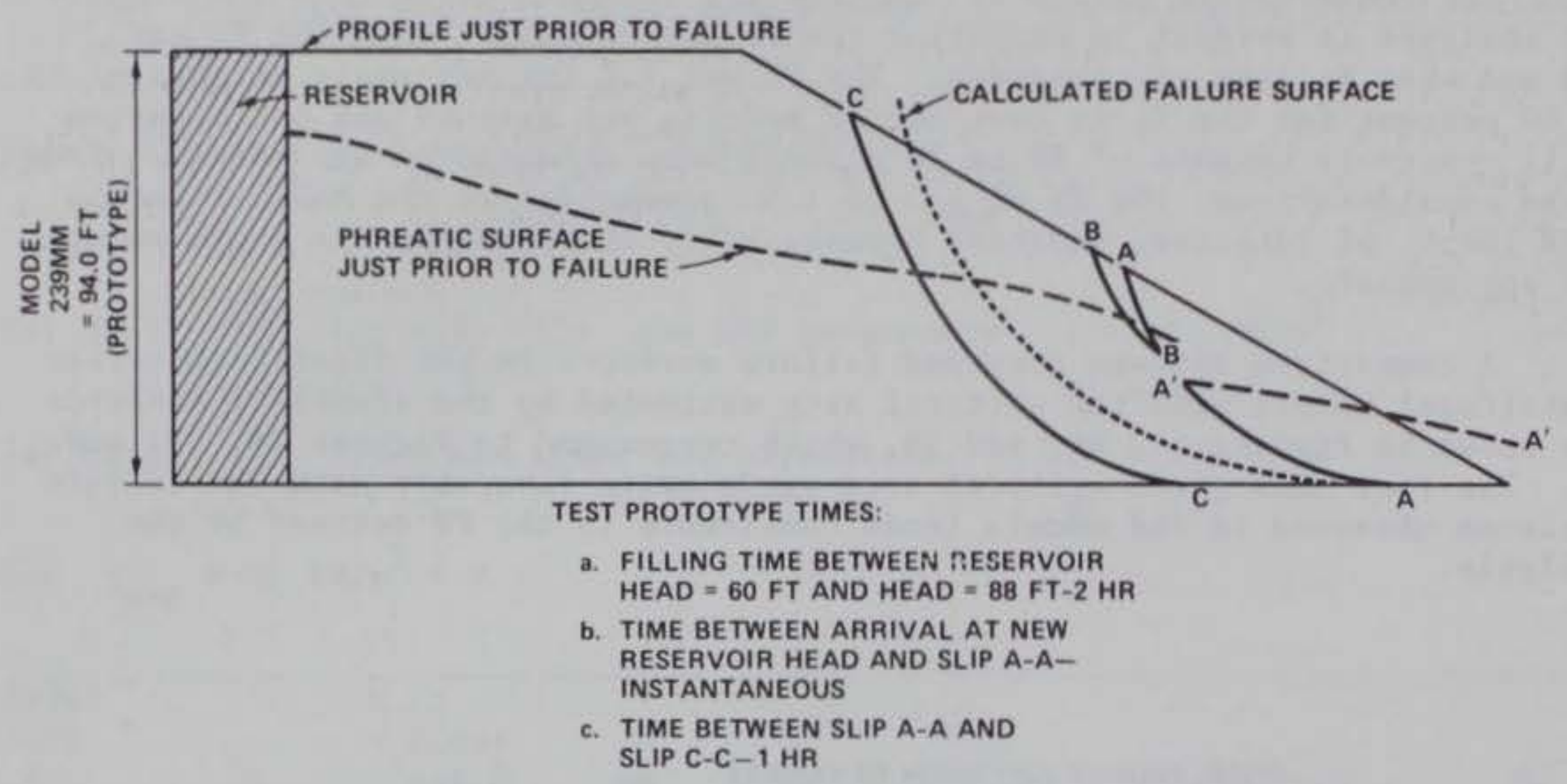

Figure 69. Schematic drawing showing location of observed and calculated failure surfaces for model test MW-10

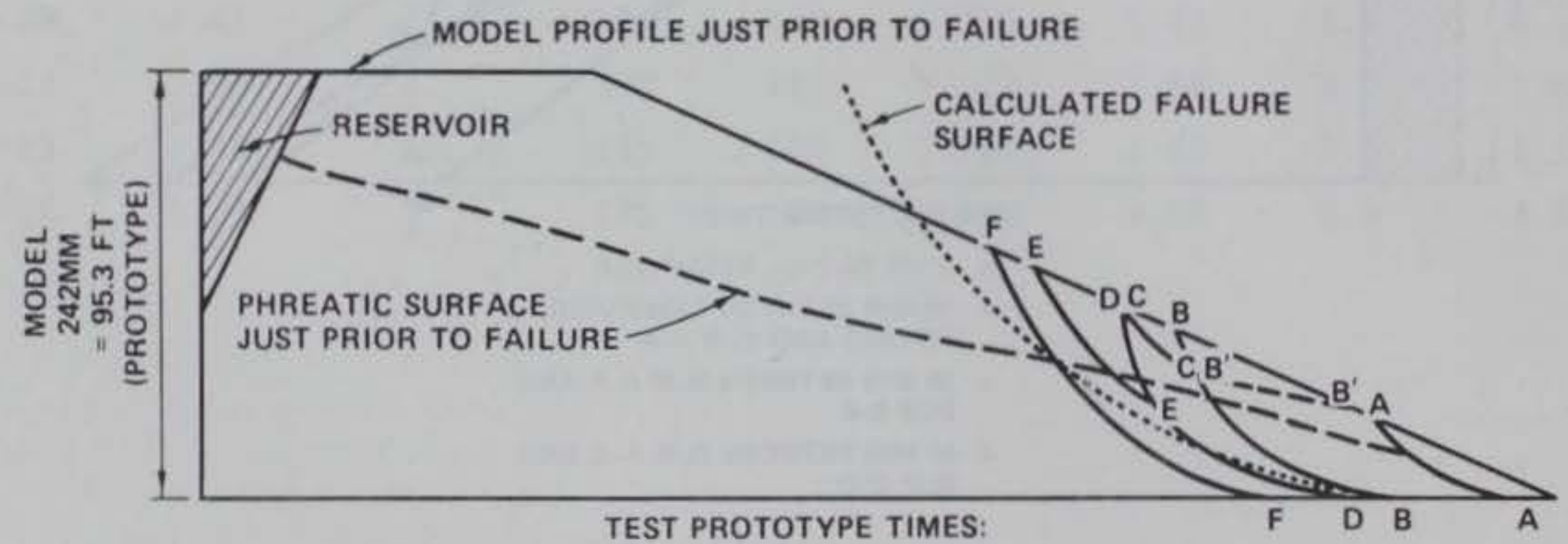
a. 20 MIN BETWEEN ARRIVAL
AT NEW RESERVOIR
b. 4 HR BETWEEN SLIP A-A AND SLIP F-F
c. 5 DAYS BETWEEN SLIP A-A AND BREACHING OF RESERVOIR

Figure 70. Schematic drawing showing location of observed and calculated failure surfaces for model test MW-11 


\section{Stability Analyses of Embankments with Toe Drain and Seepage}

Toe drains are usually provided to intercept the phreatic surface and prevent exiting on the downstream slope, as shown previously in Figure 61. The effect of this toe drain thus increases the stability of the embankment. Embankment section of model MW-13 was identical to that of MW-12, with the exception that a toe drain was provided. Stability analysis of MW-13 presented below corresponds to the worst condition, i.e., the reservoir is at full embankment height and the phreatic surface also is at its maximum height.

Factors of Safety for MW-13

\begin{tabular}{|c|c|c|c|c|c|}
\hline \multirow[b]{2}{*}{ Method of Analysis } & \multirow[b]{2}{*}{ FS } & \multicolumn{4}{|c|}{$\begin{array}{c}\text { Critical Arc } \\
\end{array}$} \\
\hline & & Radius & of Rotation & $\underline{x, f t}$ & $\mathrm{y}, \mathrm{ft}$ \\
\hline Simplified Bishop & 1.05 & & 200 & 220 & 200 \\
\hline Swedish & 1.05 & & 200 & 220 & 200 \\
\hline $\begin{array}{l}\text { Modified Swedish } \\
\quad(\mathrm{COE})\end{array}$ & 1.26 & & 200 & 220 & 200 \\
\hline $\begin{array}{l}\text { Bishop and } \\
\text { Morgenstern }\end{array}$ & 0.97 & & & & \\
\hline
\end{tabular}

The computed FS indicates (except for Bishop and Morgenstern, 1960) a stable model; however, depending upon the method of analyses, the model could be judged as marginally stable. A comparison with the modified Swedish FS for models MW-9 through MW-12 shows that a substantial increase in stability, FS $\approx 0.7-0.9$ to $F S \approx 1.3$, was achieved by placement of the toe drain. However, the FS of 1.26 still fails to reach the minimum FS of 1.3 of the MSHA, formerly MESA (Dept. of Interior, undated). Although slightly different input parameters were used for assessing stability, with the Bishop and Morgenstern's (1960) stability charts, the FS of 0.97 is much lower than the modified Swedish method. By contrast, for MW-9 through MW-12, the charts predicted higher FS values than the modified Swedish method. One disturbing observation is that with the charts, MW-11 had a higher FS than MW-13 (1.02 versus 0.97 ), yet $M W-11$ failed with $M W-13$ stable. These observations indicate the variance associated with the FS obtainable using different stability methods and input parameters, yet the guidelines are sufficiently conservative to preclude erroneous stability.

\section{Stability Analyses with No Seepage Forces (Model MW-24)}

All of the second test series centrifugal models were subjected to seepage except $M W-24$, which failed prematurely while accelerating the model to prototype acceleration. This type of failure corresponds to a rate of construction failure that occurs when high pore pressures are created by the fill 
placement being too rapid. The prototype dimensions at failure are presented in Table 8 along with the parameters used in the stability analyses. The resulting FS are presented below:

Factors of Safety for MW-24

\begin{tabular}{|c|c|c|c|c|}
\hline \multirow[b]{2}{*}{ Method of Analysis } & \multirow[b]{2}{*}{ FS } & \multicolumn{3}{|c|}{ Critical Arc } \\
\hline & & $\begin{array}{l}\text { Radius of } \\
\text { Rotation }\end{array}$ & $\underline{x, f t}$ & $\mathrm{y}, \mathrm{ft}$ \\
\hline Simplified Bishop & 3.64 & 24 & 30.7 & 24 \\
\hline Swedish & 3.53 & 24 & 30.7 & 24 \\
\hline $\begin{array}{l}\text { Modified Swedish } \\
\text { (COE) }\end{array}$ & 3.60 & 21 & 27 & 30 \\
\hline
\end{tabular}

For analyzing stability for the end of the construction case, the Corps of Engineers usually relies on total strength parameters as pore pressures are generally unknown for this case. However, as it is assumed that negative pore water pressures cannot be relied upon at low normal stresses, the lowest strength, effective or total, is used, resulting in a bilinear envelope. Figure 71 presents the bilinear envelop and values used in analyzing $\mathrm{MW}-24$. Despite this conservative approach, the results of the analysis indicate an adequate FS and failure was not predicted. 

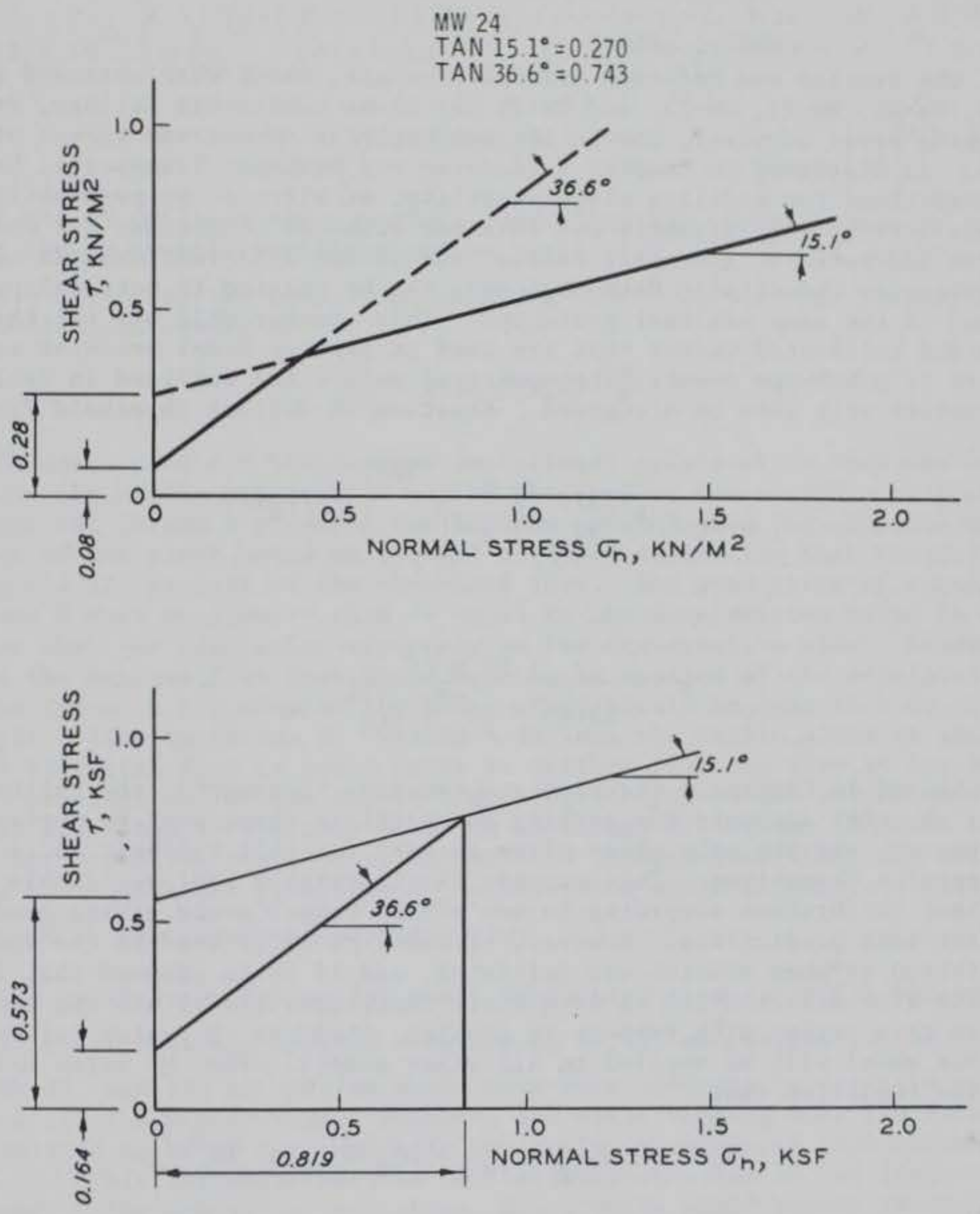

Figure 71. Failure envelopes used in analyzing stability of model test MW-24 


\section{CHAPTER 8: INTERPRETATION OF MODEL EROSION}

The erosion and sediment transport events, which were observed in models $M W-20, M W-21, M W-22, M W-23$, and $M W-25$ may alone constitute failure, even if breaching never occurred, due to the unacceptable downstream spread of mine waste. As discussed in Chapter 3 (Erosion and Sediment Transport), however, the conditions for modeling slope stability, as affected by permeability and seepage forces, will probably not coincide with the conditions for modeling erosion and sediment transport events, due to the different demands on model particle-size reduction. Both phenomena can be related to notional prototypes,* but not to the same notional prototype. This chapter will set out the equations and calibrated values that are used to predict model behavior and to relate it to prototype events; the numerical values are outlined in Table 11. The results will also be discussed. Equation 16 defines threshold flow:

$$
q_{t}=k^{\prime} D_{50}^{3 / 2} \frac{\gamma_{s}-\gamma_{w}}{\gamma_{w}} s^{-7 / 6} N^{1 / 2}
$$

where

$$
\mathrm{k}^{\prime}=\frac{1.0 * \mathrm{M}^{5 / 3}}{\left(5.25 \times 10^{-2}\right) \mathrm{D}_{50}^{1 / 6}}
$$

As mentioned in Chapter 3 (Erosion and sediment transport), the calibration factor $M$ that accounts for packing and particle shape must be derived from some source, and the only other place to turn for this calibration is to the test results themselves. This exposes the inevitable and justifiable criticism that calibration according to one's data cannot avoid giving good afterthe-fact test predictions. However, if model $\mathrm{MW}-23$ is used as the best representation of when erosion was initiated, and if it is assumed that its particle-size distribution is adequately representative of all the model soils used in this series with respect to erosion, then the $M$ value calibrated for this model will be applied to all other models. The $M$ value originates from the condition that

$$
\tau=\tau_{c}: \quad N M\left(\gamma_{s 1 g}-\gamma_{w 1 g}\right) D_{50}=\gamma_{1 g} d_{1 g} S^{0.7}
$$

in the case of a centrifugal model. In the equation for threshold flow, $M$ becomes

$$
M=\left[q\left(\frac{\gamma}{\gamma_{s}-\gamma}\right)^{5 / 3} D_{50}^{-3 / 2} s^{7 / 6} N^{-1 / 2} \frac{5.25 \times 10^{-2}}{1.0}\right]^{3 / 5}
$$

* See footnote, page 20. 
and for the case of $\mathrm{MW}-23$, by substitution

$M=\left[112 \times 10^{-6}\left(\frac{1}{1.36}\right)^{5 / 3}\left(0.4 \times 10^{-3}\right)^{3 / 2}(0.5)^{7 / 6}(75)^{-1 / 2}\right.$

$$
\left.5.25 \times 10^{-2}\right]^{3 / 5}=0.11
$$

Table 11 outlines the numerical predictons for the model series and defines the equivalent prototype median grain size $D_{50}$ based on the calibration $M=0.11$ for the models and assuming $M=0.06$ for the prototype. All calculations assume that

$$
\gamma_{\mathrm{s}}=2.36 \times 9.81 \frac{\mathrm{kg}}{\mathrm{m}^{3}}
$$

Column 4 predicts the maximum centrifugal acceleration that may be exerted and the erosion that still may be observed at the overflow or throughflow applied; column 5 predicts the maximum acceleration for complete erosion collapse of the slope based on Olivier's (1967) definition that the collapse flow equals 120 percent of the threshold flow. The prediction of acceleration in column 4 must be greater than or equal to the acceleration noted in column 6 , in order that the prediction errs only on the conservative side. Column 7 defines the minimum flow that would have to be applied at the acceleration noted in column 6 for erosion to occur. This should be less than or equal to the applied flow in column 3. Column 9 defines the stable slope at the final applied flow (the flow is noted where it differs from the flow at the initiation of erosion) and at the lowest centrifugal acceleration during which erosion was permitted to continue as noted in column 8 . Column 10 gives the equivalent prototype overflow or throughflow imposed condition, and column 11 defines the equivalent prototype $D_{50}$ size, which would demonstrate initiation of erosion at that prototype applied flow.

The calibration factor for model MW-23 predicted correctly the occurrence of erosion at the applied overflow to be $126 \mathrm{~mm}^{3} / \mathrm{sec} / \mathrm{mm}$ in the case of model $\mathrm{MW}-20$, and $129 \mathrm{~mm}^{3} / \mathrm{sec} / \mathrm{mm}$ would have been adequate to initiate erosion at $120 \mathrm{~g}$ 's. The stable angle, however, for water rushing over the material is calculated to be $27 \mathrm{deg}$, which is obviously in excess of that observed in Figure 35. This suggests that the $M$ calibration value is too large for this model. The equivalent prototype $D_{50}$, which would behave in the same fashion as the model, with respect to erosion, is $66.2 \mathrm{~mm}$.

Model MW-21 is poorly predicted using this value of M. Erosion was observed at a much higher level of centrifugal acceleration than is predicted with this calibration. This large deviation must be explained by the method of model preparation, which was by compaction.

Models MW-22, MW-23, and MW-25 should be the most successfully predicted models with respect to erosion events, provided that the calibration 
Table 11

Comparison of Predicted and Observed Model Eroston Phenomenon

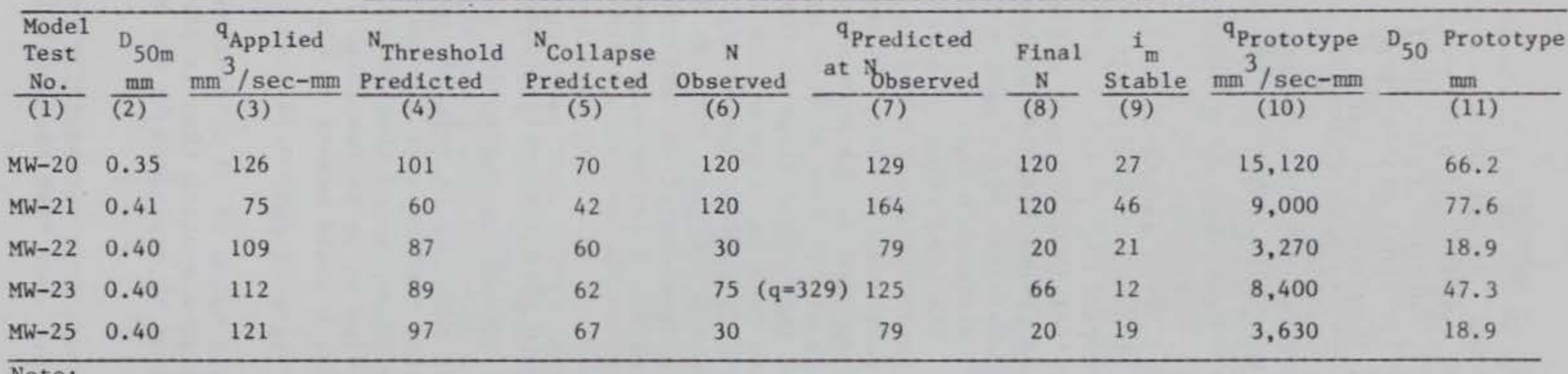

Note:

ڤ

$q_{t}=k^{\prime}\left(D_{50 m}\right)^{3 / 2}\left(\frac{\gamma_{s}-\gamma}{\gamma}\right)^{5 / 3} i^{-7 / 6} N^{1 / 2}$ or $q=C N^{1 / 2} \quad D_{50 p}=N^{1}\left(\frac{M_{m}}{M_{p}}\right)^{10 / 9} D_{50 m}$

$k^{\prime}=\frac{1.0}{5.25 \times 10^{-2}} \quad M^{5 / 3}=0.48$ when $M_{m}=0.11$ and $D_{50}$ is in metres

$N_{t}=\left[\left(\frac{q_{m}}{0.43}\right)\left(\frac{\gamma}{\gamma_{s}-\gamma}\right)^{5 / 3} i^{7 / 6}\left(\frac{1}{D_{50 m}}\right)^{3 / 2}\right]^{2}$

$q$ collapse $=1.2 q_{t}$ when $q$ is constant; then $q_{c}=q_{t}$ and $1.2 \mathrm{CN}_{0}^{1 / 2}=\mathrm{CN}_{t}$ or $\mathrm{N}_{\mathrm{c}}=\frac{\mathrm{N}_{\mathrm{t}}}{(1.2)^{2}}$

$i_{m}=\left[\frac{0.48}{q_{m}}\left(D_{50 m}\right)^{3 / 2}\left(\frac{\gamma_{s}-\gamma}{\gamma}\right)^{5 / 3} N^{1 / 2}\right]^{6 / 7}$

$q_{m}=q_{p} / N$ 
for the $M$ value was performed on a model, such as MW-23, in which the same soil and model preparation was followed for all three. In all three, erosion is successfully predicted at or before the level of centrifugal acceleration at which it was noticed. The more significant test, however, is in the final angles of repose. When measured from their respective final photographs $(M W-22,15 \mathrm{deg} ; \mathrm{MW}-23,19 \mathrm{deg}$; and MW-25, $13 \mathrm{deg})$, they compared quite favorably with the values predicted: MW-22, $21 \mathrm{deg}$; MW-23, $12 \mathrm{deg}$; and MW-25, 19 deg. A marginally too high $M$ value is indicated.

It is apparent that the soil used and the method of model preparation followed is very important to the calibration of $M$, and thus to the erodibility of the soil; a longer series of tests, however, is required to determine trends. That erosion was not noticed in models $\mathrm{MW}-22$ and $\mathrm{MW}-25$ until after it was predicted may be excused by the lack of overhead visibility inherent in these two-dimensional models, but the acceptable predictions of the stable final angles in these three models indicate that there is reasonable accuracy in both the calibration for a given soil and model preparation and the equation itself. 


\section{CHAPTER 9: CONCLUSIONS AND RECOMMENDATIONS}

\section{Conclusions}

Based upon the centrifugal models and materials tested, the following conclusions are appropriate:

a. Modeling of coal waste embankments by centrifugal techniques was successful for inducing failures of embankments due to mass instability, with high phreatic surfaces, excessive surface erosion, and too rapid rate of construction.

b. Material gradation, which greatly affects permeability and erodibility, is one of the most important factors governing the type of failure to be anticipated. However, it is impossible to model simultaneously failure due to mass instability and failure due to erosion for the same notional prototype. This is because, theoretically, resistance to erosion is proportional to $D_{50}$ size, while permeability, which governs throughflow quantities, is proportional to $D_{10}$ size; the two are not governed by the same laws of similarity. Since erosion is usually and adequately modeled at earth's gravity, centrifugal modeling of erosion is not necessary.

c. For embankments of cohesionless materials, permeability can govern the failure mode. In cases of low permeability, rate of construction may pose a problem, particularly when the initial water content is high, as in hydraulically placed fill. In case of intermediate permeability, pore pressures due to seepage can cause mass instability and retrogression. In cases of highly permeable material, or overtopping, erosion may pose a stability hazard.

d. Exiting of the phreatic surface on the downstream slope can easily lead to erosion or mass instability. In this context, positive seepage control measures, e.g., a toe drain, can alleviate this condition.

e. Estimates of the phreatic surface based upon Dupuit's (1863) parabolic assumption and FEM seepage analysis agreed well with phreatic surfaces observed in models with vertical upstream slopes. However, in models with more realistic sloping upstream surfaces, agreement was less favorable. Nevertheless, for both upstream slope conditions, theoretical estimates of the phreatic surface were higher (and thus more conservative) than surfaces observed in the models. It is possible that steady-state seepage may not have been obtained for model conditions analyzed. 
f. Permeability estimates based upon seepage quantities measured through the models were of the $10^{-3}-\mathrm{cm} / \mathrm{sec}$ range, while laboratory permeability values were of the $10^{-5}-\mathrm{cm} / \mathrm{sec}$ range. This difference may be due to anisotropic permeabilities in or leakage along the sides of the models.

g. Stability analysis using Corps of Engineers' (modified Swedish) and Bishop and Morgenstern's (1960) slope stability methods agreed well, albeit conservatively, with observed model performance. The FS ranged from 0.7 to 1.02 at the instant of failure for models with retrogressing slips. By comparison, the FS for stable embankments ranged from 1.05 to 1.7 . Thus from the standpoint of stability, the recommended minimum FS of 1.3 of the MSHA, formerly the MESA (Dept. of the Interior, undated), is sufficient.

h. Erosion instability analyses applied to the models gave reasonable results; however, the success of this prediction is dependent on the values and calibrations applied in the analyses. Because of this limitation, the MSHA's recommendation of seepage control to prevent exiting of the phreatic surface on the downstream slope cannot be overemphasized.

\section{$\underline{\text { Recommendations }}$}

Whereas conventional stability analyses accurately predicted observed model performance in cases of mass instability due to seepage forces, in the case of a rate of construction failure, total stress analysis greatly overestimated the FS. Hence, additional research concerning the mechanisms of this mode of failure and the use of bilinear failure envelopes for analysis of this case is needed.

It was found that although conventional seepage analyses provided conservative estimates of phreatic surface levels, agreement between modeled and predicted results requires improvement and warrants additional investigation.

The following general areas are of considerable importance concerning the stability of mine waste embankments but were beyond the scope and funds of this investigation. Nevertheless, additional centrifugal tests to evaluate design criteria for these areas are needed:

a. Material type. This investigation demonstrated that grain-size variation greatly affected permeability and model performance. In this context, it is recommended that some model tests be performed on a more cohesive waste material to verify observed trends.

b. Foundation type and conditions. The foundation of most of this investigation's models was a smooth steel plate, which would be akin to a prototype rigid smooth bedrock. However, soft, irregular, or sloping (side-hill) foundations can cause spreading, stress 
concentrations, or sliding conducive to cracking and failure of embankments. From these considerations, foundation effects on stability should be investigated.

c. Seepage control provisions. Since the only model with seepage control successfully resisted failure, considerations concerning the effects and performance of seepage control features warrants investigation. The functioning of filters, filter-embankment interaction, location of drains, and corresponding analyses of incorporating these features in an embankment could be ideally modeled in further centrifugal model tests. 


\section{REFERENCES}

Al-Hussaini, M. M. 1977. "Centrifugal Model Testing of Soils: A Literature Review," Miscellaneous Paper S-76-9, U. S. Army Engineer Waterways Experiment Station, CE, Vicksburg, Miss.

Bishop, A. W., and Morgenstern, N. 1960. "Stability Coefficients for Earth Slopes," Geotechnique, Vol 10, pp. 129-150.

Casagrande, A. 1940. "Seepage Through Dams," in contribution to Soil Mechanics, 1925-1940, Boston Society of Civil Engineers, Boston, Mass. (Also in Engineer Manual 1110-2-1901, "Soil Mechanics Design, Seepage Control," Department of the Army, Corps of Engineers, OCE.)

Chang, Y. L. 1939. "Laboratory Investigation of Flume Traction and Transportation," Transactions, American Society of Civil Engineers, pp. 1246-1284.

Department of the Army, Office, Chief of Engineers, Engineer Manual 1110-2-1902, "Stability of Earth and Rock-Fill Dams, Apr 1970, Washington, D. C.

Department of the Interior, Mining Enforcement and Safety Administration, Engineering and Design Manual - Coal Refuse Disposal Facilities (undated), Washington, D. C.

Dupuit, J. 1863. "Etudes theoriques et partiques sur le mouvement des eaux dans le canaux de courerts et a traves le terrains permeable," Paris, France.

Goodings, D. J. , James, R. G., Schofield, A. N., Taylor, R. N., and Townsend, F. C., 1977. "Centrifugal Model Tests of Coal Waste Embankments," Department of Engineering, University of Cambridge.

Goodings, D. J., and Schofield, A. N. 1978. "Further Centrifugal Model Tests of Coal Waste Embankments," Department of Engineering, University of Cambridge.

Goodings, D. J. 1979. "Centrifugal Hodeling of Slope Failures," Ph. D. Thesis, University of Cambridge.

Lyndon, A., and Schofield, A. N. 1978. "Centrifugal Model Tests of the Lodalen Lands1ide," Canadian Geotechnical Journal.

Malushitsky, J. I. 1975. "The Centrifugal Model Testing of Waste-Heap Embankments," Budivelnik Publishing House, Kieve, Russia, Draft Translation (1977).

Olivier, H. 1967. "Through and Overflow Rockfill Dams--New Design Techniques," Proceedings of Institution of Civil Engineers, United Kingdom, pp 433-472. 
Pokrovsky, G. I., and Fyodorov, I. S. 1975. "Centrifugal Model-Testing on the Construction Industry," Vols I and II, Moscow, Draft Translation (1969).

Rowe, P. W., Craig, W. H., and Proctor, P. C. 1977. "Dynamically Loaded Centrifugal Model Foundations," Proceedings, Ninth International Conference on Soil Mechanics and Foundation Engineering, Tokyo, Vol 2, p. 359.

Schofield, A. N. 1978. "Use of Centrifuge Modeling to Assess Slope Stability," Canadian Geotechnical Journal, p. 14.

Scott, R. F., and Morgan, N. R. 1977. "Feasibility and Desirability of Constructing a Very Large Centrifuge for Geotechnical Studies," Report 760-171, California Institute of Technology, prepared for National Science Foundation.

Tracy, F. T. 1973. "A Plane and Axisymmetric Finite Element Program for Steady-State and Transient Seepage Problems," Miscellaneous Paper K-73-4, U. S. Army Engineer Waterways Experiment Station, CE, Vicksburg, Miss .

Van Terson, F. K. 1916-1917. "Eenige Theoretisch Beschouivingen over kivel, DeIngenieur, 1940. 


\section{APPENDIX A: CHANGES IN DEPTH OF FLOW}

The changes in depth of overflow in centrifugally loaded models and the relationship to prototype flow are investigated in the following four cases. Consider first the case of two embankments, one a centrifugal model at $\mathrm{Ng}$ and one a prototoype through which groundwater in both instances is moving at the same velocity, i.e., $\mathrm{k}_{\mathrm{p}}=\mathrm{k}_{\mathrm{m} 1 \mathrm{~g}} \times \mathrm{N}$ and $\ell_{\mathrm{p}}=\ell_{\mathrm{m}} \times \mathrm{N}$, so that $\mathrm{q}_{\mathrm{p}}=\mathrm{Nq}_{\mathrm{m}}$ and impose the same flow condition on overflow. The resulting overflow depth of model and prototype will be related as follows (governed by the Chezy and Manning equations):

$$
\begin{aligned}
& \text { Chezy: } V=\sqrt{\frac{2 g}{\lambda}} \mathrm{R}^{1 / 2} \mathrm{~s}^{1 / 2} \text { or } \mathrm{c} \sqrt{\mathrm{RS}} \\
& \text { and } \mathrm{V}_{\mathrm{Ng}}=\sqrt{\frac{2 \mathrm{Ng}}{\lambda}} \mathrm{R}^{1 / 2} \mathrm{~s}^{1 / 2}=\mathrm{C} \sqrt{\mathrm{RSN}}
\end{aligned}
$$

where $V=$ velocity of flow

$\mathrm{R}=$ hydraulic radius $=$ area of $\mathrm{flow}$ divided by wetted perimeter

$\mathrm{S}=$ sine (angle of inclination)

$\mathrm{n}=$ Manning's roughness coefficient

Manning's equation can be obtained from Chezy's equation by setting

$$
\mathrm{C}=\frac{1.49}{\mathrm{n}} * \mathrm{R}^{1 / 6}
$$

so

$$
\mathrm{V}=\frac{1.49}{\mathrm{n}} \mathrm{R}^{2 / 3} \mathrm{~s}^{1 / 2}
$$

and

$$
\mathrm{V}_{\mathrm{Ng}}=\frac{1.49}{\mathrm{n}} \mathrm{R}^{2 / 3} \mathrm{~S}^{1 / 2} \mathrm{~N}^{1 / 2}
$$

In the case of wide open channel flow, $R$ can be approximated by $d$, where $d=$ depth of flow as illustrated on the following page.

* The numerator of this equation is units dependent: when $R$ is in feet, the numerator $=1.49$; and when $R$ is in metres, the numerator $=1$. 


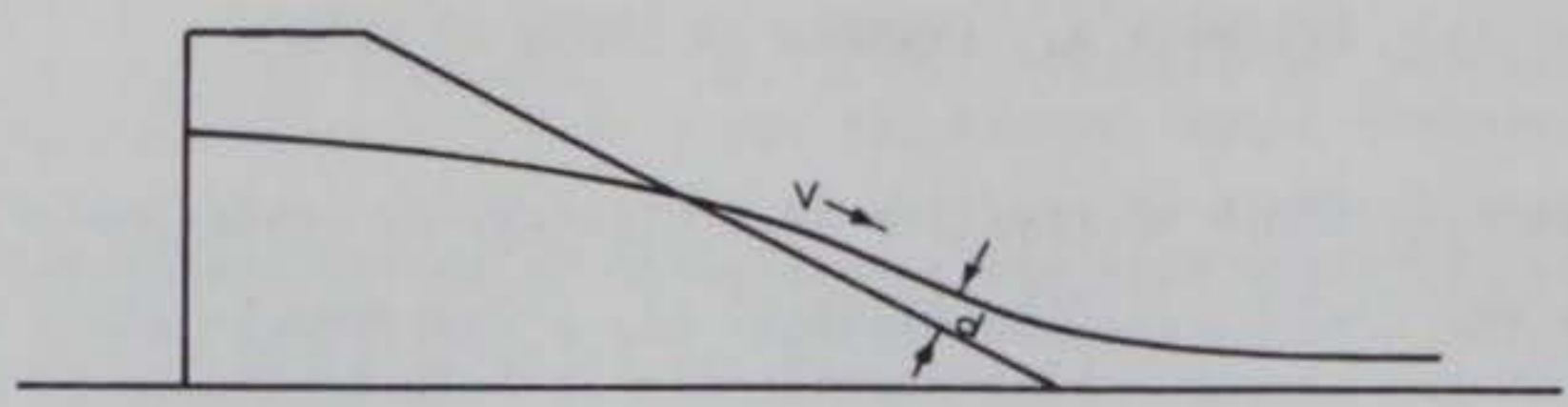

and

$$
\mathrm{V}=\frac{1.49}{\mathrm{n}} \mathrm{d}^{2 / 3} \mathrm{~s}^{1 / 2} \text { and } \mathrm{V}_{\mathrm{Ng}}=\frac{1.49}{\mathrm{n}} \mathrm{d}^{2 / 3} \mathrm{~s}^{1 / 2} \mathrm{~N}^{1 / 2}
$$

Since the quantity of flow per unit width, q, can be expressed as

$$
\mathrm{q}=\mathrm{Vd}
$$

then

$$
\mathrm{q}_{\mathrm{p}}=\frac{1.49}{\mathrm{n}_{\mathrm{p}}} \mathrm{d}_{\mathrm{p}}^{2 / 3} \mathrm{~s}^{1 / 2} \mathrm{~d}_{\mathrm{p}}
$$

and

$$
q_{m N g}=\frac{1.49}{n_{m}} d_{m}^{2 / 3} \mathrm{~s}^{1 / 2} \mathrm{~N}^{1 / 2} \mathrm{~d}_{\mathrm{m}}
$$

Since $\mathrm{q}_{\mathrm{m}}=\mathrm{q}_{\mathrm{p}} / \mathrm{N}$, then

$$
\frac{1.49}{\mathrm{n}_{\mathrm{p}}} \mathrm{d}_{\mathrm{p}}^{2 / 3} \mathrm{~s}^{1 / 2} \mathrm{~d}_{\mathrm{p}}=\frac{1.49}{\mathrm{n}_{\mathrm{m}}} \mathrm{d}_{\mathrm{m}}^{2 / 3} \mathrm{~s}^{1 / 2} \mathrm{~N}^{3 / 2} \mathrm{~d}_{\mathrm{m}}
$$

and

$$
\begin{aligned}
& \left(\frac{d_{p}}{d_{m}}\right)^{5 / 3}=\frac{{ }_{p}}{n_{m}} N^{3 / 2} \\
& \frac{d p}{d_{m}}=\left(\frac{n_{p}}{n_{m}}\right)^{3 / 5} N^{9 / 10}
\end{aligned}
$$

In the case of a model embankment with throughflow moving at velocity $V_{1 g}$, subject the model to an increase in self-weight of $\mathrm{N}$ times, but maintain the same flow net configuration, so that 
then

$$
V_{\mathrm{Ng}}=V_{1 \mathrm{~g}} \mathrm{~N}
$$

$$
{ }^{\mathrm{q}} \mathrm{Ng}=\mathrm{q}_{1 \mathrm{~g}} \mathrm{~N} \text { (for a constant hydraulic gradient) }
$$

and at $\mathrm{Ng}$

$$
{ }^{\mathrm{Ng}}=\mathrm{v}_{\mathrm{Ng}} \mathrm{d}_{\mathrm{Ng}}=\frac{1.49}{\mathrm{n}} \mathrm{d}_{\mathrm{Ng}}^{2 / 3} \mathrm{~s}^{1 / 2} \mathrm{~N}^{1 / 2} \mathrm{~d}_{\mathrm{Ng}}
$$

Since $\mathrm{q}_{\mathrm{Ng}}=\mathrm{q}_{1 \mathrm{~g}} \mathrm{~N}$, then

$$
\frac{1.49}{\mathrm{n}} \mathrm{d}_{\mathrm{Ng}}^{2 / 3} \mathrm{~s}^{1 / 2} \mathrm{~d}_{\mathrm{Ng}} \mathrm{N}^{1 / 2}=\frac{1.49}{\mathrm{n}} \mathrm{d}_{1 \mathrm{~g}}^{2 / 3} \mathrm{~s}^{1 / 2} \mathrm{~d}_{1 \mathrm{~g}} \mathrm{~N}
$$

and

$$
\left(\frac{d_{\mathrm{Ng}}}{\mathrm{d}_{1 \mathrm{~g}}}\right)^{5 / 3}=\mathrm{N}^{1 / 2}
$$

or

$$
\frac{\mathrm{d}_{\mathrm{Ng}}}{\mathrm{d}_{1 \mathrm{~g}}}=\mathrm{N}^{3 / 10}
$$

In the second test series, tests were conducted by either maintaining the rate of flow $\mathrm{q}$ and changing $\mathrm{N}$ or vice versa. In the case of a model embankment with throughflow moving at velocity $V_{1 g}$ so that the seepage rate was $\mathrm{q}_{1 \mathrm{~g}}$, subject that model to an increase in self-weight of $\mathrm{N}$ times, but maintain the same throughflow, such that $q_{1 g}=q_{\mathrm{Ng}}$. Then

$$
q_{1 g}=v_{1 g} d_{1 g}=\frac{1.49}{n} d_{1 g}^{2 / 3} s^{1 / 2} d_{1 g}
$$

and at $\mathrm{Ng}$

$$
{ }_{\mathrm{Ng}}=\mathrm{V}_{\mathrm{Ng}} \mathrm{d}_{\mathrm{Ng}}=\frac{1.49}{\mathrm{n}} \mathrm{d}_{\mathrm{Ng}}^{2 / 3} \mathrm{~s}^{1 / 2} \mathrm{~d}_{\mathrm{Ng}} \mathrm{N}^{1 / 2}
$$

Since $q$ is constant, then

$$
\frac{1.49}{\mathrm{n}} \mathrm{d}_{1 \mathrm{~g}}^{2 / 3} \mathrm{~s}^{1 / 2} \mathrm{~d}_{1 \mathrm{~g}}=\frac{1.49}{\mathrm{n}} \mathrm{d}_{\mathrm{Ng}}^{2 / 3} \mathrm{~s}^{1 / 2} \mathrm{~d}_{\mathrm{Ng}} \mathrm{N}^{1 / 2}
$$


and

$$
\left(\frac{d_{\mathrm{Ng}}}{d_{1 g}}\right)^{5 / 3}=N^{-1 / 2}
$$

or

$$
\frac{d_{N g}}{d_{1 g}}=N^{-3 / 10}
$$

For the other case where $\mathrm{Ng}$ remains constant and throughflow increases from $q_{1}$ to $q_{2}$, then

$$
\begin{aligned}
& \mathrm{q}_{1}=\frac{1.49}{\mathrm{n}} \mathrm{d}_{1}^{2 / 3} \mathrm{~s}^{1 / 2} \mathrm{~N}^{1 / 2} \mathrm{~d}_{1} \\
& \mathrm{q}_{2}=\frac{1.49}{\mathrm{n}} \mathrm{d}_{2}^{2 / 3} \mathrm{~s}^{1 / 2} \mathrm{~N}^{1 / 2} \mathrm{~d}_{2}
\end{aligned}
$$

and

$$
\frac{q_{1}}{q_{2}}=\left(\frac{d_{1}}{d_{2}}\right)^{5 / 3}
$$


APPENDIX B: CONVERSION FACTORS, U. S. CUSTOMARY TO METRIC (SI) UNITS OF MEASUREMENT

U. S. customary units of measurement used in this report can be converted to . metric (SI) units as follows:

\section{Multiply}

cubic feet

cubic feet per second

feet

gallons (U. S. liquid)

inches

pounds (force) per square inch

pounds (mass) per cubic foot

square feet

tons (2000 1b, mass)

\begin{tabular}{c} 
By \\
\hline 0.02831685 \\
0.02831685 \\
0.3048 \\
3.785412 \\
25.4 \\
6894.757 \\
16.01846 \\
0.09290304 \\
907.1847
\end{tabular}

To Obtain

cubic metres

cubic metres per second

metres

cubic decimetres

millimetres

pascals

kilograms per cubic metre

square metre

kilograms 


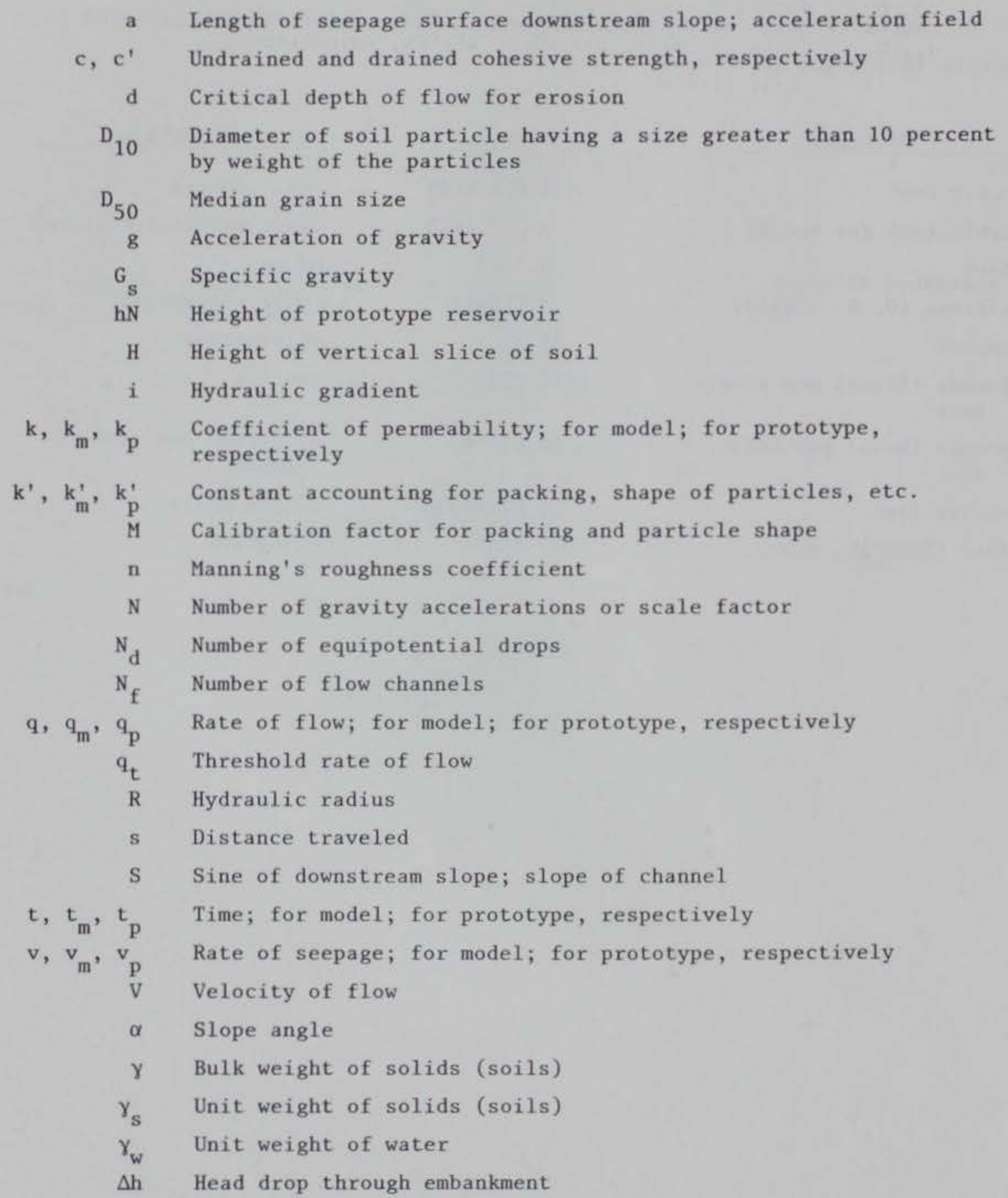




$\begin{aligned} \sigma_{\mathrm{d}} & \text { Deviator stress } \\ \sigma_{\mathrm{ff}} & \text { Normal stress on failure plane at failure } \\ \sigma, \sigma_{\mathrm{n}} & \text { Normal stress } \\ \sigma_{1}, \sigma_{3} & \text { Major and minor principal stress, respectively } \\ \tau & \text { Shear stress } \\ \tau_{\mathrm{c}} & \text { Critical shear stress } \\ \tau_{\mathrm{ff}} & \text { Shear stress on failure plane at failure } \\ \omega & \text { Rotational speed } \\ \emptyset & \text { Angle of internal friction }\end{aligned}$


In accordance with letter from DAEN-RDC, DAEN-ASI dated 22 July 1977, Subject: Facsimile Catalog Cards for Laboratory Technical Publications, a facsimile catalog card in Library of Congress MARC format is reproduced below.

Townsend, Frank Charles

Centrifugal model analysis of coal waste embankment stability / by Frank C. Townsend ... [et a1.]. Vicksburg, Miss. U. S. Waterways Experiment Station ; Springfield, Va. : available from National Technical Information Service, 1979.

117 p. : ill. ; $27 \mathrm{~cm}$. (Technical report-U. S. Army Engineer Waterways Experiment Station ; GL-79-18)

Prepared for U. S. Department of Interior, Bureau of Mines, Spokane Mining Research Center, Spokane, Washington, under Contract No. H0282018.

References: p. 109-110.

1. Centrifugal models. 2. Coal waste. 3. Embankments.

4. Seepage, 5. Shear strength. 6. Stability. I. United States. Bureau of Mines. Spokane Mining Research Center. II. Series: United States. Waterways Experiment Station, Vicksburg, Miss. Technical report ; GL-79-18.

TA7.W34 no.GL-79-18 